Portland State University

PDXScholar

$1-1-2011$

\title{
Numerical Modeling and Analyses of Steel Bridge Gusset Plate Connections
}

Thomas Sidney Kay

Portland State University

Follow this and additional works at: https://pdxscholar.library.pdx.edu/open_access_etds Let us know how access to this document benefits you.

\section{Recommended Citation}

Kay, Thomas Sidney, "Numerical Modeling and Analyses of Steel Bridge Gusset Plate Connections" (2011). Dissertations and Theses. Paper 84.

https://doi.org/10.15760/etd.84

This Thesis is brought to you for free and open access. It has been accepted for inclusion in Dissertations and Theses by an authorized administrator of PDXScholar. Please contact us if we can make this document more accessible: pdxscholar@pdx.edu. 
Numerical Modeling and Analyses of Steel Bridge Gusset Plate Connections

$$
\text { by }
$$

Thomas Sidney Kay

A thesis submitted in partial fulfillment of the requirements for the degree of

\author{
Master of Science \\ in \\ Civil and Environmental Engineering
}

Thesis Committee:

Peter Dusicka, Chair

Manouchehr Gorji

Hormoz Zareh

Portland State University

(C)2011 


\begin{abstract}
Gusset plate connections are commonly used in steel truss bridges to connect individual members together at a node. Many of these bridges are classified as non-loadpath-redundant bridges, meaning a failure of a single truss member or connection could lead to collapse. Current gusset plated design philosophy is based upon experimental work from simplified, small-scale connections which are seldom representative of bridge connections. This makes development of a refined methodology for conducting highfidelity strength capacity evaluations for existing bridge connections a highly desirable goal. The primary goal of this research effort is to develop an analytical model capable of evaluating gusset plate stresses and ultimate strength limit states. A connection-level gusset connection model was developed in parallel with an experimental testing program at Oregon State University. Data was collected on elastic stress distributions and ultimate buckling capacity. The analytical model compared different bolt modeling techniques on their effectiveness in predicting buckling loads and stress distributions. Analytical tensile capacity was compared to the current bridge gusset plate design equations for block shear. Results from the elastic stress analysis showed no significant differences between the bolt modeling techniques examined, and moderate correlation between analytical and experimental values. Results from the analytical model predicted experimental buckling capacity within $10 \%$ for most of the bolt modeling techniques examined. Tensile capacity was within $7 \%$ of the calculated tensile nominal capacity for all bolt modeling techniques examined. A preliminary parametric study was conducted to investigate the effects of member flexural stiffness and length on gusset plate buckling capacity, and
\end{abstract}


showed an increase in member length or decrease in member flexural stiffness resulted in diminished gusset plate buckling capacity. 


\section{Dedication}

To my wife Kimberly, thank you for all of your love, support and patience. You have been a great source of inspiration and strength for me during my academic pursuits. To my mother Sara, thank you for believing in my abilities and helping me along every step of the way. To my son Henry, thank you for being the best part of my day, every day and showing me the love and wonderment of childhood. 


\section{Acknowledgements}

I would like to thank my mentor Dr. Dusicka for taking me on as a graduate student and research assistant in the iSTAR laboratory. Your guidance and high standards for excellence have helped me become a better engineer and researcher, and for that I am grateful.

I would also like to thank my other committee members Dr. Zareh and Dr. Gorji. Your courses proved to be some of the most challenging and the most rewarding. You both have instilled a lasting impression on me and I owe you my thanks. 


\section{Table of Contents}

Abstract

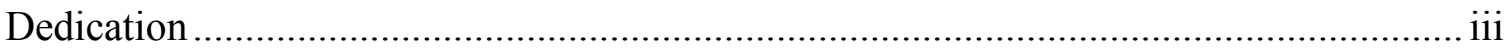

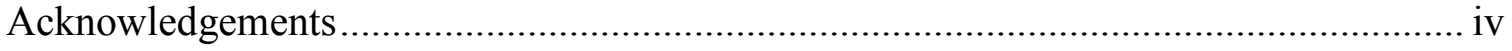

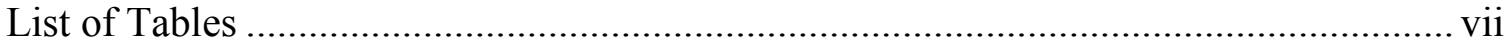

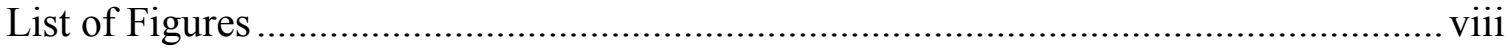

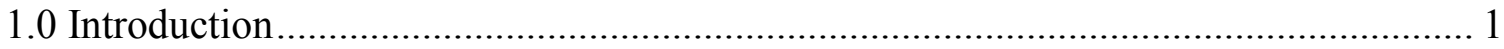

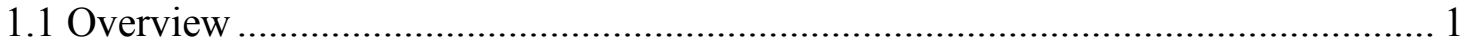

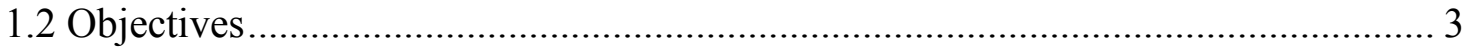

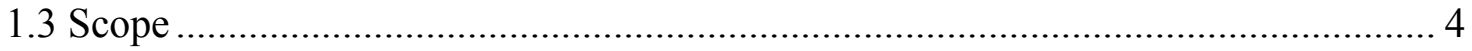

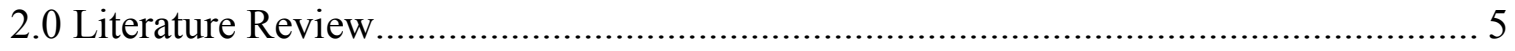

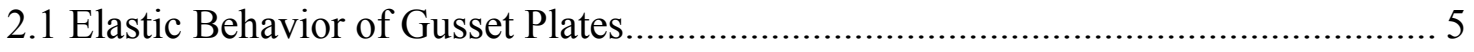

2.2 Gusset Plate Failure States in Tension .......................................................... 7

2.3 Gusset Plate Failure States in Compression .................................................... 9

2.4 Past Bridge Gusset Plate Failures .................................................................... 11

2.4.1 Grand River Bridge Gusset Plate Failure (Lake County, Ohio) ...................... 12

2.4.2 I-35W Bridge Gusset Plate Failure (Minneapolis, MN)................................ 13

2.5 Gusset Plate Load Rating Methods According to FHWA …................................. 14

2.6 Previous FEA Gusset Plate Models ....................................................................... 17

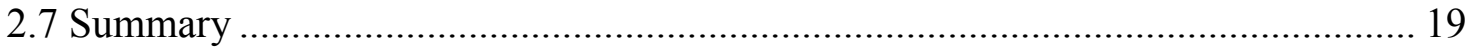

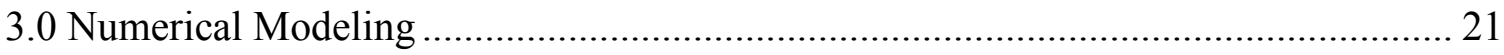

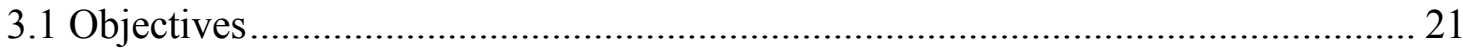

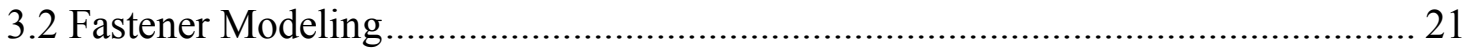

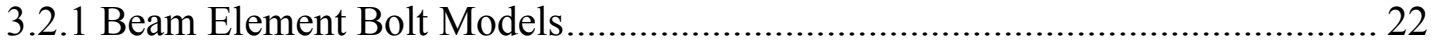

3.2.2 Three-Dimensional Contact Bolt Models ....................................................... 23

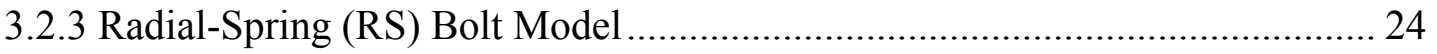

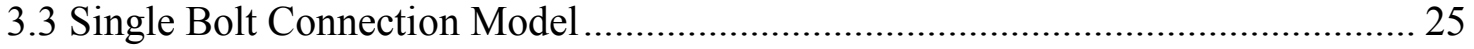

3.3.1 Single Bolt Connection Model - Results and Discussion ............................... 28

3.4 Multi-Bolt Connection Model.......................................................................... 29

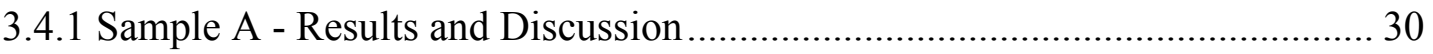

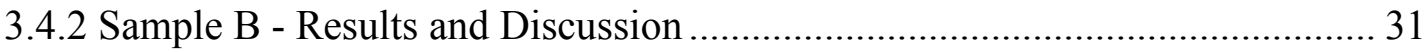

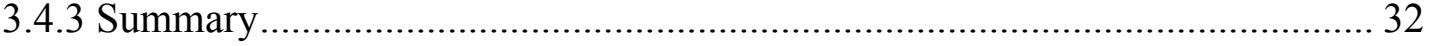

3.5 Gusset Connection Model Description ......................................................... 32 


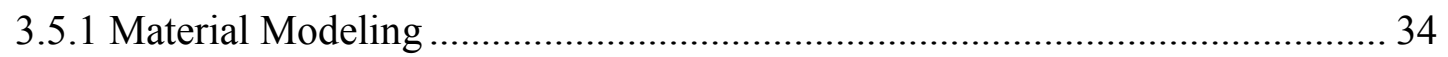

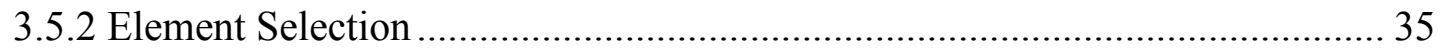

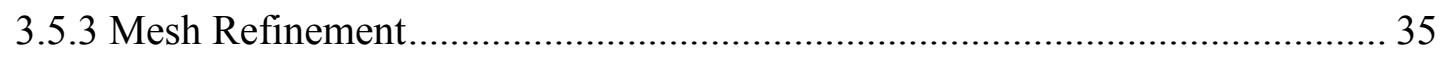

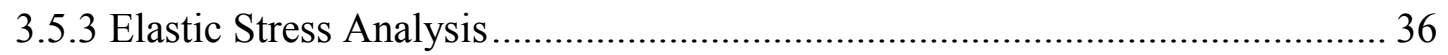

3.5.4 Buckling Capacity Analysis ....................................................................... 37

3.5.5 Tensile Capacity Analysis ........................................................................... 40

3.6 Gusset Connection Experimental Program (Oregon State)..................................... 40

3.6.1 Test 1 - Description and Results ………………………………………….... 40

3.6.2 Test 2 - Description and Results .................................................................... 43

3.6.3 Test 3 - Description and Results ............................................................... 44

3.7 Analytical Results and Experimental Validation ..................................................... 44

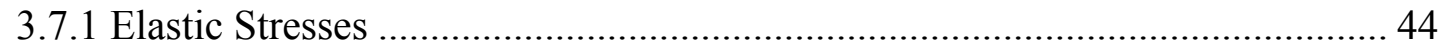

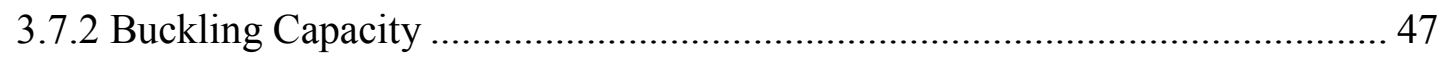

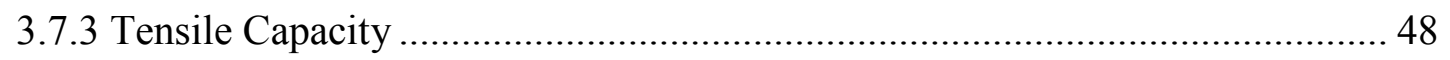

3.8 Conclusions and Modeling Recommendations ………........................................ 49

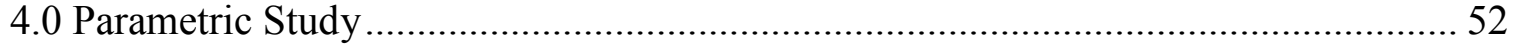

4.1 Effects of plate thickness and imperfection ……................................................ 53

4.2 Effects of adjustment of Whitmore's effective length ............................................. 54

4.3 Effects of connected member flexural stiffness and length .................................... 55

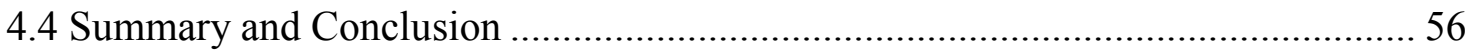

5.0 Conclusions and Recommendations for Further Study ………………………........ 58

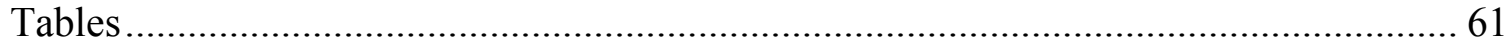

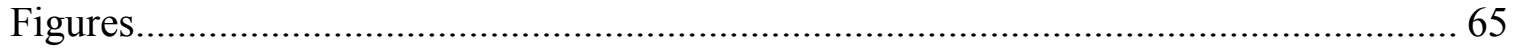

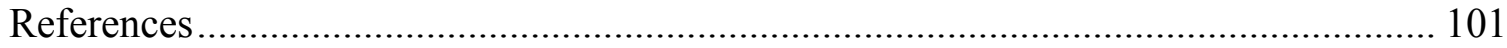

Appendix A - Capacity and Design Calculations....................................................... 104

Appendix B - Python Scripts................................................................................. 111

Multi-bolt connection model script - RS bolts ……………..................................... 111

Gusset connection model script - RS Bolts .......................................................... 118

Appendix C - Convergence plots ................................................................................ 130 


\section{List of Tables}

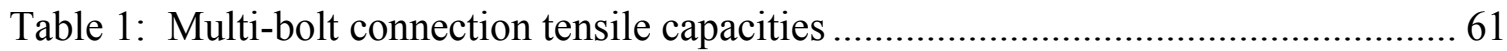

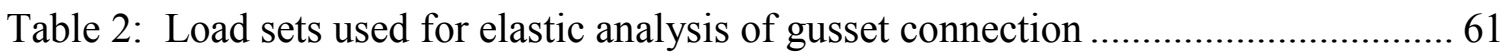

Table 3: Load sets used in Oregon State Gusset Connection - Test 1 ........................... 62

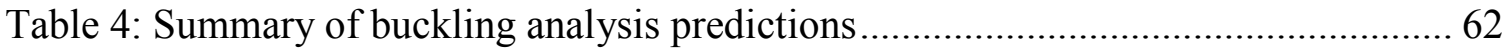

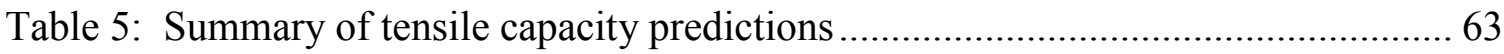

Table 6: Buckling capacity and $k$ values due to imperfections ...................................... 63

Table 7: Buckling capacity and $k$ values for different gusset plate effective lengths...... 63

Table 8: Buckling capacity and k values for different member flexural stiffnesses....... 64

Table 9: Buckling capacity and k values for different M4 lengths............................... 64 


\section{List of Figures}

Figure 1: Warren truss gusset plate connection tested by Whitmore (1957).....

Figure 2: Whitmore effective width definitions for member regions of gusset plates

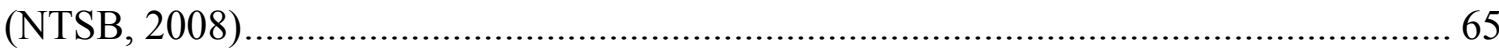

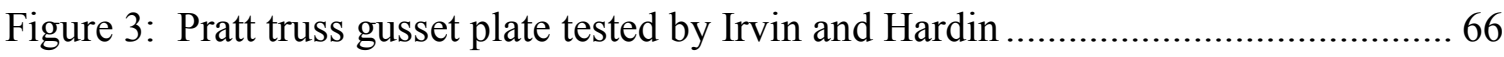

Figure 4: Gusset plate connection tested by Bjorhovde and Chakrabarti (1985) ............ 66

Figure 5: General gusset plates tested by Hardash and Bjorjovde (1985) ....................... 67

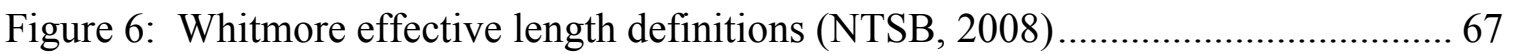

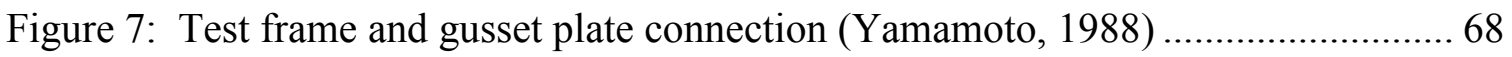

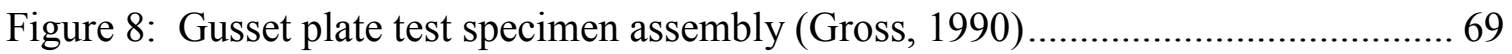

Figure 9: Gusset plate failure on the Lake County Grand River Bridge, Ohio ............... 69

Figure 10: (a) U10 gusset connection, (b) free edge distortion in 2003 ......................... 70

Figure 11: Post-collapse investigation photo of U10 connection, I35-W Bridge,

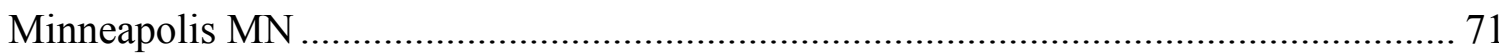

Figure 12: Radial Spring (RS) Bolt Model ............................................................. 71

Figure 13: Single bolt model, (a) 3D contact bolt, (b) radial spring bolt ...................... 72

Figure 14: Load-displacement curves for different number of radial springs used .......... 72

Figure 15: Local mesh convergence for RS bolt model .............................................. 73

Figure 16: PEEQ contours for different bolt modeling methods .................................. 74

Figure 17: Load-displacement behavior for single-bolt models ................................... 75

Figure 18: Test setup schematic and drawings for Samples A and B.......................... 75

Figure 19: Displacement measurement instrumentation for multi-bolt tests.................. 76

Figure 20: True stress-strain properties for gusset plate material property definition..... 76

Figure 21: PEEQ contours for multi-bolt models for Sample A .................................. 77

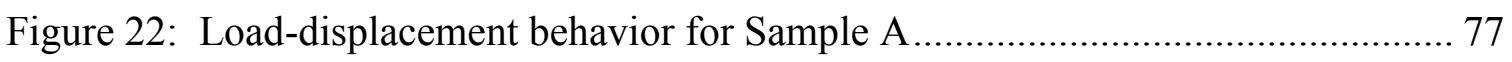

Figure 23: PEEQ contours for Sample B ....................................................................... 78

Figure 24: Load-displacement behavior for Sample B …........................................... 78

Figure 25: Gusset plate connection; (a) experimental setup, (b) FEA model.................. 79

Figure 26: Gusset connection member modeling ....................................................... 80

Figure 27: Boundary conditions and actuator load capacities for gusset plate connection

Figure 28: Stress planes and sample points used for elastic stress analysis .................. 81

Figure 29: (a) Meshes for MPC/AF and RS bolt models, (b) partitions for MPC/AF and RS bolt models, (c) detail of mesh and partition of bolted region for RS bolt model ...... 82

Figure 30: Stress contours for MPC and RS bolt gusset connection models, (a) Mises, (b)

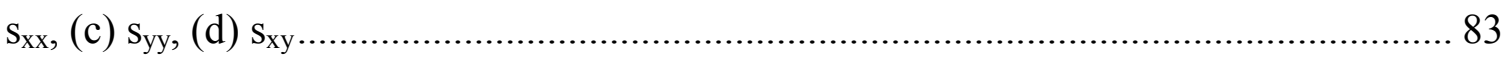

Figure 31: Stress contours for MPC and AF bolt gusset connection models, (a) Mises, (b)

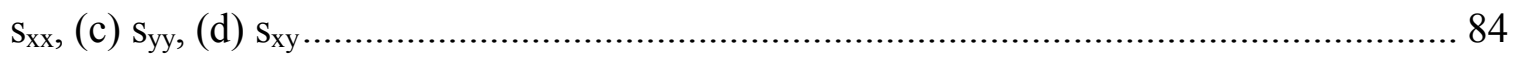

Figure 32: Plane A stress profiles for MPC, AF and RS bolt models ............................ 85 
Figure 33: Plane B stress profiles for MPC, AF and RS bolt models........................... 86

Figure 34: Imperfection comparison between EI and first buckling mode - Test 1 .......87

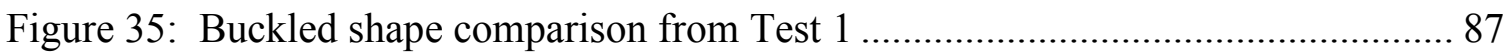

Figure 36: Plane A Mises stress profiles............................................................... 88

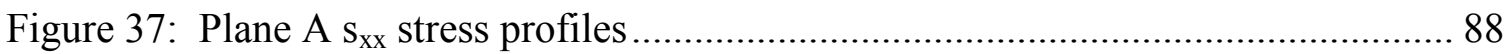

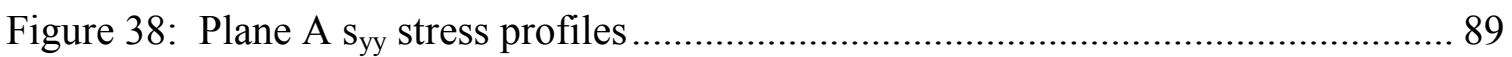

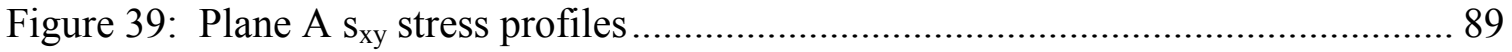

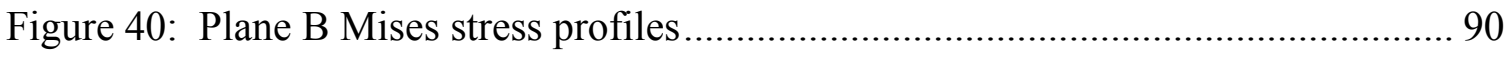

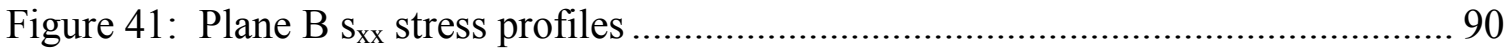

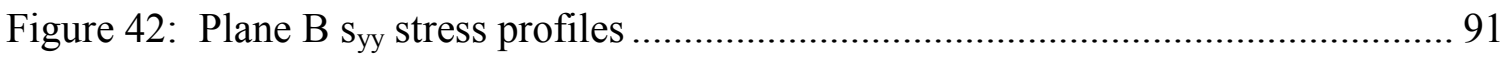

Figure 43: Plane $\mathrm{B}_{\mathrm{xy}}$ stress profiles ................................................................... 91

Figure 44: Mises stress comparison at Plane A for M4 loaded to different magnitudes . 92

Figure 45: Mises stress comparison at Plane B for M4 loaded to different magnitudes . 92

Figure 46: Measurements used to construct gusset connection load-displacement plots 93

Figure 47: Compression load-displacement comparisons between MPC, AF and RS bolt

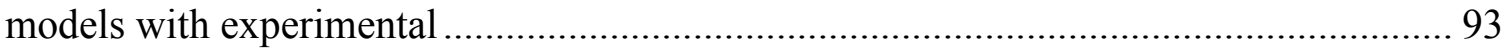

Figure 48: Compression load-displacement comparisons between analysis methods and

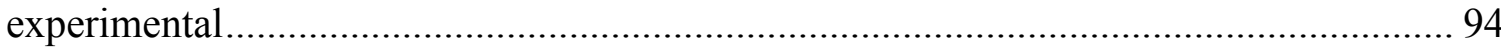

Figure 49: Buckled gusset connection - Test 2 ..................................................... 94

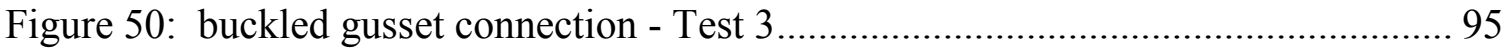

Figure 51: Tensile load-displacement curves for gusset connection ........................... 95

Figure 52: Mises and PEEQ contour comparisons from tensile failure analysis for MPC,

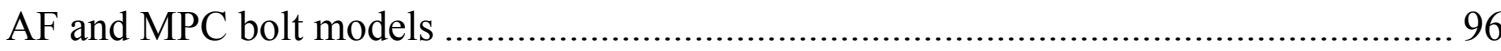

Figure 53: Mises stress contour detail for RS bolt model........................................... 97

Figure 54: Load-displacement curves for 1/4" plate and varying out-of-plane

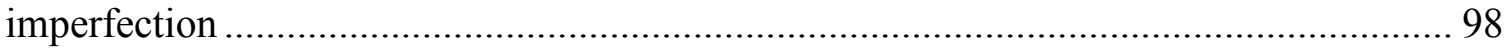

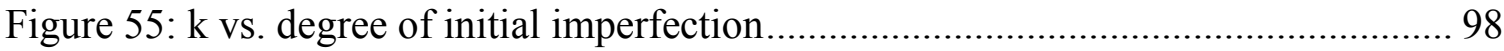

Figure 56: Load-displacement curves for different Whitmore effective lengths............ 99

Figure 57: Buckling capacity vs. Whitmore effective length ..................................... 99

Figure 58: Load-displacement curves for different M4 EI values .............................. 100

Figure 59: Load-displacement curves for different M4 lengths ................................ 100 


\subsection{Introduction}

\subsection{Overview}

Gusset plate connections are commonly used in steel truss bridges to connect individual members together at a node. The connection typically consists of a steel plate on each side of the connected members, then bolted or riveted together. A large number of steel deck truss bridges are currently in service. The Federal Highway Administration estimates that 465 steel deck truss bridges and approximately 11,000 deck truss bridges exist in the National Bridge Inventory (NTSB, 2008). Many of these bridges are further

classified as non-load-path-redundant bridges meaning a failure of a single truss member or connection could lead to collapse. This makes periodic inspections and load rating practices essential for the safe operation and maintenance of these bridge types.

Historically, only the truss members were evaluated for load capacity. The rationale for omitting load rating for connections comes from what is thought to be conservative assumptions employed during connection design, combined with a small occurrences of connection failures in the historical record; namely the 1996 gusset plate failure on the Grand River Bridge in Lake County, Ohio (NTSB, 2008) (NTSB, 2008) (NTSB, 2008), and the 2007 collapse of the I-35W Bridge in Minneapolis, Minnesota (Holt \& Hartmann, 2008). The collapse of the I-35 Bridge in Minneapolis was catastrophic - resulting in 13 deaths and 145 injuries - and was the first failure where a design error was implicated as the cause of collapse, thus revealing a new vulnerability in steel truss bridges which had previously been thought to be both economical and reliable. 
After the I-35W Bridge collapse, the Federal Highway Association (FHWA) issued a set of guidelines for load rating gusset plate connections (FHWA, 2009), yet did not provide any revised design methods beyond existing practice. Instead, a summary was compiled of existing design methods and load rating procedures for gusset plate connections.

Inclusion of gusset plate connections in load ratings poses a significant challenge to bridge owners due to the large number of connections in the inventory and the complexity of analysis required to accurately evaluate each connection. Load transfer to bridge gusset plates in situ is delivered by multiple members - all potentially with axial, shear and moment - through the fasteners into bearing on the gusset plate. However, current gusset plate design philosophy is rooted in elementary beam theory analysis and applicable specification rules, combined with the experience and judgment of the designer (Bjorhovde \& Chakrabarti, 1985). Moreover, current design philosophy is based upon experimental work done on small-scale gusset connections consisting of a single braced member acting in monotonic axial tension or compression; which is hardly representative of bridge connections. The complexity of stress fields and failure states found in gusset plates is addressed by applying approximate methods to arrive at a rapid, albeit conservative solution, but one that may lack accuracy. Thus, development of a refined methodology for conducting high-fidelity strength capacity evaluations on existing bridge connections is a highly desirable goal.

Toward this end, finite element analysis (FEA) is an appealing option for analyzing stresses and failure states of bridge gusset plate connections. FEA is widely used in structural engineering applications, with modern commercial software packages 
capable of modeling systems with non-linear material behavior, complex geometry, contact interactions and complex loading conditions. FEA implementation in bridge connection evaluations does present some challenges due to the large scale, high degree of geometric variability and complex load paths that are unique for each connection. Sophisticated non-linear FEA models may be well suited for evaluating strength capacities in bridge connections, but have yet to be calibrated with experimental results from large-scale experiments. Nor is there consensus among practitioners regarding how complex a FEA model must be to accurately capture a connection's ultimate strength capacity. Complex FEA modeling involves significant development time, specialized training, and often comes at the cost of long computation times. This consequently translates into significant cost for bridge owners, and can delay the incorporation of connection load rating into bridge inspection programs.

\subsection{Objectives}

The impetus for this work arises from the need for accurate and rapid assessment of bridge connections, a re-evaluation of existing design methods and a desire to better understand the parameters affecting the strength capacity of bridge gusset plate connections.

The objectives of this research are as follows:

1. Develop a FEA model, calibrated with experimental tests conducted at Oregon State University, capable of evaluating gusset plate stresses and ultimate strength limit states. 
2. Evaluate FEA modeling techniques for computational efficiency and ability to predict ultimate strength capacity of bridge gusset plate connections subject to tension and compression.

3. Conduct a parametric study to find the effects of initial imperfections, gusset plate thickness, gusset plate effective length, member flexural stiffness and member length on gusset plate buckling capacity.

4. Design the model to accept future modifications such as plate geometry, loading conditions, boundary conditions, and fastener load-displacement behavior for subsequent studies.

\subsection{Scope}

This work focuses on connection-level analysis of bridge gusset plates. Global models of full bridge truss systems are not considered here, although they have been used by others to study loading demands on particular connections. Only one bridge connection geometry will be included in this study, which is from the specimen being tested in a parallel experimental study at Oregon State University. Also, since the primary research focus is on stresses and failure states of the gusset plates themselves, attached members and fasteners will be modeled such that failure will only occur in the gusset plate. Therefore, fastener and member failure states will not be considered in this study. 


\subsection{Literature Review}

\subsection{Elastic Behavior of Gusset Plates}

Modern gusset plate design has been most influenced by Whitmore (1952), who studied the stress distributions in a 1/4 scale model of a bottom chord Warren truss gusset plate connection, similar to the one shown in Figure 1. Prior to Whitmore, gusset plate design consisted of sizing the plate to accommodate the required number of fasteners, then selecting a plate thickness based on classical beam formula analysis and engineering judgment. Whitmore's recognized that the use of beam theory was questionable, since gusset plates act like deep members. He aimed to characterize the stress distribution in a gusset plate subject to load, the magnitude and location of maximum stress, and develop a simplified design method for determining maximum stresses in a gusset plate. The experimental loading regime was kept in the elastic range of the gusset plate and was applied such that one diagonal member was in tension, the other diagonal member was in compression and the bottom chord was in tension. Stresses were calculated from an array of strain gages positioned across the plate.

Whitmore's findings showed that maximum stresses normal to the diagonals occurred near the ends of the compression and tension diagonals respectively. Maximum shear stress occurred along a plane just above the bottom chord and below the diagonal members. Based on his findings, he proposed a simplified method for calculating maximum normal stresses in a gusset plate, by using what has become known as the Whitmore effective width (Figure 2). The Whitmore effective width is defined as the length of the line perpendicular to the member axis passing through the last bolt row of fasteners, intersected by two 30-degree lines drawn from the first outer row of fasteners 
to the last row. Maximum normal stress is calculated by multiplying the material's yield stress by the Whitmore effective width times the plate thickness. This technique for calculating maximum normal stress in a gusset plate continues to be a fundamental rule in gusset plate design.

Two studies by Irvin (1957) and Hardin (1958) expanded on Whitmore's work using a scale model of a bottom chord of a Pratt truss gusset plate connection shown in Figure 3. Irvin's findings supported Whitmore's in regards to the location of maximum tensile, compressive and shear stresses in the gusset plate occurred at the ends of the compression, tension and plane above the horizontal chord. However, Irvin proposed an alteration to the Whitmore effective width concept by drawing the two 30 degree lines from the bolt group's center of gravity to the last bolt row, as opposed to the outer gage lines, resulting in a narrower effective width. Research by Hardin corroborated Irvin's results and recommendations.

Davis (1967) and Vasarhelyi (1971) were the first to use finite element analysis methods to investigate stress distributions in gusset plates. Davis was the first to replicate Whitmore's findings analytically. Vasarhelyi conducted both experimental tests and finite element analysis on a half-scale Warren truss with similar geometry to Whitmore's test specimen. Vasarhelyi also found that Whitmore's approximate methods were suitable for calculating the magnitude of maximum stresses, however the location of maximum stresses may differ depending on how the connection is loaded.

Yamamoto (1986) reported on elastic stress distributions in full-scale Warren truss and Pratt truss gusset plate connections, obtained from tests conducted for the Honshu-Shikoku Bridge Authority in Japan. Yamamoto found that Whitmore's methods 
were adequate for predicting maximum stress magnitudes, but the locations of the maximum stresses can shift depending on the global loading condition of the connection, specifically whether the bottom chord is loaded in tension or compression. This finding is in agreement with Vasarhelyi (1971).

\subsection{Gusset Plate Failure States in Tension}

Due to the large scale and complexity involved in testing bridge connections, most research investigating gusset plate failure states is confined to either small-scale bridge truss connections, or simple connections found in lateral bracing systems for buildings. Thornton (1984) presented a design methodology for all components of a lateral bracing connection common to buildings, including gusset plates. The design approach is based upon equilibrium, material yielding requirements and stiffness to address buckling and fracture resistance. It is assumed that gusset plate tensile capacity is governed by tear-out of the gusset plate - a failure mode analogous to the block shear where the sum of the net tensile and shear section strengths are calculated assuming bolt diameter plus $1 / 16 "$ hole allowance.

Bjorhovde and Chakrabarti (1985) tested 6 gusset plate connections under tension, similar to the connection shown in Figure 4. The test matrix included two plate thicknesses and three different bracing member orientation angles. For all samples, the gusset plate failed by tensile rupture along the last row of bolts of the bracing member. Further tearing occurred with samples where the Whitmore section intersected the edges of the gusset plate. Work by Hardash and Bjorhovde (1985) also focused on gusset plate tensile failures. Using samples like the one shown in Figure 5, block shear failure state was examined in detail. The experimental program was designed to look at the effects of 
connection length, distance between outside bolt lines, plate thickness, bolt diameter, material yield, and plate geometry on the plate's tensile strength capacity. A total of 42 samples were tested, all of which failed in block shear with the same characteristic failure progression; net tensile rupture at the last row of fasteners followed by various stages of shear yielding along the outer bolt rows. Hardish and Bjorhovde proposed that the nominal ultimate tensile capacity $\left(R_{n}\right)$ of a gusset plate is equal to the sum of the net tensile strength along the last row of fasteners and shear strength along the connection length and presented the following equations:

$$
\begin{aligned}
& R_{n}=F_{u} S_{n e t} t+1.15 F_{\text {eff }} l t \\
& F_{\text {eff }}=\left(1-C_{t}\right) F_{y}+C_{t} F_{u} \\
& C_{t}=0.95-0.047 l
\end{aligned}
$$

where:

$F_{y}, F_{u}=$ yield and ultimate tensile strength respectively

$S_{n e t}=$ net gage length between outside bolts (total gage length minus bolt holes)

$t=$ plate thickness

$F_{\text {eff }}=$ effective tensile stress

$l=$ total connection length in inches

The connection length factor $C_{t}$ was introduced to account for the experimental findings showing ultimate shear stress governing in shorter connections, and shear yield stress controlling for longer connections.

A review conducted by Kulak and Grondin (2001) comparing LRFD block shear equations from the AISC Specifications to published experimental data. The LRFD equations for block shear tensile capacity, $R_{n}$, per the Specifications are as follows: 


$$
R_{n}=0.6 F_{u} A_{n v}+U_{b s} F_{u} A_{n t} \leq 0.6 F_{y} A_{g v}+U_{b s} F_{u} A_{n t}
$$

where:

$A_{g v}=$ gross area subject to shear

$A_{n t}=$ net area subject to tension

$A_{n v}=$ net area subject to shear

$U_{b s}=1.0$ for gusset plates

Kulak found Equation [4] gave overly conservative predictions of gusset plate capacity, and did not reflect the observed failure mode progression seen in experimental tests. The reason is because the shear resistance is assumed to be 0.6 times the tensile strength, therefore assuming the tension surface has adequate ductility to develop the full capacity along the shear planes, an assumption that is in opposition to experimental evidence. Therefore, Kulak recommended the equations presented by Hardish and Bjorhovde be used for a better estimate of gusset plate tensile capacity.

\subsection{Gusset Plate Failure States in Compression}

The primary failure mode of gusset plates in compression is buckling. According to Thornton (1984), compressive capacity can be calculated by considering the gusset plate as an idealized column with a width of unity along the brace's line of action and length from the end of the Whitmore section to the plate edge, similar to that shown as $L_{2}$ in Figure 6. The slenderness ratio $k L / r$ is calculated assuming a fixed-fixed boundary conditions with an effective length factor of $k=0.65$. Alternatively, one can use the average of $L_{1}, L_{2}$ and $L_{3}$ for the section length, provided it does not produce a length greater than $L_{2}$. Thornton asserted that this is a conservative design approach since both plate action and the gusset's post-buckling strength is ignored. 
Hu and Cheng (1987) conducted experimental tests on gusset plate buckling capacity in a simple braced frame connection; considering effects of gusset plate thickness, boundary conditions, eccentricity and edge stiffening reinforcement. Thin gusset plates were found to buckle at loads significantly lower than those predicted using Whitmore's effective width approach. Load at bifurcation was also shown to be highly dependent on boundary conditions (sway and non-sway conditions were tested), plate thickness and whether edge stiffeners were used. Yam and Cheng (1993) conducted a follow-up investigation testing similar connections in compression. The test matrix included varied plate thicknesses, plate size, brace angle orientation, and other variations of the framing members. Yam and Cheng reported that the gusset plate's compressive capacity was almost directly proportional to plate thickness as well as dependent on sway versus non-sway boundary conditions. They also proposed modifying the angle used to the Whitmore effective width definition from 30 to 45 degrees to more accurately account for the high degree of plate yielding and subsequent load re-distribution that occurs pre-buckling.

Yamamoto (1988) published testing results on the buckling strength of full-scale gusset plate bridge connections similar to those from his previous study on elastic stress distributions. The loading truss used along with a representative test specimen is shown in Figure 7. Experimental results were compared to the calculated design buckling strength per guidelines by the Japan Society of Civil Engineers (JSCE, 1976). All the connections failed because of highly localized buckling surrounding the compression diagonal at loads approximately 2.5 to 3.7 times their design compression capacity. Of note, the paper makes no discussion about the boundary conditions imposed on the 
connection, although photographs of the failed samples suggest a high degree of out-ofplane constraint was present due to the short length of the members and the presence of large end plates and stiffeners at the member ends.

Gross (1990) conducted experiments on gusset plate connections for a typical building lateral bracing system. The test specimens included a top and bottom gusset

plate on either side of a beam framed into a column subassembly (Figure 8). Parameters of interest were bracing member eccentricity relative to the beam to column working point intersect, and whether a strong or weak-axis column alignment was included in the subassembly. The subassembly was loaded laterally across the two top pins, inducing tension in the top diagonal member and compression in the bottom diagonal member. Two of the three samples tested failed by buckling of the bottom gusset plate, with the third sample failing in block shear in the top gusset plate. Gross found that calculating the gusset plate buckling capacity per AISC Engineering for Steel Construction (1984), yielded values close to the experimental, provided that using an effective length factor of $k=0.5$ instead of Thornton's $k=0.65$. By decreasing the effective length factor, the calculated compressive capacity is increased, hence accounting for additional strength from post-buckling and plate action in the gusset plate.

\subsection{Past Bridge Gusset Plate Failures}

Only two known cases of gusset plate failures by the author exist on record in the United States; namely the 1996 gusset plate failure on the Grand River Bridge in Lake County, Ohio (NTSB, 2008) (NTSB, 2008) (NTSB, 2008) and the 2007 collapse of the I35W Bridge in Minneapolis, Minnesota. They are illustrative in demonstrating that the 
possibility that gusset failure is a continuing risk that can be sudden and catastrophic. Below is a brief summary of findings from the forensic investigations.

\subsubsection{Grand River Bridge Gusset Plate Failure (Lake County, Ohio)}

The Lake County Grand River Bridges were twin bridges located about 30 miles east of Cleveland, Ohio. Classified as steel deck truss bridges, each bridge consisted of 5 spans and carried two lanes of traffic in each direction for Interstate 90. Spans \#1 and \#5 were simply supported approaches; spans \#2 and \#4 were cantilevered deck trusses that supported a suspended truss at span \#5. The bridge was designed in 1958 and opened to traffic in 1960.

According to a NTSB Factual Report on Ohio Bridges (2008), on May 24, 1996, the eastbound bridge experienced a gusset plate buckling failure during a repainting project, shown in Figure 9. One of the two lanes was closed to traffic during work. Failure was supposedly initiated by vehicles and equipment involved with the repainting project positioned over the failed node, combined with an overloaded truck crossing in the open traffic lane. The gusset plate failure did not cause total collapse of the bridge, but did result in an approximately 3" displacement of the superstructure above the failed nodes. Investigation revealed that extensive corrosion from salt-contaminated water, not adequately assessed in previous inspections, which had resulted significant section loss. This section loss left the connection incapable of carrying the additional loads imposed by the maintenance project on the day of failure. Post-failure investigation included a review of the remaining connections. It was found that many gussets failed the unsupported edge length restriction per AASHTO, and many members were not mitered 
at the ends, resulting in excessive plate regions in the middle of the connection where the working points meet, effectively causing long effective lengths in the gussets. FHWA conducted FEA analysis on the failed connection, concluding that the design thickness was marginal at best; even before the section loss from corrosion was considered.

\subsubsection{I-35W Bridge Gusset Plate Failure (Minneapolis, MN)}

On August 1, 2007, the I-35W Bridge in Minneapolis, Minnesota suddenly collapsed. The bridge spanned 1907 feet over the Mississippi River and gorge. The collapse across approximately 1000 feet of the bridge occurred during the afternoon rush hour resulting in 13 deaths, 145 injuries and the loss of 111 vehicles. The bridge was a three span $\left(265^{\prime}, 458^{\prime}, 265^{\prime}\right)$ deck truss bridge with a continuous concrete deck (108' wide) running over longitudinal stringers. The bridge was designed in 1964, opened in 1967 and had undergone two major upgrades in 1977 and 1988. These upgrades imposed additional loads on the bridge by increasing the deck slab thickness by 2 inches, adding two traffic lanes (8 total) and extra reinforced concrete barriers. A patching and overlay project was underway when the failure occurred, which imposed additional construction loads due to aggregate, equipment and vehicles placed directly over the U10 connection.

The forensic investigation conducted by the NTSB (2008), implicated the U10 and U10' gussets as the likely cause of failure. Review of 2002 inspection records showed out-of-plane distortions approximately equal to the thickness of the plate in the U10 gusset plates in 2002. A sketch of the connection and photograph of the out-ofplane distortions are shown in Figure 10 (a) and (b) respectively. Evidence from the wreckage showed several fracture planes along the compression diagonal at the U10 
nodes (Figure 11). A design review revealed that the plate thicknesses at U10 and L11 nodes were required to be 1", as opposed to the $1 / 2$ " plates on the constructed bridge.

\subsection{Gusset Plate Load Rating Methods According to FHWA}

After the I-35W bridge collapse in Minneapolis, FHWA released a guidance report detailing the minimum requirements for load rating riveted and bolted gusset plates on bridges (FHWA, 2009), hereinafter referred to as the Load Rating Guidance Report, and is based on latest edition of AASHTO LRFD, LRFR and LFR. The following strength limit states are addressed: resistance of fasteners, gross section plate yielding, net section plate fracture, and both tensile and compressive resistance. The summary below briefly summarizes of the above stated strength limit states.

For the strength limit state fasteners, the axial load from each member is assumed to be distributed equally to the fasteners. Fasteners are then evaluated for shear and bearing failure.

Several strength limit states are considered for the gusset plates under tension. The factored resistance, $P_{r}$, for gross section yielding and net section fracture in a gusset plate are evaluated across the Whitmore effective width using Equations 4 and 5 respectively.

$$
\begin{aligned}
& P_{r}=\phi_{y} F_{y} A_{g} \\
& P_{r}=\phi_{u} F_{u} A_{n} U
\end{aligned}
$$

where:

$\phi_{y}=$ resistance factor for tension yielding $=0.95$

$\phi_{u}=$ resistance factor for tension fracture $=0.80$ 
$A_{n}=$ net cross-sectional area of the plates along Whitmore effective width $A_{g}=$ gross cross-sectional area of the plate along Whitmore effective width $U=$ shear lag reduction factor $=1.0$ (for gusset plates, i.e. no shear lag)

Block shear rupture resistance is calculated along the controlling pattern of tension and shear planes for each connected member as follows.

For $A_{t n} \leq 0.58 A_{v n}$, then

$$
P_{r}=\phi_{b s}\left(0.58 F_{y} A_{v g}+F_{u} A_{t n}\right)
$$

Otherwise:

$$
P_{r}=\phi_{b s}\left(0.58 F_{u} A_{v n}+F_{y} A_{t g}\right)
$$

where:

$\phi_{b s}=$ resistance factor for block shear $=0.80$

$A_{v g}=$ gross area along shear stress planes

$A_{t g}=$ gross area along tension stress planes

$A_{v n}=$ net area along shear stress planes

$A_{n t}=$ net area along tension stress planes

The factored shear resistance for gusset plates, $\mathrm{Vr}$, is evaluated across the respective governing gross and net section shear plane passing through the gusset plate.

$$
\begin{aligned}
& V_{r}=\phi_{v y} \times 0.58 F_{y} A_{g} \Omega \\
& V_{r}=\phi_{v u} \times 0.58 F_{u} A_{n}
\end{aligned}
$$

where:

$\phi_{v y}=$ resistance factor for shear yielding on the gross section $=0.95$

$\phi_{v u}=$ resistance factor for shear fracture of the net section $=0.80$

$A_{g}=$ gross area along critical shear plane

$A_{n}=$ net area along critical shear plane 
$\Omega=$ reduction factor taken as 1.0 if gusset plates have enough stiffness to prevent buckling, or 0.74 in absence of more rigorous analysis/criterion to quantify stiffness

A gusset plate's buckling capacity is complex and is influenced by the plate's state of stress, boundary conditions and system geometry. The Load Rating Guidance Report allows the ultimate factored compressive capacity $\left(P_{r}\right)$ to be calculated as follows per AASHTO LRFD Articles 6.9.2.1 and 6.9.4 in lieu of more rigorous analysis.

Given,

$$
\lambda=\left(\frac{k L}{r_{s} \pi}\right)^{2} \frac{F_{y}}{E}
$$

For $\lambda \leq 2.25$, then

$$
P_{r}=\phi_{c} 0.66^{\lambda} F_{y} A_{s}=\phi_{c} 0.66^{\lambda} F_{y} w_{l} t
$$

Otherwise:

$$
P_{r}=\phi_{c} \frac{0.88 F_{y} A_{s}}{\lambda}=\phi_{c} \frac{0.88 F_{y} w_{t} t}{\lambda}
$$

where:

$k=$ effective length factor

$L=$ Whitmore effective length (see Figure 6)

$r_{s}=$ Radius of gyration $=\sqrt{I_{g} / A_{g}}$

$w_{l}=$ Whitmore effective width

$\phi_{c}=$ resistance factor for members in compression $=0.9$

It is left to the engineer's judgment to select an appropriate effective length factor $k$, based on the anticipated boundary conditions of the gusset plate, i.e. whether sway or non-sway conditions exist. AASHTO LRFD also places an upper limit of the length-tothickness ratio of $2.06 \sqrt{E / F_{y}}$ for the design of unsupported edges of gusset plates to 
prevent gusset plate buckling, but is not required by the Load Rating Guidance Report when evaluating existing connections.

\subsection{Previous FEA Gusset Plate Models}

Many of the aforementioned studies developed analytical models based on the finite element method in conjunction with their experimental work. The following is a summary of previous methods used in the literature to model gusset plate stress distributions and failures.

Davis (1967) was among the early users of FEA to investigate gusset plate stresses in the elastic range, where he replicated Whitmore's findings analytically in his thesis research. Vasarhelyi (1971) also employed finite element analysis on stress distributions across critical planes of the gusset plates he tested experimentally. He reported close agreement between the analytical and experimental results, but did not provide specific details to the analytical approach.

More recent FEA models have been developed using Abaqus finite element software to model tensile and compressive failure states. Walbridge et al. (2005) presented a model to investigate gusset plate failure states under monotonic tension, compression and cyclic loading. The model was based upon previous analytical models developed by Yam and Cheng (1993), which were used to model gusset plate buckling capacity. Abaqus S4R shell elements were used to model the gusset plate. Both a perfect elasto-plastic and isotropic strain-hardening material models were examined. Load was delivered through two splicing members on each side of the gusset plate; with the bolt connections modeled as either rigid beam elements, or as one-dimensional spring elements to incorporate load displacement behavior of the fasteners. Bolt holes were not 
explicitly modeled in the gusset plate. The model was calibrated with experimental data from Rabinovitch and Cheng (1993) and Yam and Cheng (1993).

Walbridge found that the perfect elasto-plastic material model produced better predictions of ultimate tensile strength, whereas the isotropic strain-hardening model tended to over-predict ultimate tensile strength. Walbridge hypothesized this may be due to the exclusion of bolt holes in the model, and that the excess material along the block shear failure planes contributed to the model's overstrength. Buckling capacity was significantly affected by the magnitude of initial out-of-plane distortion introduced in the gusset plate prior to loading, as well as the state of boundary conditions imposed on the splicing members. It was also found that incorporating load-displacement behavior of the fasteners had little effect on the predicted global load-displacement behavior of the plate, or the predicted ultimate strength in tension and compression.

Sheng et al. (2002) used a model analogous to Walbridge's model to conduct a parametric study on gusset plate buckling strength. Among the parameters considered included the effects of unsupported edge length, degree of rotational restraint imposed on the brace member, and the stiffness and length of the brace member. It was shown that increased unsupported edge length, increased rotational restraint, decreased brace member flexural stiffness and increased brace member length, all decreased the gusset plate's buckling capacity.

Following the I-35W Bridge collapse in Minneapolis, a detailed finite element model was constructed to elucidate on the hypothesis that collapse was initiated at an under-designed gusset plate, and is described by Liao et al. (2011). A global model of the entire bridge was developed using the software SAP 2000 to determine the load 
demands on the U10 connection through the bridge's service life. A connection-level model of the U10 connection was developed using Abaqus. The gusset plate was modeled using C3D8 (linear brick element) elements from the Abaqus element library. Member stubs were included in the connection model. Rivets and their corresponding holes were explicitly modeled at the L9/U10 diagonal, represented by rigid cylindrical shells that transferred load through contact interaction to the rivet holes in the gusset plate. Rivets on the remaining sections were modeled with rigid beam elements through the hole centers. The contact interaction definition between the rivets and bolt holes neglected tangential friction. The model represents the highest degree of complexity in a gusset plate connection reported in the literature, containing approximately 120,000 elements per gusset and was run on an IBM Power4 supercomputer at the University of Minnesota Supercomputing Institute.

Conclusions from the FEA study corroborated the forensic and design review investigations by the NTSB (2008), namely that a significant portion of the U10 gusset plates may have already been yielded at the time of collapse. The added construction weight, combined with insufficient strength at the U10 node were the main contributors to the bridge's collapse. Liao also suggested that the interaction between compression and shear may have played an important role in the failure and recommended further study.

\subsection{Summary}

The conclusion that gusset plate tensile capacity is governed by block shear is well established in the literature. Although equations for calculating block shear differ slightly between Hardish and Bjorhovde (1985), AISC Specifications, and AASHTO, 
they all are capable of adequately predicting gusset plate tensile resistance with varying levels of conservatism. On the other hand, compressive capacity is considerably more challenging for a designer to assess given the current design approach, which relies on reducing the gusset to some equivalent column and selecting an appropriate effective length factor. This problem manifests itself in the literature by numerous alterations presented - such as adjusting the Whitmore block definition, or using different effective length factors - in order to align calculated buckling capacity with experimental and analytical results. Also, the magnitude of out-of-plane gusset plate are not incorporated into design or load rating procedures per the Load Rating Guidance Report, which can have a significant impact on buckling capacity. 


\subsection{Numerical Modeling}

\subsection{Objectives}

The primary goal of this effort is to develop a calibrated FEA model capable of evaluating gusset plate stresses and ultimate strength limit states. Experimental data from ongoing research at Oregon State was provided to validate the connection model. A secondary objective was to develop a gusset connection model such that it could be readily adapted to analyze multiple connection geometries while minimizing the development process. This was realized by utilizing the Abaqus scripting environment to automate a significant portion of the model development, thereby aiding in existing parametric studies and building in the capability for rapid analysis across multiple connection in future studies. Representative scripts used to construct some of the smallscale bolt models and gusset plate connection models are included in Appendix B. Finally, computational efficiency was addressed by examining a number of modeling techniques, ranging from simplified to more robust; to assess the level of detail required to obtain accurate results.

\subsection{Fastener Modeling}

Several approaches exist for modeling bolts and their load transfer through shear from one plate to another. The method chosen to model bolted connections has the greatest influence on the overall complexity of the connection model, particularly when considering the large number of fasteners found in bridge connections. Typically, two approaches are taken; modeling the bolted connection with or without the bolt holes included in the plate. Exclusion of bolt holes is the simplest approach from a 
development point of view, though may not be able to capture net section-related failure modes. Conversely, inclusion of the bolt holes may better capture plate behavior, since bolt holes can account for a significant amount of material lost along net-section fracture planes, but adds significant complexity to the model by creating complicated meshing tasks, increased number of elements and difficulty in applying realistic loads to the inner hole surfaces. The application of load to the bearing surfaces of the bolt holes also poses significant challenges for the modeler. One approach to alleviate this is to define equivalent edge loads along the anticipated bolt hole contact surface. This method has been used successfully by Huns et al. (2006) to model block shear failure modes and yielded analytical results close to experimental values. However, this approach is only valid when the direction of load application is known, and equal distribution of load between all fasteners in the member connection is assumed; neither of which may be appropriate for bridge connections.

\subsubsection{Beam Element Bolt Models}

Perhaps the simplest and most common method is to idealize bolts as a onedimensional rigid beam element that ties all degrees of freedom between the two connected nodes, where the nodes correspond to the bolt hole centers on adjoining plates. In Abaqus, this is achieved by using a rigid multi-point constraint (MPC) element positioned at the bolt hole center between two connected plates. Note that although this study uses rigid definitions for its beam element bolt models, Abaqus does allow experimental load-displacement behavior and failure criteria to be incorporated into the MPC element definition. Several examples exist in the literature that use this method, 
with and without fastener load-displacement behavior, to represent bolted connections (Walbridge et al. (2005), Sheng (2002), Ocel and Wright (2008)).

A related bolt modeling approach is the use of Abaqus Fastener (AF) elements, a proprietary element formulation similar to MPC elements, except that a radius of influence equal to the bolt radius about each connection point is added to the element definition. All elements inside the radius of influence are rigidly tied to the connection points, thereby "including" the influence of the bolt without explicitly modeling the bolt hole itself.

\subsubsection{Three-Dimensional Contact Bolt Models}

Three-dimensional (3D) contact modeling of bolt-plate interaction represents the most detailed method for modeling load transfer of a bolt through bearing on to a plate, and is correspondingly the most demanding regarding model development and computation time. This approach requires the use of a three-dimensional solid representation of the gusset plate, since shell element formulations lack numeric stability when contact is imposed along the shell edge. Several examples of 3D contact bolt models exist in the literature, most of which are limited to simple connections with only a few bolts. Chung and Ip (2000) developed a 3D contact model to investigate failure of bolted lap connections under tension. Correlation between experimental and analytical results were good, however several simplification measures were taken - including the use of symmetry, rigid definitions of the bolt, out-of-plane restrains, and the number of bolts (3 maximum) - in order to obtain workable computation times. Ju et al. (2004) expanded on Chung and Ip's model by including elasto-plastic behavior in the bolt shanks, bolt pre-tension and steel material failure criteria. Results were compared per 
AISC Specifications, which were in good agreement with analytical results. However, the connections considered were single lap joints with a maximum of three bolts subject to monotonic tension.

The largest scale known by this author of the use of $3 \mathrm{D}$ contact bolt modeling in a structural engineering application is in the FEA model presented by Liao et al. (2011), which was developed to investigate the U10 gusset failure on the I35-W Bridge in Minneapolis. The model used 3D contact interactions to model load transfer from rivets (152 in total) at the L9-U10 compression diagonal to the gussets, with the bolts being idealized as rigid cylindrical shells. The remaining rivets in the connection were modeled with rigid MPC elements. The model delivered a high level of detail regarding the locations and progressions of yield zones in the gussets, but at significant computational cost as illustrated by the investigators' decision to limit the implementation of the 3D contact bolts to the L9-U10 diagonal, and the use of the University of Minnesota Supercomputing Institute to run the model.

\subsubsection{Radial-Spring (RS) Bolt Model}

In an effort to develop a shell-compatible bolt model analogous to 3D contact bolt models discuss above, a simplified idealization of a bolt was constructed out of onedimensional elements. Named the Radial-Spring (RS) bolt model and shown Figure 12, this simplified model consists of three distinct types of one-dimensional elements. A rigid MPC beam element is oriented along the bolt shank connecting the member to the gusset plate. Non-linear spring elements with high compressive stiffness and very low tensile stiffness transfer bearing loads from the MPC beam element to the gusset plate bolt hole. Four wire elements radiating from the member-side of the MPC beam element 
to the bolt hole edges define a slip-plane restraint. The slip-plane restraint elements added necessary stability to the radial spring array by allowing free translation of the bolt hole edges within the plane of the gusset plate, but preventing the hole from moving outof-plane relative to the member. In essence, the slip-plane restraint simulates clamping between the bolt head and outer plate preventing excessive deflections of the hole along the bolt shank axis under high loads. Preliminary investigations showed that using four slip-plane restraint elements was the minimum required to stabilize the radial spring element array. The RS bolt model is similar in formulation to one proposed by Siekierski (2009), who compared several simplified bolt modeling techniques in angle-gusset connections subject to tension, one of which used a radial array of non-linear spring elements to transfer bolt bearing loads to the plate. Siekierski's bolt model differed in that it included radial spring arrays on both sides of the bolt and lacked a slip plane definition. Siekierski incorporated a second array of beam elements placed at the plane of contact between the bolt head/nut and the outer steel plate surface to simulate the clamping force from the bolt head and nut.

\subsection{Single Bolt Connection Model}

An Abaqus model was created to compare the above-mentioned fastener modeling techniques. A single bolt model was used to select appropriate shell elements, establish a rational mesh regime and compare load-displacement behaviors. Parallel experimental tests were not conducted for this phase, because there is sufficient data in the literature showing $3 \mathrm{D}$ contact bolt modeling correlates closely with experimental data for simple connections in tension. Therefore, a 3D contact bolt model - using modeling 
strategies consistent with published studies - was used as the benchmark to compare against the MPC, AF and RS bolt models.

For the 3D contact model, a 6-3/8" x 3-3/4" x 1/4" plate with a fixed base and a 3/4" diameter bolt hole positioned at the top was used (see Figure 13a). The fixed base boundary condition was considered realistic for modeling a simple plate subject to tension. The minimum edge distance from the bolt hole to plate edge was $1-1 / 2$ ". The bolt shank was idealized as a rigid cylindrical shell positioned at the hole center. C3D8 elements from the Abaqus element library were used throughout the plate, with three layers of elements distributed across the plate thickness. A partition consisting of a circle twice the hole diameter and a centered horizontal and vertical lines was created around the bolt hole to establish uniform element distribution. A structured mesh and advancing front algorithm were used to mesh the bolt hole partition and remaining plate respectively. The mesh refinement around the bolt hole was set to match the final mesh used in the RS bolt model. Global seed values were used on the remaining plate mesh to create element sizes close to those found in the bolt hole partition. Material properties were assigned as described in Section 3.4. A "hard" contact interaction was defined for normal behavior and tangential behavior was defined as "smooth sliding"; in other words, surface friction on the bolt hole surface was neglected. This was justified since it is not possible to replicate tangential friction in the current RS bolt model formulation, even though friction forces do exist in actual bolt hole-bearing interactions. Displacement was imposed on the bolt shank to load the plate in tension.

The plate used for the RS bolt model was idealized as a shell with an identical profile and assigned the same thickness as the 3D contact model (see Figure 13b). The 
bolt shank was idealized as a rigid beam element positioned at the hole center. S4 and S3 elements were selected from the Abaqus element library for the shell portions of the model. The radial spring array consists of axial spring elements radiating from the hole center to equally spaced vertices around the bolt hole. Non-linear stiffness definitions were assigned to the radial springs with very low tensile stiffness $(0.01 \mathrm{kip} / \mathrm{in})$ and high compressive stiffness (711.5 kip/in for 32 radial springs on 1/4" plate). Compressive stiffness was calculated based on an equivalent wedge-shape section of a shank from an A325 bolt and having the same thickness as the plate. Preliminary studies showed that load-displacement behavior was not sensitive to varying compressive spring stiffnesses. Vertical displacement was imposed at the hole center to simulate tensile loading of the plate.

The MPC beam and AF bolt models used the same plate dimensions, shell formulations and boundary conditions as the RS bolt model, except that no hole was included in the plate. The AF element was assigned a radius of influence of $3 / 8$ " which corresponds to the $3 / 4$ " bolt hole A "structural distribution" rule was used to define the constraint method for elements falling within the radius of influence. A structured mesh algorithm was used to obtain a plate mesh refinement equivalent to the RS bolt model. An additional base plate was included with the test model in the assembly in order to provide two surfaces of which to attach the MPC and AF elements. The base plate was given a fixed boundary condition and displacement was imposed on the bottom of the test plate to achieve tensile loading. 


\subsubsection{Single Bolt Connection Model - Results and Discussion}

Convergence trials were conducted on the RS bolt model to establish the minimum number of radial springs required, and the degree of local mesh refinement required. Global load-displacement behavior under tension was chosen as the convergence metric. Figure 14 shows load-displacement behavior as a function of the number of radial springs used, where it was determined that 32 equally spaced radial springs were required for convergence. Next, load-displacement behavior was checked for convergence for four local meshes of increasing refinement (Figure 15), where it was determined that two element layers around the bolt hole were sufficient.

The distribution of equivalent plastic strain (PEEQ) and load-displacement behavior are shown in Figure 16 and Figure 17 respectively for the single bolt models. The RS bolt and 3D contact models were in very close agreement regarding loaddisplacement behavior and the location of plastic deformation. The MPC beam model generated significantly different behavior compared to the 3D contact model; although this can be expected due to the lack of a bolt hole in the plate, and the fact that the MPC beam is delivering what is essentially a point load, inducing highly localized effects. The AF bolt model produced a load-displacement curve with a similar shape to the $3 \mathrm{D}$ contact model, however with significant overstrength. This can be explained by examining the PEEQ contours and deformed shape of the plate, where necking of the plate occurs below the connection point. The rigid radius of influence used in the AF definition engages all of the material surrounding the hole, forcing the zone of plastic deformation on the tension side of the bolt hole and thus increasing its tensile capacity. In essence, the AF 
behaves more like a spot weld than a bolt acting in bearing, and indicates that the using this technique to model bolt bearing-plate interactions should be done judiciously.

\subsection{Multi-Bolt Connection Model}

In order to test the bolt models' performance in capturing gusset plate tensile failures on a small scale, a series of experiments were conducted on small-scale gusset plates. The two samples, denoted Sample A and B, were designed to fail in net-section rupture and block shear respectively (Figure 18). Both samples were made from 3/16" thick A36 mild steel plate and tested on a MTS vertical load frame equipped with a 110 kip capacity actuator. The upper and lower grips were constructed to connect the samples to the load frame and were designed to remain elastic under test loads. Load was measured from an in-line load cell. Plate displacement was measured with a linear displacement transducer (LDT) as pictured in Figure 19.

The approaches used in the single bolt models were applied to create the multibolt connection models. A few additional partitions were added to the plate in order to smooth the mesh transition from the bolt holes to the plate. All four previously modeling methods were compared to experimental results. Steel coupons were prepared from the same material used to make the test samples, in both longitudinal and transverse directions relative to the rolling orientation. True stress-strain data was then calculated from an average of the longitudinal and transverse coupon data, and an approximate relationship was input into the Abaqus plasticity definition (Figure 20). 


\subsubsection{Sample A - Results and Discussion}

The observed experimental failure mode for Sample A was net-section rupture along the bottom row of bolts at the weak connection. Experimental and analytical capacities for Sample A are compared with the nominal block shear tensile capacities per the Load Rating Guidance Report in Table 1Error! Reference source not found.. Analytical to experimental $(\mathrm{A} / \mathrm{E})$ ratios are to show analytical deviations from the experimental values; where values less than one indicate a conservative prediction and values greater than one indicate a non-conservative prediction. Figure 21 and Figure 22 show PEEQ contours and load-displacement behaviors from the four models and experimental results from Samples A. Material damage definitions were not included in the models material definitions, in order to maintain high computational efficiency. Therefore "failure" of the analytical sample was defined as the greater of the maximum load reached, or the load corresponding to a vertical displacement at which the experimental sample reached maximum tensile strength. For Sample A, the displacement associated with maximum experimental tensile strength was 0.2 "'.

The calculated net-section rupture capacity of Sample A per the Load Rating Guidance Report gave a conservative estimate of strength with an A/E ratio of 0.92 . Both the 3D contact and RS bolt models gave conservative predictions of capacity as indicated by the $\mathrm{A} / \mathrm{E}$ ratios of 0.90 and 0.89 respectively, as well as similar loaddisplacement behavior. Sample A results showed that both the 3D contact and RS bolt models developed PEEQ contours consistent with rupture along the bottom row of bolts on the weak connection, similar to the observed failure mode in the experimental sample. The MPC and AF element models showed overstrength compared to the experimental 
results, with $\mathrm{A} / \mathrm{E}$ ratios of 1.4 and 1.1 respectively. The reason for this can be seen in the PEEQ contours, which indicate the majority of plastic yielding occurring in the gross section below the weak bolt group for the MPC and AF element models. The MPC and AF models reflect this since the gross section has greater capacity than the net section. The lack of holes made it difficult for the MPC and AF models to closely capture netsection effects in Sample A.

\subsubsection{Sample B - Results and Discussion}

The observed failure mode for Sample B was block shear at the weak connection. Experimental and analytical capacities for Sample B are summarized and compared in Table 1Error! Reference source not found.. Ultimate tensile capacity for the analytical models was defined as the greater of the maximum load reached, or the load corresponding to a vertical displacement at which the experimental sample reached maximum tensile strength. For Sample B, the maximum tensile capacity occurred at a displacement of 0.3 ".

Figure 23 and Figure 24 show PEEQ contours and load-displacement behaviors from the four models and experimental results from Samples B. The calculated block shear capacity for Sample B per the Load Rating Guidance Report gave a conservative estimate of strength with an $\mathrm{A} / \mathrm{E}$ ratio of 0.91 . Both the $3 \mathrm{D}$ contact and $\mathrm{RS}$ bolt models also gave conservative predictions of capacity as indicated by the $\mathrm{A} / \mathrm{E}$ ratios of 0.87 and 0.94 respectively, as well as similar load-displacement behavior. However, the 3D contact model failed to reach a solution before the model failure criteria was met and may have an artificially low tensile capacity as a result. The $3 \mathrm{D}$ contact and RS bolt models 
developed PEEQ contours consistent with block shear failure along the shear and tensile rupture planes at the weak connection, similar to the observed experimental failure mode. The MPC and AF element models showed significant overstrength compared to the experimental results, with $\mathrm{A} / \mathrm{E}$ ratios of 1.37 and 1.64 respectively. Unlike the netsection rupture models, yielding developed over the shear block planes on all four models. However, the exclusion of holes in the MPC and AF models significantly increases the material along the shear and tension planes and correspondingly artificially increased their tensile capacity predictions.

\subsubsection{Summary}

On a small scale, different bolt modeling methods have a considerable impact on predicting tensile failure. The MPC and AF models failed to reproduce net-section failure consistent with the experimental results, and exhibited overstrength when compared to analytical predictions. The 3D contact and RS bolt models were able to both predict ultimate failure and generate PEEQ profiles consistent with the observed experimental failure state. Further, the 3D contact and RS bolt models tracked well with experimental load-displacement curves and each other. This suggests that the RS bolt modeling approach, when properly formulated, can act as a 3D contact modeling equivalent in shell-formulated plates.

\subsection{Gusset Connection Model Description}

The connection-level gusset plate model was developed using Abaqus 6.9. The three primary metrics were chosen to evaluate the gusset connection were elastic stresses, and gusset plate capacity at M4 under tension and compression. Only one connection 
geometry was considered in this study, analogous to the specimen tested being used in a parallel experimental study at Oregon State University. The experimental test setup and FEA model are shown in Figure 25(a) and (b). The connection consists of a bottom chord (M1 and M5), a vertical chord (M3), and two diagonal chords (M2 and M4). M1 and M2 are fixed on the experimental load frame and actuators are attached to M3, M4 and M5, each capable of delivering compressive loads. Global boundary conditions were imposed at the ends of each member such that they reflected the conditions found in the experimental tests. Members were modeled with a combination of wire and extruded shell features; with the transition occurring where the members overlapped the gusset plates (Figure 26). The beam-to-shell junction in each member was rigidly tied to form a continuous member. Partitions were created on the shell portion of the member to define vertices corresponding to bolt hole centers. The actuator load capacities, along with the boundary conditions are illustrated in Figure 27. The gusset plate was designed to fail in compression at M4 by reducing the bolt spacing at the M4-gusset connection, which effectively narrowed the Whitmore effective width and increased the Whitmore effective length. This was to help develop a rational instrumentation plan by knowing the failure zone prior to testing, as well as insure the connection's strength capacity was kept within the testing limits of the actuators.

Three different gusset connection models utilizing the three bolt models described in Section 3.3 were implemented, hereinafter referred to as the MPC, AF and RS bolt models. Python scripts were concurrently developed to automate the construction and assembly of the gusset connection model. The MPC and AF bolt models were the least complex, using a single wire element to represent each bolt. The RS bolt model was 
substantially more complex. For each RS bolt, a hole must be created in the gusset, partitioned, individually meshed, and connected to the plate with 38 individual wire elements (32 radial spring, 1 MPC element, 4 slip-plane elements); meaning that for our gusset connection with 608 bolts, there are 23,104 wire elements required just to model the bolts. Additionally, the gusset plate mesh must be significantly denser to accommodate the required local element density around each hole. Based on the single bolt connection modeling, each hole requires a local mesh containing 64 elements. Combined with the transition from the local bolt meshes to the plate mesh, this translated to a roughly 10 fold increase in the number of gusset plate elements compared to the MPC and AF elements. The only way to fully implement RS bolts on a connection with so many bolts in a timely manner is by using Python scripts, which can automate this process. A Python script used to construct the RS bolt gusset connection model through the assembly and meshing process is included in Appendix B. Subsequent model development tasks, such as loading, steps, boundary conditions and output were carried out in the graphic user interface in Abaqus.

\subsubsection{Material Modeling}

An isotropic hardening material model was used for the gusset plates, which requires true stress-strain data derived from coupon tests. This data was not available at the time of this writing, so coupon data from the multi-bolt connection tests described in

Section 3.4 were substituted. Inspection of the gusset plate mill certs from Tests 1 and 2 reported $\mathrm{F}_{\mathrm{y}}$ and $\mathrm{F}_{\mathrm{u}}$ values within $10 \%$ of the coupon data. Material for the members was 
modeled as perfectly elastic, with a Young's modulus of 29,000 ksi. This was justified since the members from the experimental specimens were designed to remain elastic under all foreseen loading conditions. Modeling the members as perfectly elastic increased computational efficiency and insure that failure always occurred in the gusset plate.

\subsubsection{Element Selection}

Gusset plates were modeled as shells in order to avoid the additional development time and computational requirements associated with 3-dimensional modeling. S4 and S3 elements were selected from the Abaqus element library for the shell portions of the model. The S4 shell element is a rectangular element and the S3 element is a triangular element; both are fully integrated, finite-membrane-strain shell elements suitable for large-strain analysis (Simulia, 2010). The B31 element was selected for the beam portions of the model; which uses a Timoshenko beam formulation with a linear interpolation function and is suitable for both stout and slender beams (Simulia, 2010).

\subsubsection{Mesh Refinement}

A stress convergence trial was conducted to determine the gusset plate mesh necessary to converge on stresses under elastic loads. MPC element modeling was selected to represent bolts in the connections, due to their ease of implementation. Mises stress, $\mathrm{s}_{\mathrm{xx}}, \mathrm{s}_{\mathrm{yy}}$ and $\mathrm{s}_{\mathrm{xy}}$ were monitored at nodes spaced along Planes A and B, with each node corresponding to positions of strain gages from experimental tests (see Figure 28). The subscripts refer to stress in the global $\mathrm{x}$, global y and shear stress in the xy plane respectively. Convergence was defined as the point where stress change due to increased 
number elements was less than $5 \%$. Convergence plots for Mises, $\mathrm{s}_{\mathrm{xx}}, \mathrm{s}_{\mathrm{yy}}$, and $\mathrm{s}_{\mathrm{xy}}$ stresses from sample points on Planes A and B are available in Appendix C. Both Mises and $\mathrm{s}_{\mathrm{xy}}$ stresses converged rapidly and satisfied the convergence criteria at 2892 elements and 6082 elements, respectively. Convergence was more problematic at sampling points A3 and $\mathrm{B} 2$ for $\mathrm{s}_{\mathrm{xx}}$, and sampling point $\mathrm{A} 3$ for $\mathrm{s}_{\mathrm{yy}}$ due to their locations in a high stress zones on the gusset plate. However, the majority of sampling points converged readily. It was ultimately determined that a mesh of approximately 6500 elements per gusset plate was sufficient for monitoring stresses at the most of sampling points in the elastic range.

Identical gusset plate meshes were used for MPC and AF bolt models. For models using RS bolts, local meshing strategies used in the single-bolt connection model was deployed to every bolt hole in the gusset plate. The advancing front meshing algorithm initially produced a prohibitively large number of elements on the gusset plate. This was resolved by drawing additional partitions on the gusset plate. A global seed definition was defined to regions outside of the local bolt meshes to create a mesh of comparable density to that used for the MPC and AF models. Gusset plate partitions and meshes for RS and MPC/AF models are compared in Figure 29.

\subsubsection{Elastic Stress Analysis}

Gusset plate stresses due to member loading were analyzed with the specific goals of mapping gusset plate stress contours and identifying changes in the stress profile due to different loading patterns. MPC, AF and RS bolt models were compared. Loading of the gusset plate was delivered by members M3, M4 and M5 such that gusset plate stresses were kept in the elastic range. No initial out-of-plane distortions introduced into 
the model for the elastic stress analysis. The Static-General step module was used to run the analysis.

Three load sets were selected for analysis and are shown in Table 2. Global trends were tracked qualitatively using stress contours in order to compare the different bolt modeling techniques, and quantitatively across critical stress planes to make comparisons between analytical and experimental values, as shown in Figure 28. Plane A lies directly above and parallel to the horizontal chords, and is a critical plane used to check the gusset for gross section yielding and one identified by Whitmore as the location of maximum shear stress. Plane B lies directly behind the last bolt row on the M4 diagonal and corresponds to the location of maximum normal stresses as described by Whitmore.

\subsubsection{Buckling Capacity Analysis}

Three Abaqus analysis methods were considered for evaluating the buckling capacity of the gusset plate at the M4 diagonal: eigenvalue buckling analysis, the StaticRiks and Explicit-Dynamic step modules. Buckling at M4 was only considered in order to stay relevant to the experimental test conducted at Oregon State (see Section 3.7). Eigenvalue buckling analysis is the simplest, where the bifurcation load and buckling shape are estimated by solving the classic eigenvalue problem for system buckling. The first mode is typically the one of interest in static loading problems, since its associated eigenvalue is a rough estimate of the bifurcation load, and its mode shape represents the manner which the system will buckle. It cannot take into account non-linear material behavior such as plasticity, which is why eigenvalue buckling analysis by itself is not 
recommended for systems where nonlinearity is anticipated (Simulia, 2010). For this study, the first mode buckling shape was used to introduce various degrees of out-ofplane imperfections into subsequent modeling steps in order to induce buckling in the nonlinear models.

The Static-Riks module in Abaqus uses an implicit-based direct stiffness approach and is capable of analyzing systems with high geometric and material non-linearity, coupled with a modified Riks algorithm to track the load-displacement path of the system through successive increments (Simulia, 2010). The modified Riks method works well for analyzing unstable systems such as buckling where load and/or displacement may decrease as the solution progresses, and is a valid approach assuming loading is smooth and can be scaled with a single parameter (Simulia, 2010).

The Explicit-Dynamic step module is capable of analyzing complex systems with high geometric non-linearities and contact definitions, making it another candidate to use in buckling analysis. Although originally developed to analyze highly dynamic systems, the method can be used for pseudo-static loading, provided care is taken to insure the applied load rate does not impart excessive inertial effects into the system. The ExplicitDynamic module uses an explicit integration rule combined with a lumped element mass matrix to kinematically advance the solution from one increment to the next. This makes the solution of each increment highly efficient, as it does not require the assembly of a system mass matrix and the solution of a large number of simultaneous equations. The size of a stable increment is considerably smaller compared to implicit methods, but is counterbalanced by the ability to execute each increment much more rapidly. In cases of 
high model complexity, the Dynamic-Explicit module is a viable way to investigate buckling behavior.

Load was induced in the connection by applying a vertical displacement of 0.5 " in the global y direction until failure. This was to simulate the testing conditions used at Oregon State. Preliminary tests showed that the axial load and global behavior of the model were extremely close to when the displacement was applied axially down the member. MPC, AF and RS bolt models were used to model the bolted connections. The linear buckling load was determined by solving for the first mode eigenvalue for the entire connection model subject to a unit axial compressive load along the M4 diagonal. In order to initiate buckling in the non-linear model, a out-of-plane distortion equal to the first buckling mode scaled to $25 \%$ the plate thickness at the free edge was introduced prior to loading. For a $1 / 4$ " thick gusset, this means that the initial out-plane distortion at the gusset plate free edge was equal to $1 / 16$ ". For the Static-Riks method, a displacement criterion of 2 inches out-of-plane displacement at the gusset vertical free edge was used to halt the analysis. A load rate convergence trial for the Explicit-Dynamic step module was conducted to insure that inertial forces were low and the static response remained dominant.

The effect of gusset plate mesh refinement on global behavior was also checked for convergence by looking at the elastic buckling load from an eigenvalue buckling analysis and load-displacement behavior. The Static-Riks solver was used to arrive at a solution for the non-linear model. Refer to Appendix C for global behavior convergence 
plots. It was determined by inspection that a mesh of approximately 6000 elements was adequate for capturing global connection behavior.

\subsubsection{Tensile Capacity Analysis}

No tensile capacity tests were included in the Oregon State experimental testing program, so analytical values of M4 tensile capacity was compared to the nominal block shear design strength per the Load Rating Guidance Report. MPC, AF and RS bolt models were considered, and the Static-General solver was used. Preliminary investigations showed the Static-General and Static-Riks solvers produce equivalent results for tensile failures. No initial modal imperfections were introduced in the models subject to tension. Tensile load was induced in the connection by applying a vertical displacement of $1.5 "$ along in the M4 axial direction until failure.

\subsection{Gusset Connection Experimental Program (Oregon State)}

Three experimental tests were conducted at Oregon State and provided the data to validate the FEA model and are summarized below.

\subsubsection{Test 1 - Description and Results}

Test 1 used 1/4" gusset plates, and was tested under several loading combinations in increasing magnitude until failure. The loading protocol for Test 1 consisted of a series of sets, grouped by the load magnitude at M4 (Table 3). Strain gage data on the gusset plate was collected at each set. Axial load of the members was determined by an array of strain gages attached between the member connection and member end. The magnitude of the load sets increased incrementally until failure. Initial out-of-plane imperfection was assessed by Electronic Speckle Laser Interferometry (ESLI), and determined to be 
approximately $25 \%$ of the plate thickness. See Figure 34 for a comparison between outof-plane displacement contours from ESLI and the first buckling mode shape from eigenvalue buckling analysis.

The mode of failure was in buckling at the M4 diagonal which occurred at a bifurcation load of 270 kip. An effective length factor of $k=0.61$ was found by backcalculating from the experimental buckling load according to the Load Rating and Guidance Report. Figure 35 compares the post-buckled shape from Test 1 and FEA model. Contours on the FEA model indicate out-of-plane displacement, and M4 has been removed for clarity. The timing at which buckling occurred in Test 1 was somewhat unexpected, being that the gusset buckled while the M4 diagonal was loaded at approximately $275 \mathrm{kip}$ and the M5 was in the process of being unloaded from 225 kip to zero.

Due to the many load combinations tested and a low low-frequency sampling rate, load-displacement behavior was not captured in Test 1 at the time of buckling. However, the strain gage data obtained was used to compare with analytical values in the elastic range. Three load sets (100 kip, $175 \mathrm{kip}, 250 \mathrm{kip})$ from the Test 1 data were selected to make stress comparisons between experimental and analytical values. Comparisons were made in two ways. The first, used the 100 kip load set to examine the effects of loading combinations of the horizontal chord (M5), vertical chord (M3) and diagonal chord (M4) have on the stress profiles across Planes A and B. The second comparison was made between M4 loaded at 100 kip, 175 kip and 250 kip, while M3 and M5 were kept at 1 kip, to estimate the resulting Mises stress increases across Planes A and B. Stresses were calculated from strain assuming elastic conditions with $\mathrm{E}=29,000 \mathrm{ksi}$, then transformed 
into a global xy orientation. Positive values indicate tensile stresses and negative values indicate compressive stresses. Stress in the global $\mathrm{x}\left(\mathrm{s}_{\mathrm{xx}}\right)$, global $\mathrm{y}\left(\mathrm{s}_{\mathrm{yy}}\right)$, shear stress in the xy plane $\left(\mathrm{s}_{\mathrm{xy}}\right)$ and Mises stresses were examined positioned at sampling points along Planes A and B (see Figure 28).

Results for the experimental stress profiles along Plane A are presented in Figure 36 through Figure 39. The $\mathrm{x}$-axis in these figures plots stresses from the left gusset edge to the right along Plane A due to load combinations from M4 only, M4 + M5, and M3 + M4 + M5, with load magnitudes of 100 kip for M4, 94 kip for M5, and 24 kip for M3. Maximum Mises, $\mathrm{s}_{\mathrm{xx}}$ and $\mathrm{s}_{\mathrm{xy}}$ stresses occurred at the strain gage 38 " from the left edge of the gusset; the zone corresponding to the gap between M1 and M5. Experimental values for $\mathrm{s}_{\mathrm{yy}}$ fell within $4 \mathrm{ksi}$ and $5 \mathrm{ksi}$ at strain gages between 15" and 55" along Plane A. Both Mises and $\mathrm{s}_{\mathrm{xy}}$ stresses increased on the left side of Plane A and decreases on the right side of Plane A due to preloading from M5 and M3. The positive values for $\mathrm{s}_{\mathrm{xx}}$ indicate the presence of tensile stresses in the x-direction, which is contrary to intuition and to analytical results. $\mathrm{s}_{\mathrm{xx}}$ decreased significantly in response to preloading of M5, but little due to preloading of both M5 and M3. Changes in $\mathrm{s}_{\mathrm{yy}}$ showed minimal effects due to M5 and M3 preloading.

Results for the experimental stress profiles along Plane B are presented in Figure 40 through Figure 43 . Plane B follows the Whitmore effective width along the last bolt row from M4. The $\mathrm{x}$-axis in these figures plots stresses from left to right along Plane B due to load combinations from M4 only, M4 + M5, and M3 + M4 + M5, with load magnitudes of 100 kip for M4, 94 kip for M5, and 24 kip for M3. Maximum Mises, $\mathrm{s}_{\mathrm{yy}}$ 
and $\mathrm{s}_{\mathrm{xy}}$ stresses occurred at the strain gage centered in the middle of Plane B. Maximum $\mathrm{S}_{\mathrm{xx}}$ values were again positive, indicating tensile stresses along Plane $\mathrm{B}$, occurred at the strain gages on the left and right side for the M4 only load case. $\mathrm{s}_{\mathrm{xx}}$ stress profiles for the M4 + M5 and M3 + M4 + M5 load cases showed diminishing stresses moving from left to right.

Figure 44 and Figure 45 shows experimental Mises stresses along Planes A and B due to increasing M4 compression loads of 100 kip, 175 kip or 250 kip, while M3 and M5 were each loaded to 1 kip. Mises stress profiles along Plane A increased in a linear fashion across the entire plane due to the M4 load increases. Mises stresses along Plane B showed in increasing trend as load increases, but not as uniformly as the Plane A stress increases.

\subsubsection{Test 2 - Description and Results}

Test 2 used 1/4" gusset plates, where M4 was loaded monotonically in compression until failure to obtain time-history data. M3 and M5 were loaded at 1 kip each for the duration of the test. Initial out-of-plane imperfection by ESLI was determined to be approximately $25 \%$ of the plate thickness. The mode of failure was buckling at the M4 gusset, at a bifurcation load of 300 kip. The effective length factor $k$ $=0.58$ was found by back-calculating from the experimental buckling load according to the Load Rating and Guidance Report. Figure 49 shows the final buckling shape, which is similar to the buckling shape from Test 1 except that it occurred in the opposite direction. M4 load and out-of-plane displacement at the gusset free edge was captured and used to compare with the analytical results, and is shown Figure 48. 


\subsubsection{Test 3 - Description and Results}

Test 3 used 3/8" gusset plates, and underwent a similar loaded protocol as Test 1 did, except that 50 kip increments on M4 were used between load sets instead of 25 kip increments. The gussets did not fail initially using the full capacity of the actuator (550 kip), so additional out-of-plane displacement equivalent to $79 \%$ of the plate thickness was induced using a braced hydraulic ram. The mode of failure was again buckling at the M4 gusset, at a bifurcation load of 533 kip. Strain gage data was gathered similarly to Test 1 , but was not available at the time of this writing.

\subsection{Analytical Results and Experimental Validation}

Analytical results from the gusset connection elastic stress, buckling capacity and tensile capacity analyses are summarized below, followed by a comparison with experimental findings.

\subsubsection{Elastic Stresses}

A qualitative examination of the analytical stress contours from MPC, RS and AF bolt models is presented in Figure 30 and Figure 31, showing stresses induced by a 100 kip compressive load at M4. All three models show nearly identical global stress distributions for Mises, $\mathrm{s}_{\mathrm{xx}}, \mathrm{s}_{\mathrm{yy}}$ and $\mathrm{s}_{\mathrm{xy}}$ stresses. Figure 32 and Figure 33 show profile stresses across Planes A and B for MPC, AF and RS models due to a 100 kip compressive load at M4. All three models trended similar stress profiles, except for a few cases. Stress deviations between the different models occurred for $\mathrm{s}_{\mathrm{Xx}}$ along Plane A at about 30" from the left free edge of the gusset; which is associated with the point between the bottom of the M2 diagonal and M1. The other noticeable difference can be 
seen along Plane B, where $\mathrm{s}_{\mathrm{xx}}$ and $\mathrm{s}_{\mathrm{yy}}$ values for the MPC model are lower between 12" and 26" on Plane B; the region associated with the location of the last row of bolts on M4. Otherwise, there were no other significant qualitative differences in plate stress distributions from the different bolt models.

Direct comparisons between analytical and experimental stresses were made along Planes A and B (Figure 36 through Figure 43) due to preloading at M3 and M5, and revealed numerous differences between the analytical and experimental values. One major distinction lies between analytical and experimental stress. Analytical stress from the model output is in the form of membrane stresses and represents an averaged stress across the plate thickness, whereas experimental stress is derived from strain gages that record on the outer plate surface. Also, out-of-plane distortions can potentially color the experimental data due to bending stresses induced in the plate. Other complications can be associated with instrumentation and data acquisition using strain gages that may arise in data errors. However, the author will not hypothesize or speculate as to whether this was a factor here, since he did not directly participate in the experimental implementation.

Striking differences can be seen with $\mathrm{s}_{\mathrm{xx}}$ on Plane $\mathrm{A}$ and $\mathrm{B}$, and $\mathrm{s}_{\mathrm{xx}}$ on Plane B. The positive values for $\mathrm{s}_{\mathrm{xx}}$ indicate the presence of tensile stresses in the global $\mathrm{x}$ direction, which is contrary to intuition and to analytical results considering the location of the sampling points. The experimental profile for $\mathrm{s}_{\mathrm{yy}}$ on Plane A did not track well with the analytical either. It is less concerning that there is a difference in sign for $\mathbf{s}_{\mathrm{xy}}$ 
between analytical and experimental, as this may be attributed to different sign conventions and theoretically do not affect the principal stresses.

Mises and $\mathrm{s}_{\mathrm{xy}}$ stresses (ignoring the sign difference) provided the closest correlation between analytical and experimental values, with peak values occurring approximately midway along Planes A and B. The trend that Mises stress increases on the left side of Plane A and decreases on the right side of Plane A due to preloading from M5 and M3 was also observed for analytical and experimental values. Mises stresses on Plane B shared a common profile between analytical and experimental, although the experimental data seemed more sensitive to change due to preloading than the analytical data did.

The strongest correlation between the analytical and experimental can be seen in Figure 44 and Figure 45, which plot Mises profile changes to increased compressive load at M4 along Planes A and B respectively. An increase in load causes linear increases in the Mises stress profiles for both the analytical and experimental along Plane A. A similar trend occurs along Plane B, although not as close as with Plane A. This is finding is expected since loading of gusset plate was kept within the elastic range.

In summary, more experimental data stress data is needed to fully validate the model, although analytical values for Mises and $\mathrm{s}_{\mathrm{xy}}$ stresses were within a reasonable margin of error. It may be helpful to increase the density of the strain gage array on the plate in future experiments, as well as sampling strain on both sides of the plate. Another tool in potentially validating analytical stresses is the use of ESLI to map full stress contours across the gusset plate. 


\subsubsection{Buckling Capacity}

Load-displacement data was used to assess buckling predictions between the different modeling approaches, where the load is the axial force in M4, and out-of-plane displacement is measured at the midpoint of the gusset free edge between M4 and M5, as illustrated in Figure 46. Figure 47 shows load-displacement curves for experimental Test 2 compared to MPC, AF and RS bolt models. Figure 48 similarly compares Test 2 loaddisplacement curves with buckling predictions from the first mode eigenvalue, ExplicitDynamic and Static-Riks analysis methods using the MPC bolt model only. Table 4 summarizes the various analytical buckling capacity predictions for $1 / 4$ " gusset plates, $\mathrm{A} / \mathrm{E}$ ratios and back-calculated values for $k$. The experimental value used to calculate the $\mathrm{A} / \mathrm{E}$ ratios was taken as $285 \mathrm{kip}$; the average of the buckling loads from experimental Tests 1 and 2. The post-buckling shape was the same for each model case, and is shown along with the experimental buckled shape in Figure 35. The Static-Riks solver was selected to assess the bolt models because it gave the closest prediction to experimental buckling capacity, and was more computationally efficient than the Dynamic-Explicit solver. Attempts to solve the RS Bolt model with the Explicit-Dynamic solver proved to be computationally prohibitive. The MPC and RS bolt models gave very accurate predictions of the experimental buckling load, with $\mathrm{A} / \mathrm{E}$ ratios of 1.04 and 1.07 respectively. The AF bolt model had an $\mathrm{A} / \mathrm{E}$ ratio of 1.57 , significantly over predicted experimental buckling strength. The analytical buckling capacity for the $3 / 8$ " plate 559.6 kip, assuming $75 \%$ initial imperfection, and producing an $\mathrm{A} / \mathrm{E}$ ratio of 1.05 .

In summary, the experimental data validates the FEA model for buckling capacity. Use of the Static-Riks solver and the RS bolt predicted experimental buckling 
capacity within $4 \%$. The use of the MPC bolt model is also a viable option for analyzing gusset connection buckling, predicting experimental buckling capacity within $7 \%$ for the $1 / 4$ " plate and within $5 \%$ for the $3 / 8$ " plate. This makes the use of MPC bolts more appealing for buckling analysis as it substantially cuts down on the development time associated with the RS bolt model, while only sacrificing 3\% in accuracy.

\subsubsection{Tensile Capacity}

No tensile capacity tests were included in the Oregon State experimental testing program, so analytical values of M4 tensile capacity was compared to the nominal block shear design strength per the Load Rating Guidance Report. Figure 52 shows PEEQ and Mises stress comparisons for the MPC, AF and RS bolt models; where color contours for Mises stresses indicate stress states beyond the yield stress in the material definition (50 ksi), and colors for the PEEQ contours indicate permanent plastic deformation greater than 2\%. Figure 51 shows load-displacement curves for MPC, AF and RS bolt models. Nominal block shear capacity was calculated to be 794 kip. A line representing the nominal block shear capacity is included in Figure 51 for reference. Table 5 summarizes the analytical predictions and $\mathrm{A} / \mathrm{E}$ ratios from each model, where the nominal block shear design strength was used for the "experimental" values in the ratio.

The observed mode of failure was block shear at the M4 portion of the gusset, with significant yielding and plastic deformation occurring around the outer bolt holes at M1, M2 and M3. There were no significant deviations from the calculated block shear capacity and the different models; the largest difference being the AF bolt model, which over-predicted block shear capacity by $9 \%$. The MPC bolt model over-predicted block 
shear capacity by $6 \%$. The RS bolt was extremely close to the calculated block shear capacity; so close that the A/E ratio came out to be 1.0. Examining the contours from Figure 52 show very little plastic strain beyond 2\% for the MPC model, however this may be due to the fact that the solution diverged before M4 could be pulled the entire 1.5 " as defined in the imposed displacement boundary condition. The RS bolt model was able to produce extremely high detail contours and are explored in Figure 53. Although not presented here, observing the time history of the RS bolt model shows the stress flow progression as the plate goes through failure. Once tensile rupture occurs at the M4 block, shear yielding along the shear planes at M2 begin to mobilize, while yielding continues along shear planes at M1 and M2 connections.

In summary, the analytical models produced strength predictions very close to the nominal calculated values, and showed the expected failure mode of block shear. The current code provisions for block shear are based on a large body of experimental investigations, so the model is validated based on the code evaluation.

\subsection{Conclusions and Modeling Recommendations}

Throughout this study, the complexity of the bolt modeling approach was evaluated in the context of predictive accuracy and computational efficiency. Each bolt modeling approach will be discussed in turn to summarize their strengths and weaknesses in FEA gusset connection modeling.

For their relative simplicity, the MPC bolt model produced reasonable predictions in all the gusset connection analyses. It did not do as well capturing small-scale connection behavior in tension as the RS bolt model. For the gusset connection, the 
elastic stress profiles produced intuitively reasonable stress contours - largely consistent with the AF and RS bolt models - that were responsive to different loading conditions. Buckling capacity and tensile capacity A/E ratios were 1.07 and 1.06 respectively. The MPC bolt model did lack in stress distributions at the bolt hole level compared to the RS bolt model, but this is to be expected. Overall, the MPC bolt model is a good candidate for implementing in FEA studies for load rating of multiple connections and to be used in parametric studies. This is because the simplicity of the MPC bolt model is its great advantage over the RS bolt model, which requires extensive development time.

The AF bolt model did the worst regarding predicting failures, both at the smallscale and gusset connection level. It is therefore not recommended by this author for use in gusset connection modeling. The formulation presented here, which is essentially a MPC element with a rigid radius of influence (structural distribution) equal to the bolt radius defined at each connected surface. The AF bolt model acts more like a spot weld than a bolt, and should be used judiciously for bolt-modeling applications. It may be possible to improve the performance of the AF bolt with further studies that use experimental load-displacement data to calibrate the $\mathrm{AF}$ element.

The RS bolt model has been demonstrated to provide a suitable shell-equivalent approach to 3D contact bolt modeling, for gusset plates with both small and large numbers of bolts. RS bolt model is compatible with elastic, buckling and block shear failure analyses and gives predictions that were close to experimental and calculated capacities. Compared to the MPC bolt model, The RS bolt model was slightly better for predicting ultimate capacity and was able to provide a greater stress detail. However, the 
RS bolt model is several orders of magnitude more complex, to such a degree that it may not be useful to devote the development time in order to gain a small increase in accuracy. The most compelling potential use for the RS bolt model is in an academic setting, where high accuracy and detail may be of greater importance than rapid development and efficiency.

In conclusion, the analysis methods presented here represent an approach that can be used to model alternate gusset connections with different geometries, members and plate thicknesses. If the connection has a large number of bolts, MPC bolt models can be used without decreasing the predictive capacity. Otherwise, RS bolts can be deployed over portions of the connection as needed. 


\subsection{Parametric Study}

It is known that buckling capacity is greatly influenced by the plate's boundary conditions, which is often difficult to assess for a complex system such as a gusset plate. Design calculations take boundary conditions into account using the effective length factor, $k$, where the designer assumes a value based on intuition and engineering judgment. Gusset plate buckling capacity is highly dependent on $k$, which is itself is a product bracing, lengths and stiffnesses of the connection components. Accurate assumptions of $k$ can be difficult to make in the context of load-rating existing connections. Also, out-of-plane distortions are commonly found in gusset plates in the field, but there is no way outside of FEA, to estimate the resulting degradation in capacity.

A preliminary parametric study was conducted to identify factors that impact a gusset plates buckling capacity. It was hypothesized that $k$ is dependent on the magnitude of out-of-plane distortion, the lengths and the flexural stiffnesses of the plate and connected members. Using the calibrated gusset connection FEA model presented above, the following parameters were analyzed for their impact on buckling capacity: gusset plate thickness, magnitude of out-of-plane distortions, changes to the gusset Whitmore effective length, flexural stiffness of the member and length of the member. MPC bolt modeling was chosen for subsequent parametric studies for compression, due to their simple and rapid implementation, and reasonable predictive accuracy. 


\subsection{Effects of plate thickness and imperfection}

A primary parameter used to calculate gusset plate buckling capacity is the plate thickness. Gusset connection models with plates of different thicknesses were analyzed in an effort to develop a relationship between out-of-plane gusset plate distortions and capacity. The aim was to develop a relationship between the governing design code equations and analytical results to use as a load rating aid without having to perform full FEA on every connection. Four plate thicknesses were selected (1/4", 3/8", 1/2" and 5/8") and input into the gusset connection model described above. Degrees of the first mode buckling imperfection were input to the model to the equivalent of $25,50,75$ or $100 \%$ of the plate thickness. Compression at M4 was applied to the gusset connection model until failure. The failure load was then used to back-calculate an equivalent $k$ value per the Load Rating Guidance Report.

Figure 54 shows load-displacement curves for 1/4" gusset plate with varying degrees in initial imperfection. Capacity degradation was significant as the degree of imperfection increased. Table 6 summarizes the buckling capacities for all of the trials, along with percent differences from the $25 \%$ imperfection cases for each plate thickness. Buckling capacity decreased by the same degree for each level of imperfection. Another way to look at the data is shown in Figure 55, which plots back-calculated $k$ values as a function of normalized plate imperfection. From the equation perspective, $k$ is a measure of the classical anticipated buckled shape where a $k=0.5$ represents a full fix-fix condition and $k=2.0$ represents a cantilever beam condition. Values of $k$ that fall in between represent boundary conditions with partial releases. Two trends emerge by looking at Figure 55. The first is that $k$ increases as more imperfection is introduced and 
is true for each plate thickness, which makes intuitive sense since the addition of imperfection in the gusset acts by decreasing its fixity. The second is that the $k$ increases in magnitude as the plate thickness increases. This finding does not follow logic of classical buckling analysis, because it suggests that as the plate thickness increases, you are moving from a more restrained boundary condition to a less restrained boundary condition. This is clearly not the case, as the analytical buckled shapes do not change, and buckling loads increase significantly as the gusset plate thickness increases. This suggests that increasing buckling capacity by modifying the cross-section of the gusset can produce an artificial increase in $k$ that is not representative of the boundary conditions present.

\subsection{Effects of adjustment of Whitmore's effective length}

Another essential parameter used to calculate buckling capacity is the Whitmore effective length. This was first used by Thornton (1984) and is discussed in Section 2.3 of the Literature Review. The number of bolt rows attaching M4 to the gusset was adjusted from its base position, to $+/-2$ " or 4 " axially along M4 to look at the effects on analytical buckling capacity. Only $1 / 4$ " plates were used in the connection for this portion of the study.

Figure 56 shows load-displacement curves for effective lengths of 11", 13", 15" 17" and 19" at the M4 region of the gusset plate. As expected, buckling capacity decreases with an increase in the gusset plate effective length. Table 7 summarizes the buckling capacities and back-calculated $k$ values, which increased from 0.5 to 0.68 as the effective length went from 19" down to 11". Again, the relationship between $k$ and the 
decrease in the effective length is observed, suggesting that boundary conditions are trending towards a less fixed condition. This is one of the few parameters that can be directly compared to the calculated nominal buckling capacity equations. Figure 57 plots the analytical results with calculated nominal buckling capacities for $k=0.5$ and 1.0. The analytical values track closely to the nominal for the longer effective length move towards the middle of the two contours as the effective length decreases. Aside from noting this trend, it is difficult speculate as to why is the case without further study, or generalize to other connections without a rational means of normalizing gusset plate effective length.

\subsection{Effects of connected member flexural stiffness and length}

The effects of member stiffness and length were examined to see their influence on gusset plate buckling capacity. Although not explicitly addressed in the design equations, they do participate in defining the boundary conditions seen by the gusset. To investigate member stiffness on gusset plate buckling capacity, the original M4 cross section (HSS 20 x 13 x 5/8”) was replaced with different HSS-like sections while keeping the length constant. Each section was designed to provide the same axial capacity as well as the same strong-axis flexural stiffness, while varying the weak-axis flexural stiffness. This was realized by giving the different member sections same cross-sectional area, the same I.x, but different I.y values equal to $0.8,0.6,0.4,0.2$ and 0.1 of the original EI.y. Figure 58 shows load-displacement curves for the different EI M4 region of the gusset plate. Little effect was seen until the original EI was reduced $60 \%$. 
Table 8 summarizes the buckling capacities and back-calculated $k$ values, which increased from 0.58 to 0.62 as the member's flexural stiffness decreased. The overall effect was small, but suggests that member stiffness does play a role in gusset plate buckling capacity. The small effect can be explained by the fact that M4 is substantially shorter than a typical bridge member, thus requiring a large reduction in flexural stiffness in order to induce an effect.

To examine the effects of member length on gusset plate buckling capacity, the length of M4 ( $\left.\mathrm{L}_{\mathrm{M} 4}\right)$ was increased from its original length of 110 " to 165 ", 220 " and 275". Figure 59 shows load-displacement curves for the different EI M4 region of the gusset plate. Table 9 summarizes the buckling capacities and back-calculated $k$ values, which increased from 0.58 to 0.65 as the member's length was increased. Increasing member length had a significant impact on the gusset's buckling capacity, and produced a trend of decreasing $k$ values with increasing member length.

Modifications to the member stiffness and length did change the buckling capacity of the gusset plate. This change can be rationally reflected by comparing backcalculated $k$ values. Unlike the gusset plate modifications, reduction of member flexural stiffness or increasing member length resulted in an increase in $k$, i.e. the addition of flexibility in the member resulted in a relaxation of the boundary fixity seen by the gusset.

\subsection{Summary and Conclusion}

This parametric study was a preliminary effort in order to identify factors that impact gusset plate buckling capacity. Parameters considered were plate thickness, 
degree of initial imperfection, gusset plate effective length, connected member flexural stiffness and member length. Effective length factors were back-calculated from analytical buckling loads in order to identify trends that may help in evaluating buckling capacity without the use of FEA modeling.

Findings suggest that gusset plate buckling capacity is not solely a function of its own geometric and material properties, but also a product of the connected member. Attempts to identify trends in $k$ due to gusset plate modifications resulted in an artificial increase of $k$, making $k$ unsuitable for a calibration measure for gusset plate thickness or effective length parameters. However, gusset plate imperfections and member modifications resulted in trends in $k$ that reflect rational changes in boundary conditions. Further parametric studies would be required in order to develop guidelines for the designer that taken into account plate imperfection and member effects that apply to a larger set of gusset connections. 


\subsection{Conclusions and Recommendations for Further Study}

Connection-level FEA analysis has been shown to be an effective method for evaluating the strength capacity of steel bridge gusset plate connections. The model presented here has been validated with experimental tests conducted at Oregon State, and with design equations from the Load Rating Guidance Report. Several bolt modeling methods were also evaluated for their predictive accuracy and computational efficiency.

From a load-rating perspective, connection-level FEA models are appealing due to their relatively rapid development time compared to developing a global bridge model. For the connection considered here, the FEA model using MPC bolts proved to be the most efficient in assessing compressive capacity of the experimental tests, with reasonable accuracy. Analytical predictions tensile capacity were in close agreement with block shear capacity equations from the Load Rating Guidance Report. Although this study only examined one M4 portion of the gusset plate for strength limit states, the FEA development methods can be easily generalized to the evaluation of failure states at different portions of the gusset plate, as well as different connections.

The RS bolt model developed for this research performed very well in tensile, compression and elastic stress analyses, and has the potential to be applied in other modeling efforts involving bolted connections where load is transferred in shear across the bolt shank. Their increased complexity makes them less suitable for parametric studies; however they have significant academic value as a shell-equivalent alternative to 3D contact bolt modeling. 
The parametric study showed that member properties play a significant role in gusset plate bucking capacity, by changing the boundary conditions that the gusset plate sees. However, efforts to compensate differences in gusset plate buckling due to geometric changes in the plate resulted in artificial increases in $k$ that were not representative of the observed buckling shapes.

Recommendations for further study are as follows.

1) There is a discrepancy between the predictive ability of MPC bolt models between connections with a small number of bolts and connections with a large number of bolts. This suggests that there is transition where MPC bolt model capacity predictions approach RS bolt model predictions as the number of bolts increase. Quantifying this transition would be of value as it would aid in implementation decisions for gusset connections with fewer bolts than the connection considered here.

2) The fasteners were idealized as rigid members in this study in order to focus on failure states of the gusset plate itself. However, fastener behavior may play a role in gusset plate behavior, particularly in tension-related failures. Implementation of fastener load-displacement behavior into the bolt model definitions is possible for MPC, AF and RS bolt models and would extend the model's capabilities of detecting fastener-related failure states.

3) Connection-level models are well-suited to evaluate capacity for individual member connections. However, a means of delivering loads that are more representative in situ conditions to the connection-level model have not been considered. Analyzing 
the connection-level model as part of a more complex truss could provide additional insight into connection behavior, and reveal more complex failure states beyond those outlined in the Load Rating Guidance Report.

4) The preliminary parametric study conducted showed that member properties have an effect on gusset plate buckling capacity. This concept has the potential to be developed into a more comprehensive set of guidelines for estimations of $k$-using a set of normalized member-related parameters - for load-rating application purposes. 


\section{Tables}

Table 1: Multi-bolt connection tensile capacities

Sample A

Sample B

\begin{tabular}{rcccc}
\hline & Tensile Capacity (kip) & A/E Ratio & Tensile Capacity (kip) & A/E Ratio \\
\hline Experimental & 46.76 & -- & 57.41 & -- \\
FHWA & 43.03 & 0.92 & 52.49 & 0.91 \\
3D Contact & 42.14 & 0.90 & $49.92^{*}$ & 0.87 \\
RS Bolt & 41.63 & 0.89 & 53.96 & 0.94 \\
MPC Bolt & 65.58 & 1.40 & 78.4 & 1.37 \\
AF Bolt & 51.27 & 1.10 & 94.43 & 1.64 \\
& & & \\
† - Nominal capacity calculated per FHWA Load Rating Guidance Report for net-section & \\
rupture (Sample A) and block shear (Sample B), assuming $\mathrm{F}_{\mathrm{y}}=50$ ksi and $\mathrm{F}_{\mathrm{u}}=68 \mathrm{ksi}$ & \\
* - Model failed to converge on final solution before failure criteria was met &
\end{tabular}

Table 2: Load sets used for elastic analysis of gusset connection

\begin{tabular}{rccc} 
& \multicolumn{3}{c}{ Compressive Load (kip) } \\
\hline Load Set Label & M4 & M3 & M5 \\
\hline $100: 1: 1$ & 100 & 1 & 1 \\
$100: 1: 94$ & 100 & 1 & 94 \\
$100: 24: 94$ & 100 & 24 & 94 \\
$175: 1: 1$ & 175 & 1 & 1 \\
$175: 1: 164.5$ & 175 & 1 & 164.5 \\
$175: 42: 164.5$ & 175 & 42 & 164.5 \\
$250: 1: 1$ & 250 & 1 & 1 \\
$250: 1: 235$ & 250 & 1 & 235 \\
$250: 60: 235$ & 250 & 60 & 235
\end{tabular}


Table 3: Load sets used in Oregon State Gusset Connection - Test 1

\begin{tabular}{|c|c|c|c|}
\hline \multirow[b]{2}{*}{ Load Set Label } & \multicolumn{3}{|c|}{$\begin{array}{l}\text { Compressive Load } \\
\text { (kip) }\end{array}$} \\
\hline & M4 & M3 & M5 \\
\hline 1:1:1 & 1 & 1 & 1 \\
\hline $25: 1: 1$ & 25 & 1 & 1 \\
\hline $25: 6: 1$ & 25 & 6 & 1 \\
\hline $25: 1: 23.5$ & 25 & 1 & 23.5 \\
\hline $50: 1: 1$ & 50 & 1 & 1 \\
\hline $50: 12: 1$ & 50 & 12 & 1 \\
\hline $50: 1: 47$ & 50 & 1 & 47 \\
\hline $75: 1: 1$ & 75 & 1 & 1 \\
\hline $75: 18: 1$ & 75 & 18 & 1 \\
\hline $75: 1: 70.5$ & 75 & 1 & 70.5 \\
\hline $75: 18: 70.5$ & 75 & 18 & 70.5 \\
\hline $100: 1: 1$ & 100 & 1 & 1 \\
\hline $100: 24: 1$ & 100 & 24 & 1 \\
\hline 100:1:94 & 100 & 1 & 94 \\
\hline $100: 24: 94$ & 100 & 24 & 94 \\
\hline $125: 1: 1$ & 125 & 1 & 1 \\
\hline $125: 30: 1$ & 125 & 30 & 1 \\
\hline 125:1:117.5 & 125 & 1 & 117.5 \\
\hline $125: 30: 117.5$ & 125 & 30 & 117.5 \\
\hline$:$ & $:$ & $:$ & $:$ \\
\hline$:$ & $:$ & $:$ & $:$ \\
\hline : & $\begin{array}{c}: \\
\text { Pattern } \\
\text { followed } \\
\text { until } \\
\text { failure }\end{array}$ & $:$ & $:$ \\
\hline
\end{tabular}

Table 4: Summary of buckling analysis predictions

FEA Methods

\begin{tabular}{ccccc}
\hline Analysis & Bolt Model & $\begin{array}{c}\text { Buckling Capacity } \\
\text { (kip) }\end{array}$ & A/E Ratio* & $\mathrm{k}$ \\
\hline \hline Mode 1 Eigenvalue & MPC Bolt & 386.3 & 1.36 & 0.51 \\
Explicit-Dynamic & MPC Bolt & 337.2 & 1.18 & 0.55 \\
Static-Riks & MPC Bolt & 305.3 & 1.07 & 0.58 \\
Static-Riks & RS Bolt & 297.4 & 1.04 & 0.59 \\
Static-Riks & AF Bolt & 447.9 & 1.57 & 0.46
\end{tabular}

* Calculated based on average experimental buckling load from experimental Tests 1 and 2 
Table 5: Summary of tensile capacity predictions

\begin{tabular}{ccc}
\hline Model & Tensile Capacity (kip) & A/E Ratio \\
\hline \hline MPC Bolt & 838.0 & 1.06 \\
AF Bolt & 866.6 & 1.09 \\
RS Bolt & 794.1 & 1.00
\end{tabular}

Table 6: Buckling capacity and $\boldsymbol{k}$ values due to imperfections

\begin{tabular}{ccccc}
\hline $\begin{array}{c}\text { Plate Thickness } \\
\text { (in) }\end{array}$ & $\begin{array}{c}\text { Imperfection } \\
\text { (\% Plate Thickness) }\end{array}$ & $\begin{array}{c}\text { Buckling Capacity } \\
\text { (kip) }\end{array}$ & k & $\begin{array}{c}\text { Difference } \\
(\%)\end{array}$ \\
\hline \hline 0.25 & 25 & 305.3 & 0.58 & 0.0 \\
0.25 & 50 & 269.2 & 0.61 & -11.8 \\
0.25 & 75 & 245.3 & 0.64 & -19.7 \\
0.25 & 100 & 227.3 & 0.67 & -25.5 \\
0.375 & 25 & 704.6 & 0.67 & 0.0 \\
0.375 & 50 & 616.8 & 0.73 & -12.5 \\
0.375 & 75 & 559.6 & 0.78 & -20.6 \\
0.375 & 100 & 519.2 & 0.81 & -26.3 \\
0.5 & 25 & 1156.1 & 0.72 & 0.0 \\
0.5 & 50 & 1008.8 & 0.83 & -12.7 \\
0.5 & 75 & 912.6 & 0.92 & -21.1 \\
0.5 & 100 & 843.8 & 0.96 & -27.0 \\
0.625 & 25 & 1628.2 & 0.76 & 0.0 \\
0.625 & 50 & 1423.2 & 0.92 & -12.6 \\
0.625 & 75 & 1289.4 & 1.02 & -20.8 \\
0.625 & 100 & 1189.6 & 1.10 & -26.9
\end{tabular}

Table 7: Buckling capacity and $\boldsymbol{k}$ values for different gusset plate effective lengths

\begin{tabular}{ccc}
\hline Effective Length (in) & $\begin{array}{c}\text { Buckling Capacity } \\
\text { (kip) }\end{array}$ & k \\
\hline \hline 19 & 249.1 & 0.50 \\
17 & 275.3 & 0.54 \\
15 & 304.9 & 0.58 \\
13 & 351.8 & 0.62 \\
11 & 400.3 & 0.68
\end{tabular}


Table 8: Buckling capacity and $k$ values for different member flexural stiffnesses

\begin{tabular}{ccc}
\hline \% Original EI & $\begin{array}{c}\text { Buckling Capacity } \\
\text { (kip) }\end{array}$ & $\mathrm{k}$ \\
\hline \hline 10 & 261.6 & 0.62 \\
20 & 286.7 & 0.60 \\
40 & 299.9 & 0.58 \\
60 & 303.1 & 0.58 \\
80 & 304 & 0.58 \\
100 & 304.9 & 0.58
\end{tabular}

Table 9: Buckling capacity and $k$ values for different M4 lengths

\begin{tabular}{ccc}
\hline M4 Length (in) & $\begin{array}{c}\text { Buckling Capacity } \\
\text { (kip) }\end{array}$ & k \\
\hline \hline 110 & 304.9 & 0.58 \\
165 & 265.7 & 0.62 \\
220 & 242.3 & 0.64 \\
275 & 234.7 & 0.65
\end{tabular}




\section{Figures}

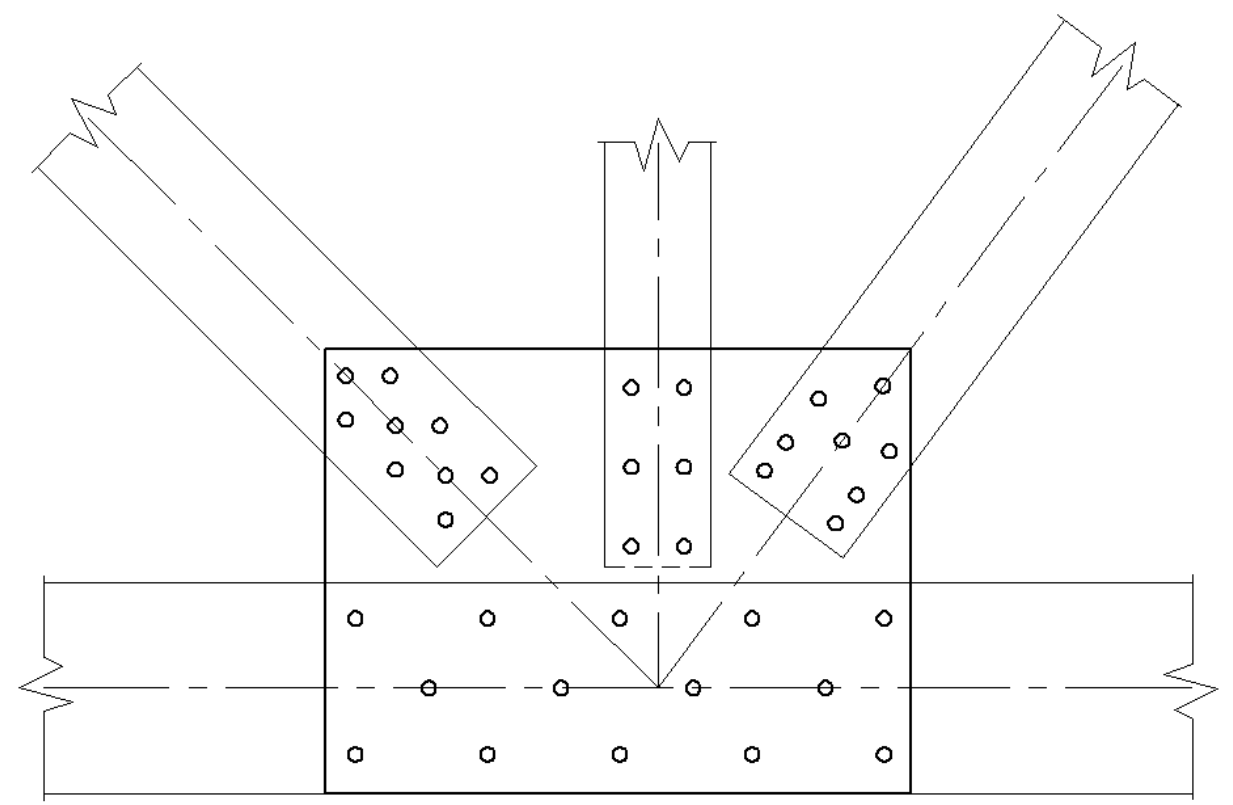

Figure 1: Warren truss gusset plate connection tested by Whitmore (1957)
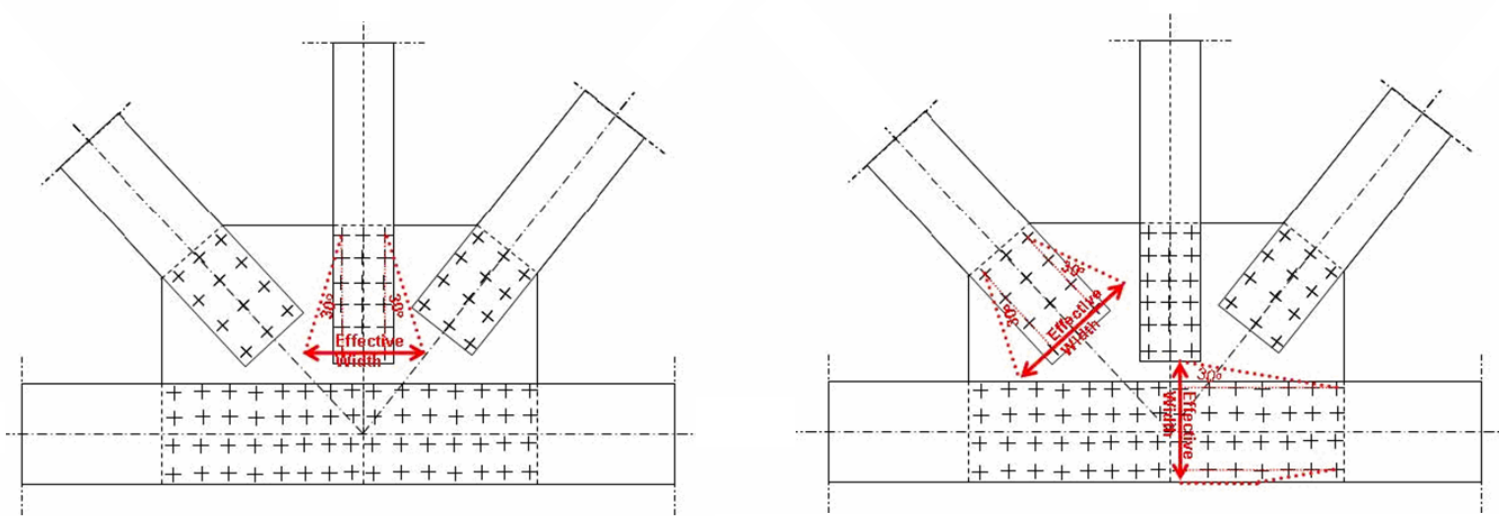

Figure 2: Whitmore effective width definitions for member regions of gusset plates (NTSB, 2008) 


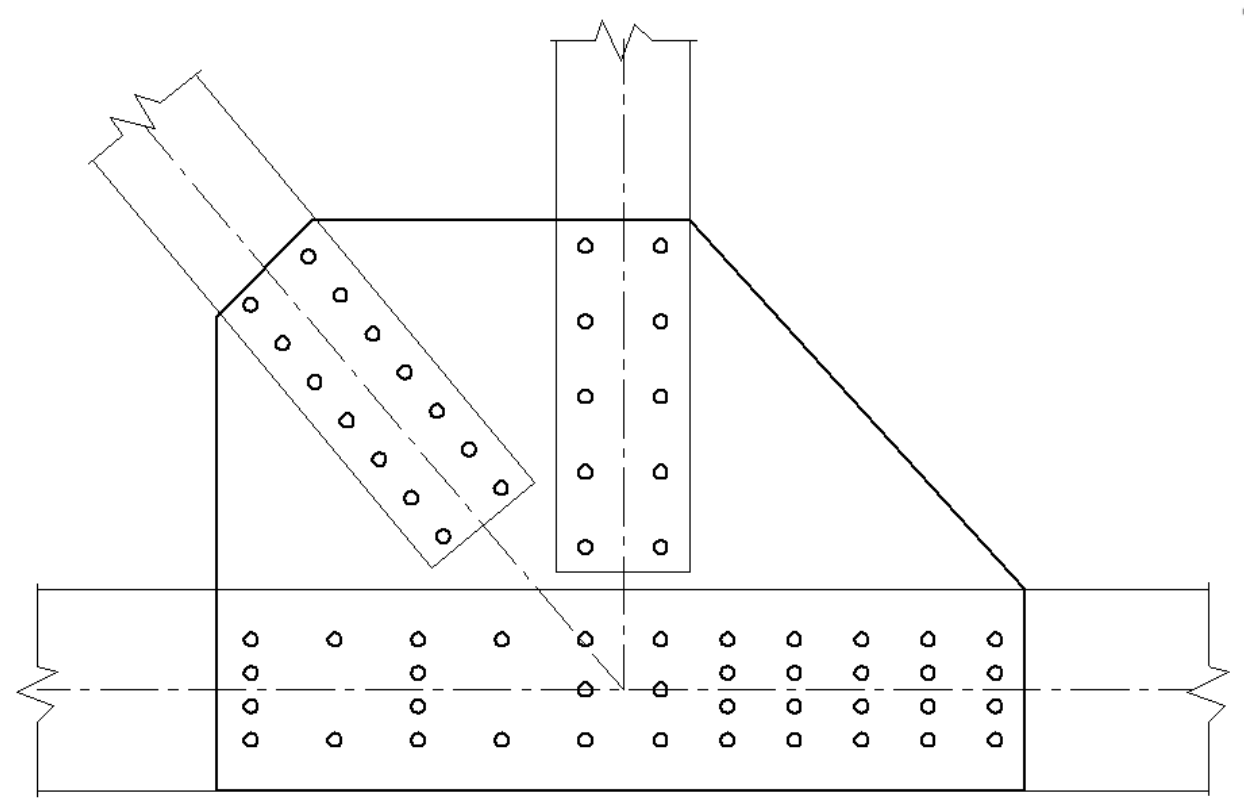

Figure 3: Pratt truss gusset plate tested by Irvin and Hardin

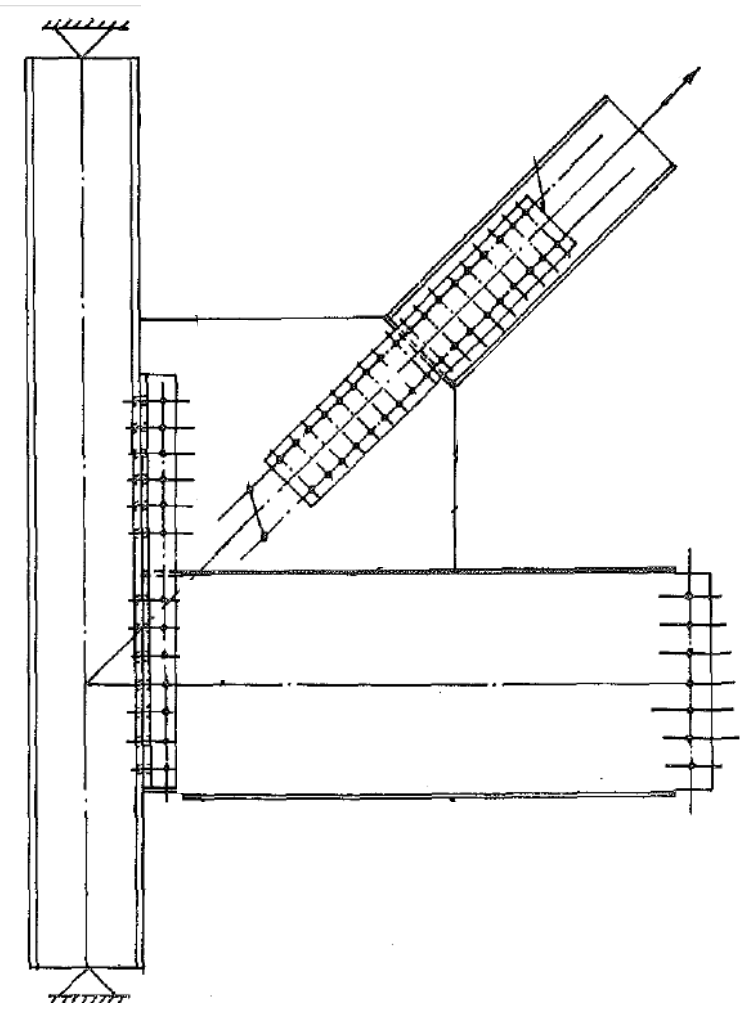

Figure 4: Gusset plate connection tested by Bjorhovde and Chakrabarti (1985) 


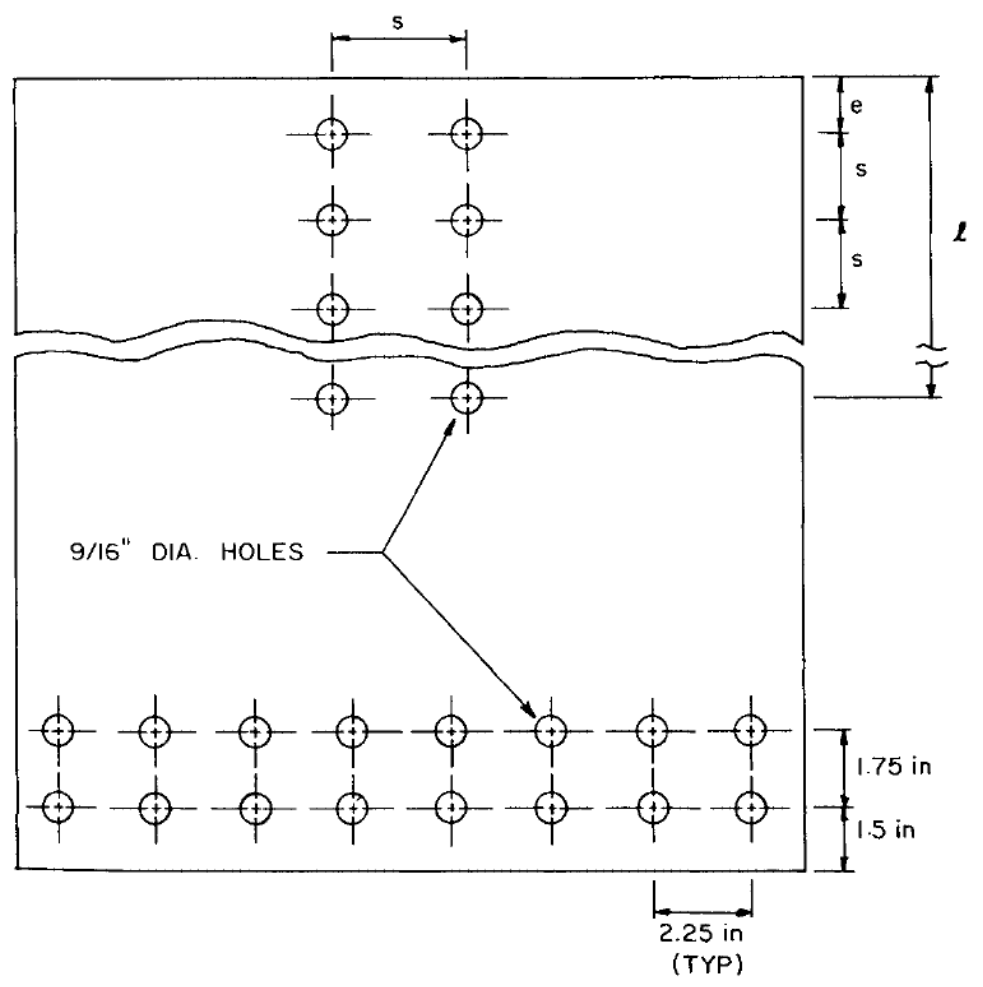

Figure 5: General gusset plates tested by Hardash and Bjorjovde (1985)

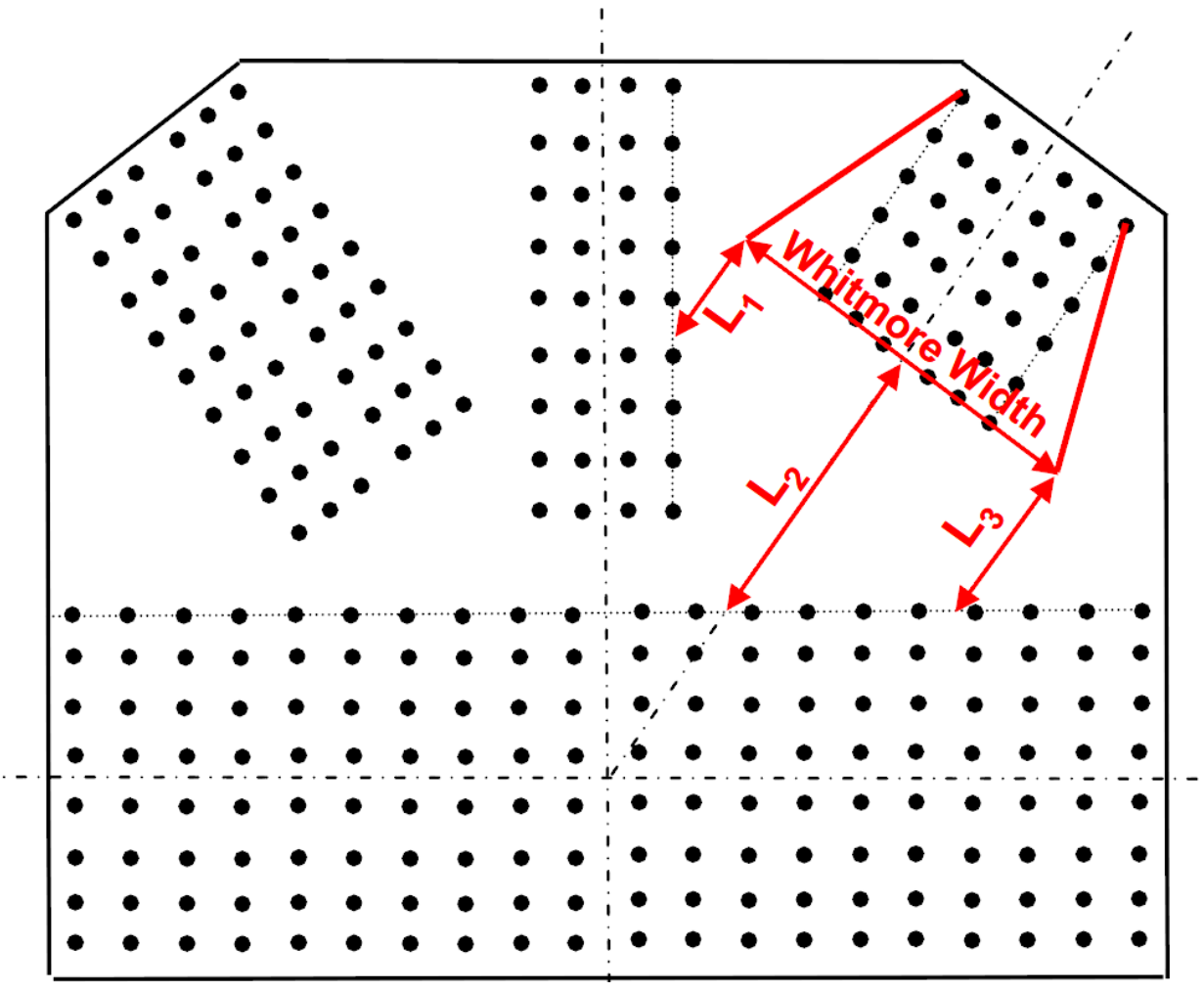

Figure 6: Whitmore effective length definitions (NTSB, 2008) 


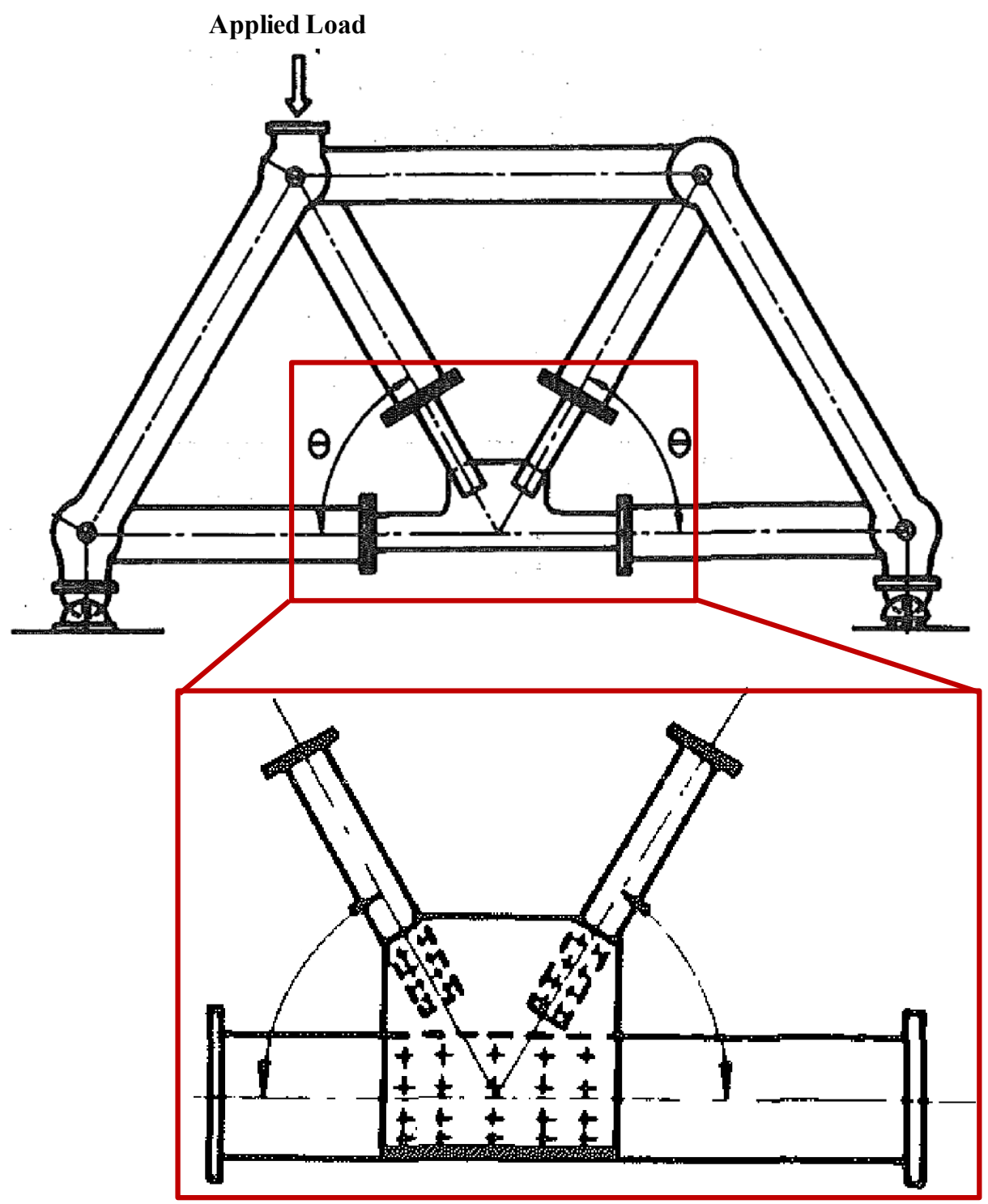

Figure 7: Test frame and gusset plate connection (Yamamoto, 1988) 


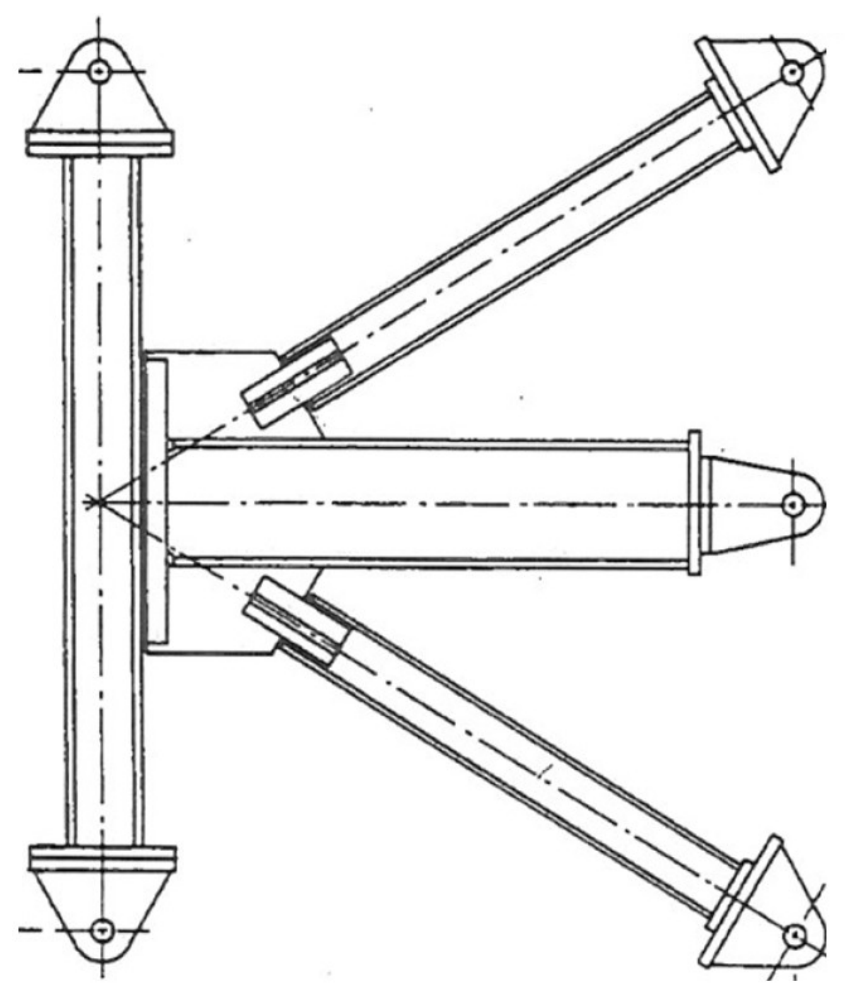

Figure 8: Gusset plate test specimen assembly (Gross, 1990)

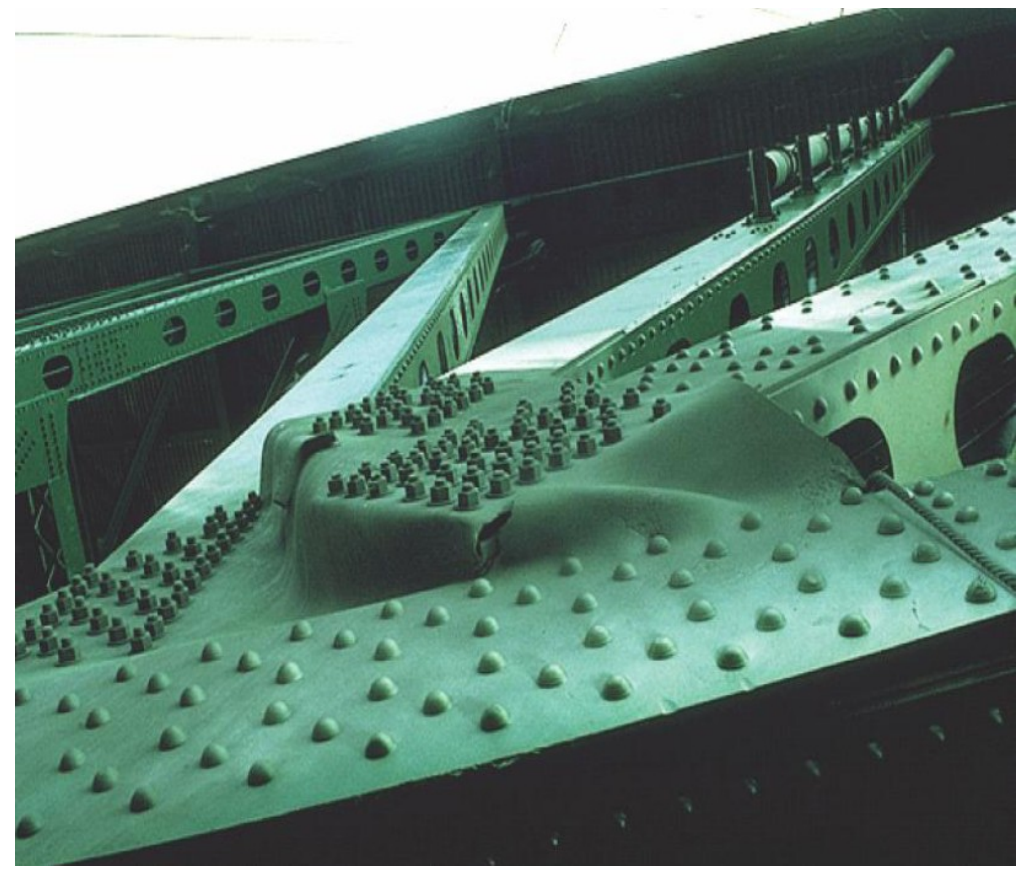

Figure 9: Gusset plate failure on the Lake County Grand River Bridge, Ohio 


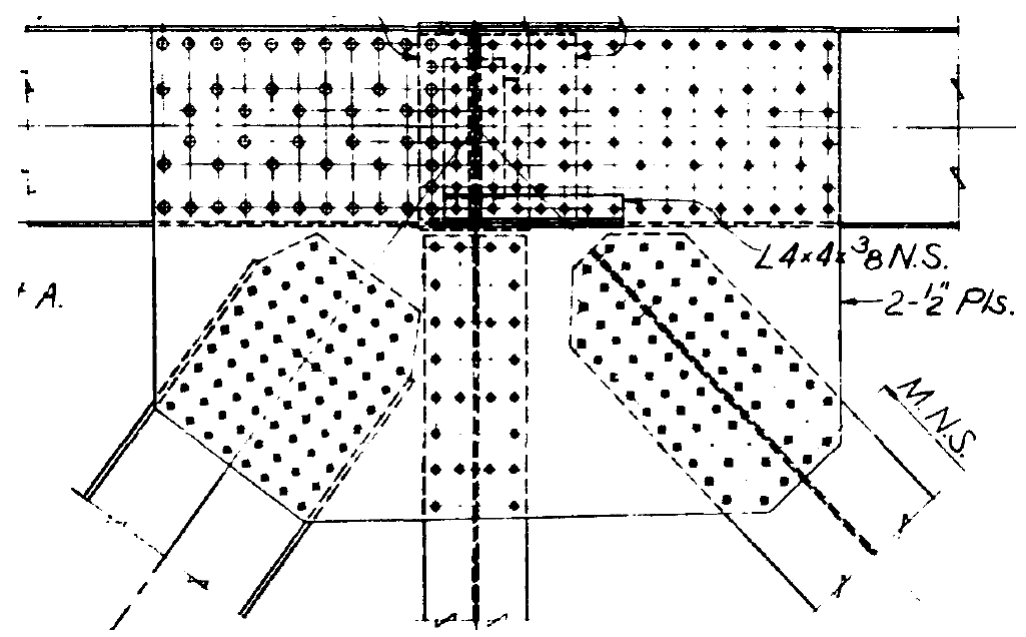

(a)

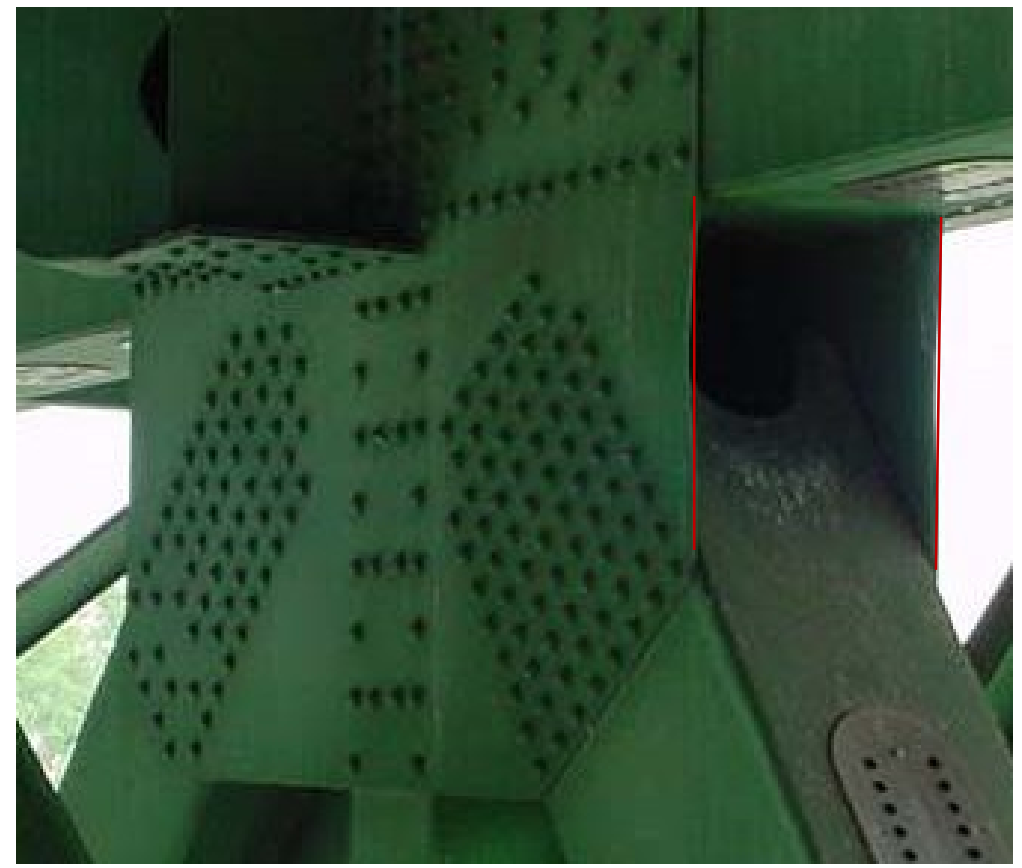

(b)

Figure 10: (a) U10 gusset connection, (b) free edge distortion in 2003 


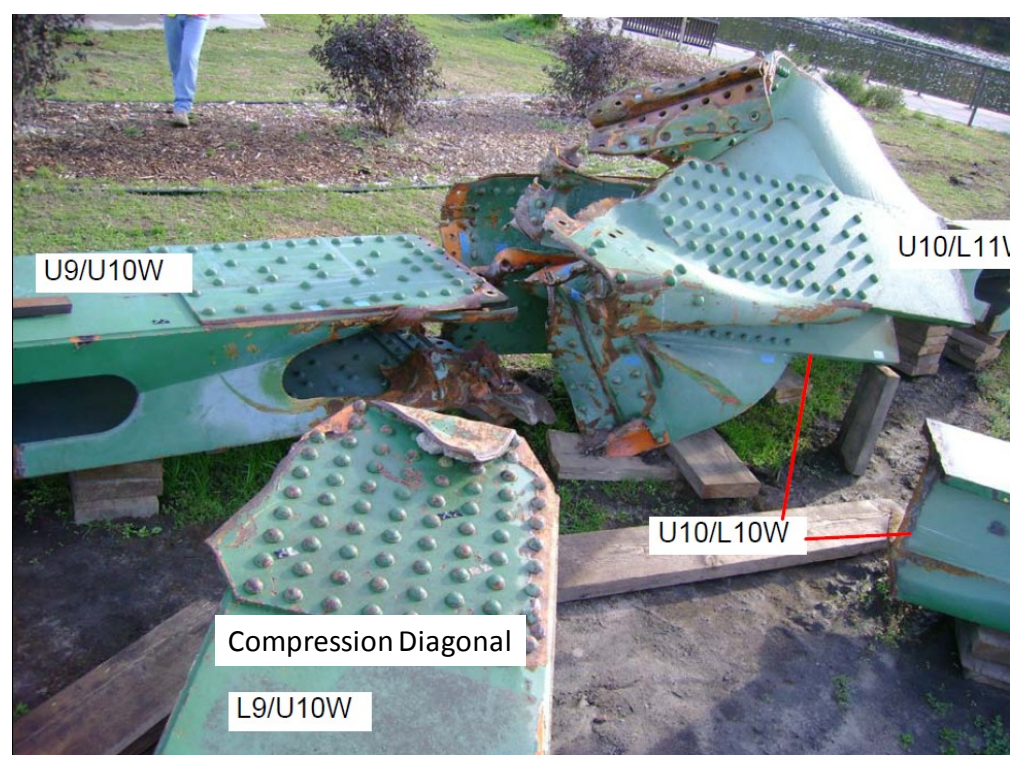

Figure 11: Post-collapse investigation photo of U10 connection, I35-W Bridge, Minneapolis MN

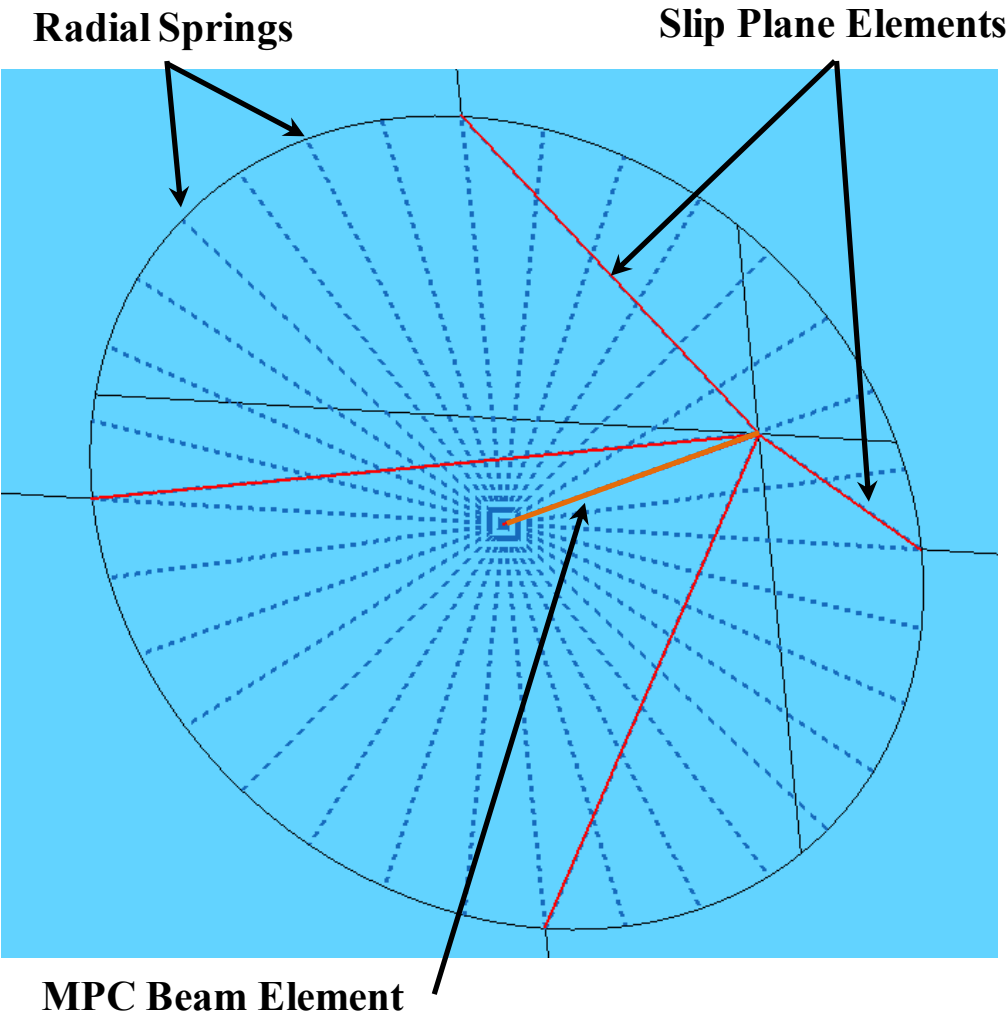

Figure 12: Radial Spring (RS) Bolt Model 


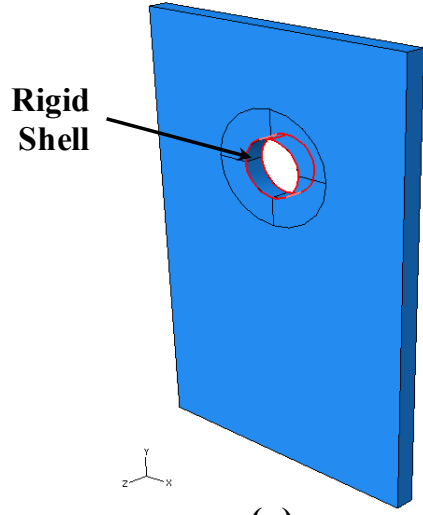

(a)

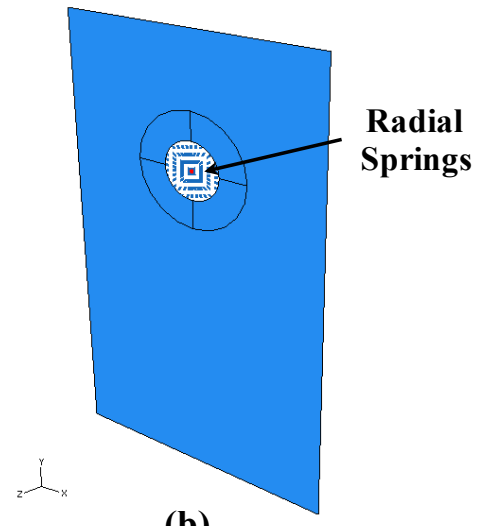

(b)

Figure 13: Single bolt model, (a) 3D contact bolt, (b) radial spring bolt

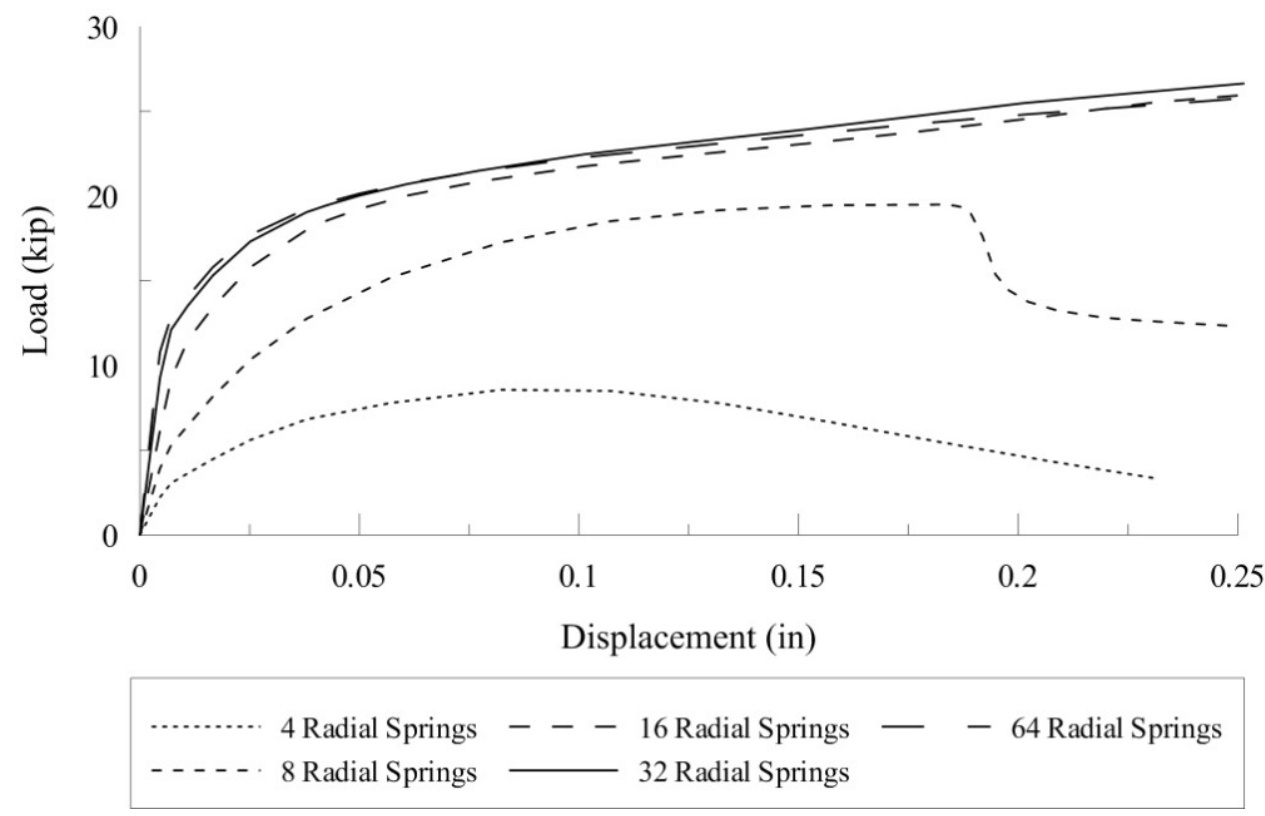

Figure 14: Load-displacement curves for different number of radial springs used 


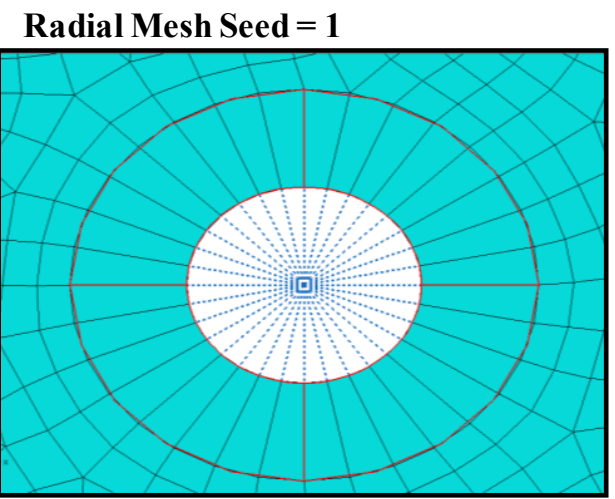

Radial Mesh Seed $=2$

Radial Mesh Seed $=4$

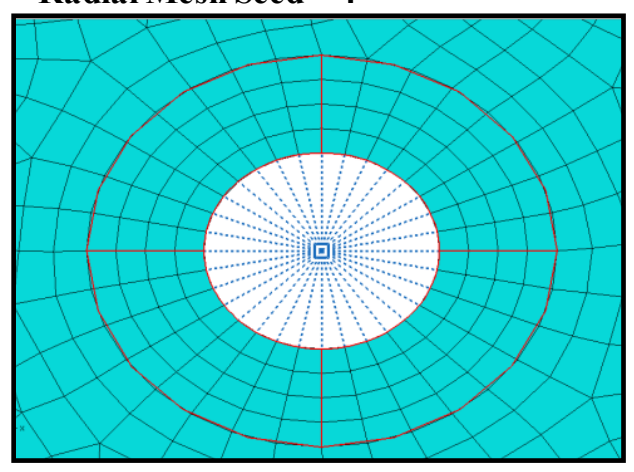

\section{Radial Mesh Seed $=6$}
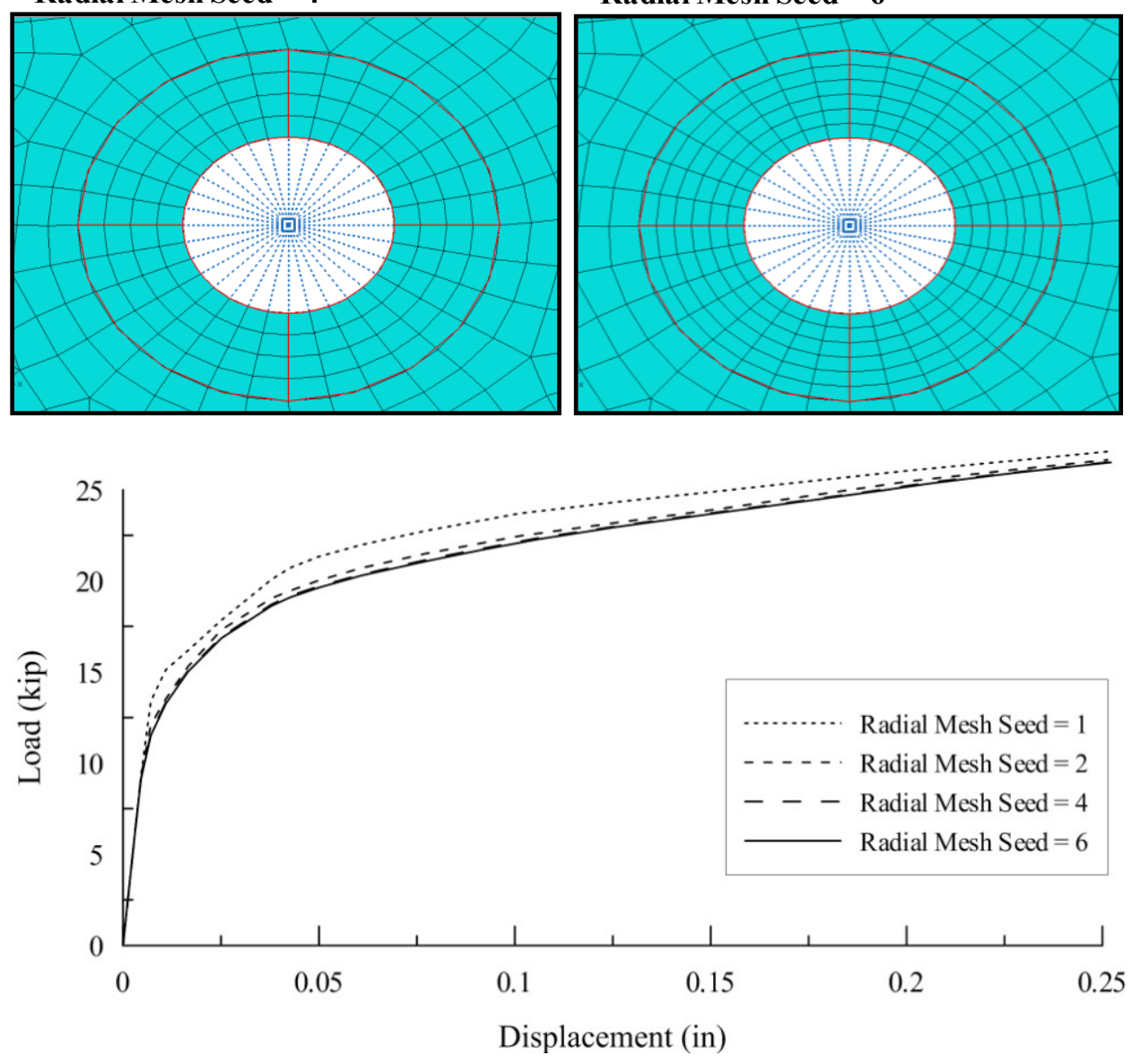

Figure 15: Local mesh convergence for RS bolt model 

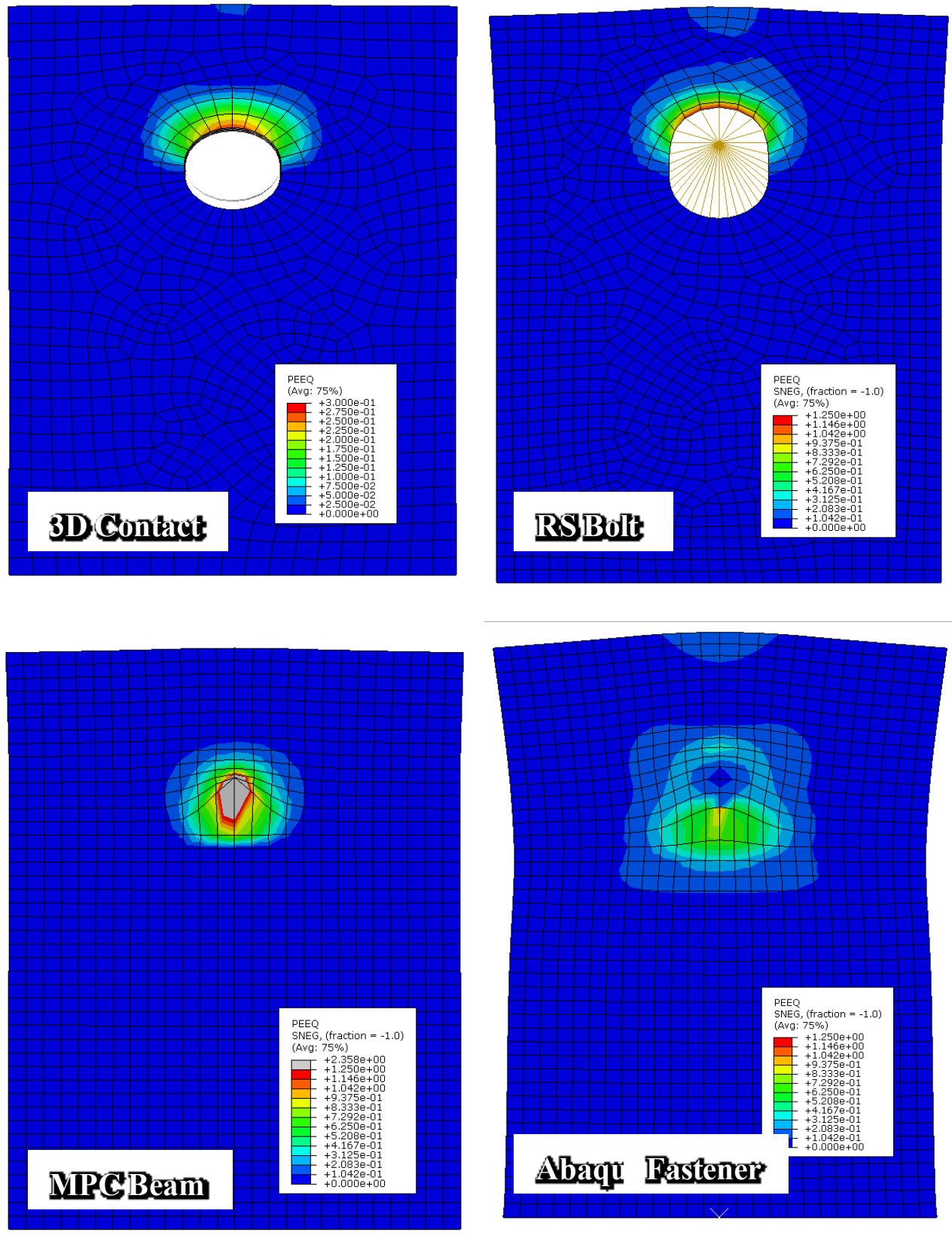

Figure 16: PEEQ contours for different bolt modeling methods 


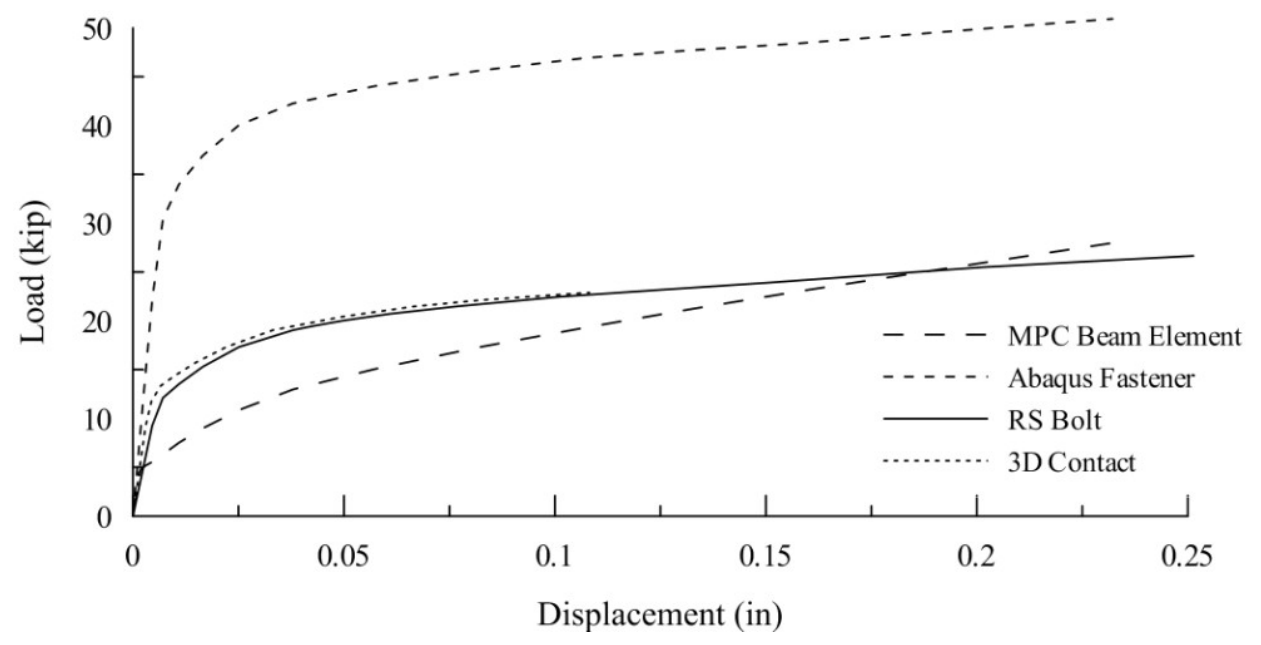

Figure 17: Load-displacement behavior for single-bolt models
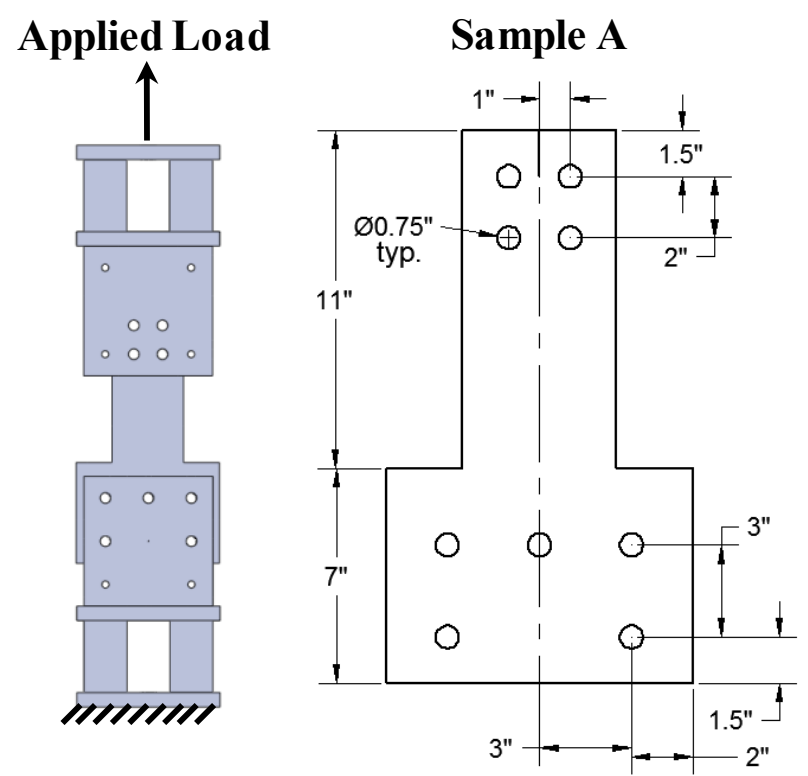

\section{Sample B}

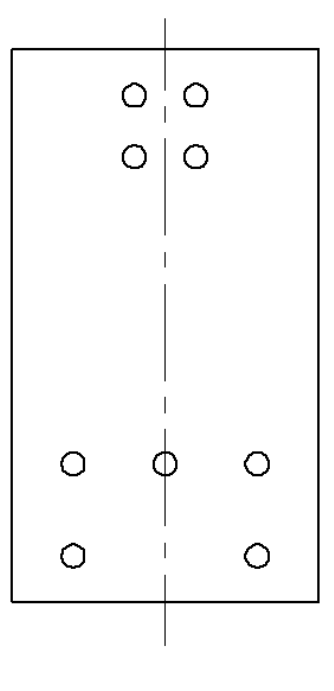

Figure 18: Test setup schematic and drawings for Samples A and B. 


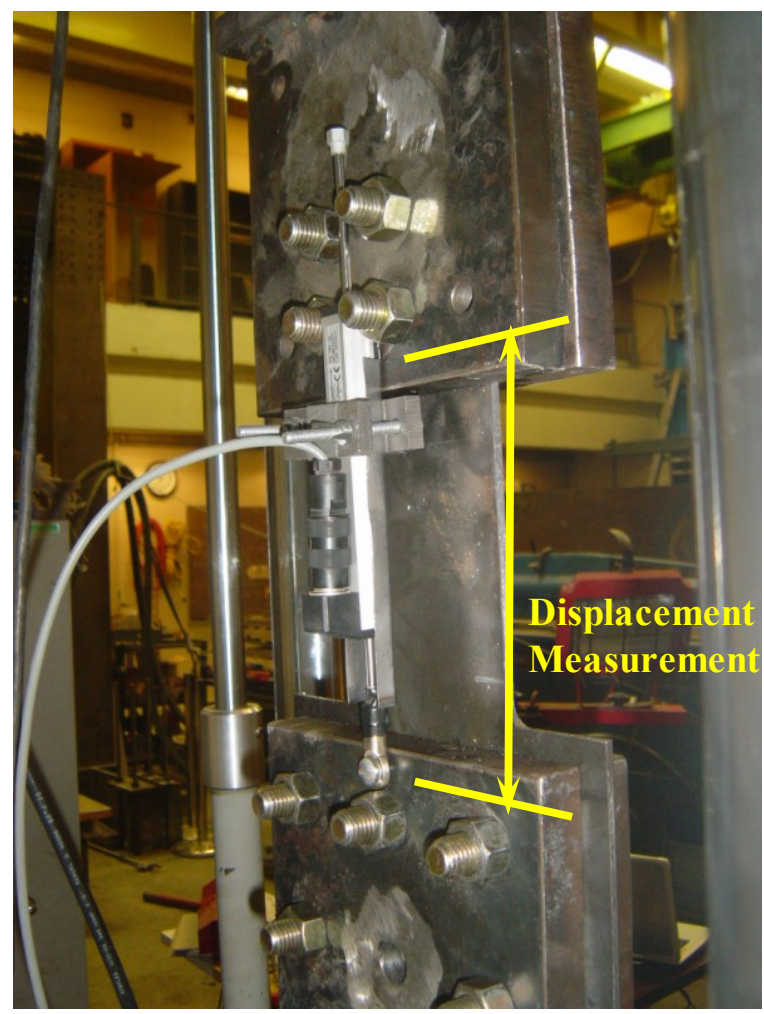

Figure 19: Displacement measurement instrumentation for multi-bolt tests

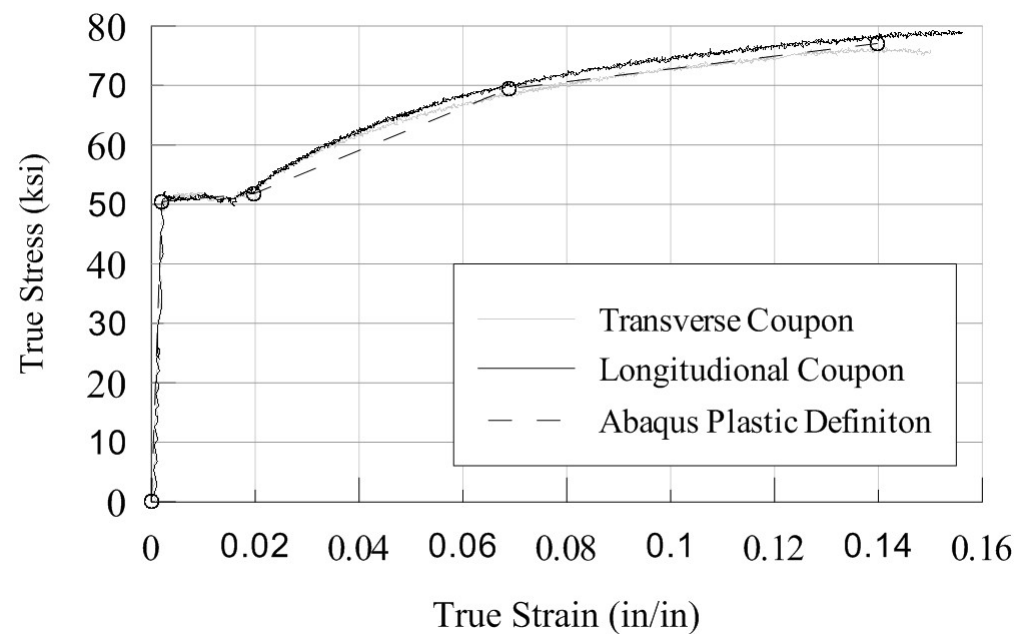

Figure 20: True stress-strain properties for gusset plate material property definition 

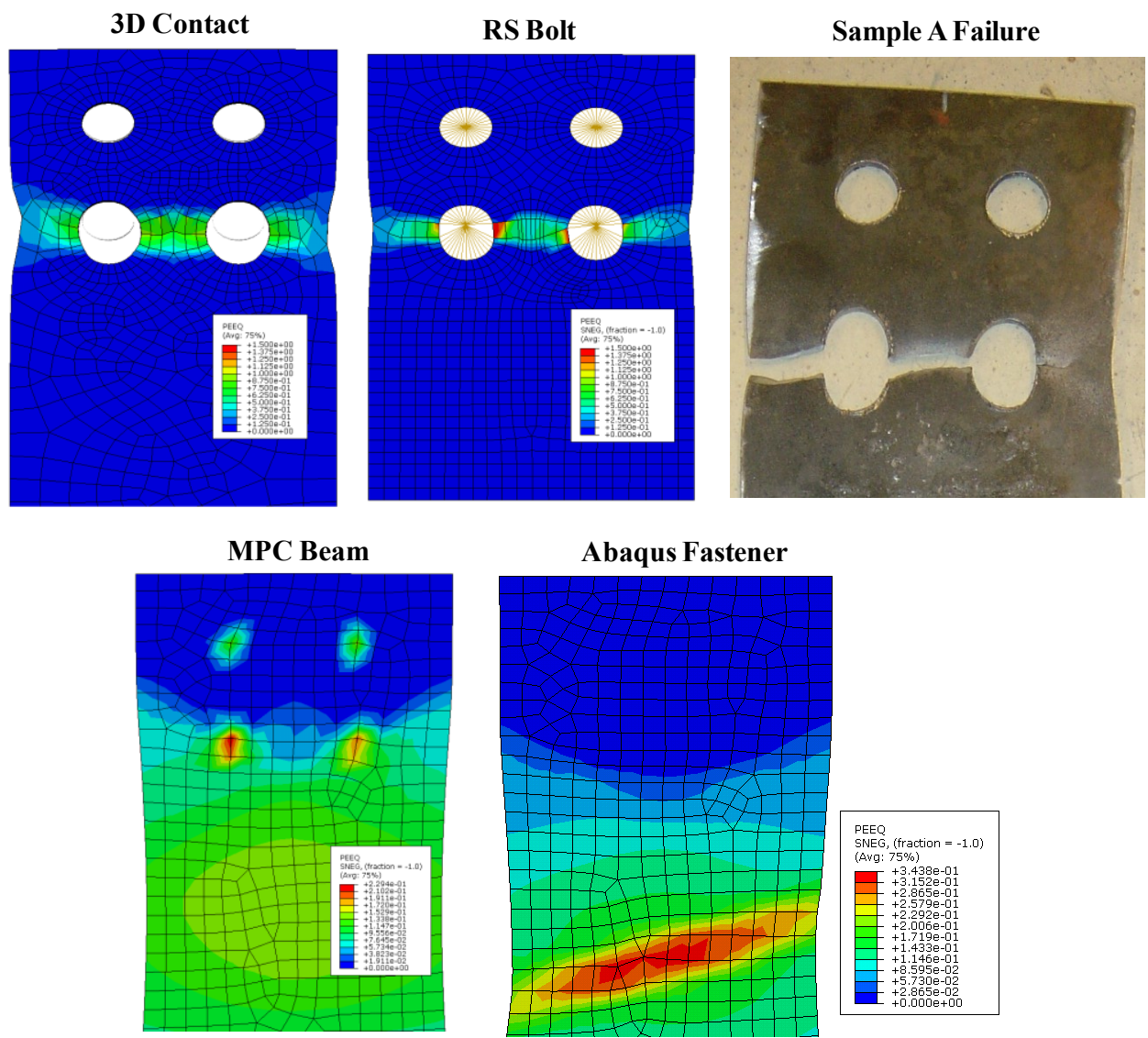

Figure 21: PEEQ contours for multi-bolt models for Sample A

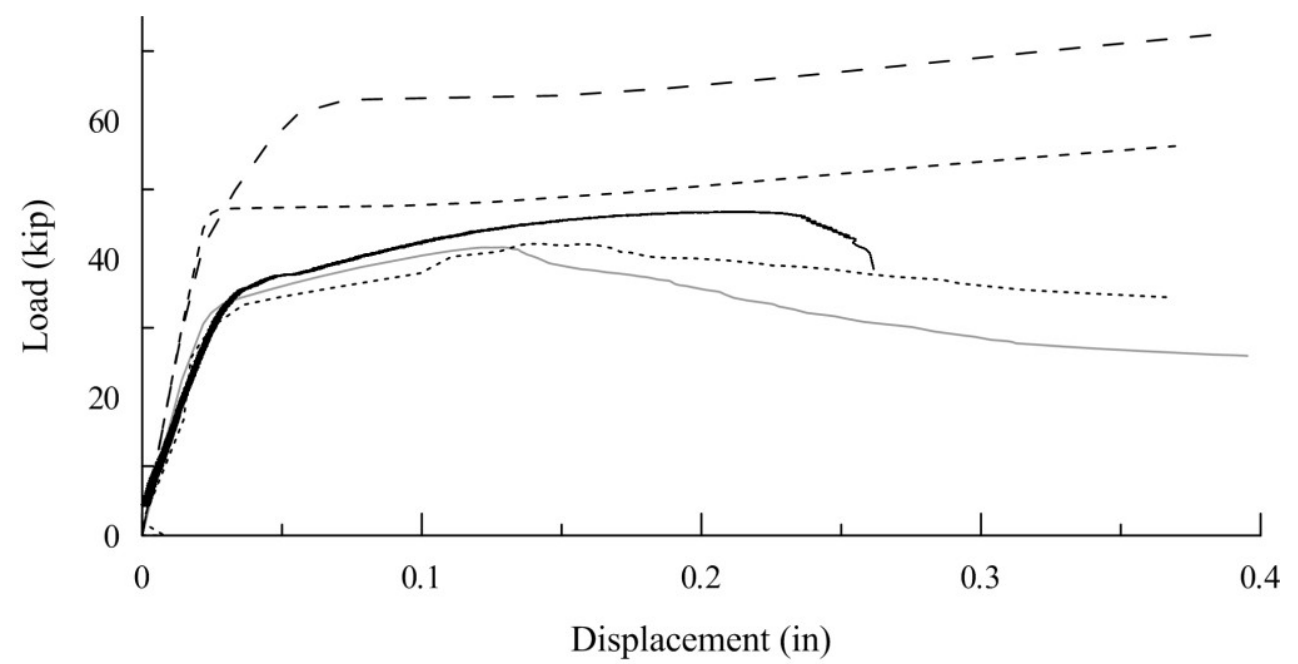

Experimental - Sample A - - MPC Beam Element 3D Contact $\quad \cdots$ Abaqus Fastener RS Bolt

Figure 22: Load-displacement behavior for Sample A 

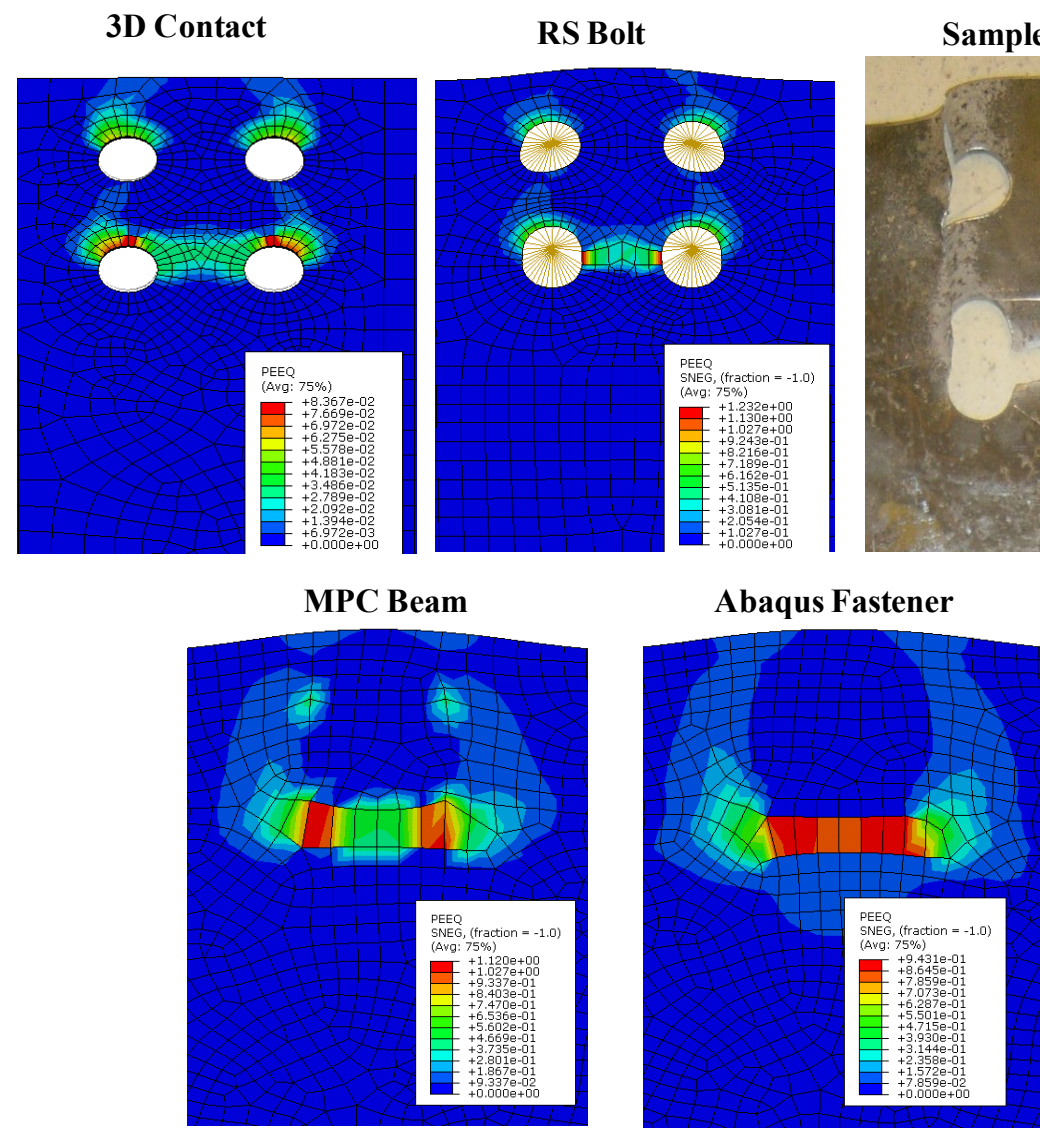

Figure 23: PEEQ contours for Sample B

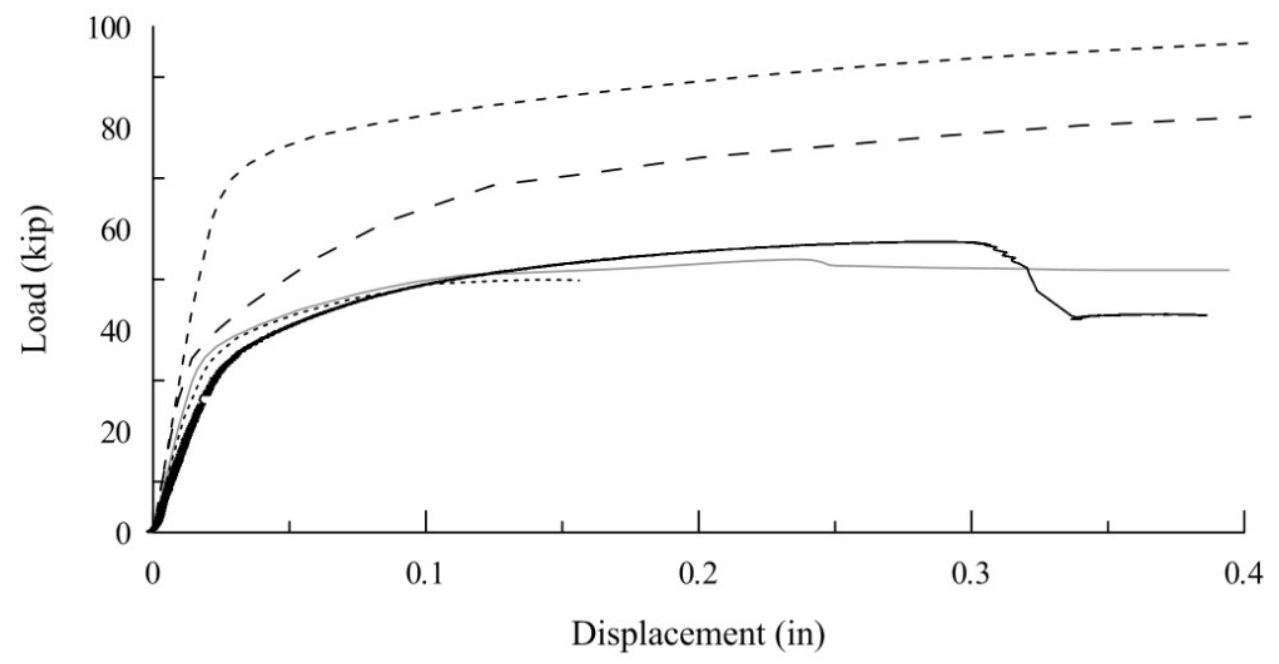
— Experimental - Sample B - - MPC Beam Element 3D Contact $\quad \cdots$ Abaqus Fastener RS Bolt

Figure 24: Load-displacement behavior for Sample B 


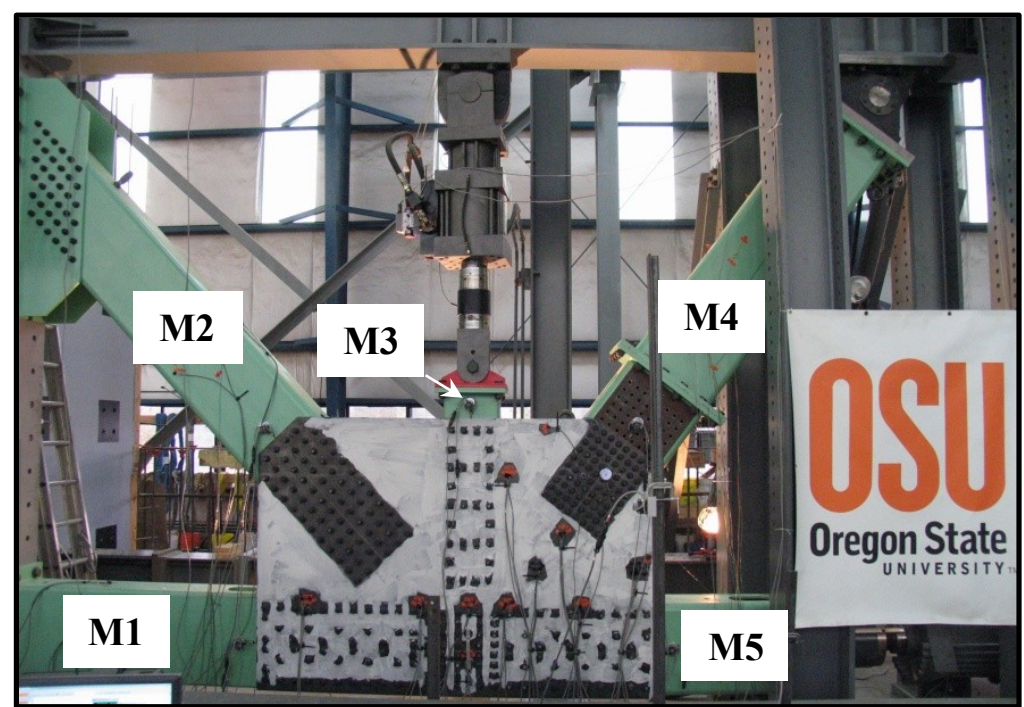

(a)

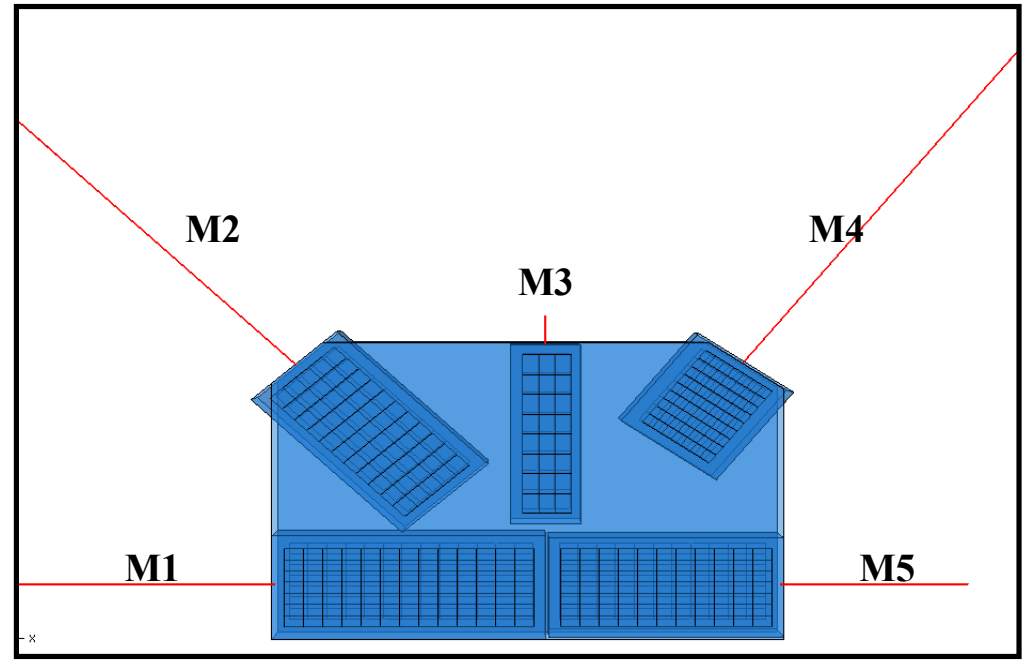

(b)

Figure 25: Gusset plate connection; (a) experimental setup, (b) FEA model 


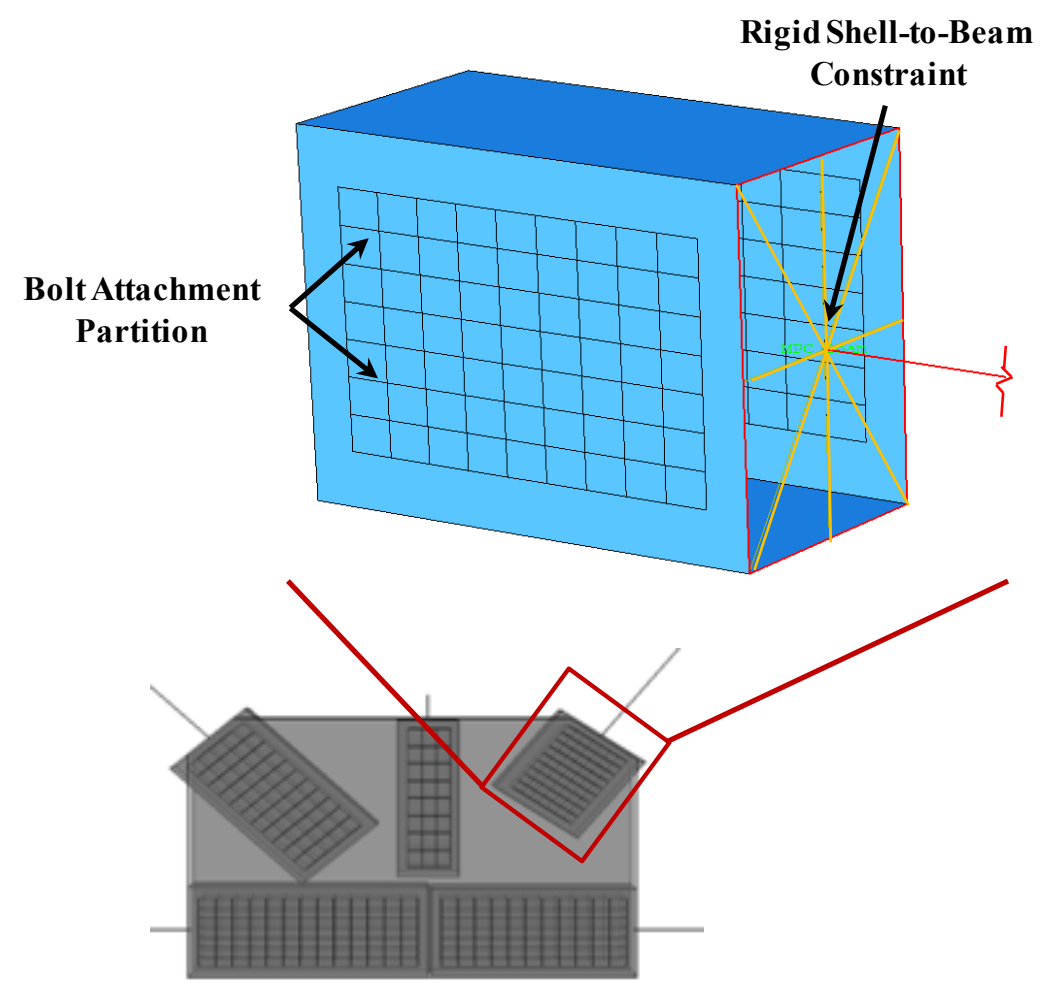

Figure 26: Gusset connection member modeling

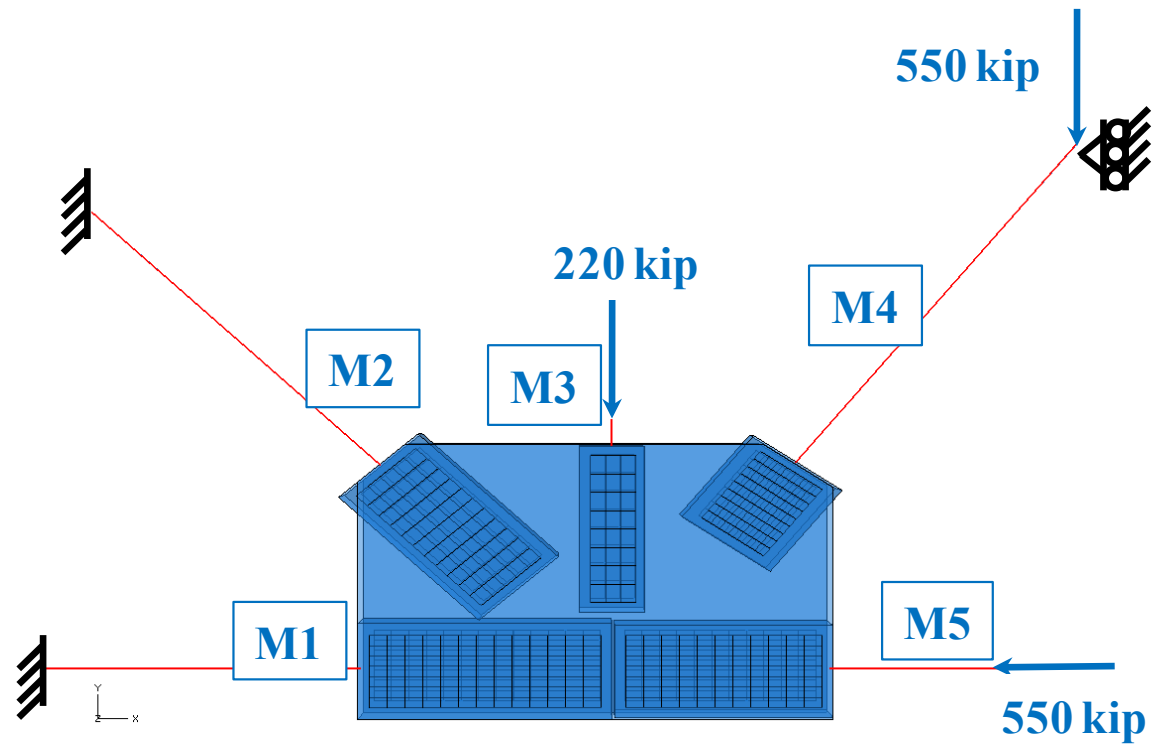

Figure 27: Boundary conditions and actuator load capacities for gusset plate connection 


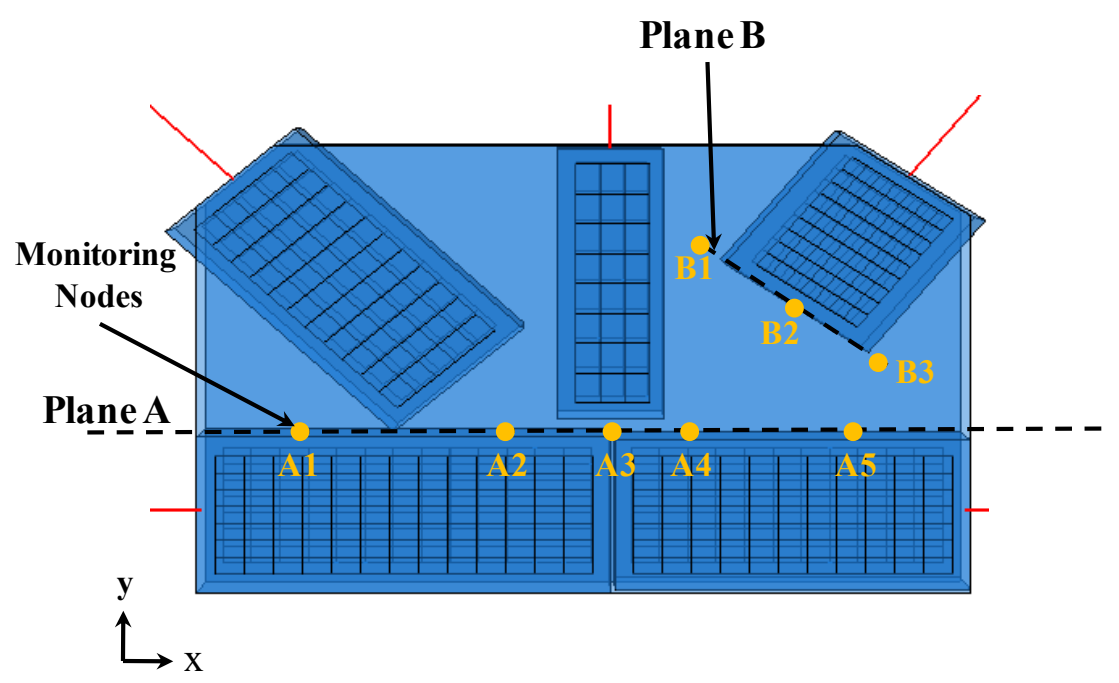

Figure 28: Stress planes and sample points used for elastic stress analysis 
MPC/AF Bolt Mesh

(a)

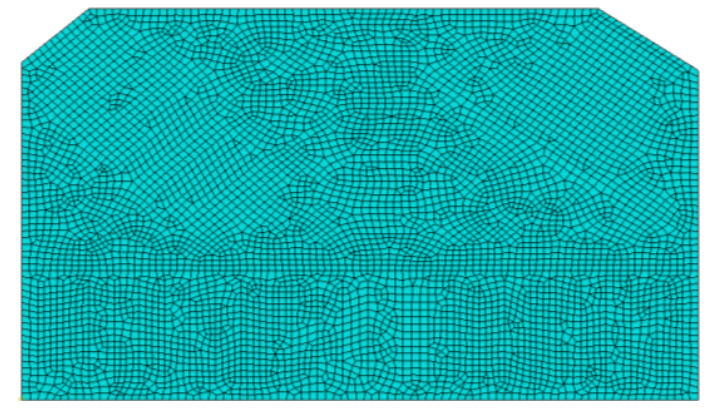

(b)

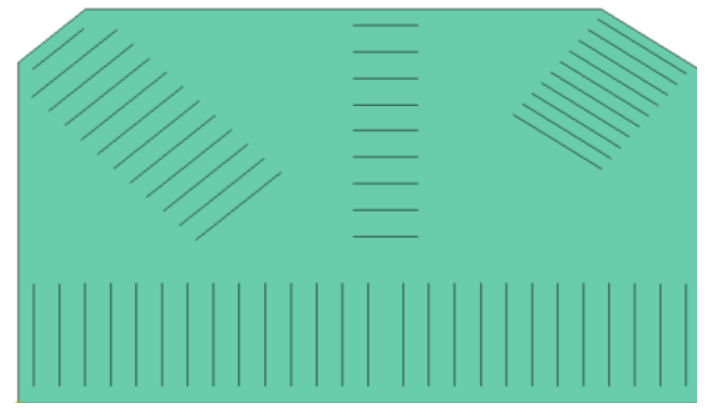

(c)

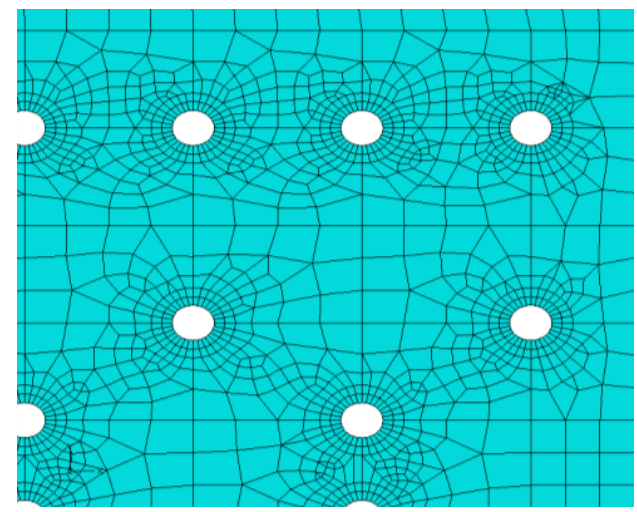

RS Bolt Mesh
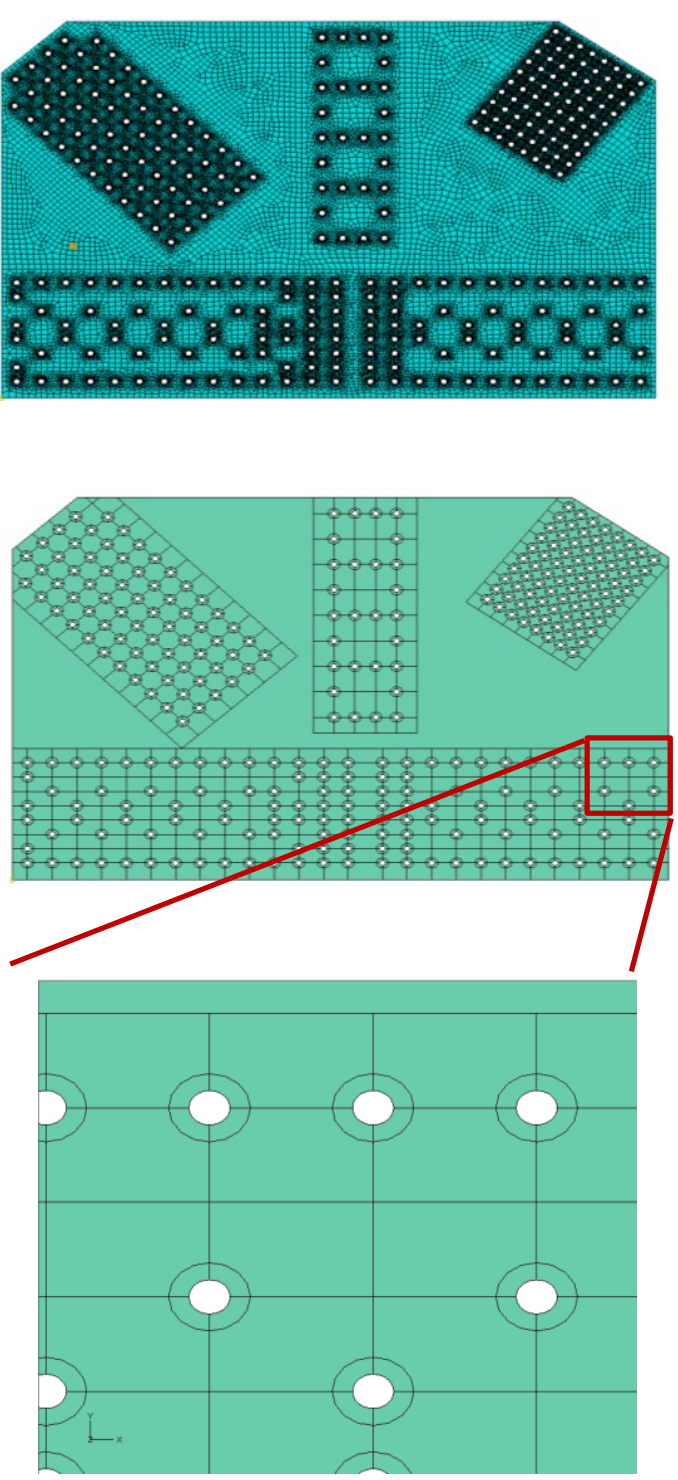

Figure 29: (a) Meshes for MPC/AF and RS bolt models, (b) partitions for MPC/AF and RS bolt models, (c) detail of mesh and partition of bolted region for RS bolt model 

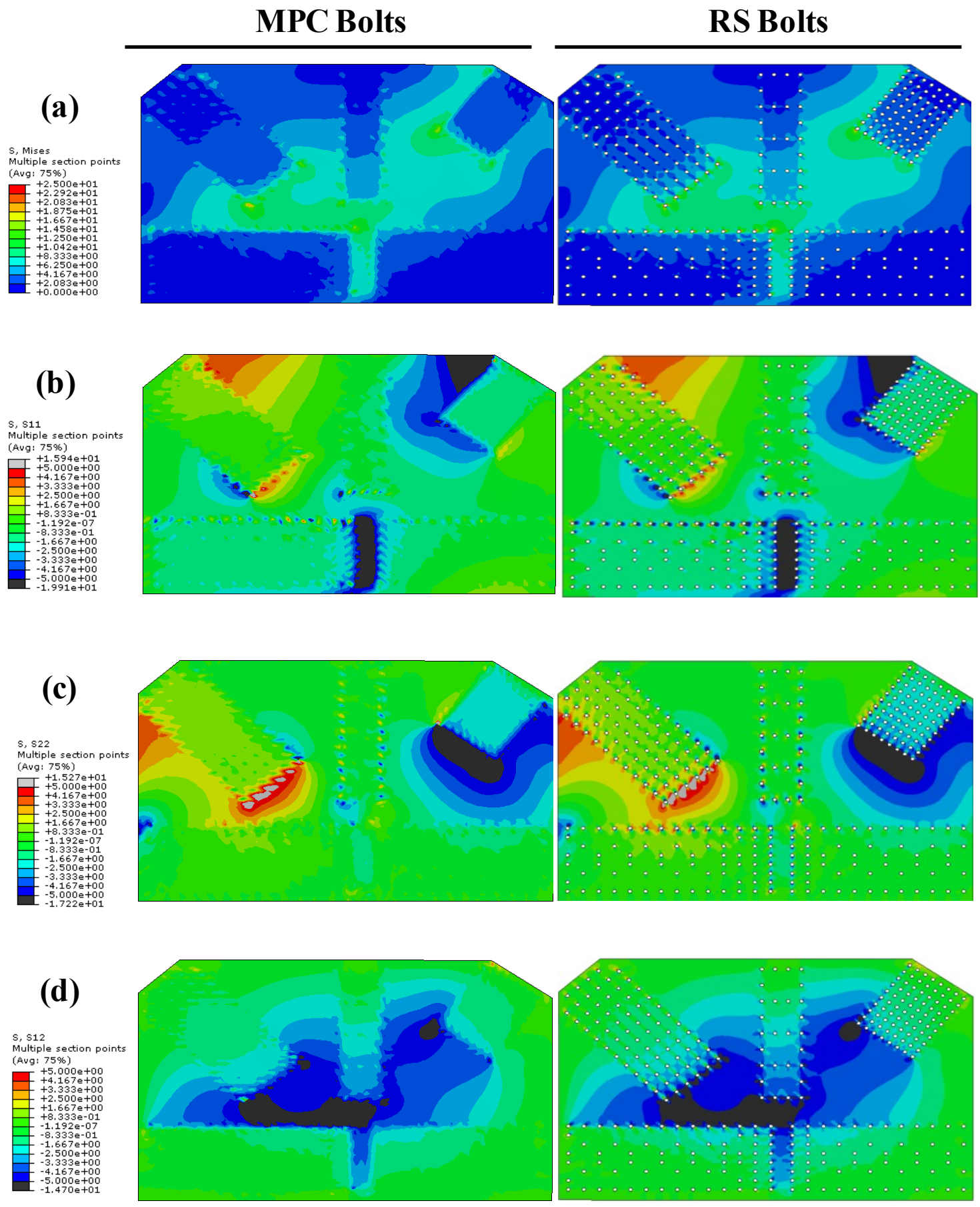

Figure 30: Stress contours for MPC and RS bolt gusset connection models, (a) Mises, (b) $s_{x x}$, (c) $s_{y y}$, (d) $s_{x y}$ 

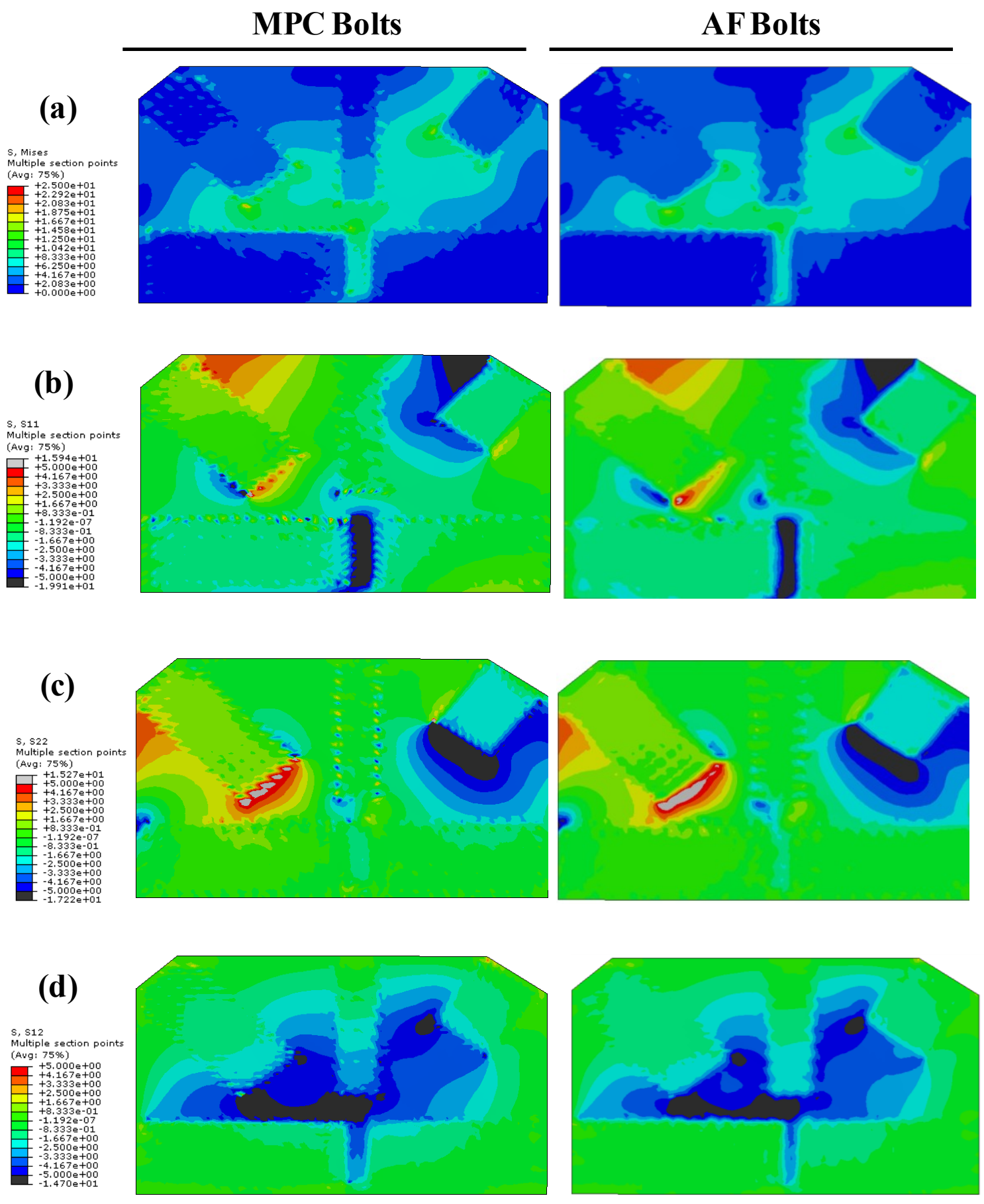

Figure 31: Stress contours for MPC and AF bolt gusset connection models, (a) Mises, (b) $s_{x x}$, (c) $s_{y y}$, (d) $\mathbf{s}_{\mathbf{x y}}$ 

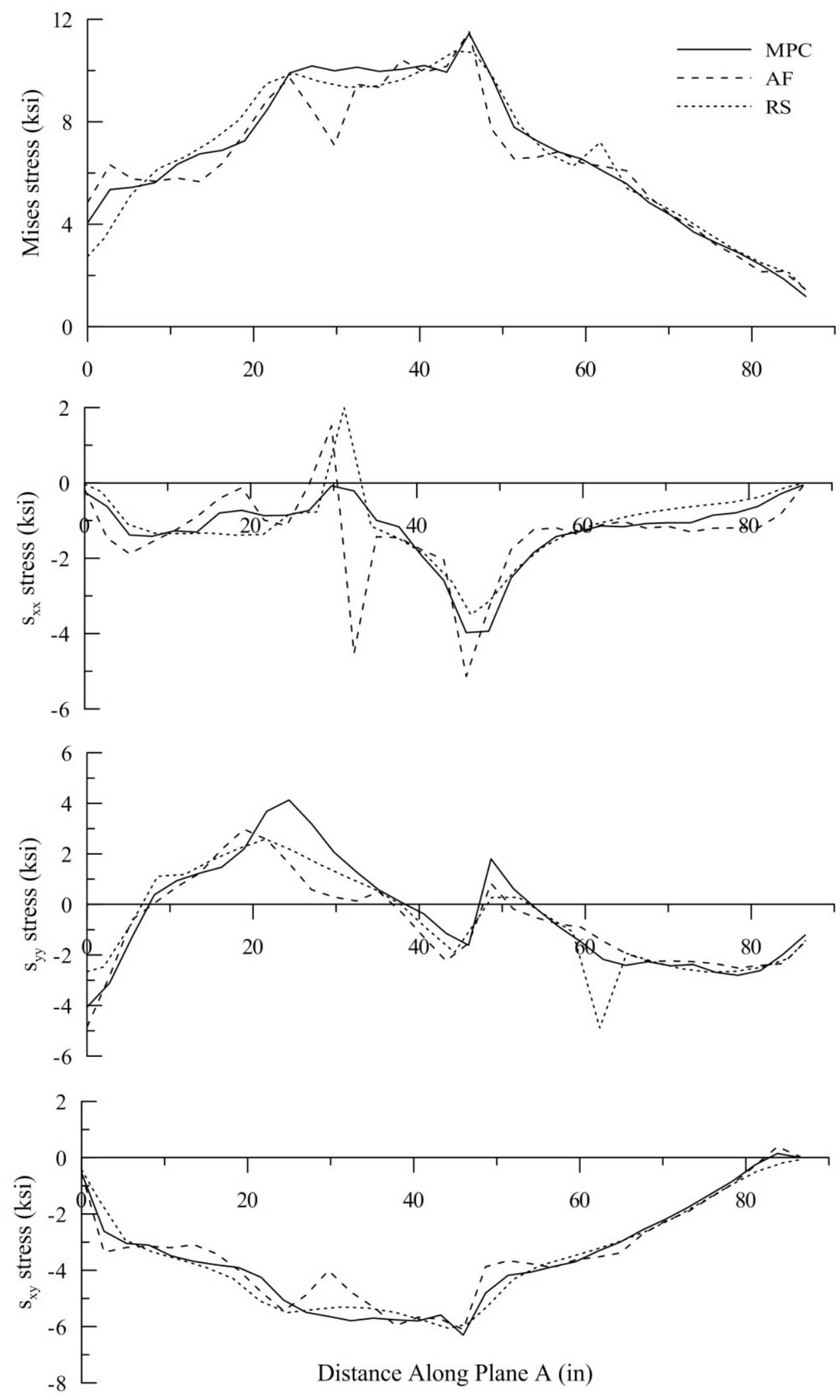

Figure 32: Plane A stress profiles for MPC, AF and RS bolt models 

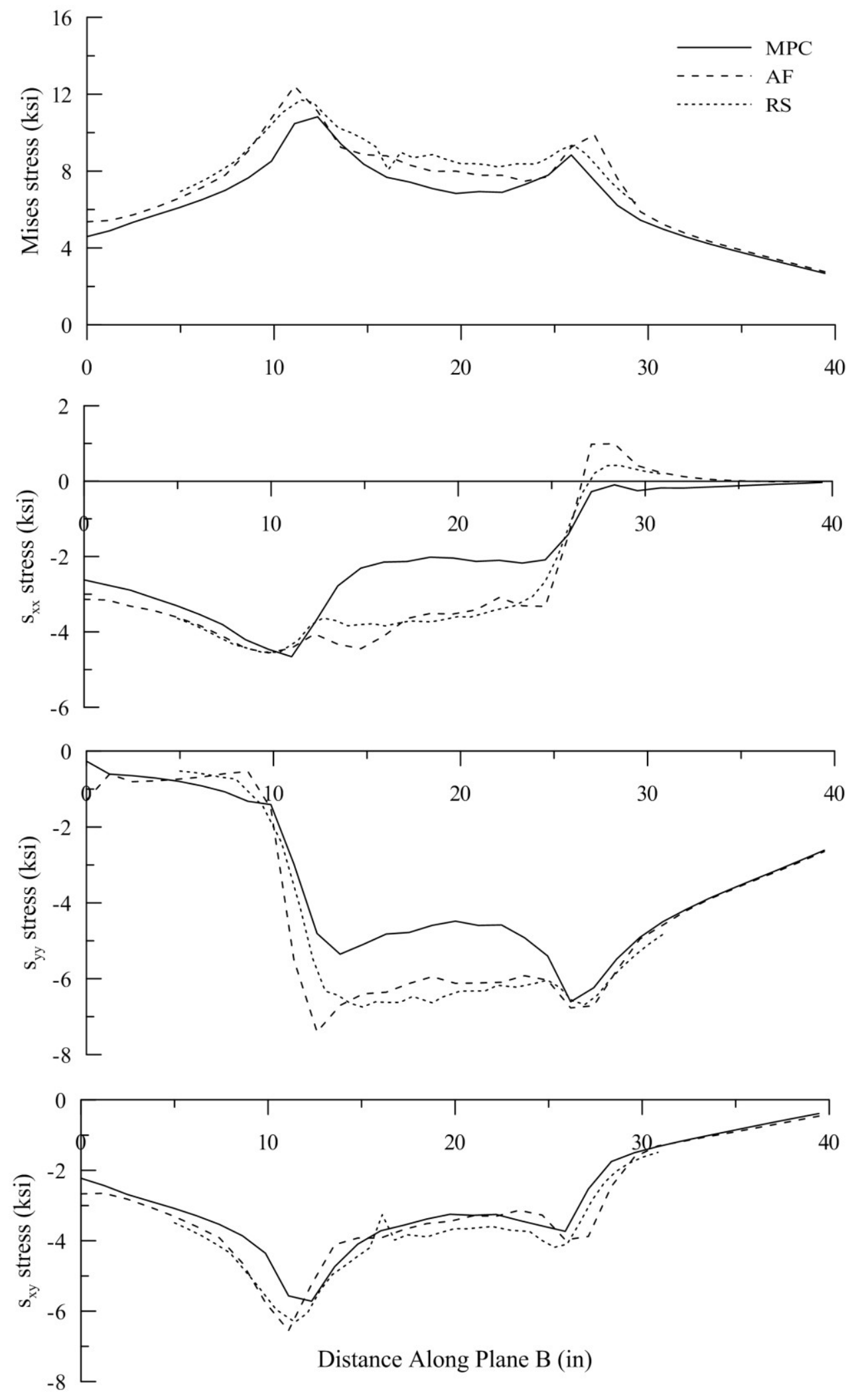

Figure 33: Plane B stress profiles for MPC, AF and RS bolt models 

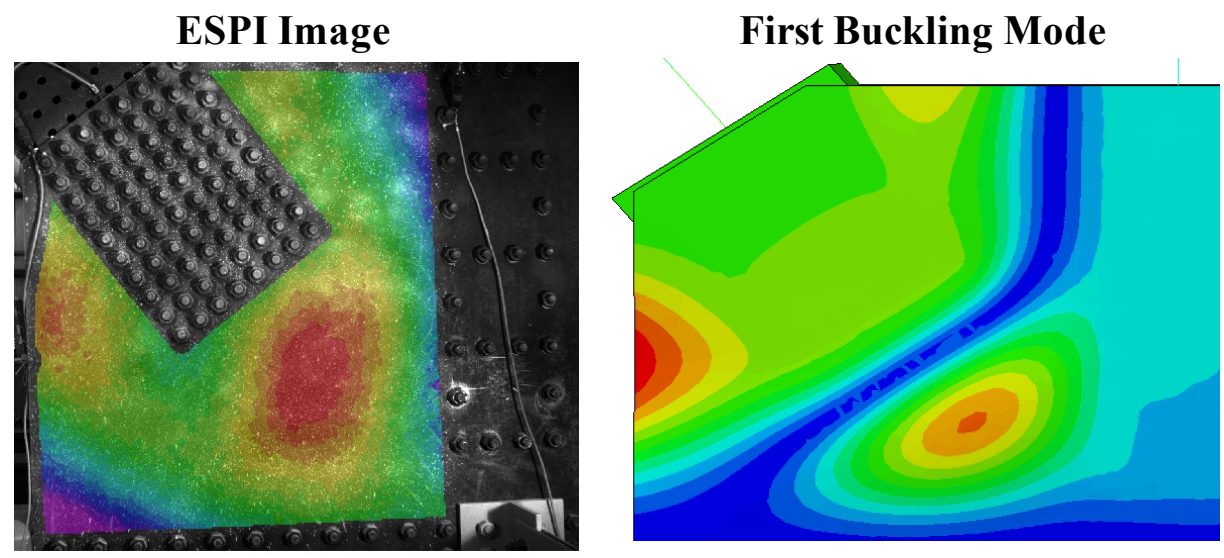

Figure 34: Imperfection comparison between EI and first buckling mode - Test 1
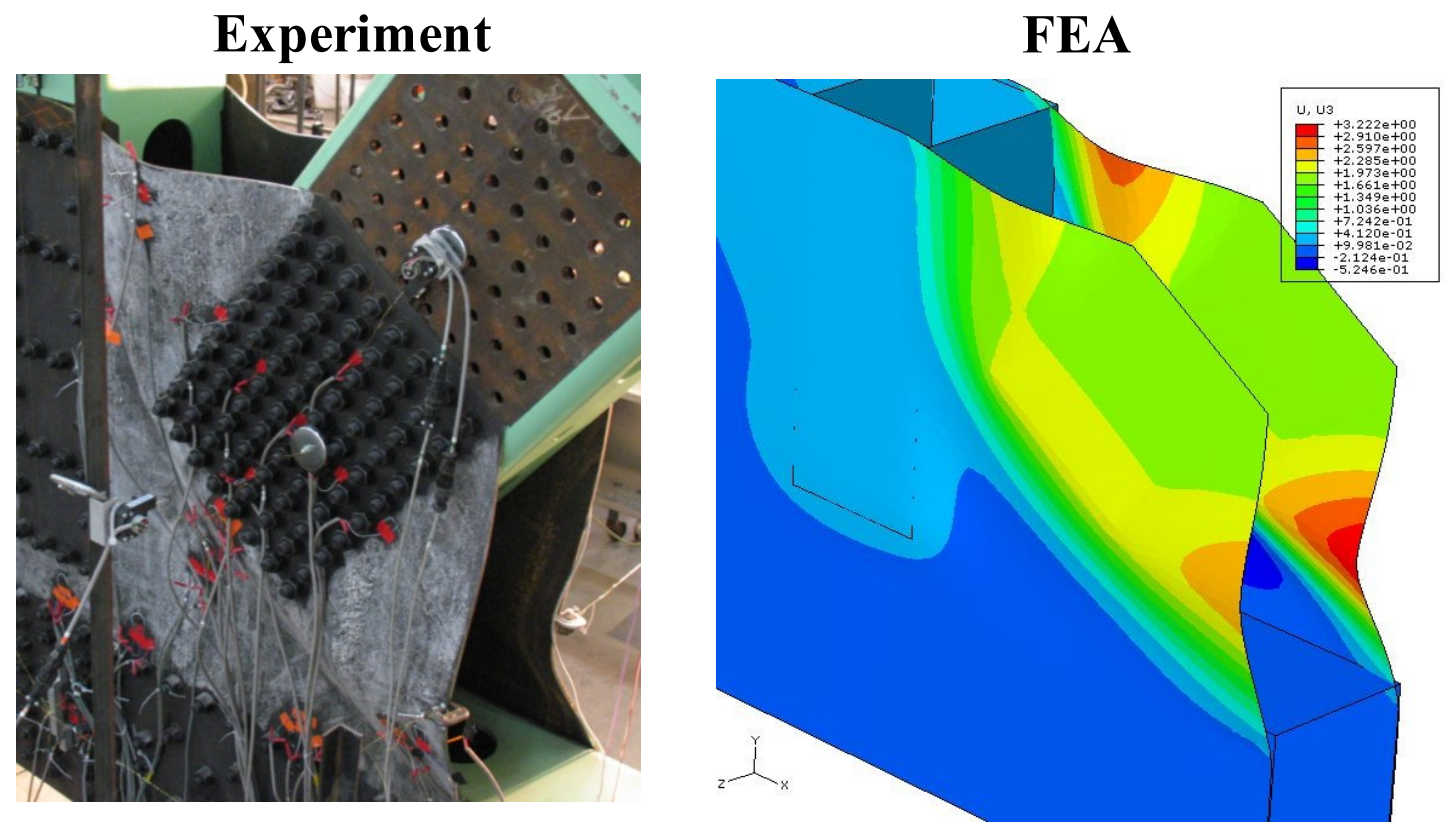

Figure 35: Buckled shape comparison from Test 1 


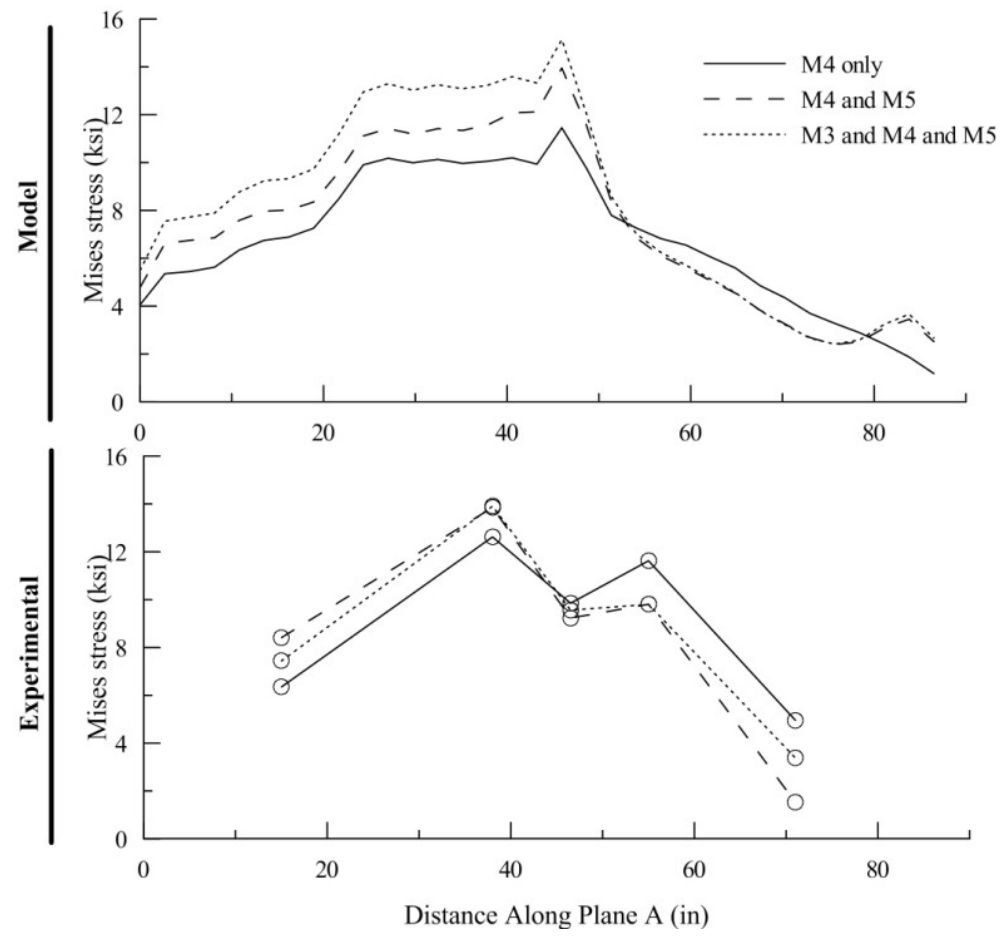

Figure 36: Plane A Mises stress profiles
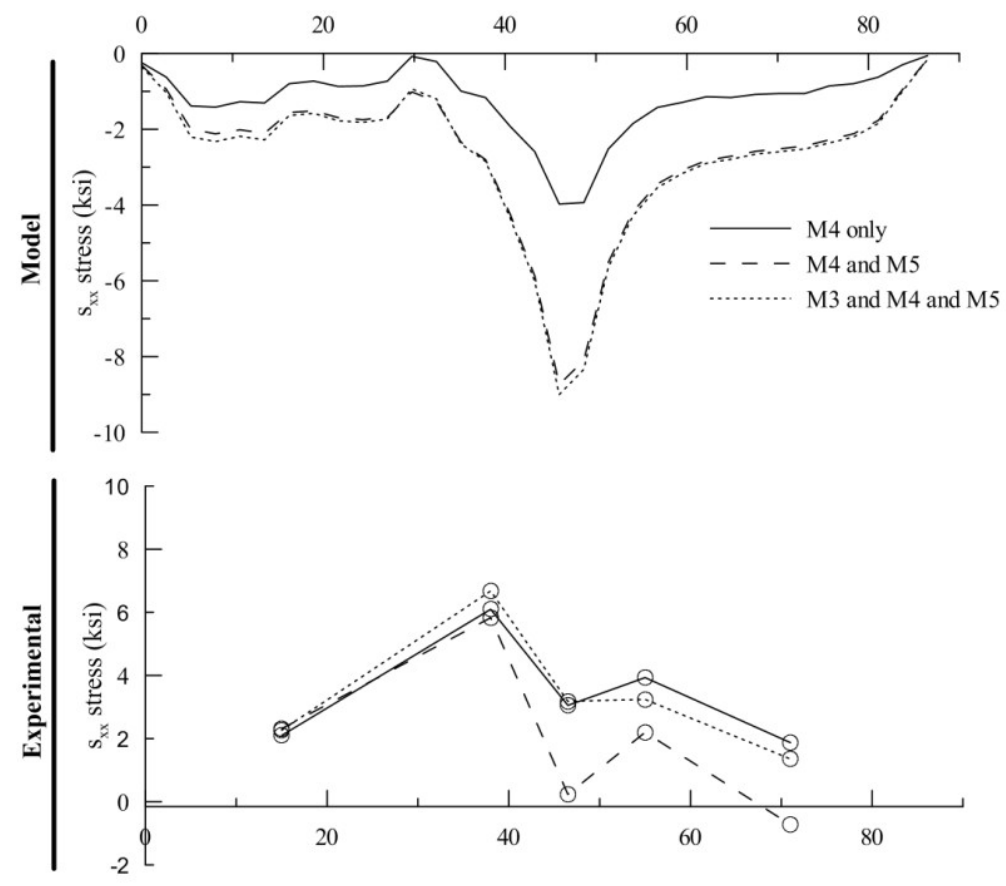

Distance Along Plane A (in)

Figure 37: Plane A $s_{x x}$ stress profiles 


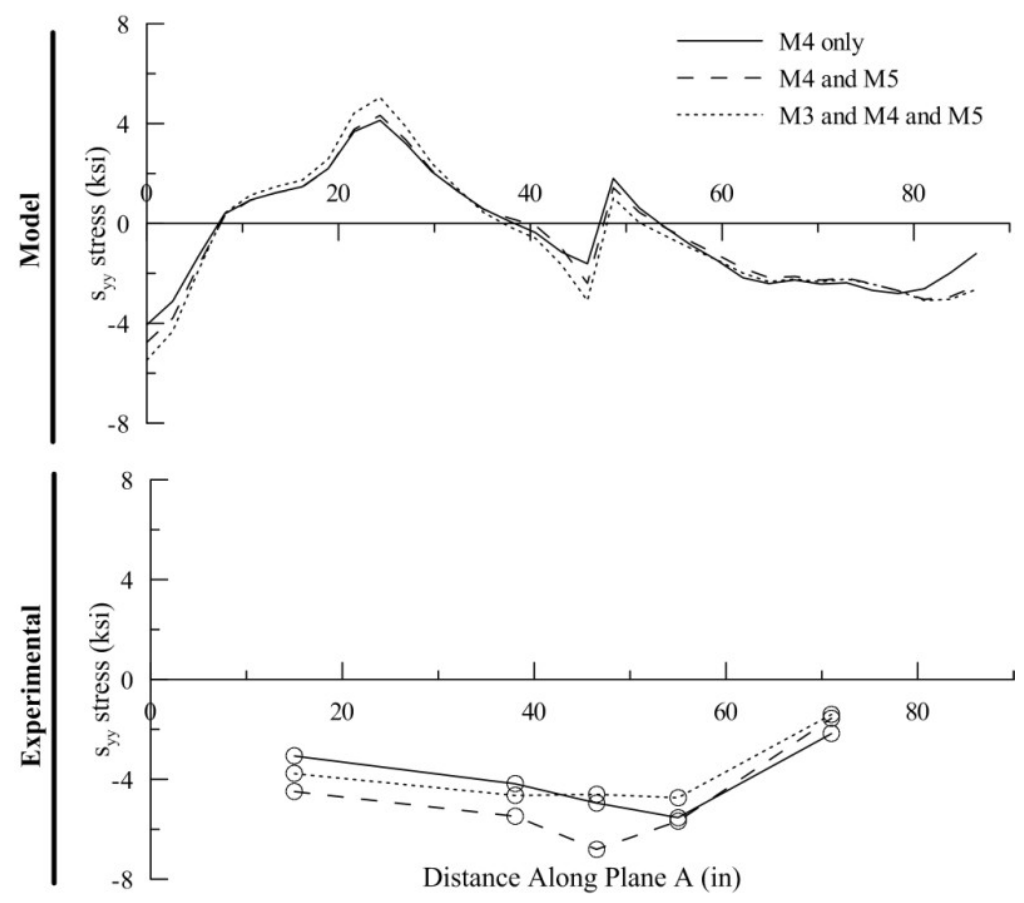

Figure 38: Plane A $s_{y y}$ stress profiles
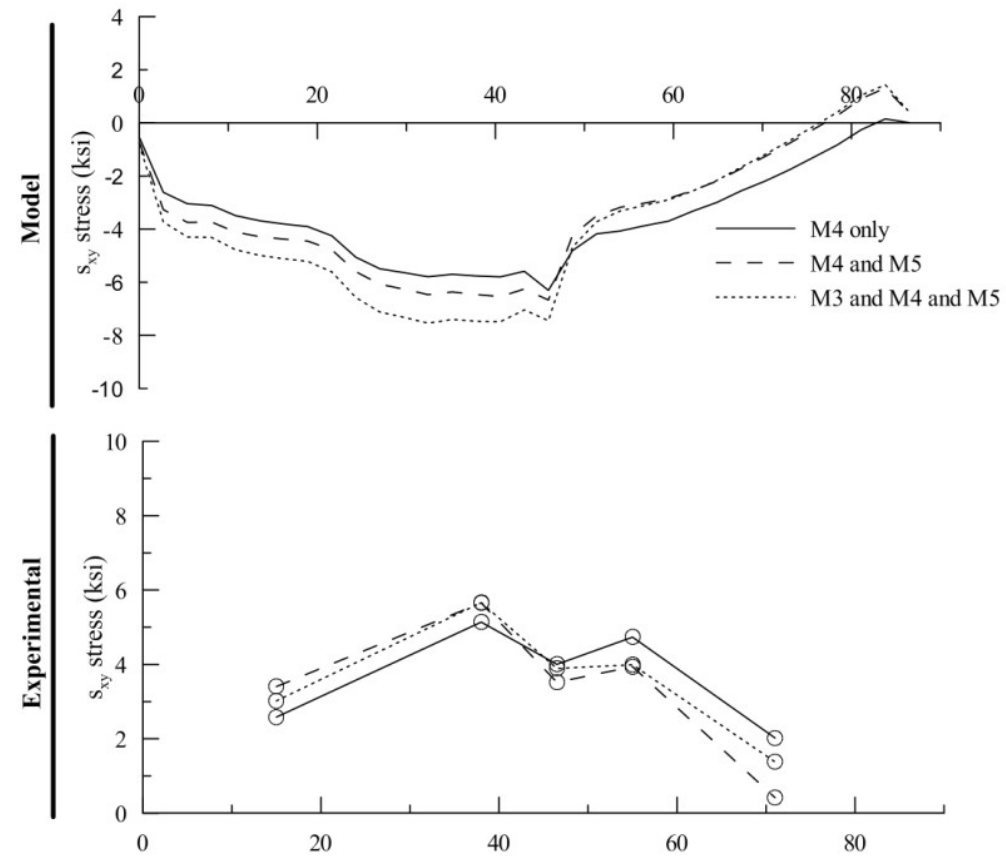

Distance Along Plane A (in)

Figure 39: Plane A $s_{x y}$ stress profiles 

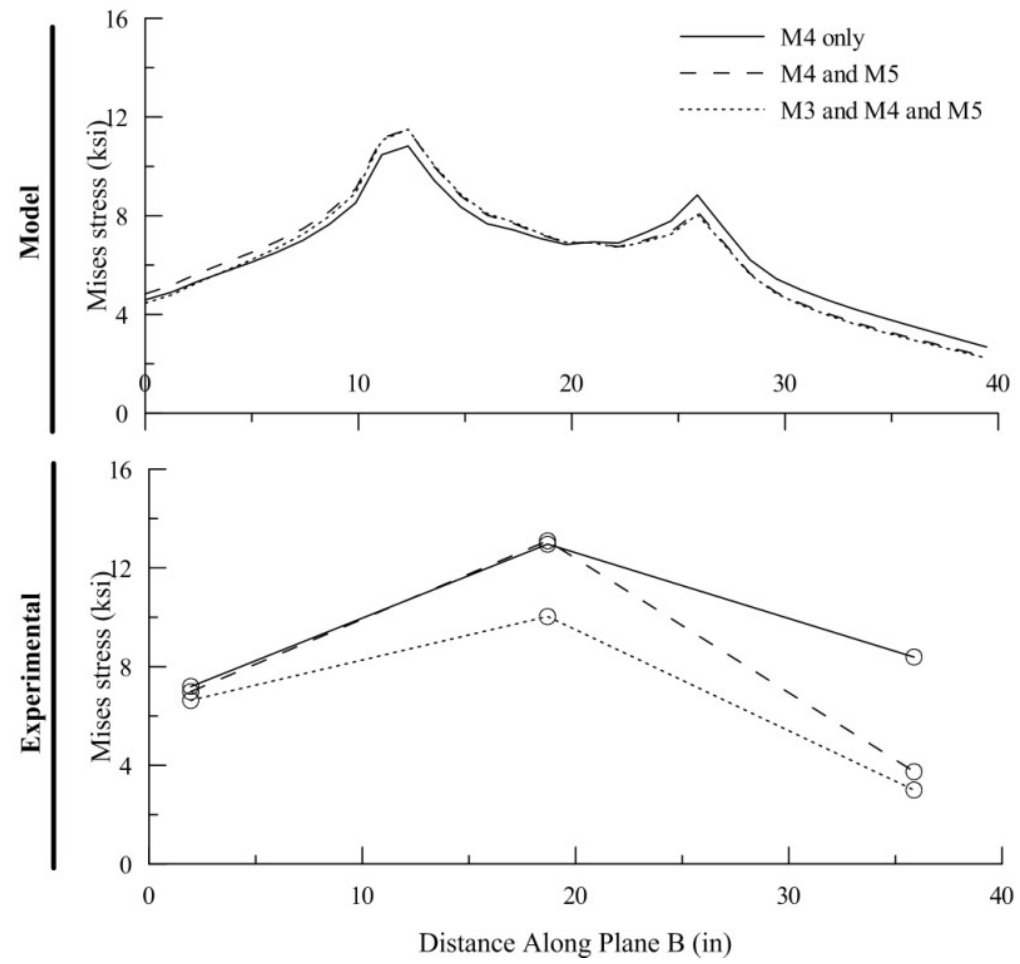

Figure 40: Plane B Mises stress profiles

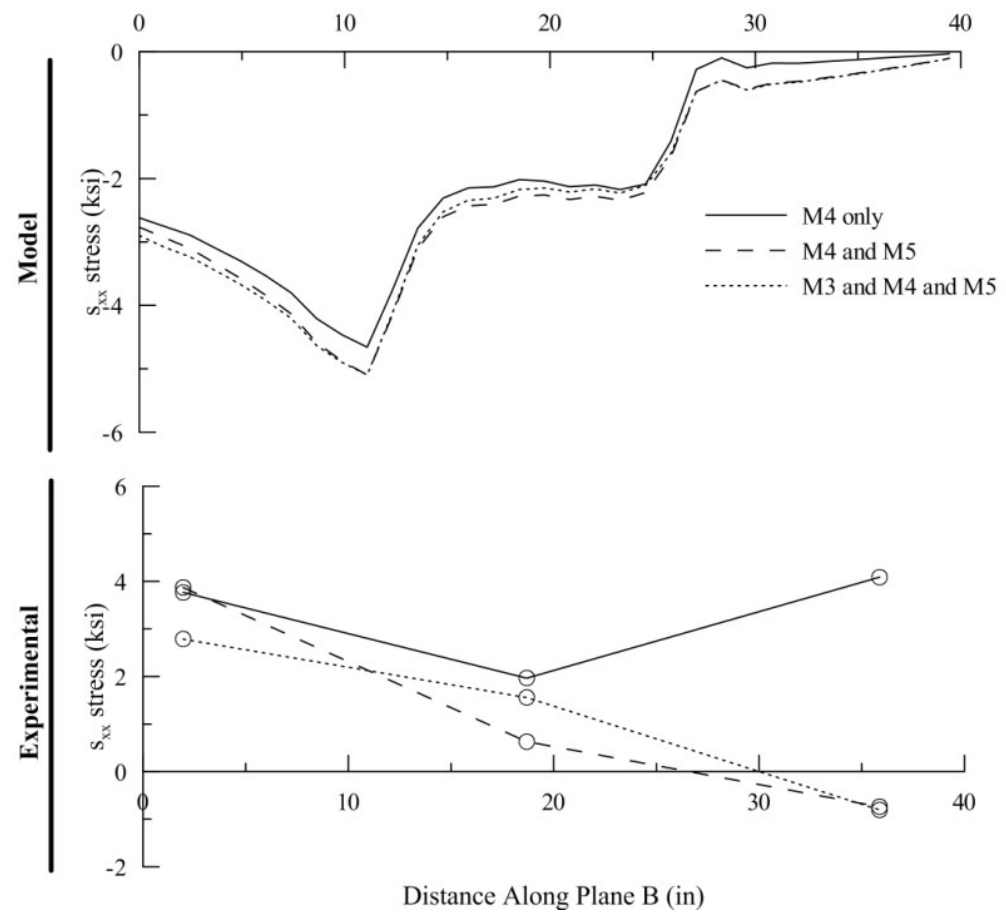

Figure 41: Plane $B s_{x x}$ stress profiles 

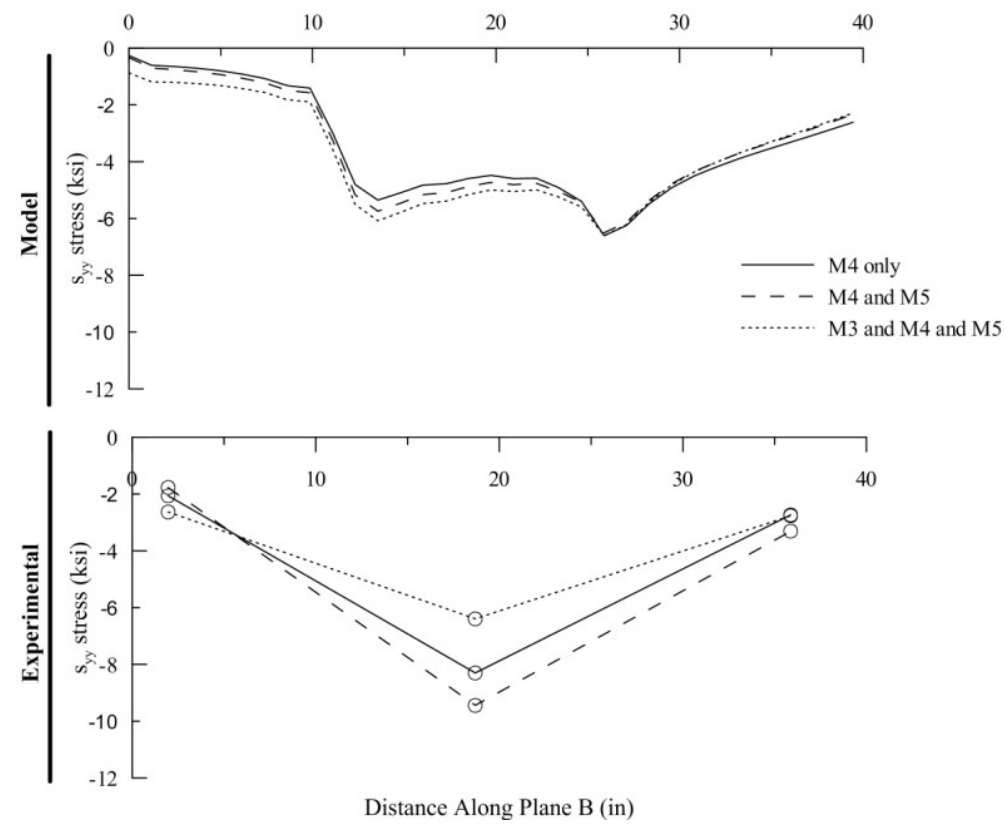

Figure 42: Plane $B s_{y y}$ stress profiles
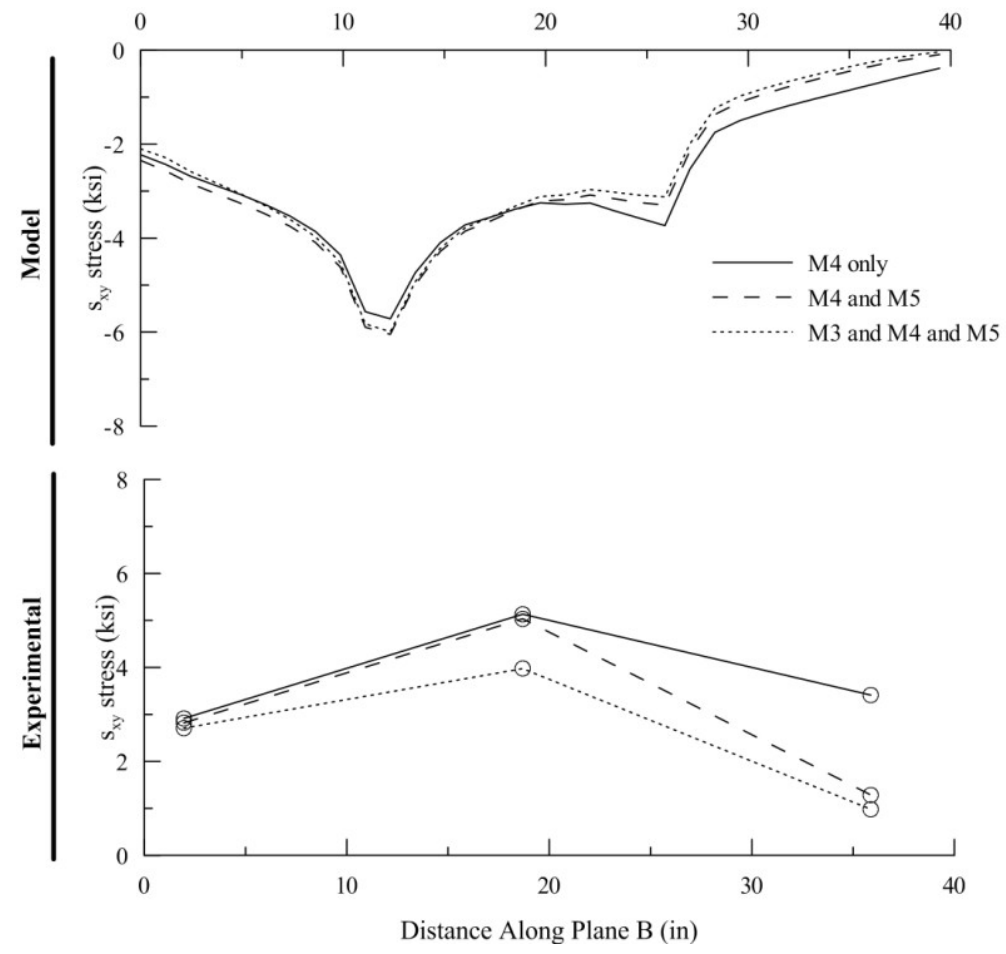

Figure 43: Plane $B s_{x y}$ stress profiles 

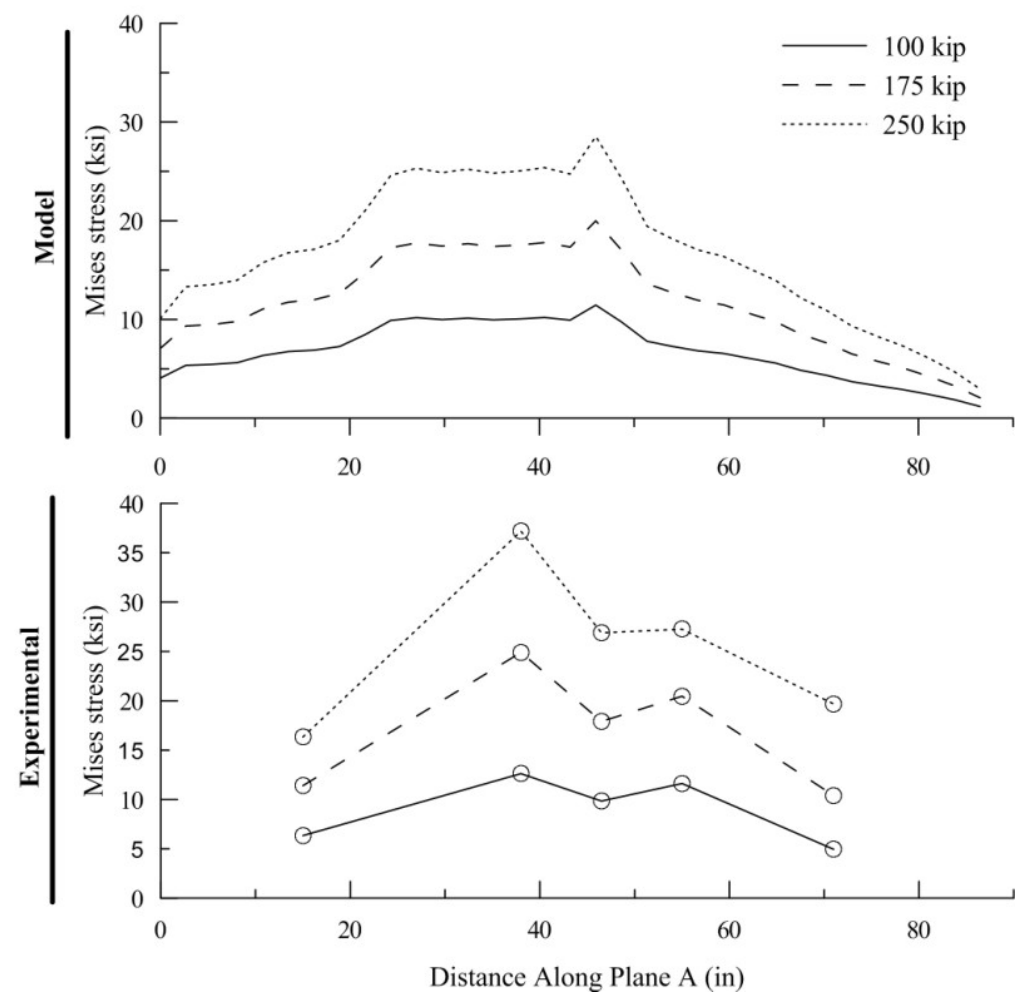

Figure 44: Mises stress comparison at Plane A for M4 loaded to different magnitudes
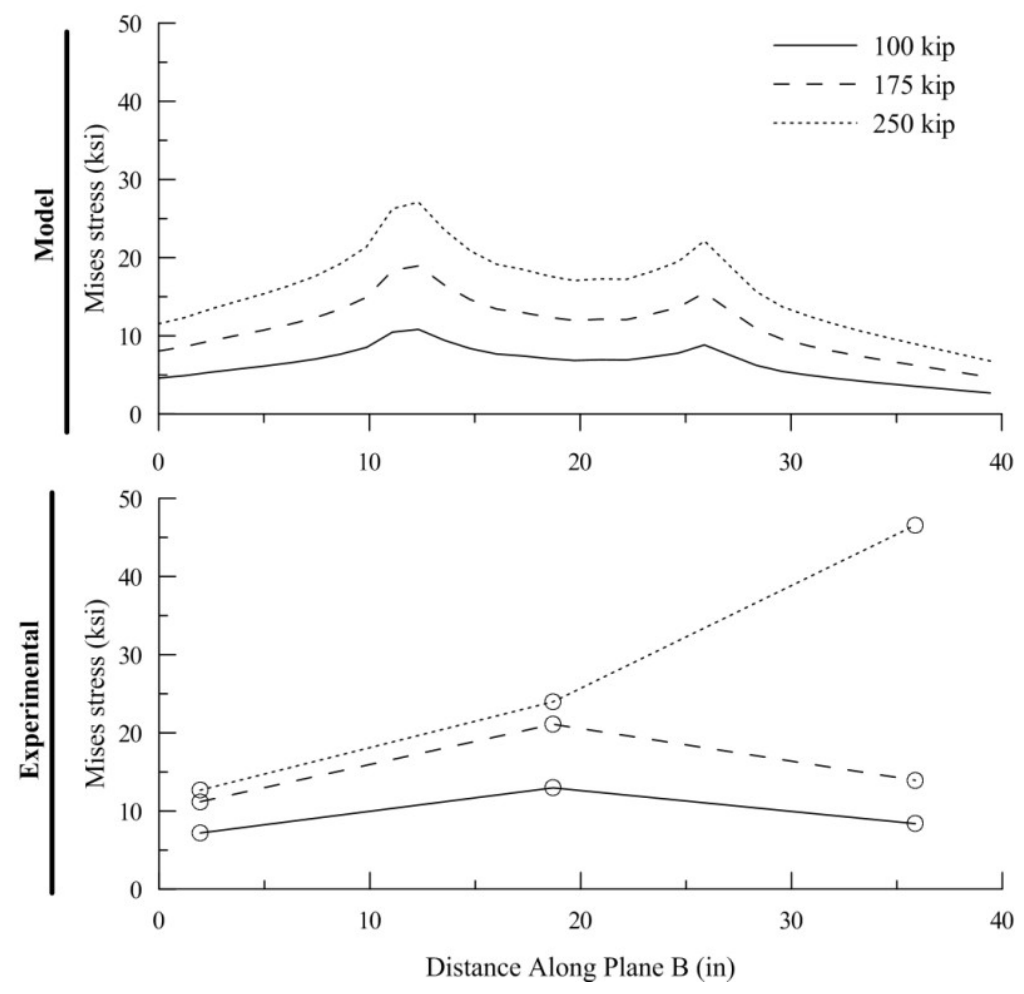

Figure 45: Mises stress comparison at Plane B for M4 loaded to different magnitudes 


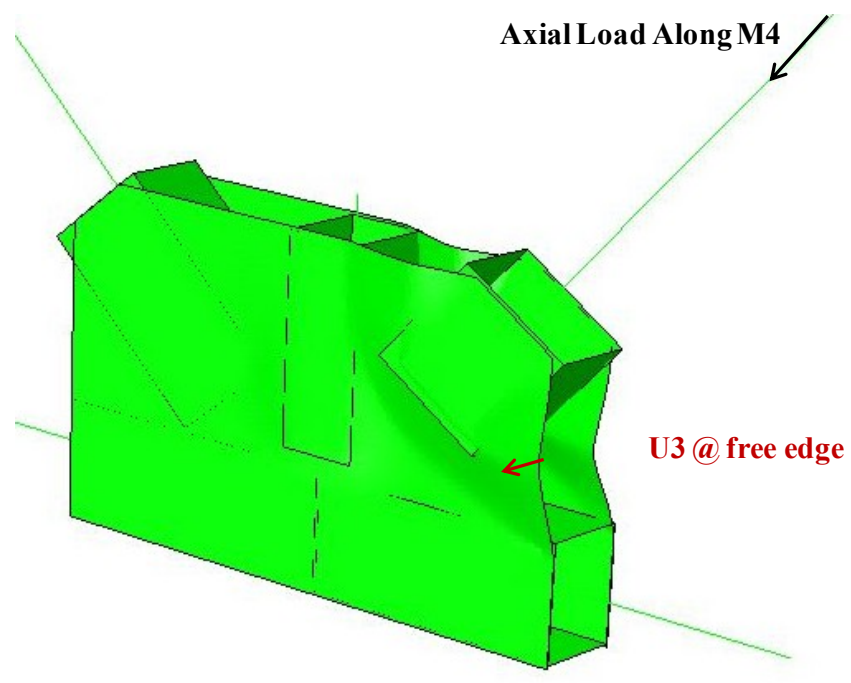

Figure 46: Measurements used to construct gusset connection load-displacement plots

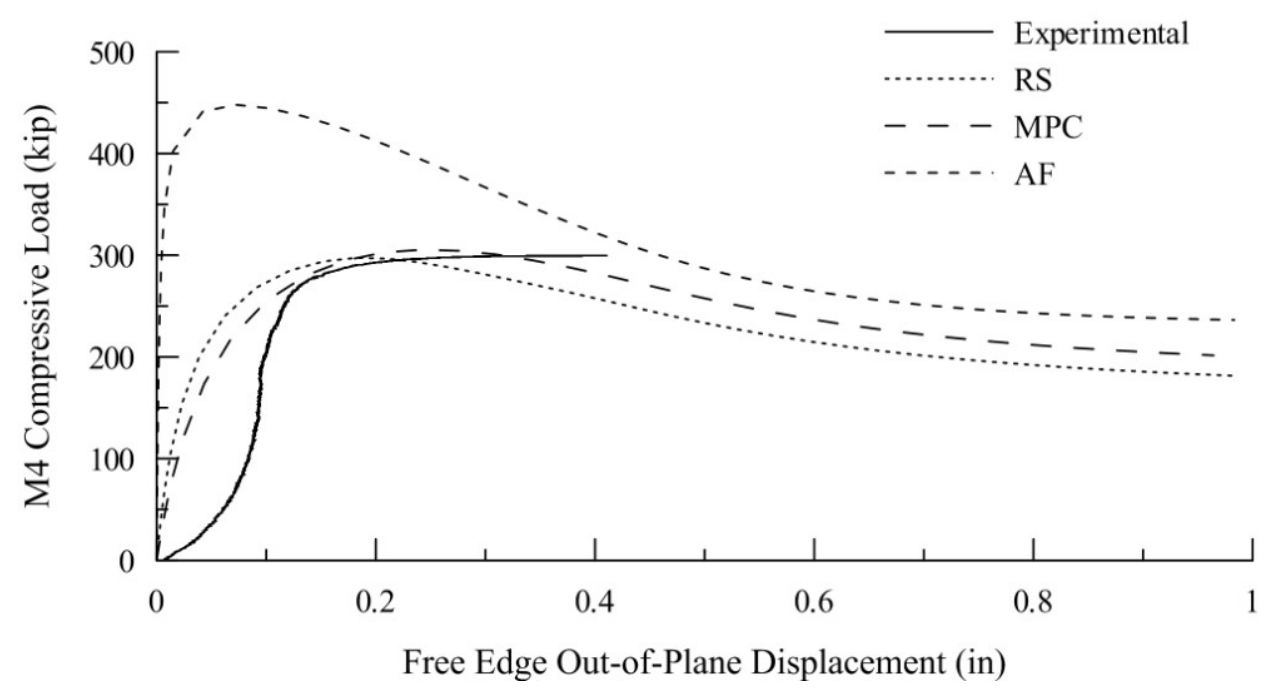

Figure 47: Compression load-displacement comparisons between MPC, AF and RS bolt models with experimental 


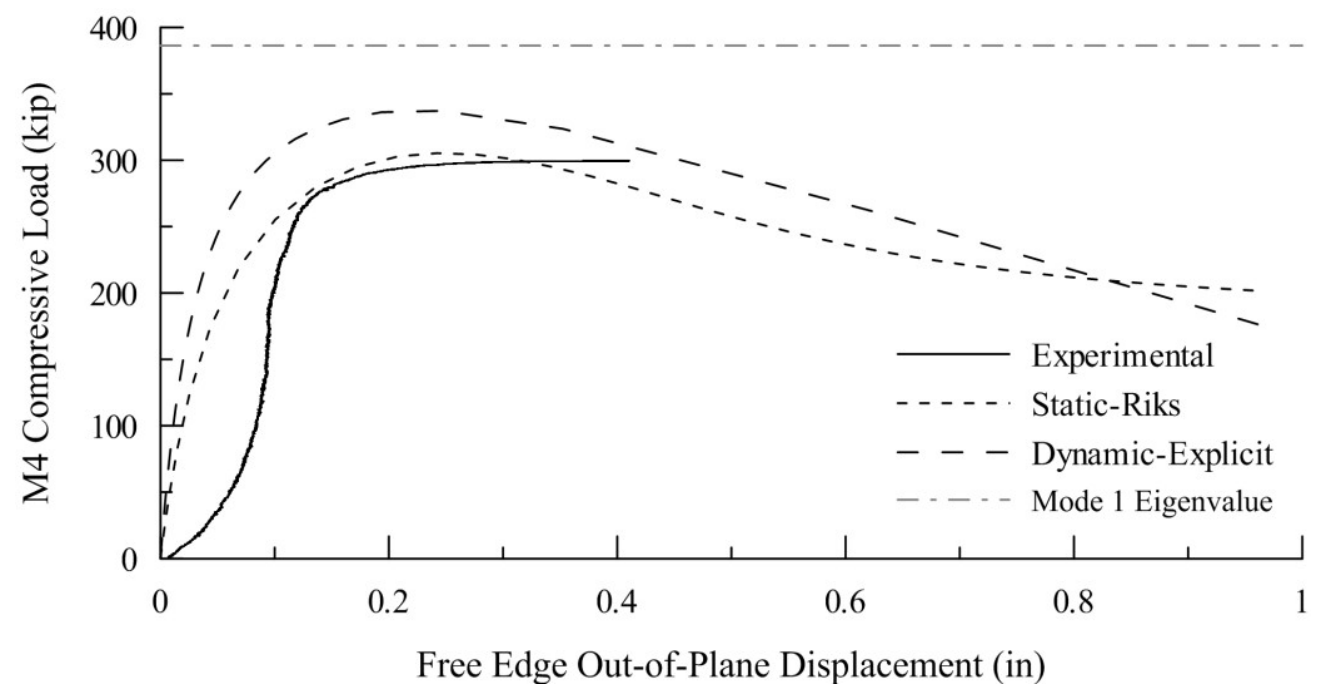

Figure 48: Compression load-displacement comparisons between analysis methods and experimental

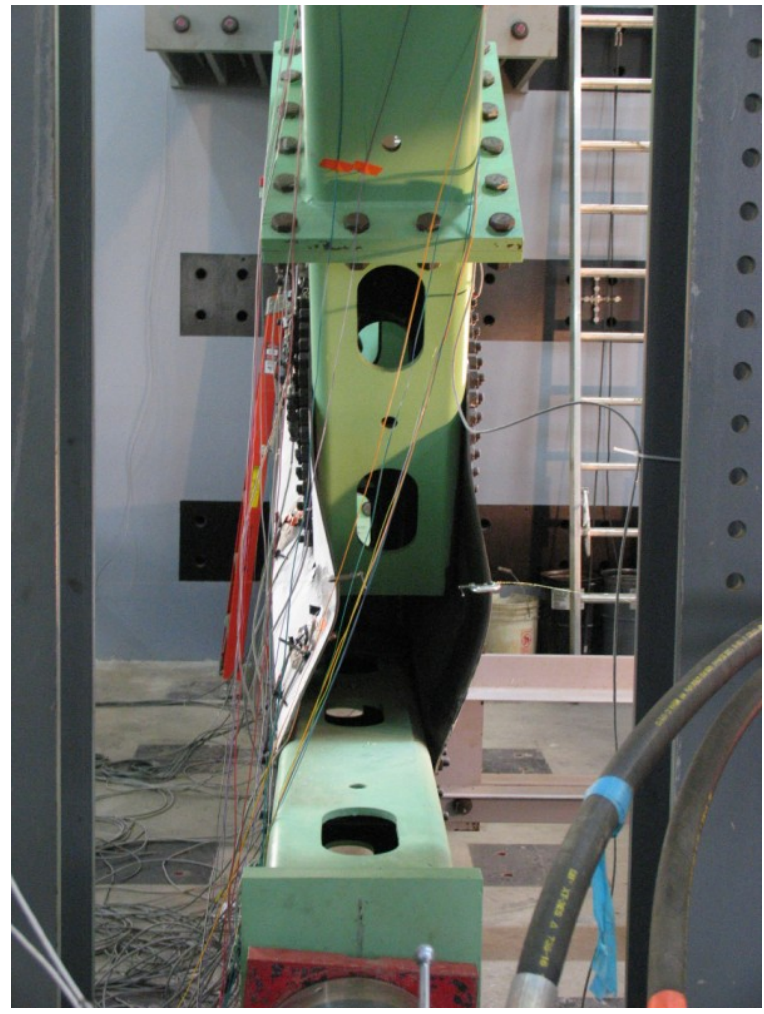

Figure 49: Buckled gusset connection - Test 2 


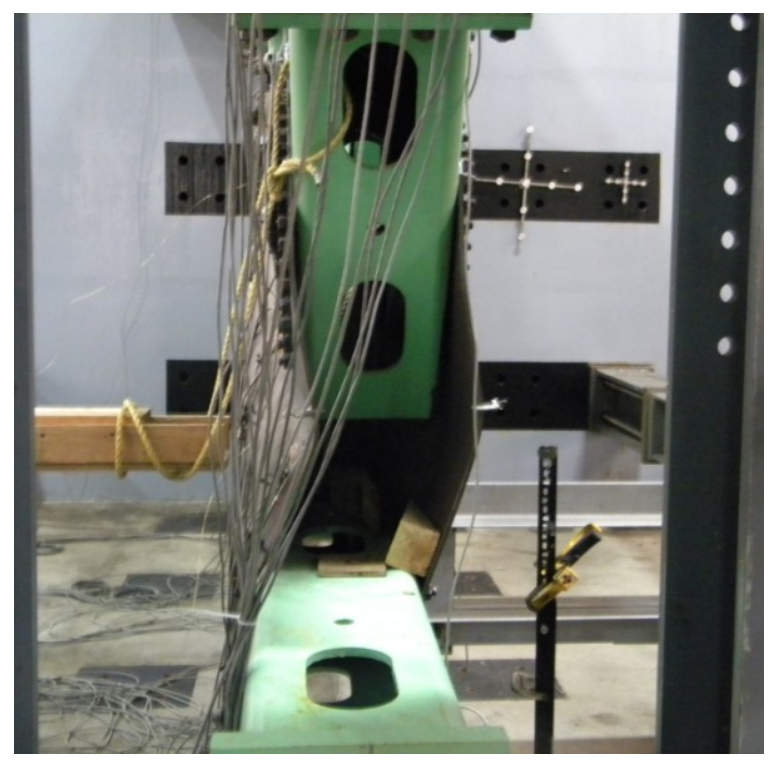

Figure 50: buckled gusset connection - Test 3

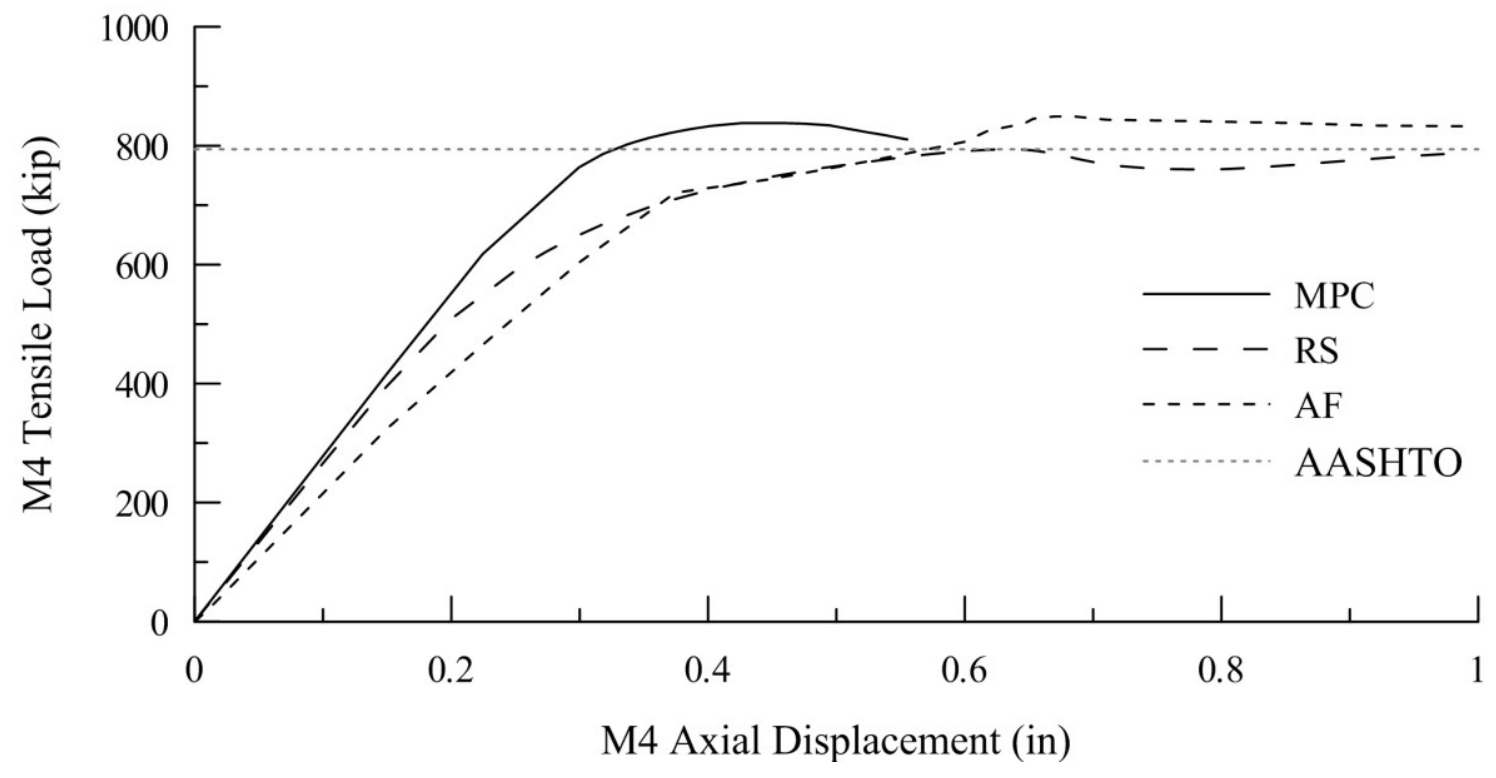

Figure 51: Tensile load-displacement curves for gusset connection 

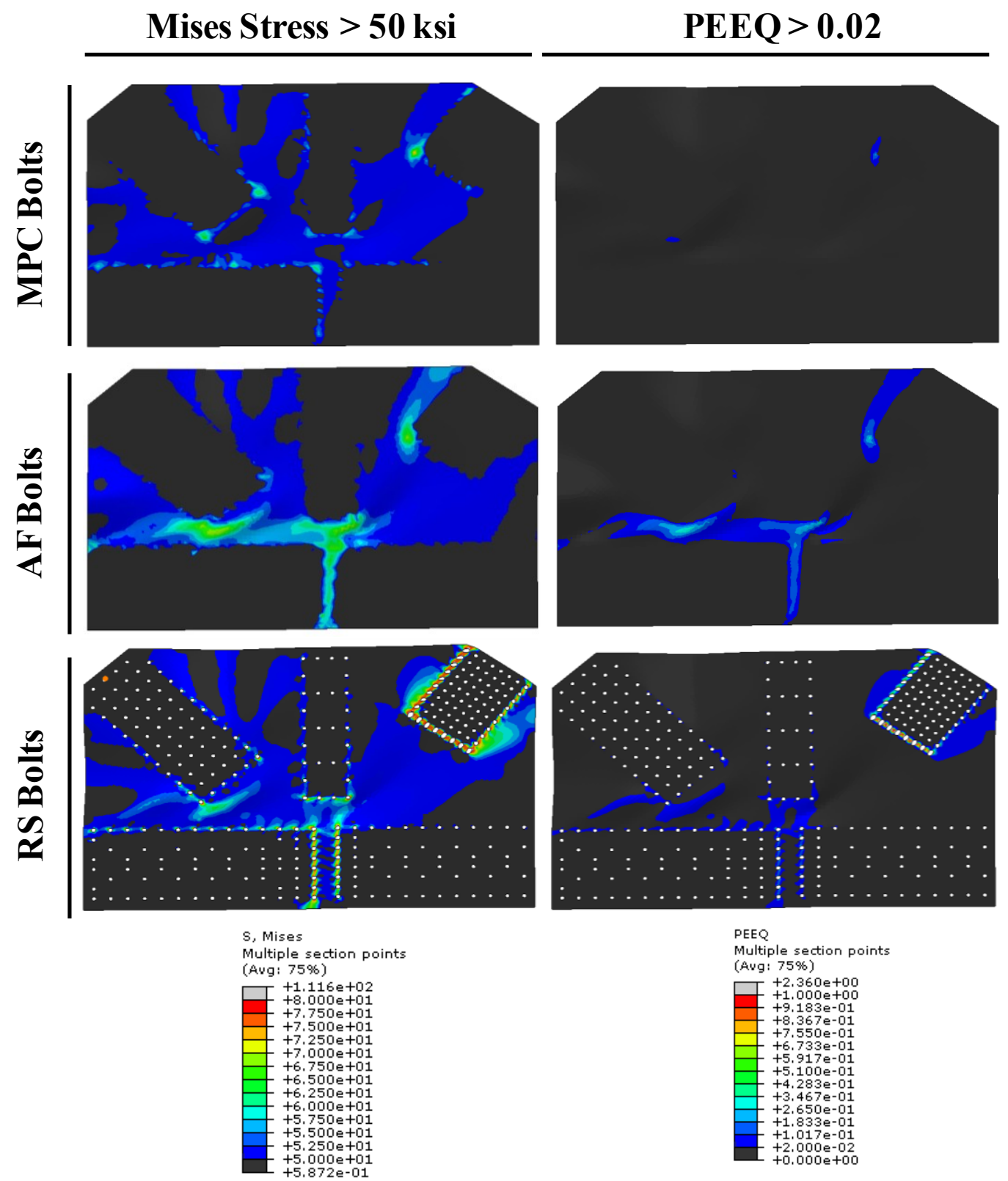

Figure 52: Mises and PEEQ contour comparisons from tensile failure analysis for MPC, AF and MPC bolt models 


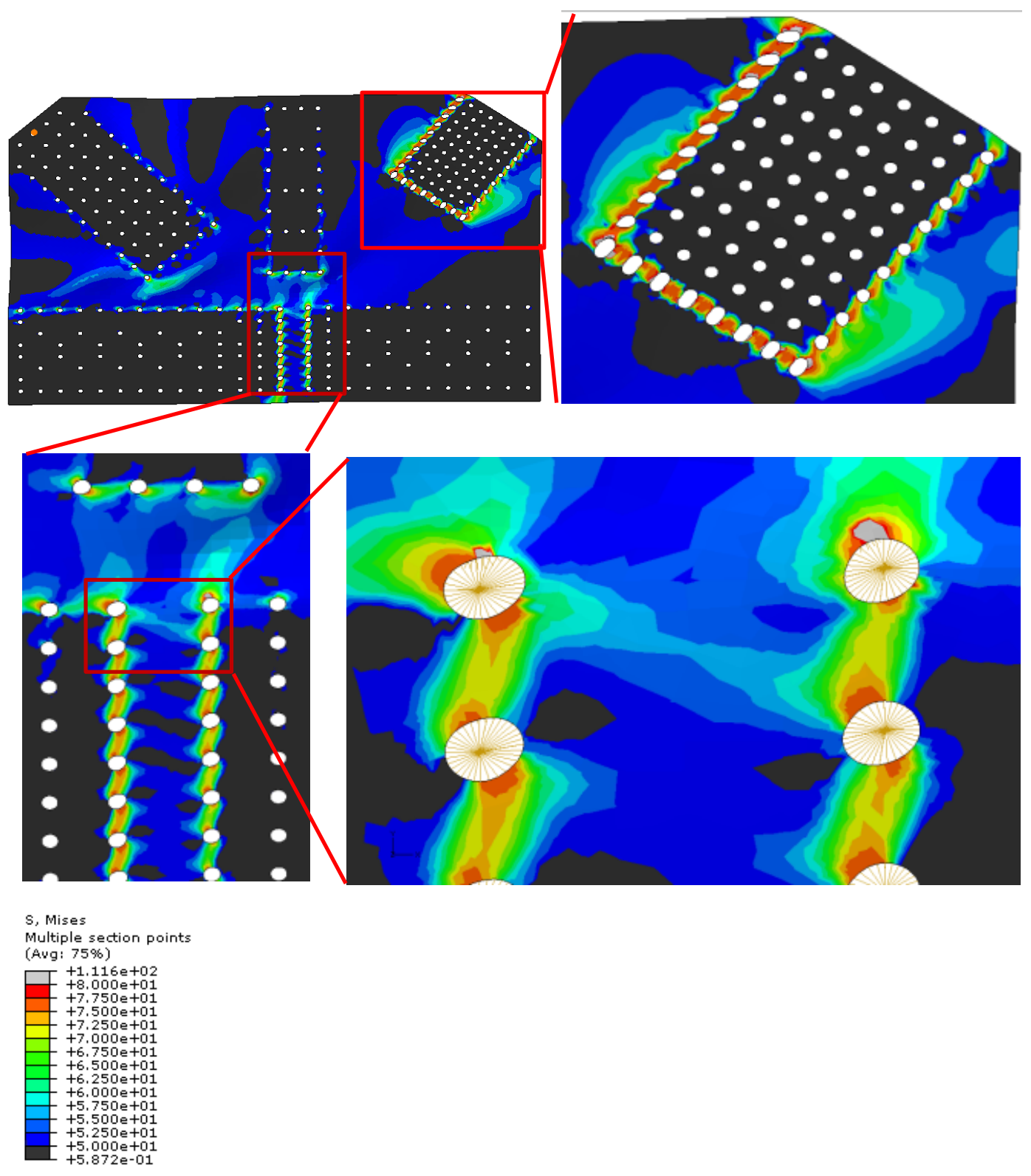

Figure 53: Mises stress contour detail for RS bolt model 


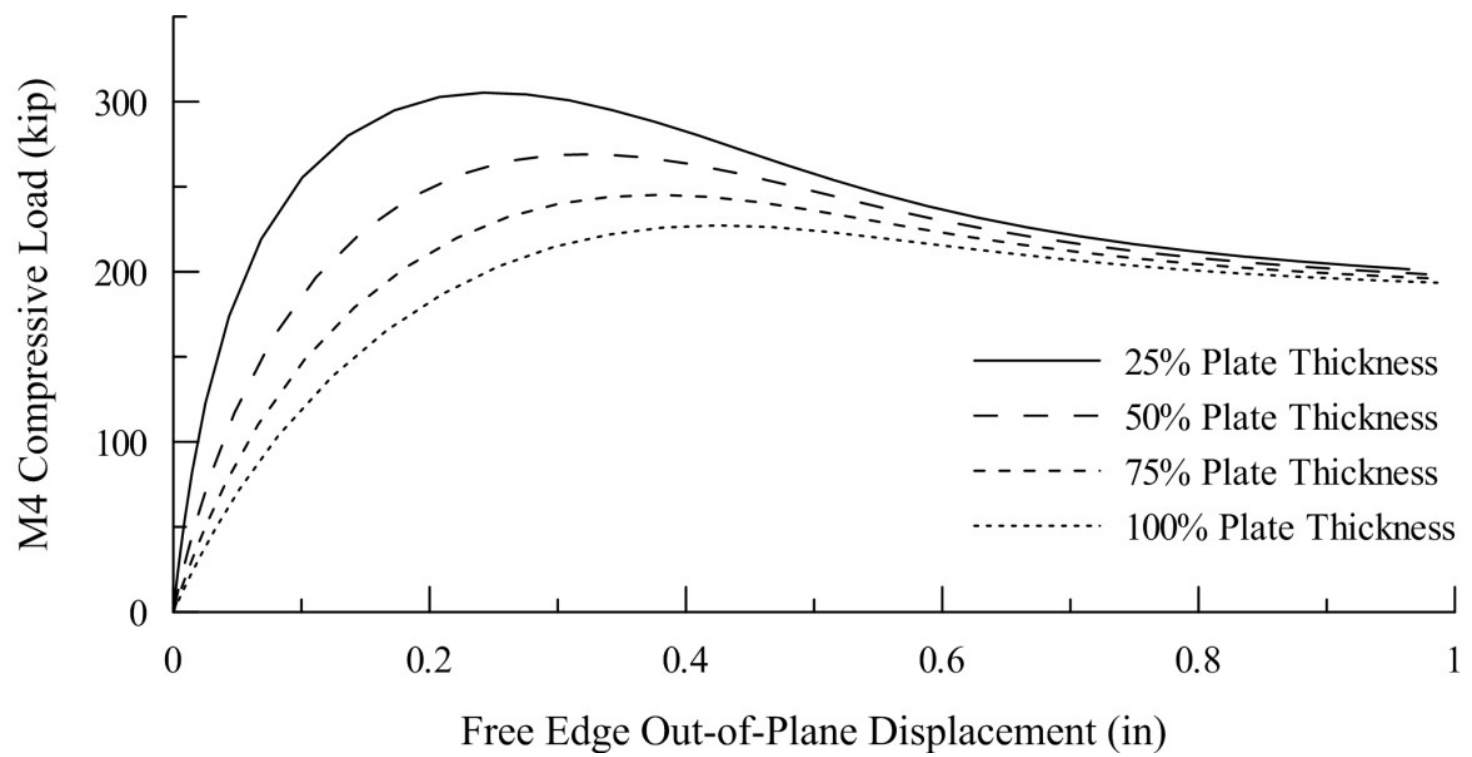

Figure 54: Load-displacement curves for 1/4" plate and varying out-of-plane imperfection

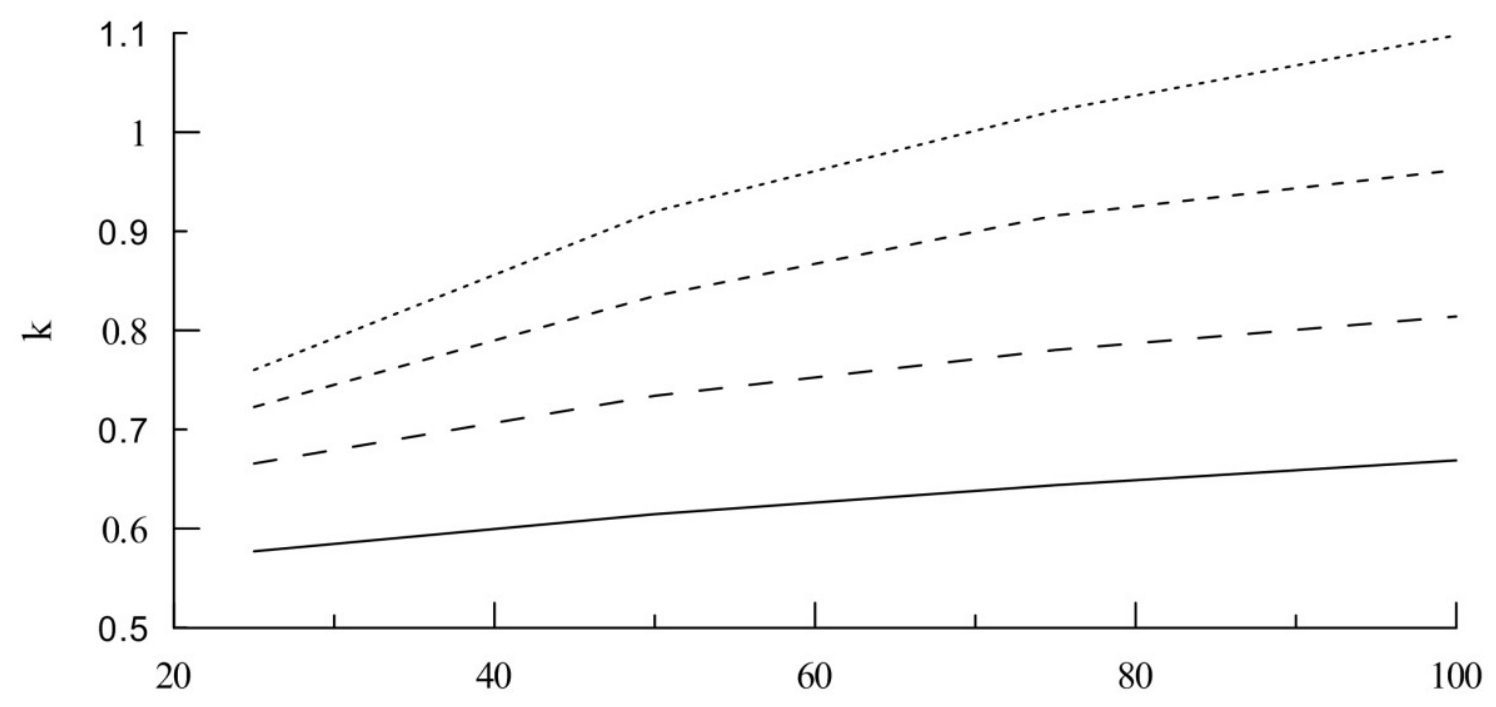

Out-of-Plane Imperfection (\% of Plate Thickness)

$$
\mathrm{t}=0.25^{\prime \prime}--\mathrm{t}=0.375^{\prime \prime}-\cdots \mathrm{t}=0.5^{\prime \prime} \quad \cdots \cdots \cdots \cdot \mathrm{t}=0.625 "
$$

Figure 55: k vs. degree of initial imperfection 


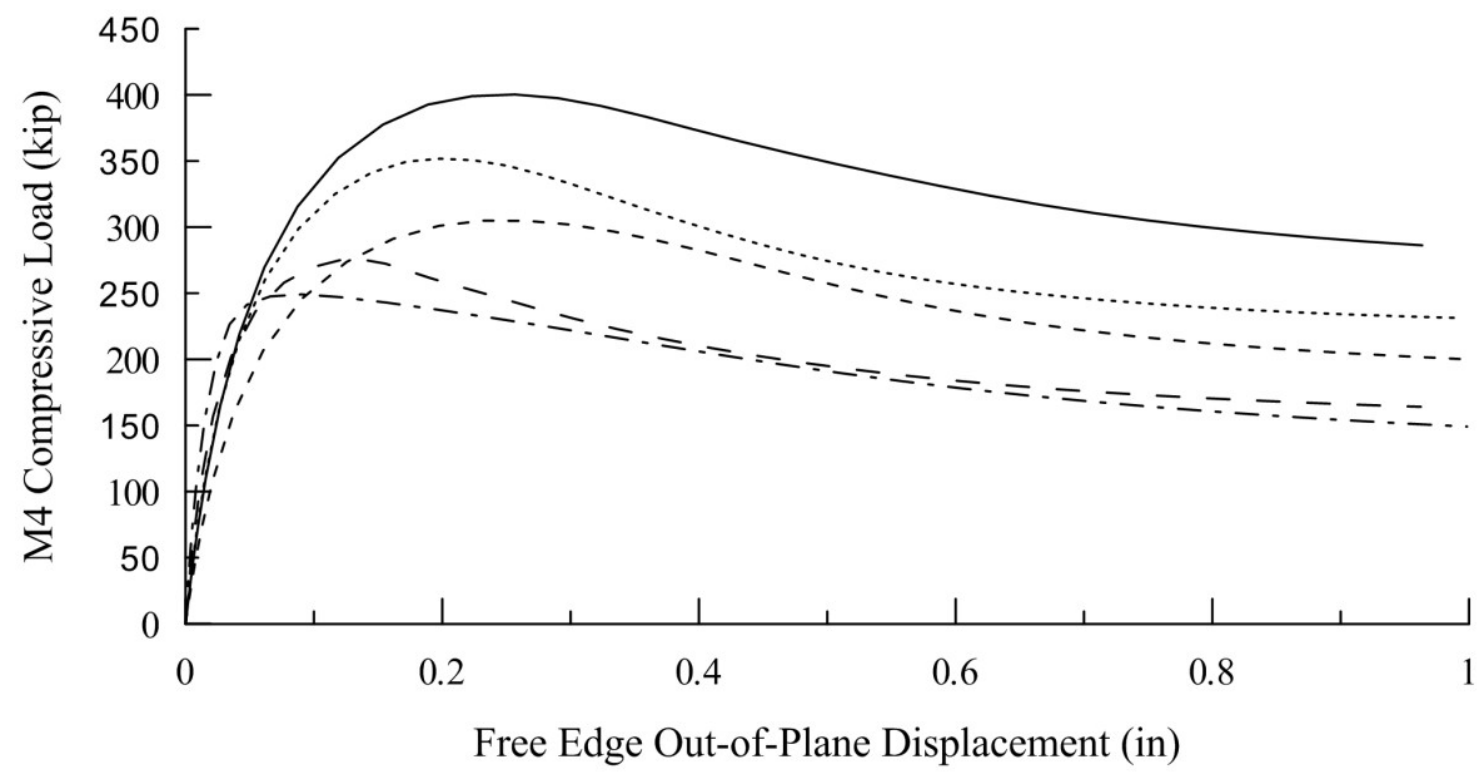

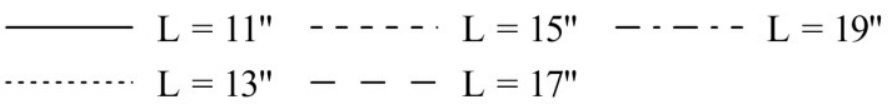

Figure 56: Load-displacement curves for different Whitmore effective lengths

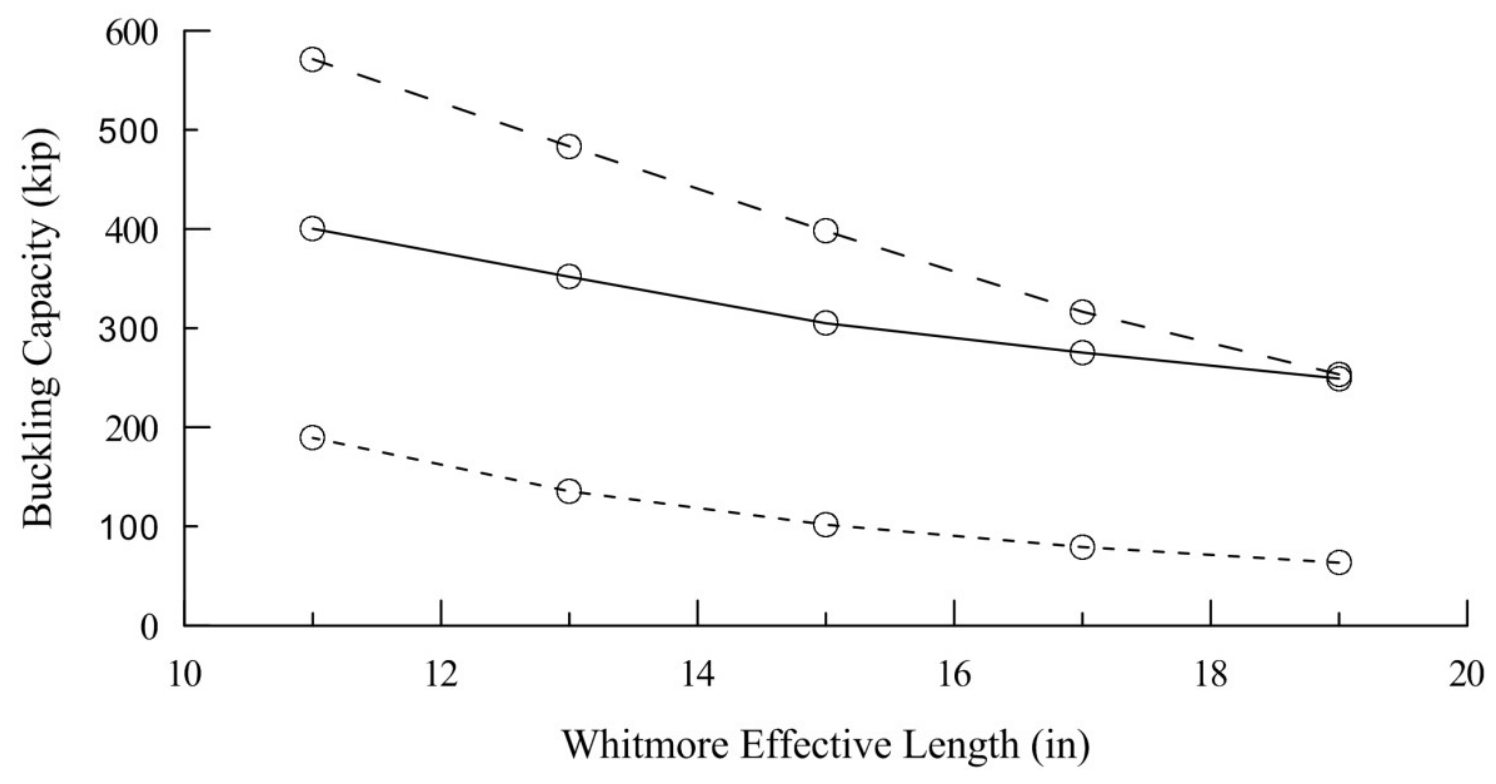

$\longrightarrow$ Model $\quad-\cdots \mathrm{k}=0.5 \quad \cdots \quad \cdots \quad \mathrm{k}=1.0$

Figure 57: Buckling capacity vs. Whitmore effective length 


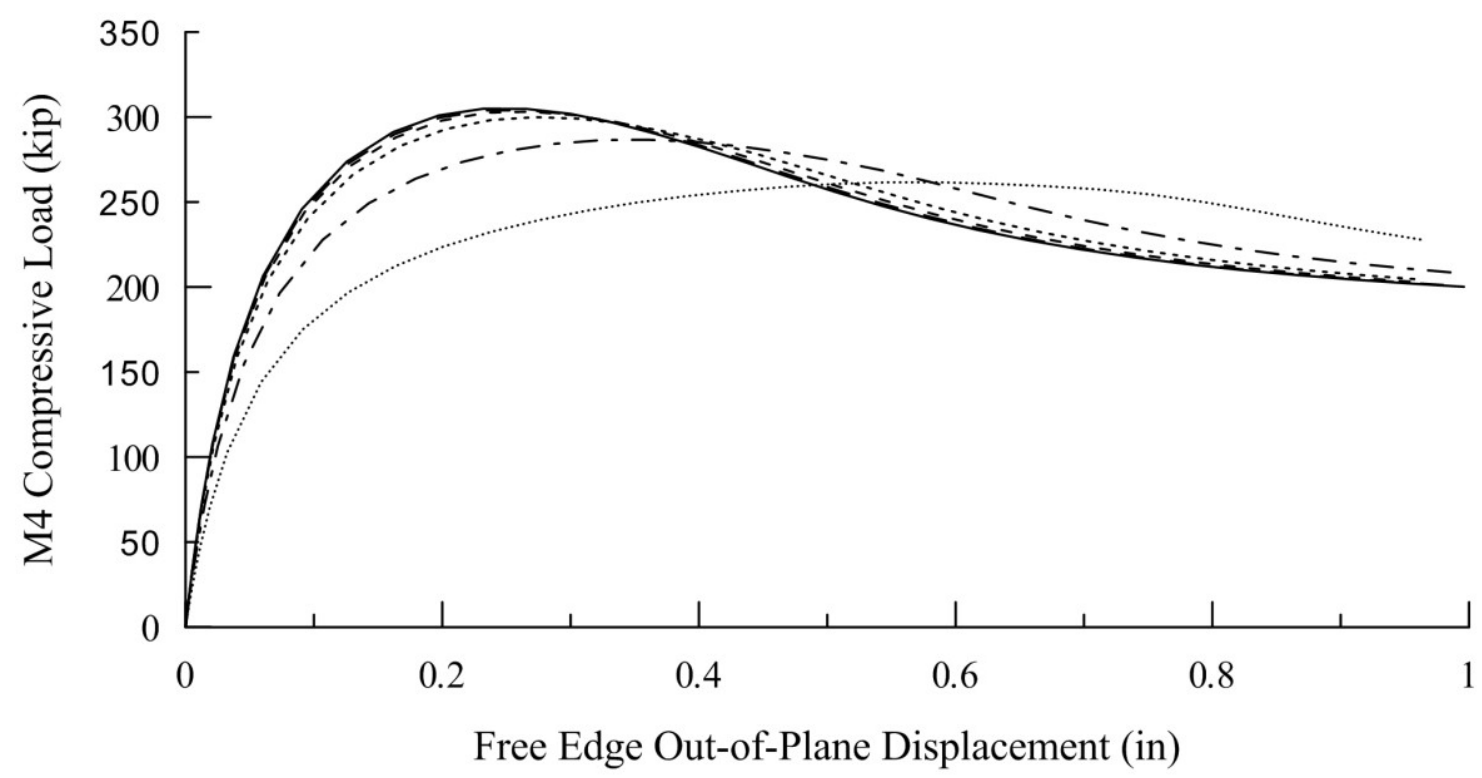

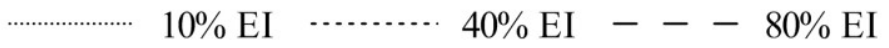

$$
\begin{aligned}
& -\cdots 20 \% \text { EI - - - } 60 \% \text { EI } 100 \% \text { EI }
\end{aligned}
$$

Figure 58: Load-displacement curves for different M4 EI values

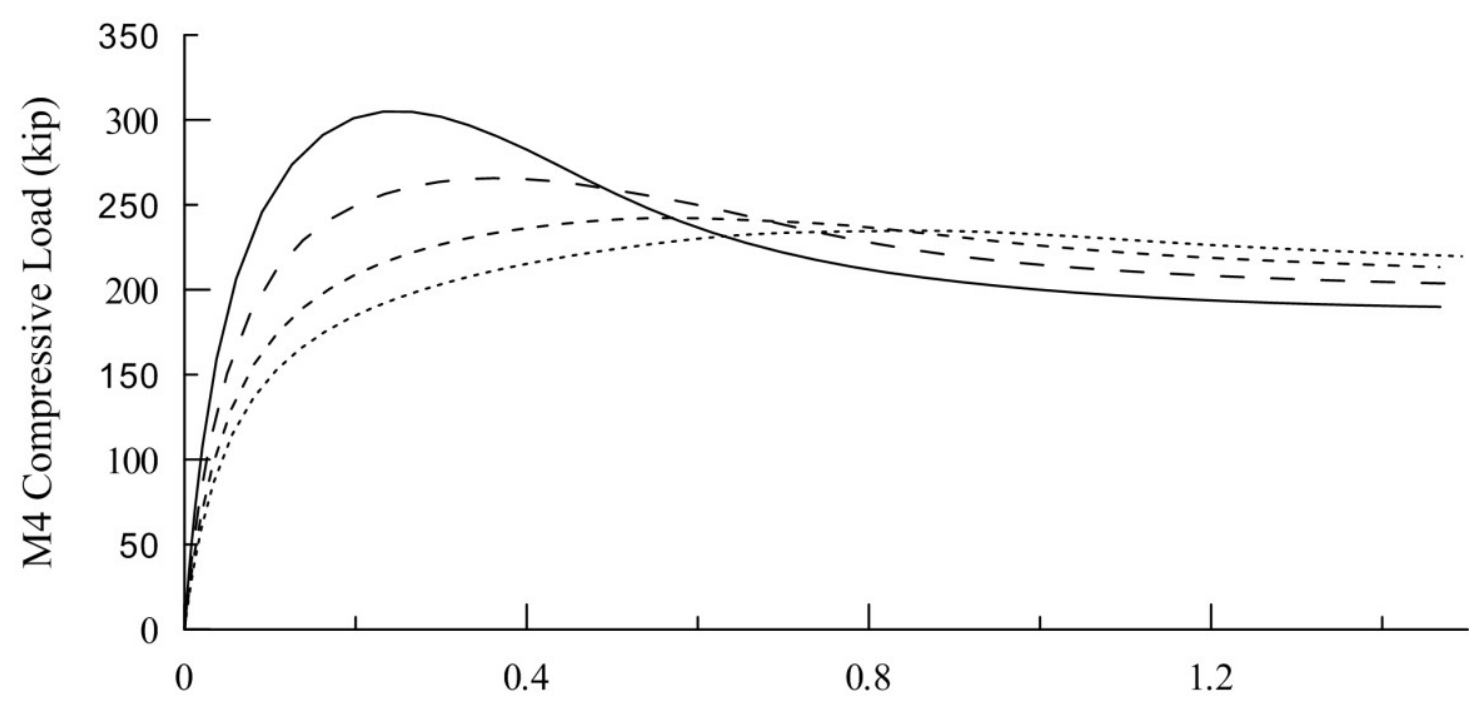

Free Edge Out-of-Plane Displacement (in)

$$
\begin{aligned}
& \longrightarrow \mathrm{L}_{\mathrm{M} 4}=110^{\prime \prime} \quad \ldots-\cdot \mathrm{L}_{\mathrm{M} 4}=220^{\prime \prime} \\
& --\mathrm{L}_{\mathrm{M} 4}=165^{\prime \prime} \quad \cdots \cdots \ldots . . . \mathrm{L}_{\mathrm{M} 4}=275^{\prime \prime}
\end{aligned}
$$

Figure 59: Load-displacement curves for different M4 lengths 


\section{References}

AISC. (1984). Engineering for Steel Construction. Chicago.

AISC Manual. (2005). Steel Construction Manual Thirteenth Edition. Chicago, Illinois: American Institute of Steel Construction, Inc.

Bjorhovde, R., \& Chakrabarti, S. (1985). Test of Full-Scale Gusset Plate Connections. Journal of Structrual Engineering , 111 (3), 667-684.

Chesson, E., \& Munse, M. (1958). Behavior of riveted truss-type connections. ASCE Transactions , 123, 1087-1128.

Chesson, E., \& Munse, W. (1963). Riveted and bolted joints: truss-type tensile connections. ASCE Journal of the Structural Division , 89 (ST1), 67-106.

Chung, K., \& Ip, K. (2000). Finite elemt modeling of bolted connections between coldformed steel strips and hot rolled steel plates under static shear loading. Engineering Structures , 22, 1271-1284.

Davis, C. (1967). Computer Analysis of the Stresses in a Gusset Plate. Seattle, WA: Thesis, University of Washinton.

FHWA. (2009). Load Rating Guidance and Examples for Bolted and Riveted Gusset Plates In Truss Bridges. FHWA-IF-09-014, U.S. Department of Transportation.

Gross, J. (1990, Third Quarter). Experimental study of gusseted connections. Engineering Journal , 89-97.

Hardin, B. (1958). Experimental investigation of teh primary stress distribution in the gusset paltes of a gouble plate Pratt truss joint with chord splice at the joint. University of Kentucky Engieering Experiemnt Station (Bulletin No. 49).

Holt, R., \& Hartmann, J. (2008). Adequacy of the U10 \& U11 gusset plate designs for the Minnesota Bridge No. 9340 (I-35W over the Mississippi River). Federal Highway Administration.

Irvan, W. (1957). Experimental study of premary stresses in gusset paltes of a double plate Pratt truss. Engineering Experiment Station (Bulletin No. 46).

JSCE. (1976). Tentative design guildelines of gussetetd truss joints. Japan Society of Civil Engineers. Tokyo, Japan: Sponsored by Honshu-Shikoku Bridge Authority.

Kulak, G., \& GY, G. (2001). AISC LRFD rules for block shear in bolted connections - A review. AISC Engineering Journal (Fourth Quarter), 199-203. 
Liao, M., Okazaki, T., Ballarini, R., Schultz, A., \& Galambos, T. (2011). Nonlinear finite-element analysis of critical gusset plates in the I-35W Bridge in Minnesota. Journal of Structural Engineering , 137 (1), 59-68.

NTSB. (2008, November). Corroded gusset plates of Ohio bridges. Retrieved from http://www.ntsb.gov/dockets/Highway/HWY07MH024/404914.pdf

NTSB. (2008, Janurary). National Transportation Safety Board Safety Recommentation . Retrieved from http://www.ntsb.gov/Recs/letters/2008/H08_1.pdf

Ocel, J., \& Wright, W. (2008). Finite element modeling of I-35W Bridge Collapse - Final report. Turner-Fairbank Highway Research Center Report. Federal Highway Administration.

Rabinovitch, J., \& Cheng, J. (1993). Cyclic behaviour of steel gusset plate connections. Structural Engineering Report no. 191, University of Alberta, Edmonton, Department of Civil and Environmental Engineering, Edmonton.

SG Hardish, R. B. (1985). New Design Criteria for Gusset Plates in Tension. Engineering Journal, Second Quarter, 77-93.

Sheng, N., Yam, C., \& Iu, V. (2002). Analytical investigation and the design of the compressive strength of steel gusset plate connections. Journal of Construction Steel Research , 58, 1473-1493.

Simulia. (2010). Abaqus Users Manual V. 6.9. Providence, RI: Dassault Systems Simulia. Thornton, W. (1984). Bracing connections for heavy construction. Engineering Journal, AISC, 139-148.

Vasarhelyi, D. (1971). Tests of gusset plate models. Journal of the Structural Division, 97 (ST2), 665-678.

Walbridge, S., Grondin, G., \& Cheng, J. (2005). Gusset plate connections under montonic and cyclic loading. Canadian Journal of Civil Engineering , 32, 981-995.

Whitmore, R. (1952). Experimental Investigation of Stresses in Gusset Plates. Engineering Experiment Station (Bulletin No. 13).

Wiekierski, W. (2009). Cirtical stress assessment in angle to gusset plate bolted connections by simplified FEM modeling. 18th International Converence on the Application of Computer Science and Mathematics in Architecture and Civil Engineering, (pp. 1-8). Weimar, Germany. 
Yam, M., \& Cheng, J. (1993). Experimental investigation of the compressive behaviour of gusset plate connections. Structural Engineering Report, University of Alberta, Edmonton, Department of Civil and Environmental Engineering.

Yamamoto, K., Akiyama, N., \& Okumura, T. (1988). Buckling Strengths of Gusseted Truss Joints. Journal of Structural Engineering , 114 (3), 575-590.

Yamamoto, K., Akiyama, N., \& Okumura, T. (1985). Elastic Analysis of Gusseted Truss Joints. Journal of Structural Engineering , 111 (2), 2545-2564. 


\section{Appendix A - Capacity and Design Calculations}

$$
\begin{aligned}
& \text { Small-Scale Gusset Plate -- Strong Bolt Connection -- Design Calculations } \\
& \mathrm{d}_{\mathrm{b}}:=.75 \\
& \mathrm{n}_{\text {bolts }}:=6 \\
& F_{\text {nvBolt }}:=48 \\
& \mathrm{t}_{\mathrm{gp}}:=0.1875 \\
& f_{u}:=68 \\
& f_{y}:=50 \\
& \mathrm{~L}_{\mathrm{e}}:=2 \\
& \mathrm{~s}_{\mathrm{b}}:=3
\end{aligned}
$$

@ bolts:

$$
\begin{aligned}
& \mathrm{d}_{\mathrm{h}}:=\mathrm{d}_{\mathrm{b}}+\frac{1}{16}=0.813 \\
& \mathrm{~A}_{\mathrm{b}}:=0.253 .1415 \mathrm{~d}_{\mathrm{b}}{ }^{2}=0.442 \\
& \mathrm{R}_{\mathrm{nb}}:=2 \cdot \mathrm{A}_{\mathrm{b}} \cdot \mathrm{F}_{\mathrm{nvB} \text { olt }}=42.41 \quad \text { (double shear) } \mathrm{R}_{\mathrm{nb}} \cdot \mathrm{n}_{\text {bolts }}=254.462 \text { kip }
\end{aligned}
$$

@gp vield:

$$
A_{g}:=2 \cdot\left(L_{e}+s_{b}\right) \cdot t_{g p}=1.875
$$

$\mathrm{A}_{\mathrm{g}} \cdot \mathrm{f}_{\mathrm{y}}=93.75 \quad$ kip

$@ g p$ fracture: $\quad U:=1$

$$
\mathrm{A}_{\mathrm{n}}:=\mathrm{A}_{\mathrm{g}}-\left(\frac{\mathrm{n}_{\text {bolts }}}{2}\right) \cdot \mathrm{d}_{\mathrm{h}} \cdot \mathrm{t}_{\mathrm{gp}}=1.418 \quad \mathrm{U} \cdot \mathrm{A}_{\mathrm{n}} \cdot \mathrm{f}_{\mathrm{u}}=96.422 \quad \text { kip }
$$

$$
\begin{aligned}
& \text { @ bearing: } \\
& \qquad \mathrm{L}_{\mathrm{ev}}:=1.5 \\
& \mathrm{~L}_{\mathrm{co}}:=\mathrm{L}_{\mathrm{ev}}-0.5 \mathrm{~d}_{\mathrm{h}}=1.094 \\
& \text { outer holes: } \mathrm{R}_{\mathrm{no}}:=\begin{array}{l}
\mathrm{a} \leftarrow 1.2 \cdot \mathrm{L}_{\mathrm{co}} \cdot \mathrm{t}_{\mathrm{gp}} \cdot \mathrm{f}_{\mathrm{u}} \\
\mathrm{b} \leftarrow 2.4 \mathrm{~d}_{\mathrm{b}} \cdot \mathrm{t}_{\mathrm{gp}} \cdot \mathrm{f}_{\mathrm{u}} \\
\mathrm{c} \leftarrow \mathrm{a} \leq \mathrm{b} \\
\mathrm{d} \leftarrow \mathrm{a} \text { if } \mathrm{c}=1 \\
\mathrm{~d} \leftarrow \mathrm{b} \text { otherwise } \\
\mathrm{d}
\end{array} \quad 1.2 \cdot \mathrm{L}_{\mathrm{co}} \cdot \mathrm{t}_{\mathrm{gp}} \cdot \mathrm{f}_{\mathrm{u}} \leq 2.4 \mathrm{~d}_{\mathrm{b}} \cdot \mathrm{t}_{\mathrm{gp}} \cdot \mathrm{f}_{\mathrm{u}} \cdot \mathrm{t}_{\mathrm{gp}} \cdot \mathrm{f}_{\mathrm{u}}=16.734
\end{aligned}
$$

inner holes: $\quad \mathrm{L}_{\mathrm{ci}}:=\mathrm{s}_{\mathrm{b}}-\mathrm{d}_{\mathrm{h}}=2.188$

$$
\begin{aligned}
& \mathrm{R}_{\mathrm{ni}}:=\mid \begin{array}{l}
\mathrm{a} \leftarrow 1.2 \cdot \mathrm{L}_{\mathrm{ci}} \cdot \mathrm{t}_{\mathrm{gp}} \cdot \mathrm{f}_{\mathrm{u}} \\
\mathrm{b} \leftarrow 2.4 \mathrm{~d}_{\mathrm{b}} \cdot \mathrm{t}_{\mathrm{gp}} \cdot \mathrm{f}_{\mathrm{u}} \\
\mathrm{c} \leftarrow \mathrm{a} \leq \mathrm{b} \\
\mathrm{d} \leftarrow \mathrm{a} \text { if } \mathrm{c}=1 \\
\mathrm{~d} \leftarrow \mathrm{b} \text { otherwise } \\
\mathrm{d}
\end{array} \\
& \mathrm{R}_{\mathrm{no}}=16.734 \quad \mathrm{R}_{\mathrm{ni}}=22.95 \\
& \mathrm{R}_{\mathrm{ni}}:=\mid \mathrm{a} \leftarrow 1.2 \cdot \mathrm{L}_{\mathrm{ci}} \cdot \mathrm{t}_{\mathrm{gp}} \cdot \mathrm{f}_{\mathrm{u}} \quad 1.2 \cdot \mathrm{L}_{\mathrm{ci}} \cdot \mathrm{t}_{\mathrm{gp}} \cdot \mathrm{f}_{\mathrm{u}} \leq 2.4 \mathrm{~d}_{\mathrm{b}} \cdot \mathrm{t}_{\mathrm{gp}} \cdot \mathrm{f}_{\mathrm{u}} \\
& 1.2 \cdot \mathrm{L}_{\mathrm{ci}} \cdot \mathrm{t}_{\mathrm{gp}} \cdot \mathrm{f}_{\mathrm{u}}=33.469 \\
& 2.4 d_{b} \cdot t_{g p} \cdot f_{u}=22.95 \\
& 2 \cdot \mathrm{R}_{\mathrm{no}}+2 \cdot \mathrm{R}_{\mathrm{ni}}=79.369 \text { kip }
\end{aligned}
$$




$$
\mathrm{U}_{\mathrm{bs}}:=1.0
$$

$$
\begin{aligned}
\mathrm{w}_{\mathrm{gp}}:=2 \cdot \mathrm{L}_{\mathrm{e}}+\mathrm{s}_{\mathrm{b}}=7 \\
\mathrm{~A}_{\mathrm{gv}}:=2 \cdot\left(\mathrm{s}_{\mathrm{b}}+\mathrm{L}_{\mathrm{ev}}\right) \cdot \mathrm{t}_{\mathrm{gp}}=1.688 \\
\mathrm{~A}_{\mathrm{nv}}:=\mathrm{A}_{\mathrm{gv}}-3 \mathrm{~d}_{\mathrm{h}} \cdot \mathrm{t}_{\mathrm{gp}}=1.23 \\
\mathrm{~A}_{\mathrm{nt}}:=\left(2 \cdot \mathrm{s}_{\mathrm{b}}-\mathrm{d}_{\mathrm{h}}\right) \cdot \mathrm{t}_{\mathrm{gp}}=0.973 \\
\mathrm{R}_{\mathrm{na}}:=\mid \begin{array}{l}
\mathrm{a} \leftarrow 0.6 \mathrm{f}_{\mathrm{u}} \cdot \mathrm{A}_{\mathrm{nv}} \\
\mathrm{b} \leftarrow 0.6 \mathrm{f}_{\mathrm{y}} \cdot \mathrm{A}_{\mathrm{gv}} \\
\mathrm{c} \leftarrow \mathrm{a} \text { if } \mathrm{a}<\mathrm{b}=1 \\
\mathrm{c} \leftarrow \mathrm{b} \text { otherwise } \\
\mathrm{d} \leftarrow \mathrm{c}+\mathrm{U}_{\mathrm{bs}} \cdot \mathrm{f}_{\mathrm{u}} \cdot \mathrm{A}_{\mathrm{nt}} \\
\mathrm{d}
\end{array}
\end{aligned}
$$

@ block shear (case B):

$$
\begin{aligned}
\mathrm{A}_{\mathrm{gvb}} & :=\left(2 \cdot \mathrm{s}_{\mathrm{b}}+\mathrm{L}_{\mathrm{e}}\right) \mathrm{t}_{\mathrm{gp}}=1.5 \\
\mathrm{~A}_{\mathrm{nvb}} & :=\mathrm{A}_{\mathrm{gvb}}-3 \mathrm{~d}_{\mathrm{h}} \cdot \mathrm{t}_{\mathrm{gp}}=1.043 \\
\mathrm{~A}_{\mathrm{ntb}} & :=\left(2.5 \mathrm{~s}_{\mathrm{b}}+\mathrm{L}_{\mathrm{ev}}\right) \mathrm{t}_{\mathrm{gp}}-1.5 \mathrm{~d}_{\mathrm{h}} \cdot \mathrm{t}_{\mathrm{gp}}=1.459 \\
\mathrm{R}_{\mathrm{m} m b \mathrm{~g}}:= & \begin{array}{l}
\mathrm{a} \leftarrow 0.6 \mathrm{f}_{\mathrm{u}} \cdot \mathrm{A}_{\mathrm{nvb}} \\
\mathrm{b} \leftarrow 0.6 \mathrm{f}_{\mathrm{y}} \cdot \mathrm{A}_{\mathrm{gvb}} \\
\mathrm{c} \leftarrow \mathrm{a} \text { if } \mathrm{a}<\mathrm{b}=1 \\
\mathrm{c} \leftarrow \mathrm{b} \text { otherwise } \\
\mathrm{d} \leftarrow \mathrm{c}+\mathrm{U}_{\mathrm{bs}} \cdot \mathrm{f}_{\mathrm{u}} \cdot \mathrm{A}_{\mathrm{ntb}} \\
\mathrm{d}
\end{array}
\end{aligned}
$$

@ block shear (case C): $\quad \mathrm{A}_{\mathrm{gvc}}:=\mathrm{A}_{\mathrm{gv}}=1.688$

$$
\begin{aligned}
& \mathrm{A}_{\mathrm{nvc}}:=\mathrm{A}_{\mathrm{nv}}=1.23 \\
& \mathrm{~A}_{\mathrm{ntc}}:=2 \cdot \mathrm{L}_{\mathrm{e}} \cdot \mathrm{t}_{\mathrm{gp}}-\mathrm{d}_{\mathrm{h}} \cdot \mathrm{t}_{\mathrm{gp}}=0.598 \\
& \mathrm{R}_{\mathrm{nc}}:=\mid \begin{array}{l}
\mathrm{a} \leftarrow 0.6 \mathrm{f}_{\mathrm{u}} \cdot \mathrm{A}_{\mathrm{nvc}} \\
\mathrm{b} \leftarrow 0.6 \mathrm{f}_{\mathrm{y}} \cdot \mathrm{A}_{\mathrm{gvc}} \\
\mathrm{c} \leftarrow \mathrm{a} \text { if } \mathrm{a}<\mathrm{b}=1 \\
\mathrm{c} \leftarrow \mathrm{b} \text { otherwise } \\
\mathrm{d} \leftarrow \mathrm{c}+\mathrm{U}_{\mathrm{bs}} \cdot \mathrm{f}_{\mathrm{u}} \cdot \mathrm{A}_{\mathrm{ntc}} \\
\mathrm{d} \quad 105
\end{array}
\end{aligned}
$$$$
\mathrm{R}_{\mathrm{nc}}=91.266 \quad \text { kip }
$$ 
Small-Scale Gusset Plate -- Tensile Rupture (Weak Connection) -- Design Calculations

* units in kip, in

$$
\begin{array}{llll}
\mathrm{d}_{\mathrm{b}}:=.75 & \mathrm{n}_{\text {bolts }}:=4 & \mathrm{~F}_{\mathrm{nvBolt}}:=48 & \mathrm{t}_{\mathrm{gp}}:=0.1875 \\
\mathrm{f}_{\mathrm{u}}:=68 & \mathrm{f}_{\mathrm{y}}:=50 & \mathrm{~L}_{\mathrm{e}}:=1.5 & \mathrm{~s}_{\mathrm{b}}:=2
\end{array}
$$

@ bolts:

$$
\begin{aligned}
& \mathrm{d}_{\mathrm{h}}:=\mathrm{d}_{\mathrm{b}}+\frac{1}{16}=0.813 \\
& \mathrm{~A}_{\mathrm{b}}:=0.253 .1415 \mathrm{~d}_{\mathrm{b}}{ }^{2}=0.442 \\
& \mathrm{R}_{\mathrm{nb}}:=2 \cdot \mathrm{A}_{\mathrm{b}} \cdot \mathrm{F}_{\mathrm{nvB} \text { olt }}=42.41 \quad \text { (double shear } \mathrm{R}_{\mathrm{nb}} \cdot \mathrm{n}_{\text {bolts }}=169.641
\end{aligned}
$$

@gp yield:

$$
A_{g}:=\left(2 L_{e}+s_{b}\right) \cdot t_{g p}=0.938
$$$$
\mathrm{A}_{\mathrm{g}} \cdot \mathrm{f}_{\mathrm{y}}=46.875 \quad \text { kip }
$$

@gp fracture:

$$
\mathrm{U}:=1
$$

$$
A_{n}:=A_{g}-\left(\frac{n_{\text {bolts }}}{2}\right) \cdot d_{h} \cdot t_{g p}=0.633 \quad U \cdot A_{n} \cdot f_{u}=43.031 \quad \text { kip }
$$

\section{@ bearing:}

$$
\mathrm{L}_{\mathrm{ev}}:=1.5
$$

$$
\mathrm{L}_{\mathrm{co}}:=\mathrm{L}_{\mathrm{ev}}-0.5 \mathrm{~d}_{\mathrm{h}}=1.094
$$

outer holes:

$$
\mathrm{R}_{\mathrm{no}}:=\mid \begin{aligned}
& \mathrm{a} \leftarrow 1.2 \cdot \mathrm{L}_{\mathrm{co}} \cdot \mathrm{t}_{\mathrm{gp}} \cdot \mathrm{f}_{\mathrm{u}} \\
& \mathrm{b} \leftarrow 2.4 \mathrm{~d}_{\mathrm{b}} \cdot \mathrm{t}_{\mathrm{gp}} \cdot \mathrm{f}_{\mathrm{u}} \\
& \mathrm{c} \leftarrow \mathrm{a} \leq \mathrm{b} \\
& \mathrm{d} \leftarrow \mathrm{a} \text { if } \mathrm{c}=1 \\
& \mathrm{~d} \leftarrow \mathrm{b} \text { otherwise } \\
& \mathrm{d}
\end{aligned}
$$

inner holes:

$$
\begin{aligned}
& \mathrm{L}_{\mathrm{ci}}:=\mathrm{s}_{\mathrm{b}}-\mathrm{d}_{\mathrm{h}}=1.188 \\
& \mathrm{R}_{\mathrm{ni}}:=\mid \begin{array}{ll}
\mathrm{a} \leftarrow 1.2 \cdot \mathrm{L}_{\mathrm{ci}} \cdot \mathrm{t}_{\mathrm{gp}} \cdot \mathrm{f}_{\mathrm{u}} & 1.2 \cdot \mathrm{L}_{\mathrm{ci}} \cdot \mathrm{t}_{\mathrm{gp}} \cdot \mathrm{f}_{\mathrm{u}} \leq 2.4 \mathrm{~d}_{\mathrm{b}} \cdot \mathrm{t}_{\mathrm{gp}} \cdot \mathrm{f}_{\mathrm{u}} \\
\mathrm{b} \leftarrow 2.4 \mathrm{~d}_{\mathrm{b}} \cdot \mathrm{t}_{\mathrm{gp}} \cdot \mathrm{f}_{\mathrm{u}} & 1.2 \cdot \mathrm{L}_{\mathrm{ci}} \cdot \mathrm{t}_{\mathrm{gp}} \cdot \mathrm{f}_{\mathrm{u}}=18.169 \\
\mathrm{c} \leftarrow \mathrm{a} \leq \mathrm{b} & 2.4 \mathrm{~d}_{\mathrm{b}} \cdot \mathrm{t}_{\mathrm{gp}} \cdot \mathrm{f}_{\mathrm{u}}=22.95 \\
\mathrm{~d} \leftarrow \mathrm{a} \text { if } \mathrm{c}=1 & \\
\mathrm{~d} \leftarrow \mathrm{b} \text { otherwise } & \\
\mathrm{d} & 2 \cdot \mathrm{R}_{\mathrm{no}}+2 \cdot \mathrm{R}_{\mathrm{ni}}=69.806 \quad \mathrm{kip}
\end{array}
\end{aligned}
$$

$$
\begin{gathered}
1.2 \mathrm{~L}_{\mathrm{co}} \cdot \mathrm{t}_{\mathrm{gp}} \cdot \mathrm{f}_{\mathrm{u}} \leq 2.4 \mathrm{~d}_{\mathrm{b}} \cdot \mathrm{t}_{\mathrm{gp}} \cdot \mathrm{f}_{\mathrm{u}} \\
1.2 \cdot \mathrm{L}_{\mathrm{co}} \cdot \mathrm{t}_{\mathrm{gp}} \cdot \mathrm{f}_{\mathrm{u}}=16.734 \\
2.4 \mathrm{~d}_{\mathrm{b}} \cdot \mathrm{t}_{\mathrm{gp}} \cdot \mathrm{f}_{\mathrm{u}}=22.95
\end{gathered}
$$




$$
\mathrm{U}_{\mathrm{bs}}:=1.0
$$

$$
\begin{aligned}
\mathrm{w}_{\mathrm{gp}}:=2 \cdot \mathrm{L}_{\mathrm{e}}+\mathrm{s}_{\mathrm{b}}=5 \\
\mathrm{~A}_{\mathrm{gv}}:=2 \cdot\left(\mathrm{s}_{\mathrm{b}}+\mathrm{L}_{\mathrm{ev}}\right) \cdot \mathrm{t}_{\mathrm{gp}}=1.313 \\
\mathrm{~A}_{\mathrm{nv}}:=\mathrm{A}_{\mathrm{gv}}-3 \mathrm{~d}_{\mathrm{h}} \cdot \mathrm{t}_{\mathrm{gp}}=0.855 \\
\mathrm{~A}_{\mathrm{nt}}:=\left(2 \cdot \mathrm{s}_{\mathrm{b}}-\mathrm{d}_{\mathrm{h}}\right) \cdot \mathrm{t}_{\mathrm{gp}}=0.598 \\
\mathrm{R}_{\mathrm{na}}:=\mid \begin{array}{l}
\mathrm{a} \leftarrow 0.6 \mathrm{f}_{\mathrm{u}} \cdot \mathrm{A}_{\mathrm{nv}} \\
\mathrm{b} \leftarrow 0.6 \mathrm{f}_{\mathrm{y}} \cdot \mathrm{A}_{\mathrm{gv}} \\
\mathrm{c} \leftarrow \mathrm{a} \text { if } \mathrm{a}<\mathrm{b}=1 \\
\mathrm{c} \leftarrow \mathrm{b} \text { otherwise } \\
\mathrm{d} \leftarrow \mathrm{c}+\mathrm{U}_{\mathrm{bs}} \cdot \mathrm{f}_{\mathrm{u}} \cdot \mathrm{A}_{\mathrm{nt}} \\
\mathrm{d}
\end{array}
\end{aligned}
$$

$@$ block shear (case B):

$$
\begin{aligned}
\mathrm{A}_{\mathrm{gvb}} & :=\left(2 \cdot \mathrm{s}_{\mathrm{b}}+\mathrm{L}_{\mathrm{e}}\right) \mathrm{t}_{\mathrm{gp}}=1.031 \\
\mathrm{~A}_{\mathrm{nvb}} & :=\mathrm{A}_{\mathrm{gvb}}-3 \mathrm{~d}_{\mathrm{h}} \cdot \mathrm{t}_{\mathrm{gp}}=0.574 \\
\mathrm{~A}_{\mathrm{ntb}} & :=\left(2.5 \mathrm{~s}_{\mathrm{b}}+\mathrm{L}_{\mathrm{ev}}\right) \mathrm{t}_{\mathrm{gp}}-1.5 \mathrm{~d}_{\mathrm{h}} \cdot \mathrm{t}_{\mathrm{gp}}=0.99 \\
\mathrm{R}_{\mathrm{mban}}:= & \begin{array}{l}
\mathrm{a} \leftarrow 0.6 \mathrm{f}_{\mathrm{u}} \cdot \mathrm{A}_{\mathrm{nvb}} \\
\mathrm{b} \leftarrow 0.6 \mathrm{f}_{\mathrm{y}} \cdot \mathrm{A}_{\mathrm{gvb}} \\
\mathrm{c} \leftarrow \mathrm{a} \text { if } \mathrm{a}<\mathrm{b}=1 \\
\mathrm{c} \leftarrow \mathrm{b} \text { otherwise } \\
\mathrm{d} \leftarrow \mathrm{c}+\mathrm{U}_{\mathrm{bs}} \cdot \mathrm{f}_{\mathrm{u}} \cdot \mathrm{A}_{\mathrm{ntb}} \\
\mathrm{d}
\end{array}
\end{aligned}
$$

@ block shear (case C):

$$
\begin{aligned}
& \mathrm{A}_{\mathrm{gvc}}:=\mathrm{A}_{\mathrm{gv}}=1.313 \\
& \mathrm{~A}_{\mathrm{nvc}}:=\mathrm{A}_{\mathrm{nv}}=0.855 \\
& \mathrm{~A}_{\mathrm{ntc}}:=2 \cdot \mathrm{L}_{\mathrm{e}} \cdot \mathrm{t}_{\mathrm{gp}}-\mathrm{d}_{\mathrm{h}} \cdot \mathrm{t}_{\mathrm{gp}}=0.41 \\
& \mathrm{R}_{\mathrm{nc}}:=\mid \begin{array}{l}
\mathrm{a} \leftarrow 0.6 \mathrm{f}_{\mathrm{u}} \cdot \mathrm{A}_{\mathrm{nvc}} \\
\mathrm{b} \leftarrow 0.6 \mathrm{f}_{\mathrm{y}} \cdot \mathrm{A}_{\mathrm{gvc}} \\
\mathrm{c} \leftarrow \mathrm{a} \text { if } \mathrm{a}<\mathrm{b}=1 \\
\mathrm{c} \leftarrow \mathrm{b} \text { otherwise } \\
\mathrm{d} \leftarrow \mathrm{c}+\mathrm{U}_{\mathrm{bs}} \cdot \mathrm{f}_{\mathrm{u}} \cdot \mathrm{A}_{\mathrm{ntc}} \\
\mathrm{d}
\end{array}
\end{aligned}
$$


Small-Scale Gusset Plate -- Tensile Rupture (Weak Connection) -- Design Calculations

* units in kip, in

$$
\begin{array}{clll}
\mathrm{d}_{\mathrm{b}}:=.75 & \mathrm{n}_{\text {bolts }}:=4 & \mathrm{~F}_{\mathrm{nvB} \text { olt }}:=48 & \mathrm{t}_{\mathrm{gp}}:=0.1875 \\
\mathrm{f}_{\mathrm{u}}:=68 & \mathrm{f}_{\mathrm{y}}:=50 & \mathrm{~L}_{\mathrm{e}}:=4 & \mathrm{~s}_{\mathrm{b}}:=2
\end{array}
$$

@bolts:

$$
\begin{aligned}
& \mathrm{d}_{\mathrm{h}}:=\mathrm{d}_{\mathrm{b}}+\frac{1}{16}=0.813 \\
& \mathrm{~A}_{\mathrm{b}}:=0.253 .1415 \mathrm{~d}_{\mathrm{b}}{ }^{2}=0.442 \\
& \mathrm{R}_{\mathrm{nb}}:=2 \cdot \mathrm{A}_{\mathrm{b}} \cdot \mathrm{F}_{\mathrm{nvBolt}}=42.41 \quad\left(\text { double shear } \mathrm{R}_{\mathrm{nb}} \cdot \mathrm{n}_{\mathrm{bolts}}=169.641 \quad \mathrm{kip}\right.
\end{aligned}
$$

@gp yield:

$$
\mathrm{A}_{\mathrm{g}}:=\left(2 \mathrm{~L}_{\mathrm{e}}+\mathrm{s}_{\mathrm{b}}\right) \cdot \mathrm{t}_{\mathrm{gp}}=1.875 \quad \mathrm{~A}_{\mathrm{g}} \cdot \mathrm{f}_{\mathrm{y}}=93.75 \quad \text { kip }
$$

$@ g p$ fracture: $\quad U:=1$

$$
\mathrm{A}_{\mathrm{n}}:=\mathrm{A}_{\mathrm{g}}-\left(\frac{\mathrm{n}_{\text {bolts }}}{2}\right) \cdot \mathrm{d}_{\mathrm{h}} \cdot \mathrm{t}_{\mathrm{gp}}=1.57 \quad \mathrm{U} \cdot \mathrm{A}_{\mathrm{n}} \cdot \mathrm{f}_{\mathrm{u}}=106.781 \quad \text { kip }
$$

@ bearing: $\quad \mathrm{L}_{\mathrm{ev}}:=1.5$

$$
\mathrm{L}_{\mathrm{co}}:=\mathrm{L}_{\mathrm{ev}}-0.5 \mathrm{~d}_{\mathrm{h}}=1.094
$$

outer holes: $\quad \mathrm{R}_{\mathrm{no}}:=\mid \begin{array}{lr}\mathrm{a} \leftarrow 1.2 \cdot \mathrm{L}_{\mathrm{co}} \cdot \mathrm{t}_{\mathrm{gp}} \cdot \mathrm{f}_{\mathrm{u}} & 1.2 \cdot \mathrm{L}_{\mathrm{co}} \cdot \mathrm{t}_{\mathrm{gp}} \cdot \mathrm{f}_{\mathrm{u}} \leq 2.4 \mathrm{~d}_{\mathrm{b}} \cdot \mathrm{t}_{\mathrm{gp}} \cdot \mathrm{f}_{\mathrm{u}} \\ \mathrm{b} \leftarrow 2.4 \mathrm{~d}_{\mathrm{b}} \cdot \mathrm{t}_{\mathrm{gp}} \cdot \mathrm{f}_{\mathrm{u}} & \\ \mathrm{c} \leftarrow \mathrm{a} \leq \mathrm{b} & 1.2 \cdot \mathrm{L}_{\mathrm{co}} \cdot \mathrm{t}_{\mathrm{gp}} \cdot \mathrm{f}_{\mathrm{u}}=16.734 \\ \mathrm{~d} \leftarrow \mathrm{a} \text { if } \mathrm{c}=1 & \\ \mathrm{~d} \leftarrow \mathrm{b} \text { otherwise } & 2.4 \mathrm{~d}_{\mathrm{b}} \cdot \mathrm{t}_{\mathrm{gp}} \cdot \mathrm{f}_{\mathrm{u}}=22.95 \\ \mathrm{~d} & \end{array}$

inner holes: $\quad \mathrm{L}_{\mathrm{ci}}:=\mathrm{s}_{\mathrm{b}}-\mathrm{d}_{\mathrm{h}}=1.188$

$$
\begin{aligned}
& \mathrm{R}_{\mathrm{ni}}:=\mid \begin{array}{l}
\mathrm{a} \leftarrow 1.2 \cdot \mathrm{L}_{\mathrm{ci}} \cdot \mathrm{t}_{\mathrm{gp}} \cdot \mathrm{f}_{\mathrm{u}} \\
\mathrm{b} \leftarrow 2.4 \mathrm{~d}_{\mathrm{b}} \cdot \mathrm{t}_{\mathrm{gp}} \cdot \mathrm{f}_{\mathrm{u}} \\
\mathrm{c} \leftarrow \mathrm{a} \leq \mathrm{b} \\
\mathrm{d} \leftarrow \mathrm{a} \text { if } \mathrm{c}=1 \\
\mathrm{~d} \leftarrow \mathrm{b} \text { otherwise } \\
\mathrm{d}
\end{array} \\
& 1.2 \cdot \mathrm{L}_{\mathrm{ci}} \cdot \mathrm{t}_{\mathrm{gp}} \cdot \mathrm{f}_{\mathrm{u}} \leq 2.4 \mathrm{~d}_{\mathrm{b}} \cdot \mathrm{t}_{\mathrm{gp}} \cdot \mathrm{f}_{\mathrm{u}} \\
& \mathrm{R}_{\mathrm{no}}=16.734 \quad \mathrm{R}_{\mathrm{ni}}=18.169 \\
& 2 \cdot \mathrm{R}_{\mathrm{no}}+2 \cdot \mathrm{R}_{\mathrm{ni}}=69.806 \mathrm{kip}
\end{aligned}
$$




$$
\begin{array}{ll}
\mathrm{R}_{\mathrm{ni}}:=\mid \begin{array}{lc}
\mathrm{a} \leftarrow 1.2 \mathrm{~L}_{\mathrm{ci}} \cdot \mathrm{t}_{\mathrm{gp}} \cdot \mathrm{f}_{\mathrm{u}} & 1.2 \mathrm{~L}_{\mathrm{ci}} \cdot \mathrm{t}_{\mathrm{gp}} \cdot \mathrm{f}_{\mathrm{u}} \leq 2.4 \mathrm{~d}_{\mathrm{b}} \cdot \mathrm{t}_{\mathrm{gp}} \cdot \mathrm{f}_{\mathrm{u}} \\
\mathrm{b} \leftarrow 2.4 \mathrm{~d}_{\mathrm{b}} \cdot \mathrm{t}_{\mathrm{gp}} \cdot \mathrm{f}_{\mathrm{u}} & 1.2 \cdot \mathrm{L}_{\mathrm{ci}} \cdot \mathrm{t}_{\mathrm{gp}} \cdot \mathrm{f}_{\mathrm{u}}=18.169 \\
\mathrm{c} \leftarrow \mathrm{a} \leq \mathrm{b} & \\
\mathrm{d} \leftarrow \mathrm{a} \text { if } \mathrm{c}=1 & 2.4 \mathrm{~d}_{\mathrm{b}} \cdot \mathrm{t}_{\mathrm{gp}} \cdot \mathrm{f}_{\mathrm{u}}=22.95 \\
\mathrm{~d} \leftarrow \mathrm{b} \text { otherwise } & \\
\mathrm{d} & \left.2 \cdot \mathrm{R}_{\mathrm{no}}+2 \cdot \mathrm{R}_{\mathrm{ni}}=69.806 \mathrm{ki}\right]
\end{array}
\end{array}
$$

@ block shear (case A): $\quad \mathrm{U}_{\mathrm{bs}}:=1.0$

$$
\begin{aligned}
\mathrm{w}_{\mathrm{gp}}:=2 \cdot \mathrm{L}_{\mathrm{e}}+\mathrm{s}_{\mathrm{b}}=10 \\
\mathrm{~A}_{\mathrm{gv}}:=2 \cdot\left(\mathrm{s}_{\mathrm{b}}+\mathrm{L}_{\mathrm{ev}}\right) \cdot \mathrm{t}_{\mathrm{gp}}=1.313 \\
\mathrm{~A}_{\mathrm{nv}}:=\mathrm{A}_{\mathrm{gv}}-3 \mathrm{~d}_{\mathrm{h}} \cdot \mathrm{t}_{\mathrm{gp}}=0.855 \\
\mathrm{~A}_{\mathrm{nt}}:=\left(\mathrm{s}_{\mathrm{b}}-\mathrm{d}_{\mathrm{h}}\right) \cdot \mathrm{t}_{\mathrm{gp}}=0.223 \\
\mathrm{R}_{\mathrm{na}}:=\mid \begin{array}{l}
\mathrm{a} \leftarrow 0.6 \mathrm{f}_{\mathrm{u}} \cdot \mathrm{A}_{\mathrm{nv}} \\
\mathrm{b} \leftarrow 0.6 \mathrm{f}_{\mathrm{y}} \cdot \mathrm{A}_{\mathrm{gv}} \\
\mathrm{c} \leftarrow \mathrm{a} \text { if } \mathrm{a}<\mathrm{b}=1 \\
\mathrm{c} \leftarrow \mathrm{b} \text { otherwise } \\
\mathrm{d} \leftarrow \mathrm{c}+\mathrm{U}_{\mathrm{bs}} \cdot \mathrm{f}_{\mathrm{u}} \cdot \mathrm{A}_{\mathrm{nt}} \\
\mathrm{d}
\end{array}
\end{aligned}
$$

@ block shear (case B):

$$
\begin{aligned}
& \mathrm{A}_{\mathrm{gvb}}:=\left(2 \cdot \mathrm{s}_{\mathrm{b}}+\mathrm{L}_{\mathrm{e}}\right) \mathrm{t}_{\mathrm{gp}}=1.5 \\
& \mathrm{~A}_{\mathrm{nvb}}:=\mathrm{A}_{\mathrm{gvb}}-3 \mathrm{~d}_{\mathrm{h}} \cdot \mathrm{t}_{\mathrm{gp}}=1.043 \\
& \mathrm{~A}_{\mathrm{ntb}}:=\left(2.5 \mathrm{~s}_{\mathrm{b}}+\mathrm{L}_{\mathrm{ev}}\right) \mathrm{t}_{\mathrm{gp}}-1.5 \mathrm{~d}_{\mathrm{h}} \cdot \mathrm{t}_{\mathrm{gp}}=0.99 \\
& \mathrm{~N}_{\text {whbi }}:=\mid \begin{array}{l}
\mathrm{a} \leftarrow 0.6 \mathrm{f}_{\mathrm{u}} \cdot \mathrm{A}_{\mathrm{nvb}} \\
\mathrm{b} \leftarrow 0.6 \mathrm{f}_{\mathrm{y}} \cdot \mathrm{A}_{\mathrm{gvb}} \\
\mathrm{c} \leftarrow \mathrm{a} \text { if } \mathrm{a}<\mathrm{b}=1 \\
\mathrm{c} \leftarrow \mathrm{b} \text { otherwise } \\
\mathrm{d} \leftarrow \mathrm{c}+\mathrm{U}_{\mathrm{bs}} \cdot \mathrm{f}_{\mathrm{u}} \cdot \mathrm{A}_{\mathrm{ntb}} \\
\mathrm{d}
\end{array}
\end{aligned}
$$

@ block shear (case C):

$$
\begin{aligned}
& \mathrm{A}_{\mathrm{gvc}}:=\mathrm{A}_{\mathrm{gv}}=1.313 \\
& \mathrm{~A}_{\mathrm{nvc}}:=\mathrm{A}_{\mathrm{nv}}=0.855 \\
& \mathrm{~A}_{\mathrm{ntc}}:=2 \cdot \mathrm{L}_{\mathrm{e}} \cdot \mathrm{t}_{\mathrm{gp}}-\mathrm{d}_{\mathrm{h}} \cdot \mathrm{t}_{\mathrm{gp}}=1.348
\end{aligned}
$$

$$
\mathrm{R}_{\mathrm{nc}}:=\mid \begin{aligned}
& \mathrm{a} \leftarrow 0.6 \mathrm{f}_{\mathrm{u}} \cdot \mathrm{A}_{\mathrm{nvc}} \\
& \mathrm{b} \leftarrow 0.6 \mathrm{f}_{\mathrm{y}} \cdot \mathrm{A}_{\mathrm{gvc}} \\
& \mathrm{c} \leftarrow \mathrm{a} \text { if } \mathrm{a}<\mathrm{b}=1 \\
& \mathrm{c} \leftarrow \mathrm{b} \text { otherwise }
\end{aligned}
$$


Small-Scale Gusset Plate -- Weak Connection Design Calculations per AASF

Sample A: * units in kips, inches $\quad \mathrm{F}_{\mathrm{y}}:=50 \quad \mathrm{~F}_{\mathrm{u}}:=68$

@ gross section yielding,

$$
\mathrm{A}_{\mathrm{g}}:=\frac{3}{16} \cdot 5=0.938 \quad \mathrm{P}_{\mathrm{n}}:=\mathrm{F}_{\mathrm{y}} \cdot \mathrm{A}_{\mathrm{g}}=46.875 \text { kip }
$$

@ net section fracture,

$$
\mathrm{A}_{\mathrm{n}}:=\mathrm{A}_{\mathrm{g}}-\frac{3}{16} \cdot 2 \cdot 0.8125=0.633 \quad \mathrm{P}_{\mathrm{M}}:=\mathrm{A}_{\mathrm{n}} \cdot \mathrm{F}_{\mathrm{u}}=43.031 \text { kip }
$$

\section{Sample B:}

@ block shear,

$$
\begin{aligned}
& \mathrm{A}_{\mathrm{gt}}:=2 \cdot \frac{3}{16}=0.375 \\
& \mathrm{~A}_{\mathrm{nt}}:=\left(\frac{3}{16}\right) \cdot\left(2-1 \cdot \frac{13}{16}\right)=0.223 \\
& \mathrm{~A}_{\mathrm{nv}}:=(2)\left(2+1.5-1.5 \frac{13}{16}\right)\left(\frac{3}{16}\right)=0.855 \\
& 0.58 \mathrm{~A}_{\mathrm{nv}}=0.496>\text { than Ant, therefore } \\
& \mathrm{P}_{\mathrm{Mmi}}:=0.58 \mathrm{~F}_{\mathrm{u}} \cdot \mathrm{A}_{\mathrm{nv}}+\mathrm{F}_{\mathrm{y}} \cdot \mathrm{A}_{\mathrm{gt}}=52.49 \mathrm{kip}
\end{aligned}
$$




\section{Appendix B - Python Scripts}

\section{Multi-bolt connection model script - RS bolts}

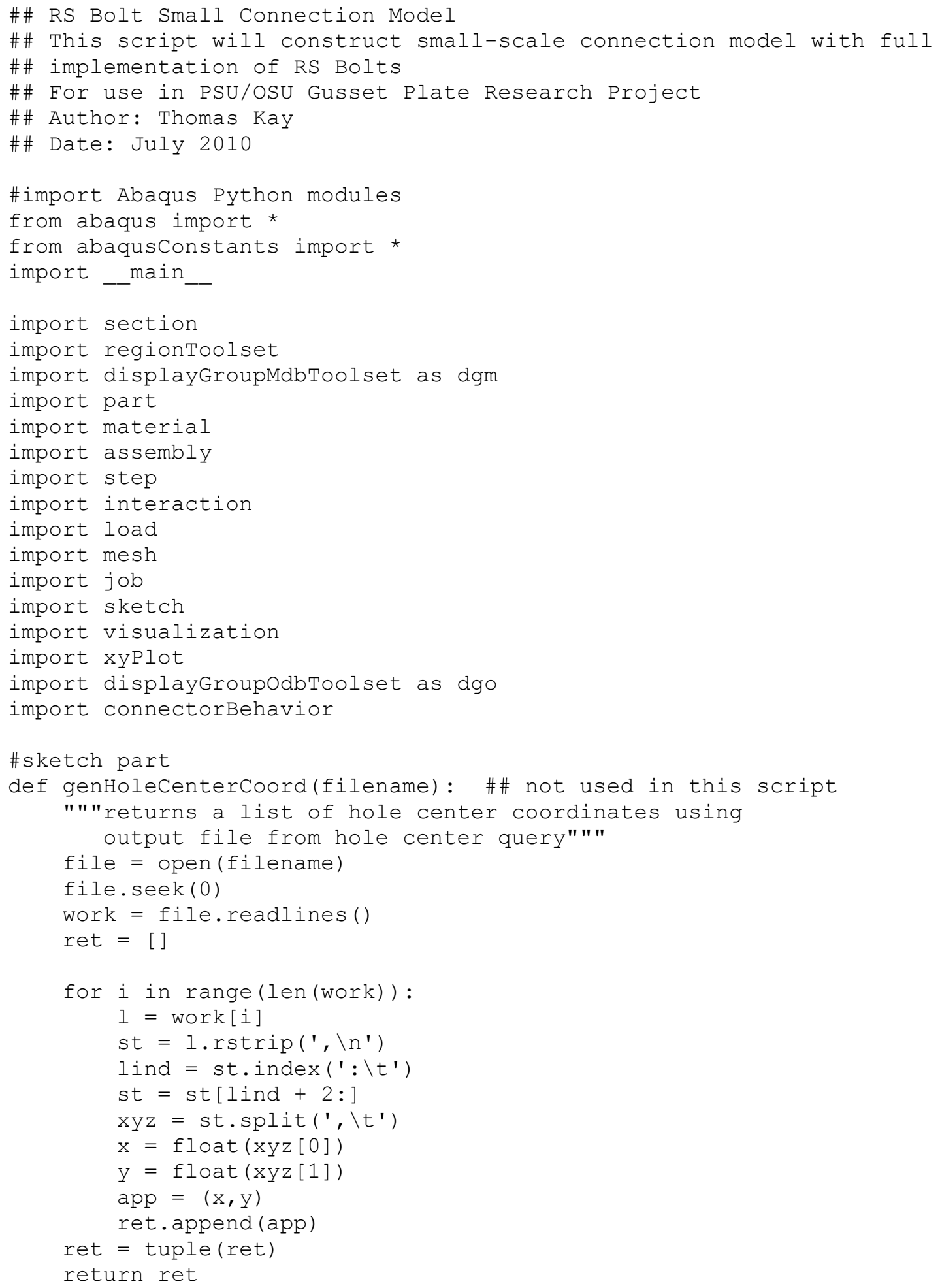




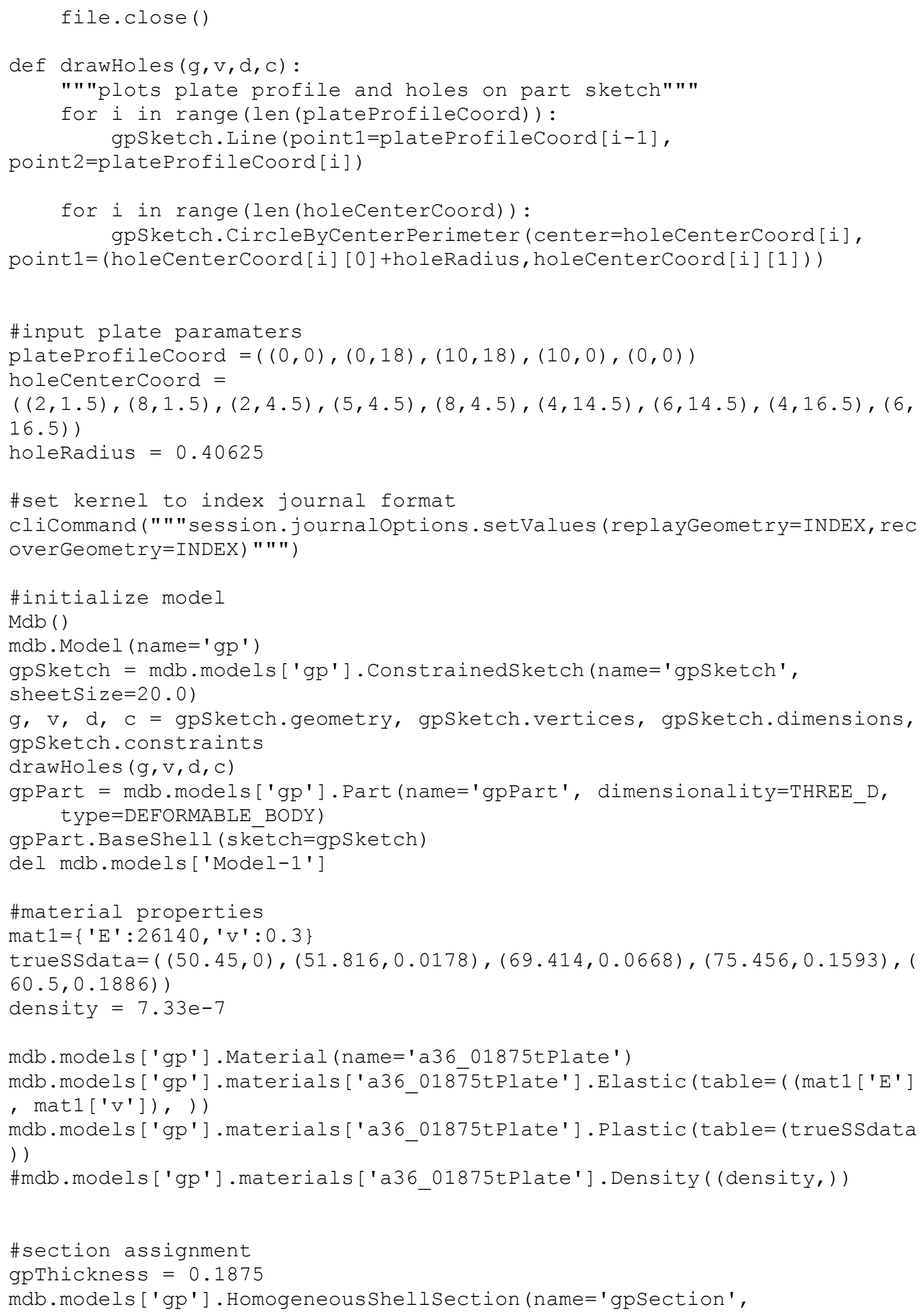




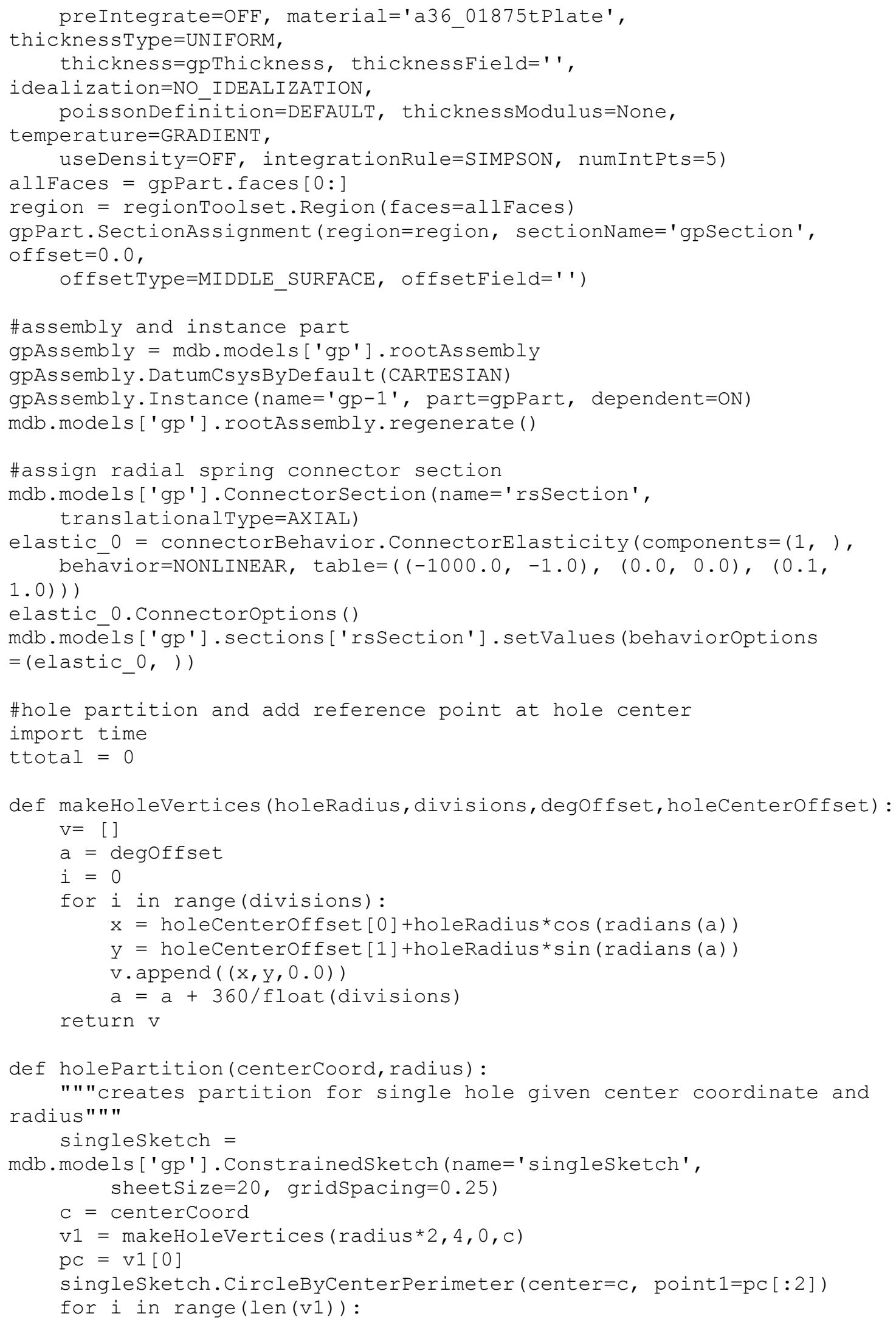




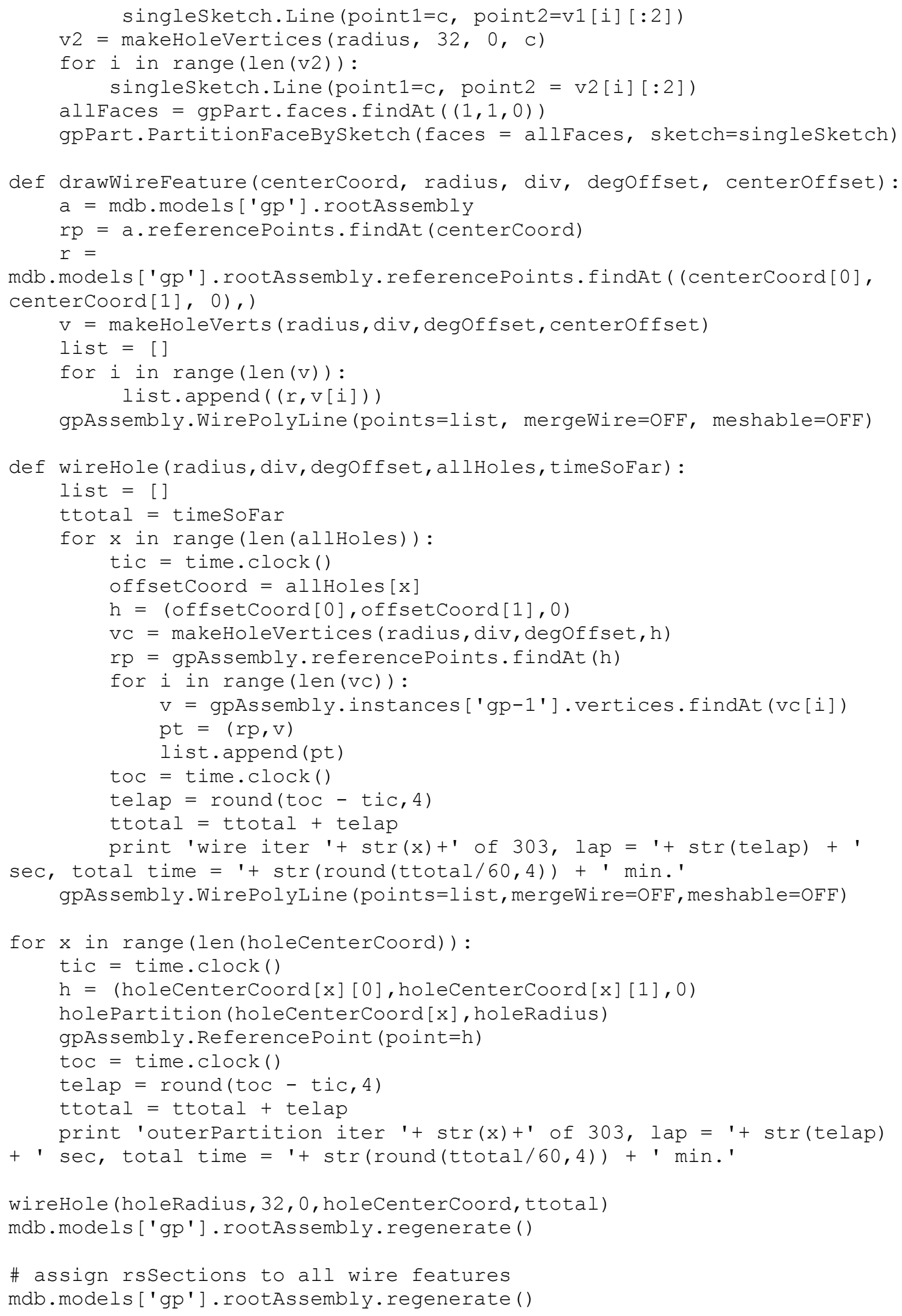




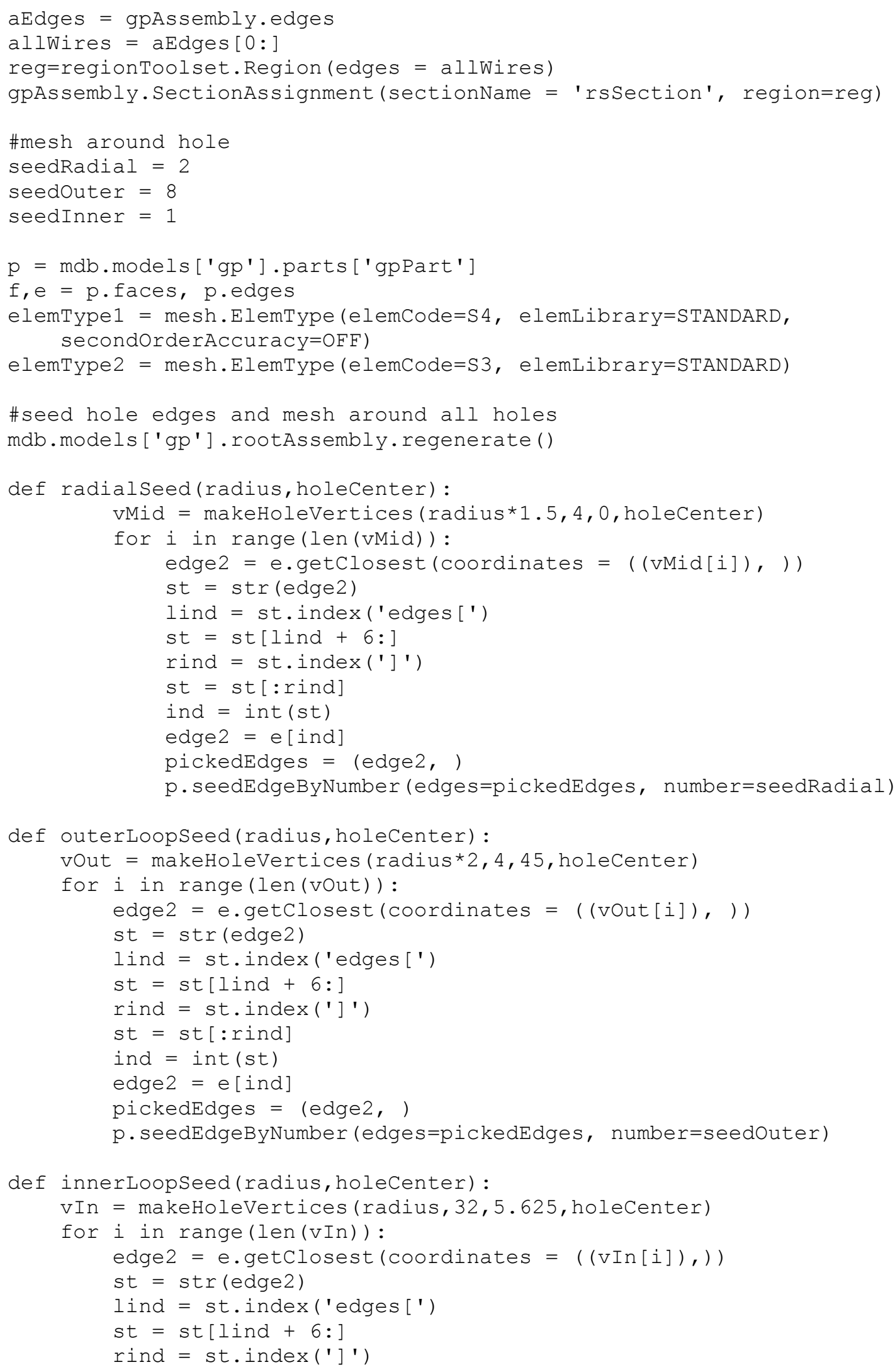




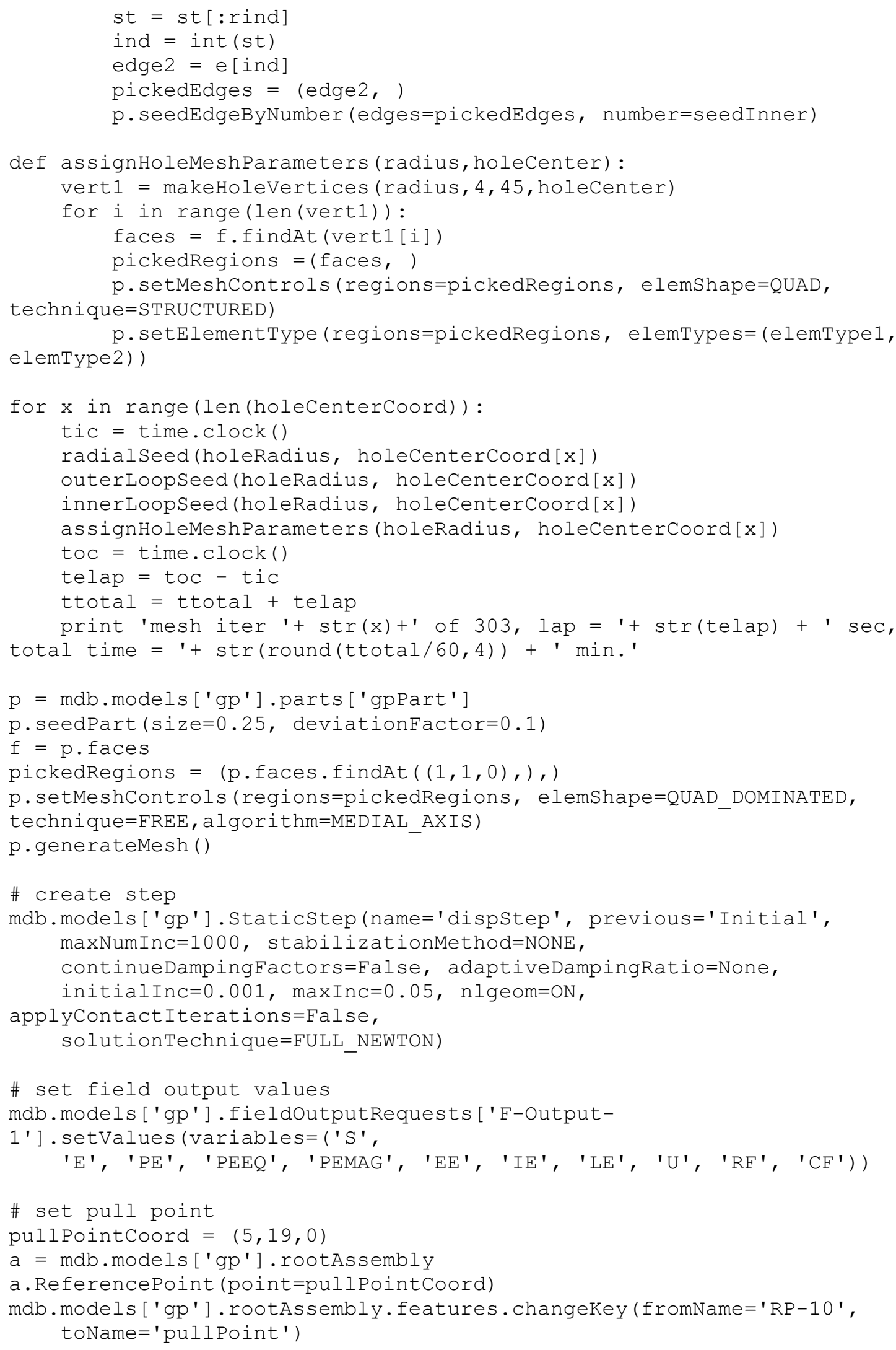




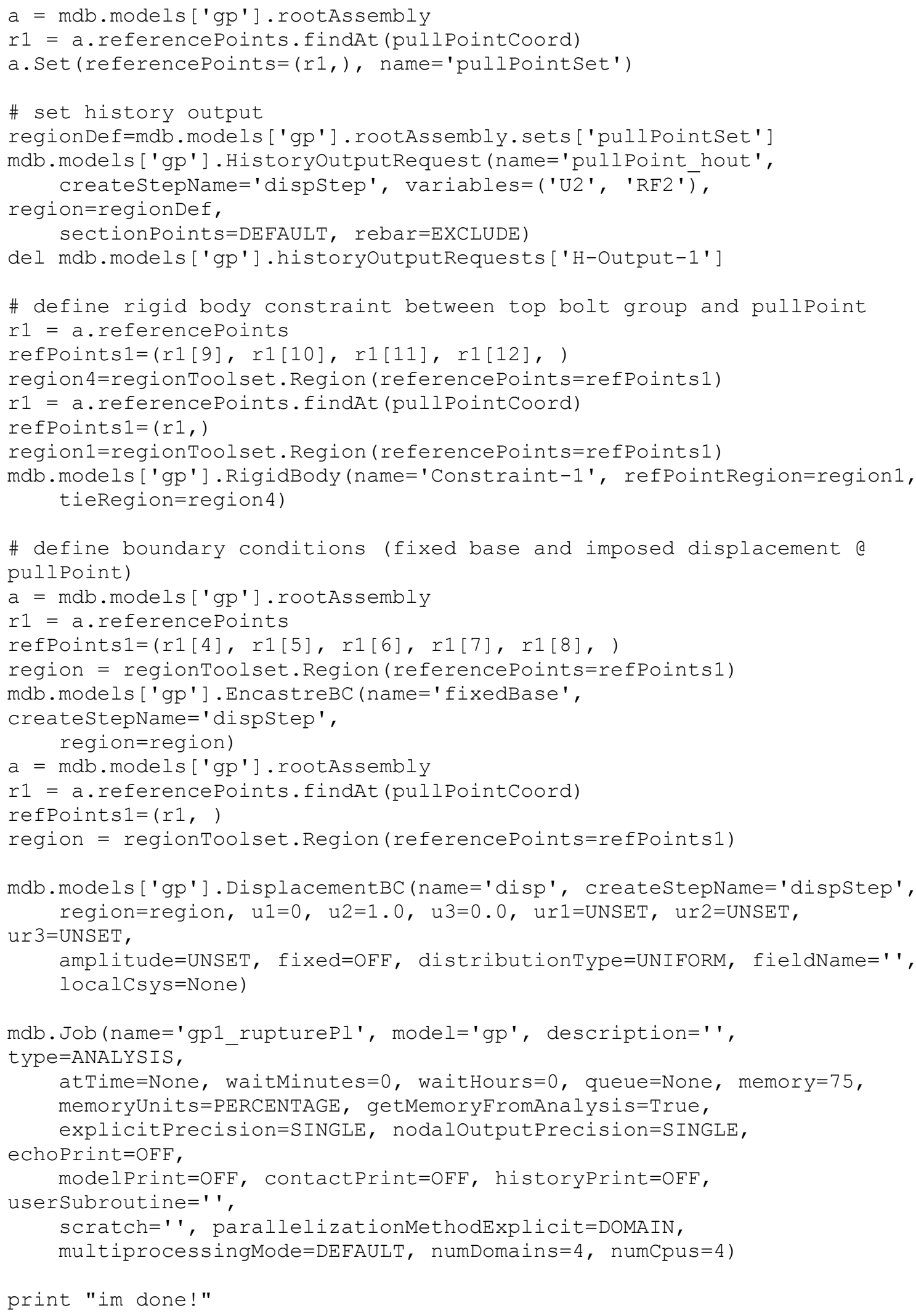




\section{Gusset connection model script - RS Bolts}

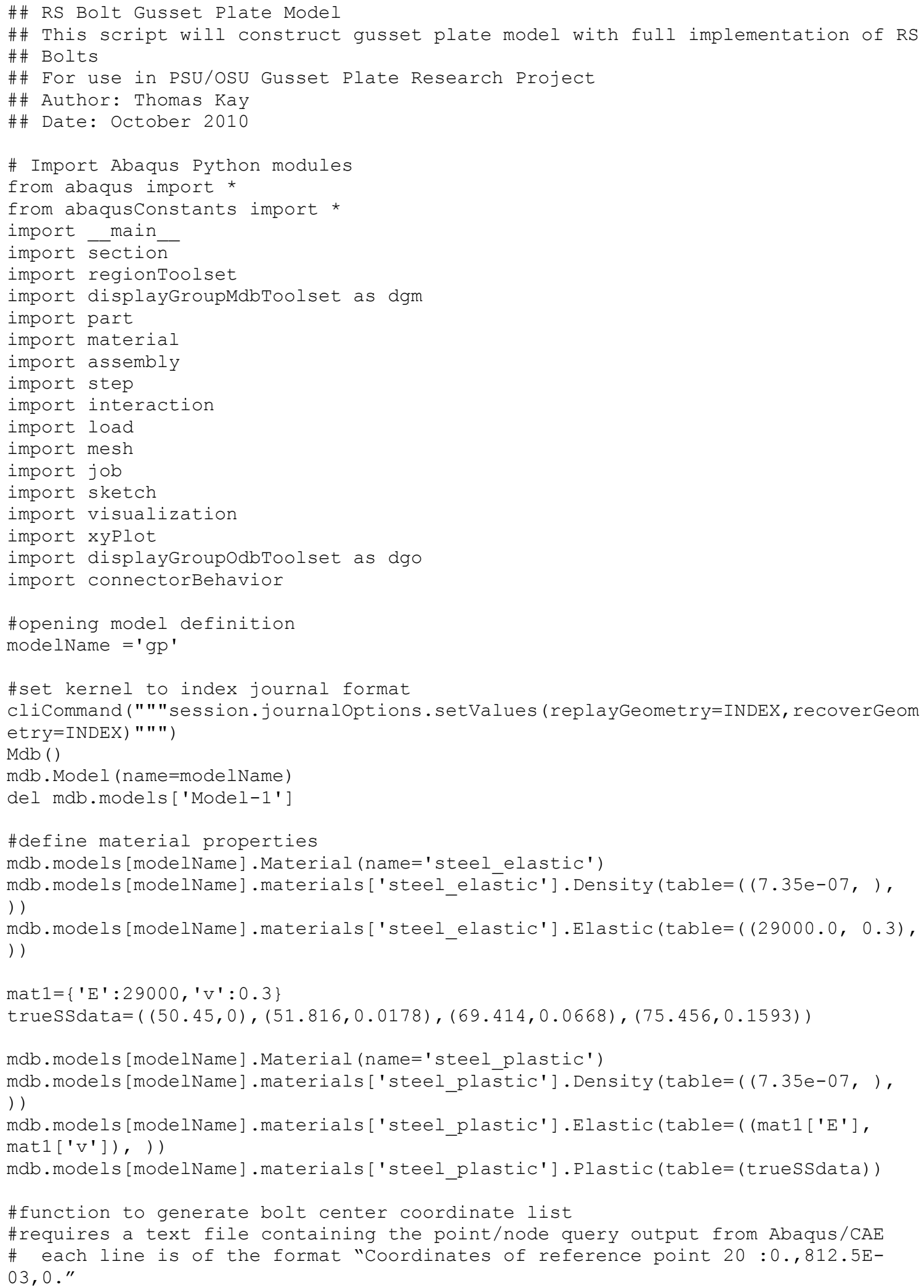


\# and represents a single reference point corresponding to a bolt hole center on the \# gusset plate

def genHoleCenterCoord(filename):

"" returns a list of hole center coordinates using output file from hole center query""

file = open (filename)

file.seek(0)

work $=$ file.readlines ()

ret $=[$ ]

for $i$ in range (len (work)):

$l=$ work[i]

st $=1 . r \operatorname{strip}\left({ }^{\prime}, \backslash \mathrm{n}^{\prime}\right)$

lind $=$ st.index (': \t')

st $=$ st [lind $+2:$ ]

$\mathrm{xyz}=$ st.split $\left(', \backslash t^{\prime}\right)$

$x=$ float $(x y z[0])$

$y=$ float $(x y z[1])$

app $=(x, y)$

ret. append (app)

ret $=$ tuple (ret)

return ret

file.close ()

\#\#create gusset plate

\#gusset plate profile coordinates

gp_plateProfileCoord $=((0,0),(86.5,0),(86.5,50.585),(73.751,60.0)$,

$(8.568,60.0),(0.0,51.828),(0,0))$

\#hole center coordinates

gp_holeCenterCoord = genHoleCenterCoord ('holeData.txt')

\#gusset plate thickness

gp_gpThickness $=0.25$

gp_gpTag = 'gp'

\# function creating gusset plate part, section, and section assignments def

createGussetPlate (plateProfileCoord, holeCenterCoord, gpThickness, gpTag, holeRadiu s) :

\#name definitions

partName $=$ gpTag + 'Part'

sketchName = gpTag + 'Sketch'

sectionName = gpTag + 'Section'

partitionsketchName = gpTag + 'PartitionSketch'

\# draw gusset plate

gpProfilesketch = mdb.models[modelName]. ConstrainedSketch (name=sketchName, sheetSize=200.0)

m4holeCoord $=$ holeCenterCoord

for $i$ in range (len (plateProfilecoord)) : gpProfilesketch. Line (point1=plateProfileCoord[i-1], point2=plateProfileCoord[i])

for $i$ in range(len(m4holecoord)): gpProfileSketch.CircleByCenterPerimeter (center=m4holeCoord [i], point $1=(m 4 h o l e C o o r d[i][0]+h o l e R a d i u s, m 4 h o l e C o o r d[i][1]))$

gpPart $=$ mdb.models ['gp'].Part (name='gpPart', dimensionality=THREE_D, type=DEFORMABLE BODY)

gpPart. BaseShell (skētch=gpProfilesketch)

\#define gusset plate section

mdb.models ['gp'] .HomogeneousShellsection (name=sectionName, preIntegrate $=O F F$, material='steel plastic', thicknessType=UNIFORM, thickness=gpThickness, thicknessField=' ', idealization=NO_IDEALIZATION, 
poissonDefinition=DEFAULT, thicknessModulus=None, temperature=GRADIENT, useDensity=OFF, integrationRule=SIMPSON, numIntPts=5)

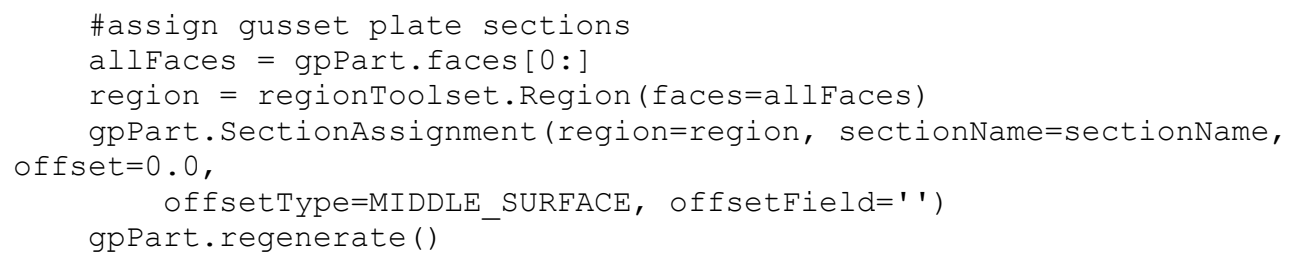




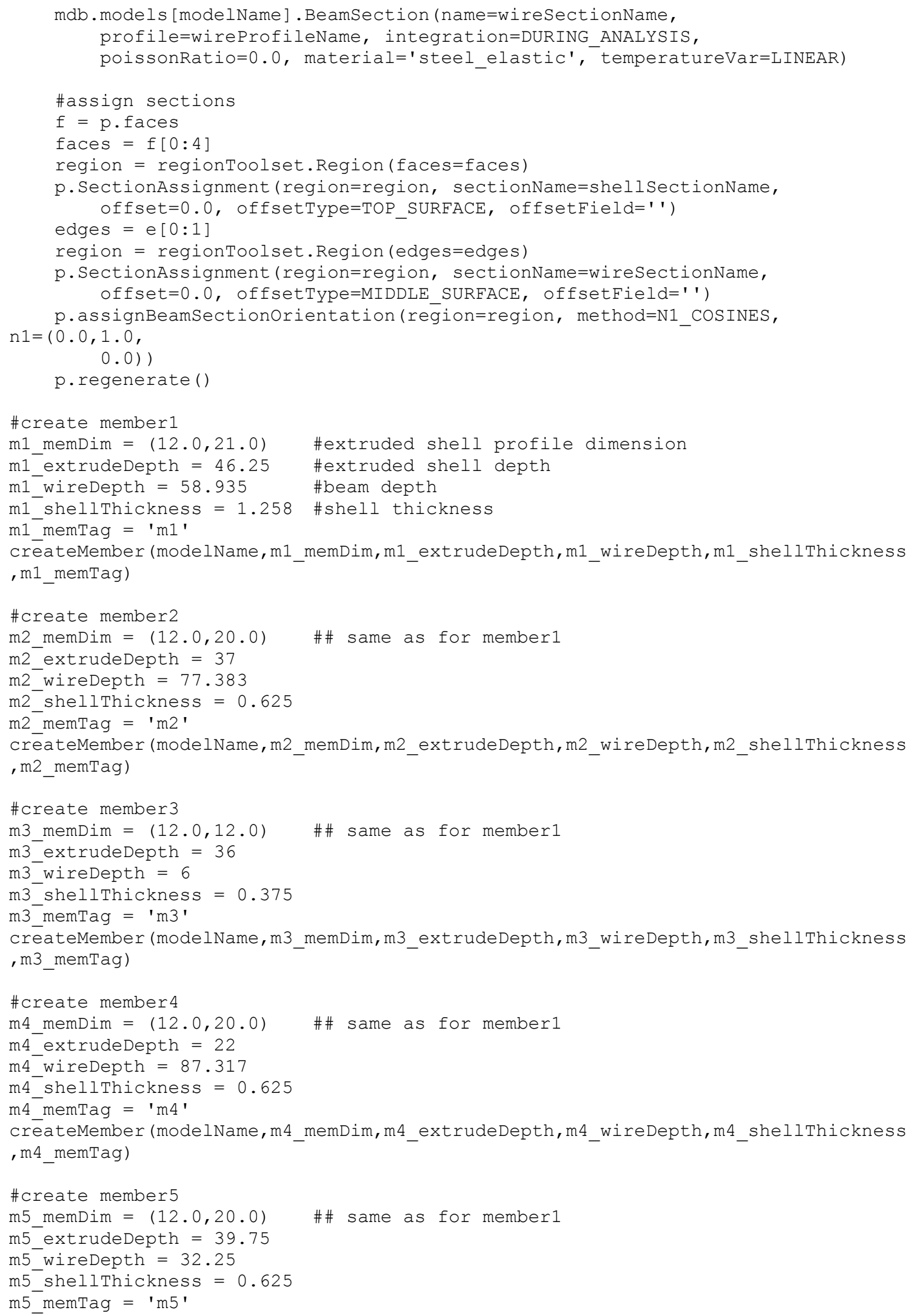




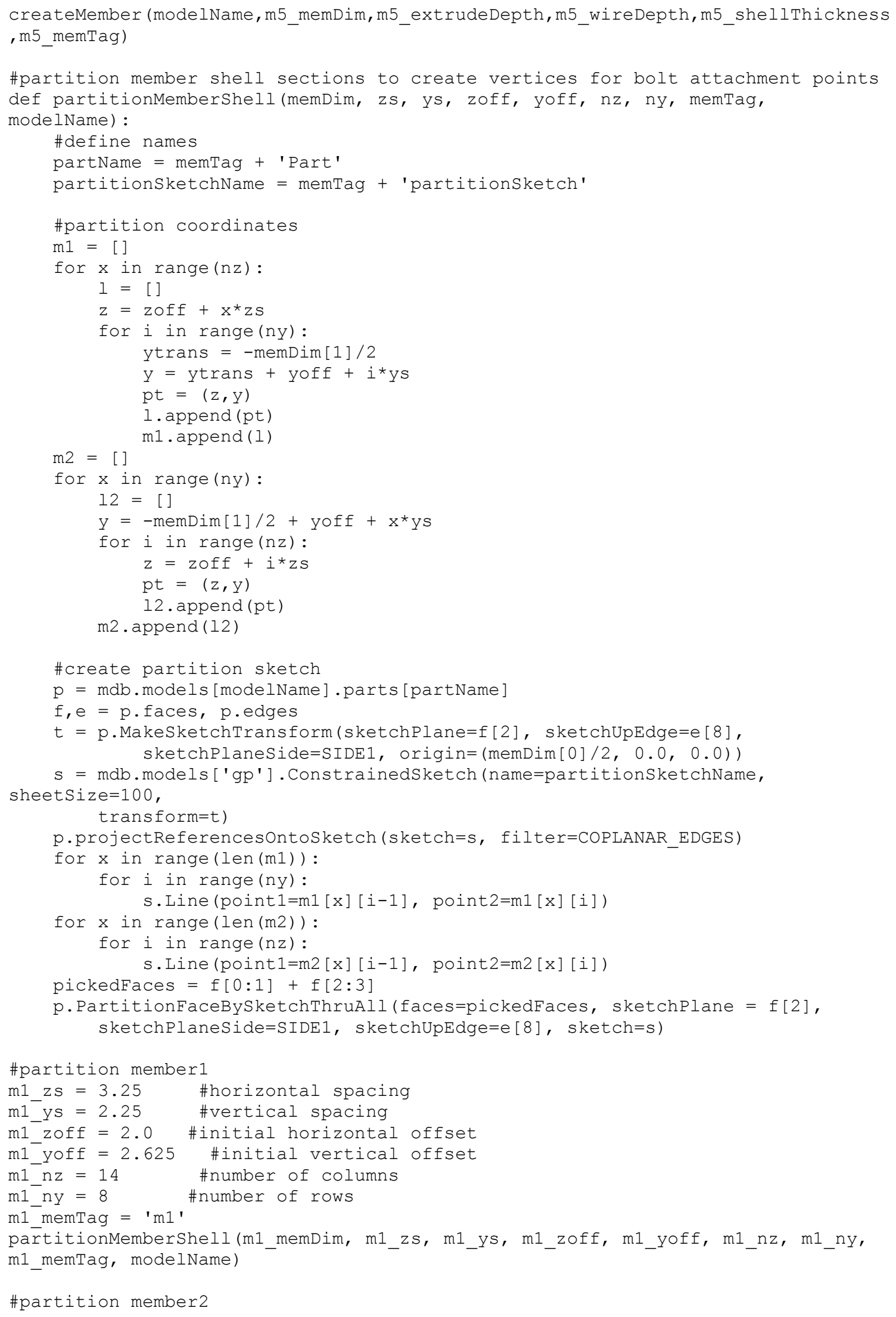




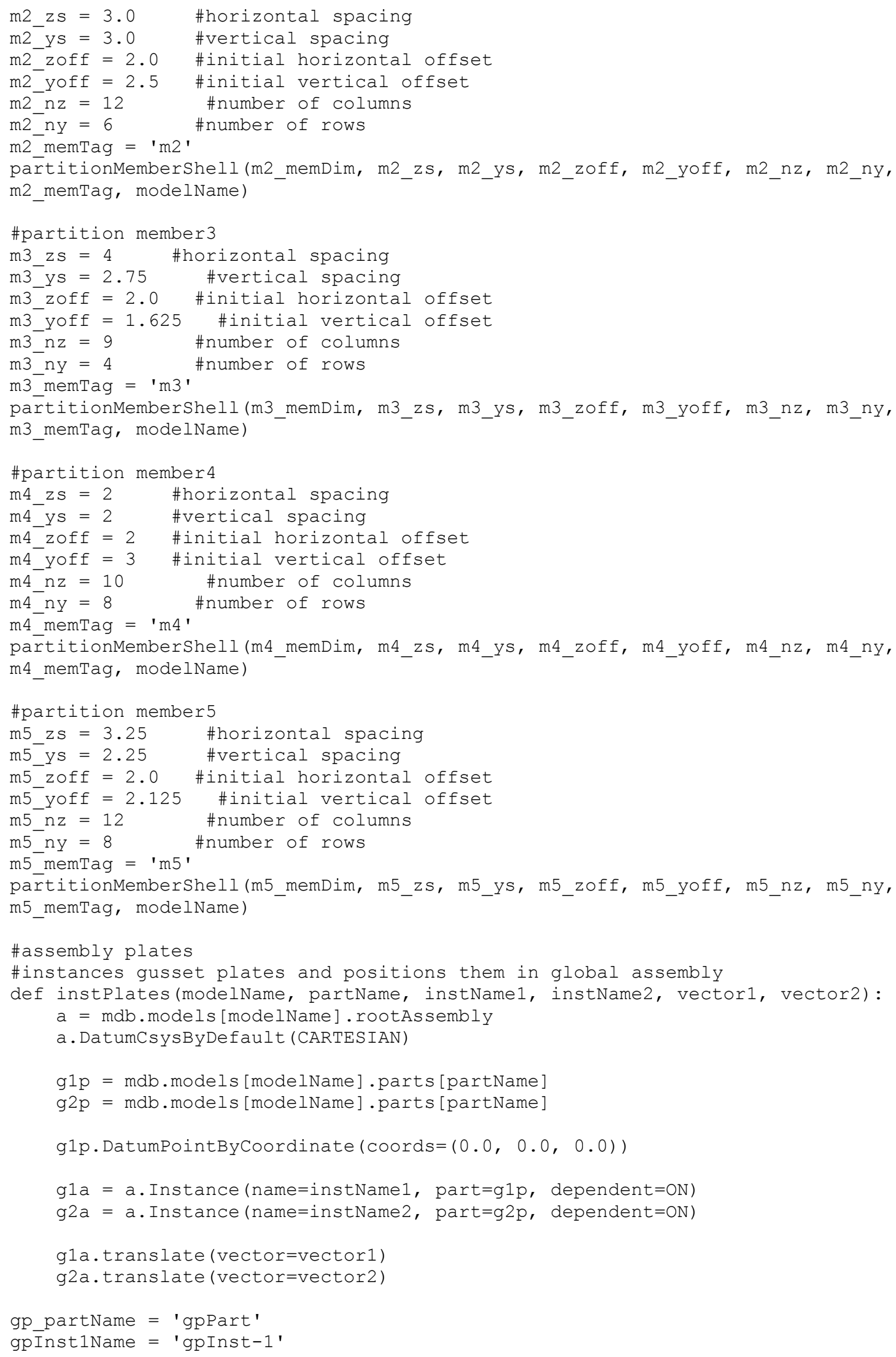




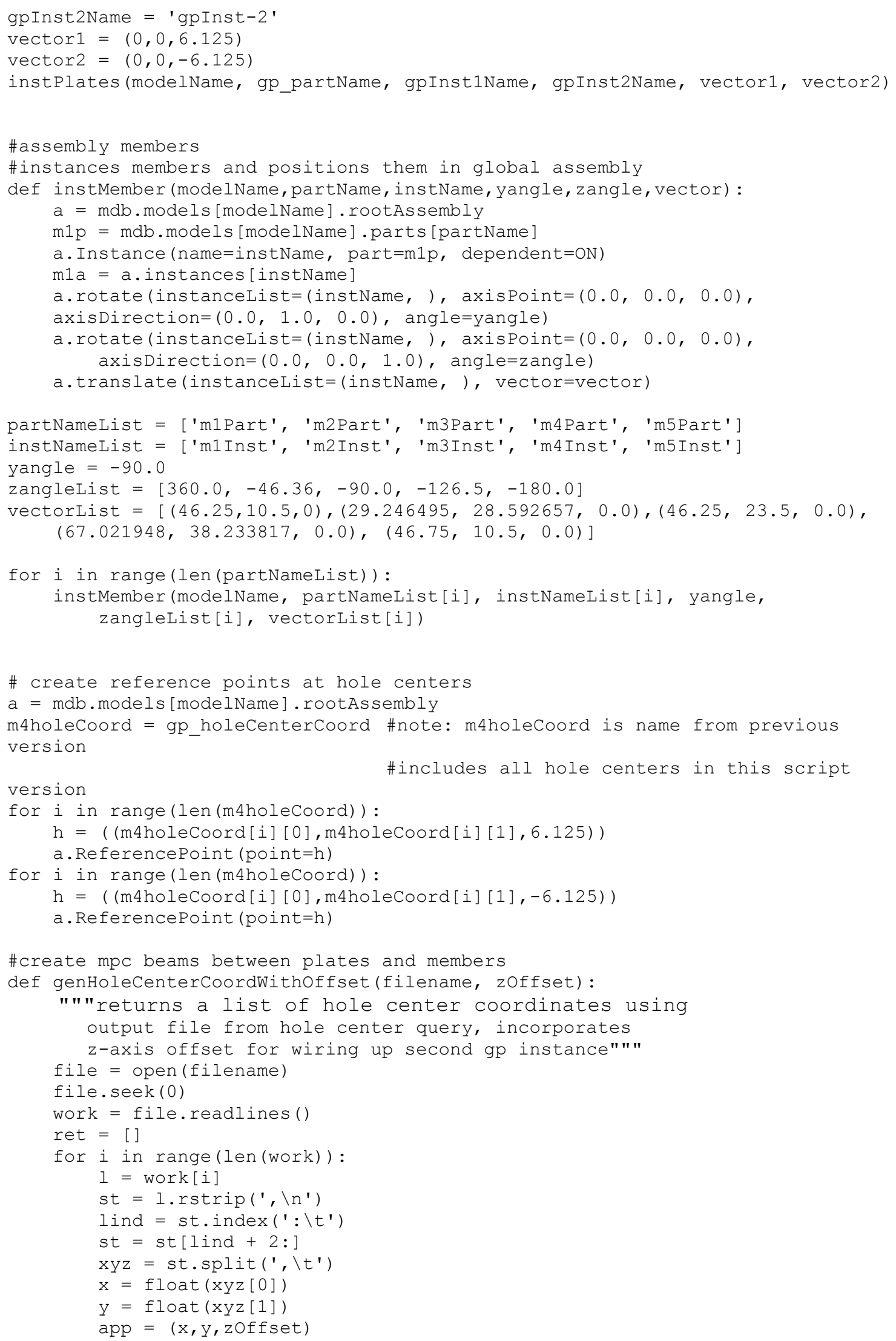




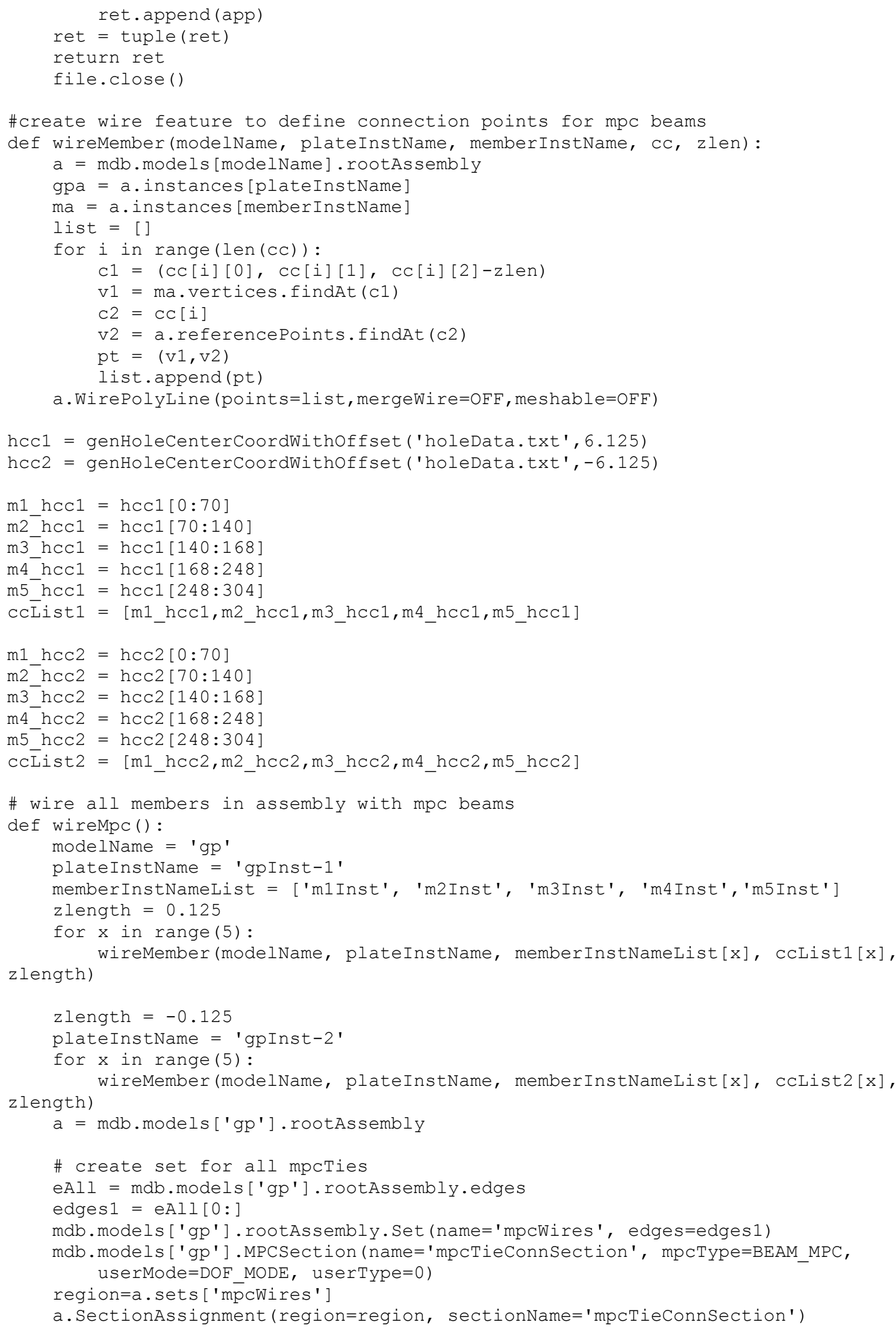




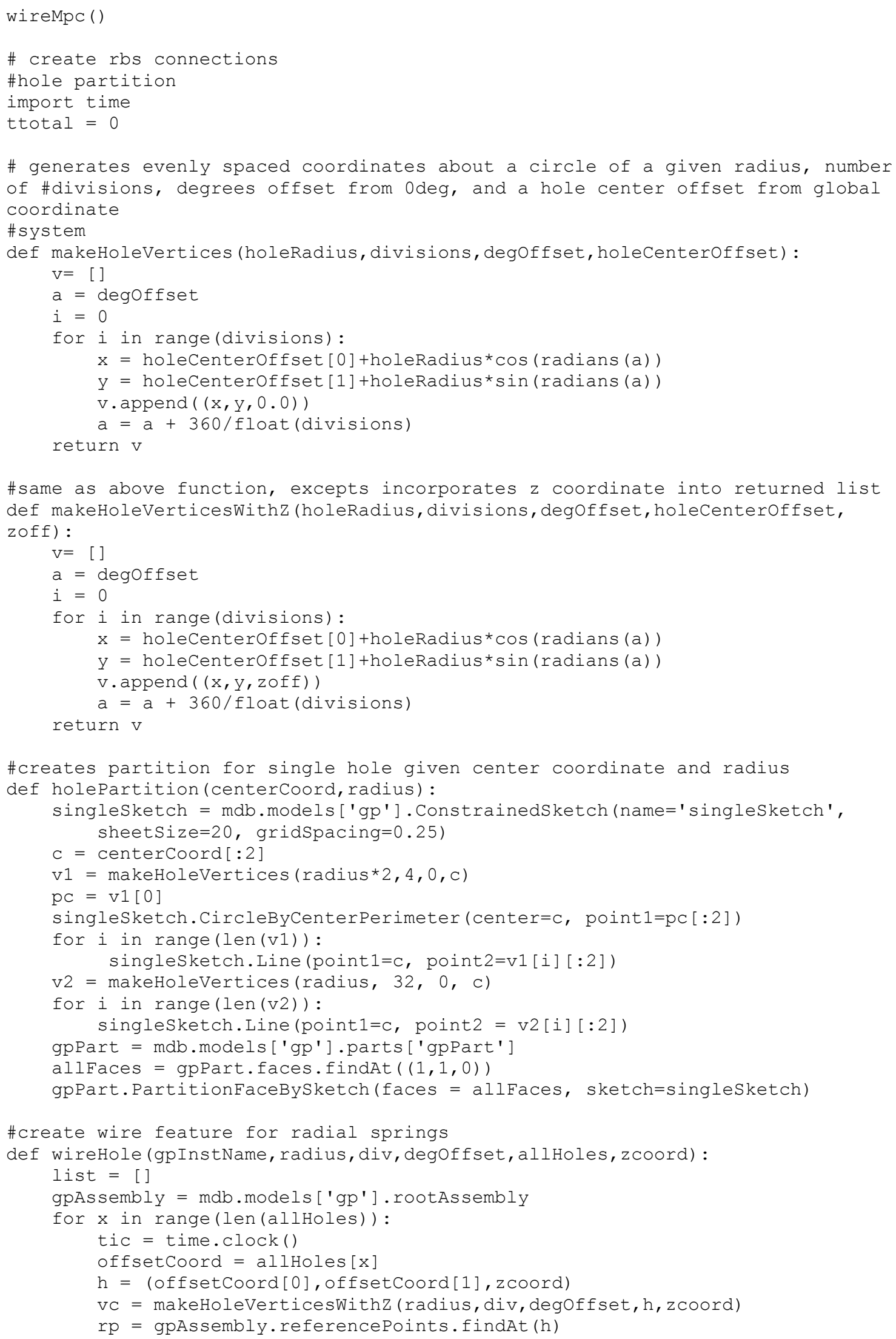




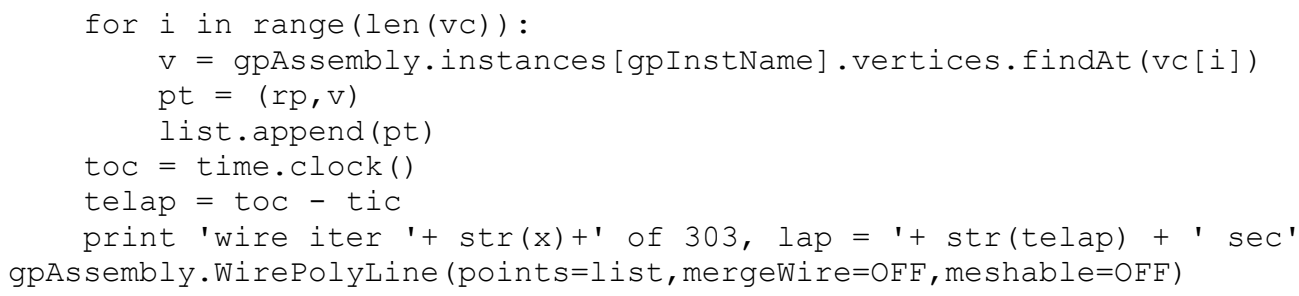




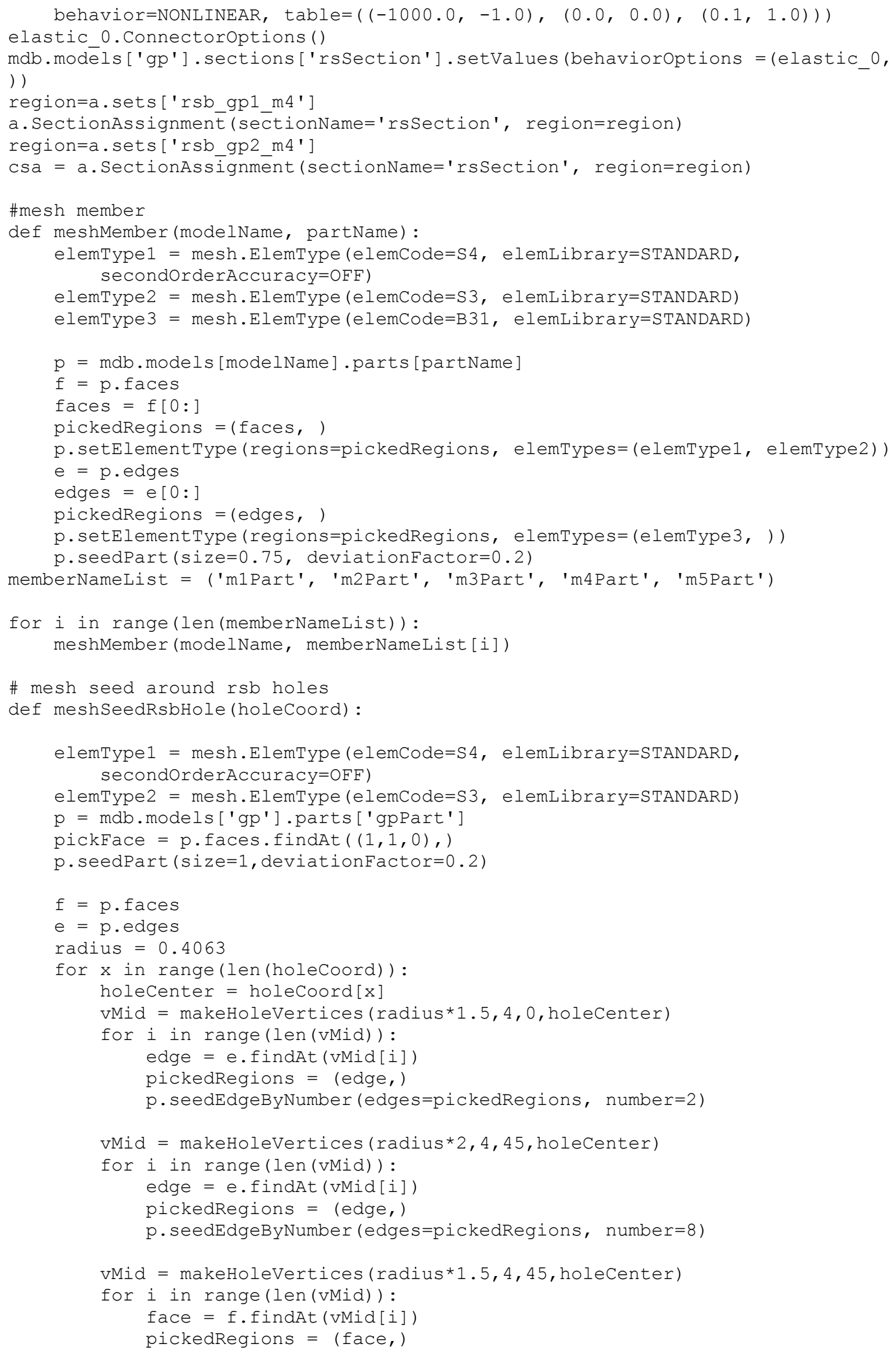




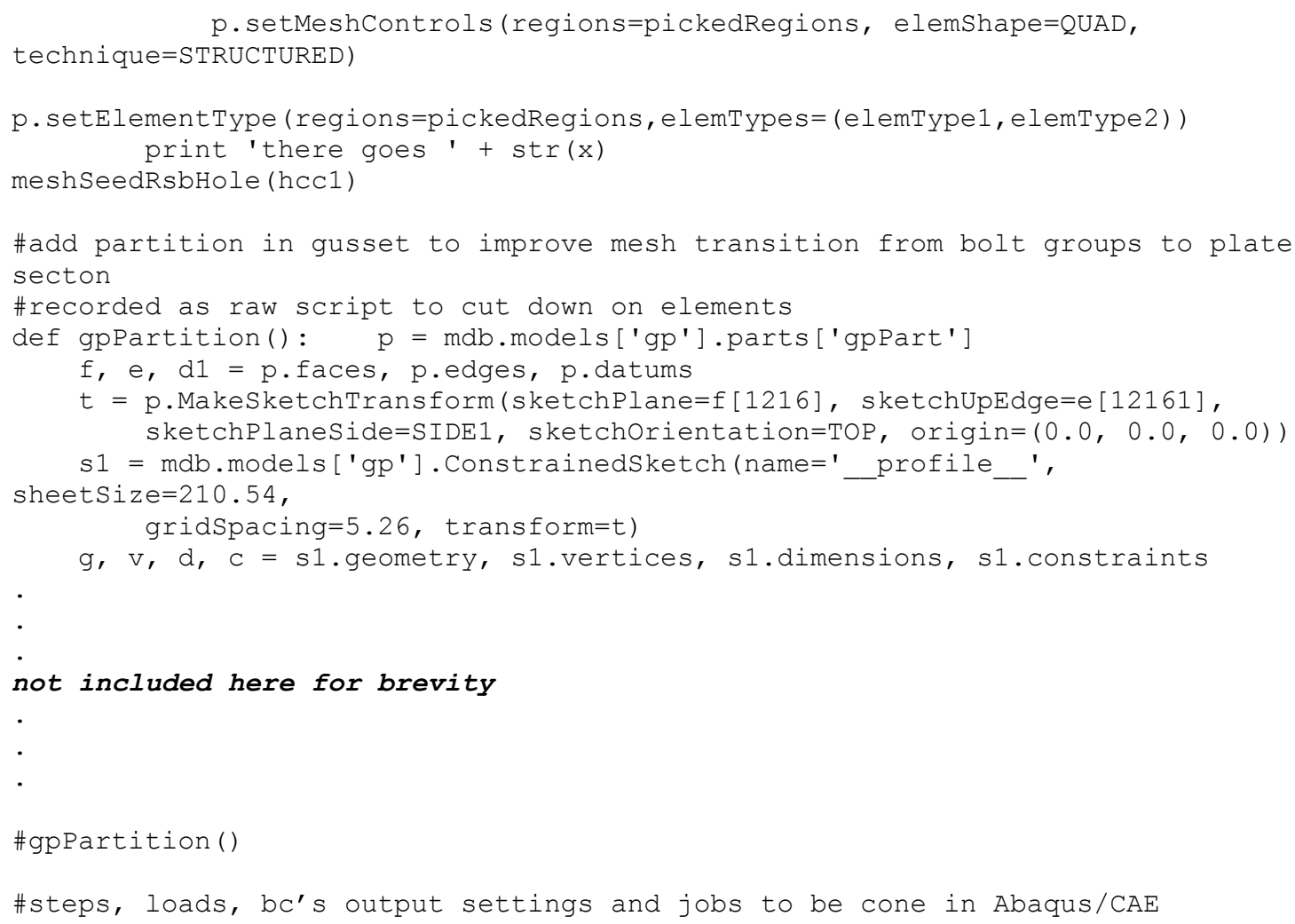




\section{Appendix C - Convergence plots}
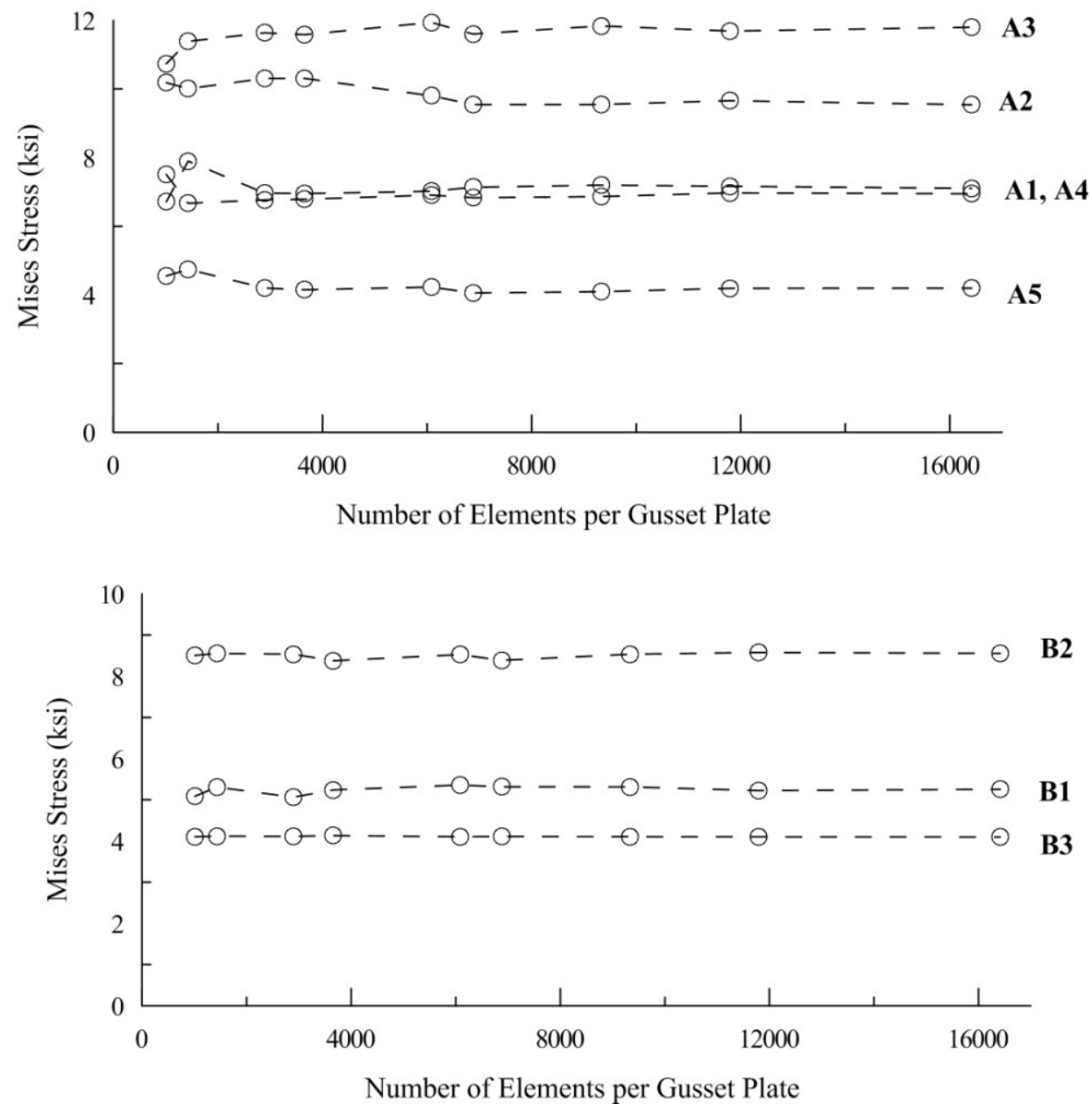

Mises stress convergence plots - Planes A and B 

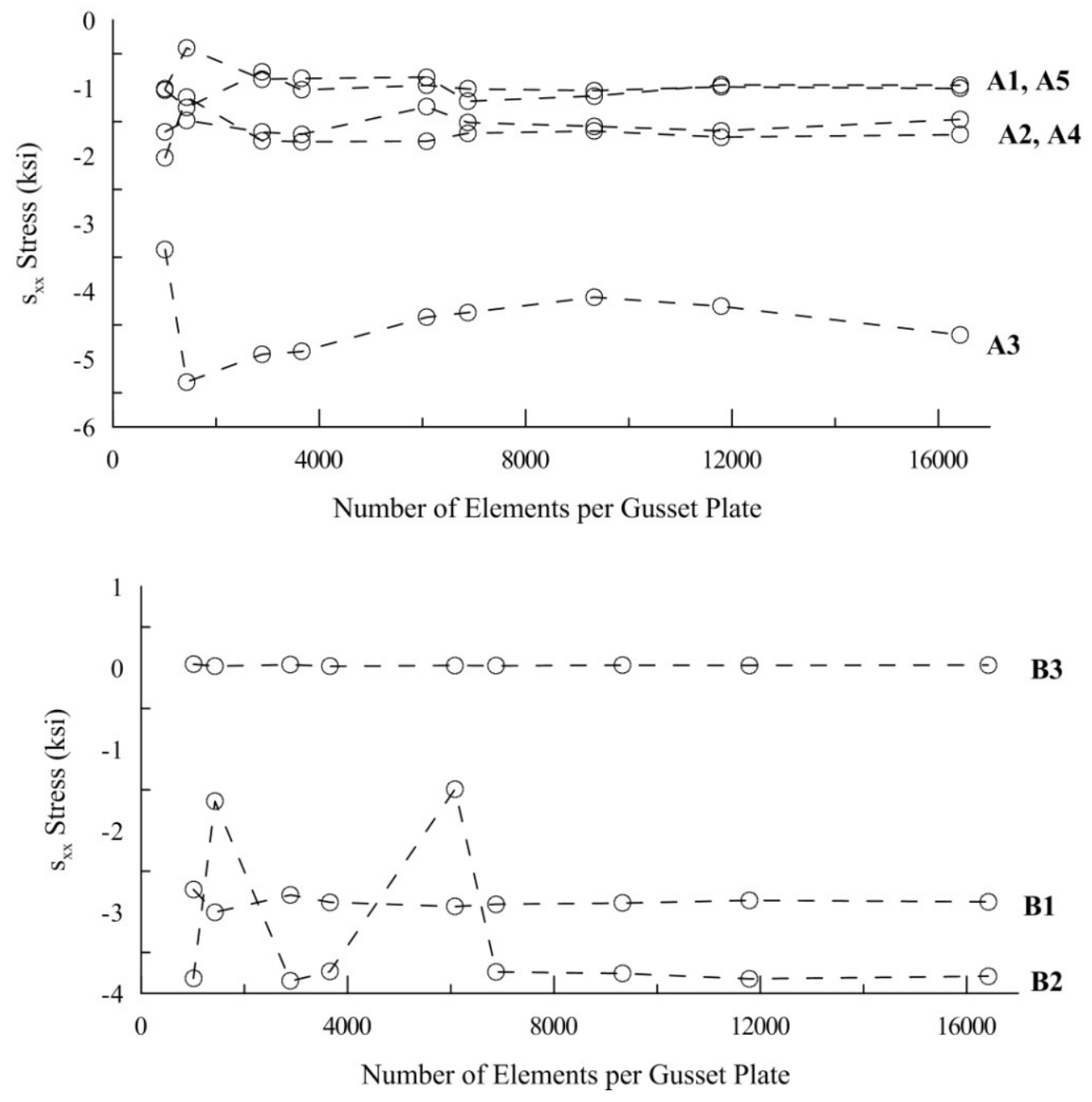

$\mathrm{s}_{\mathrm{xx}}$ stress convergence plots - Planes A and B 

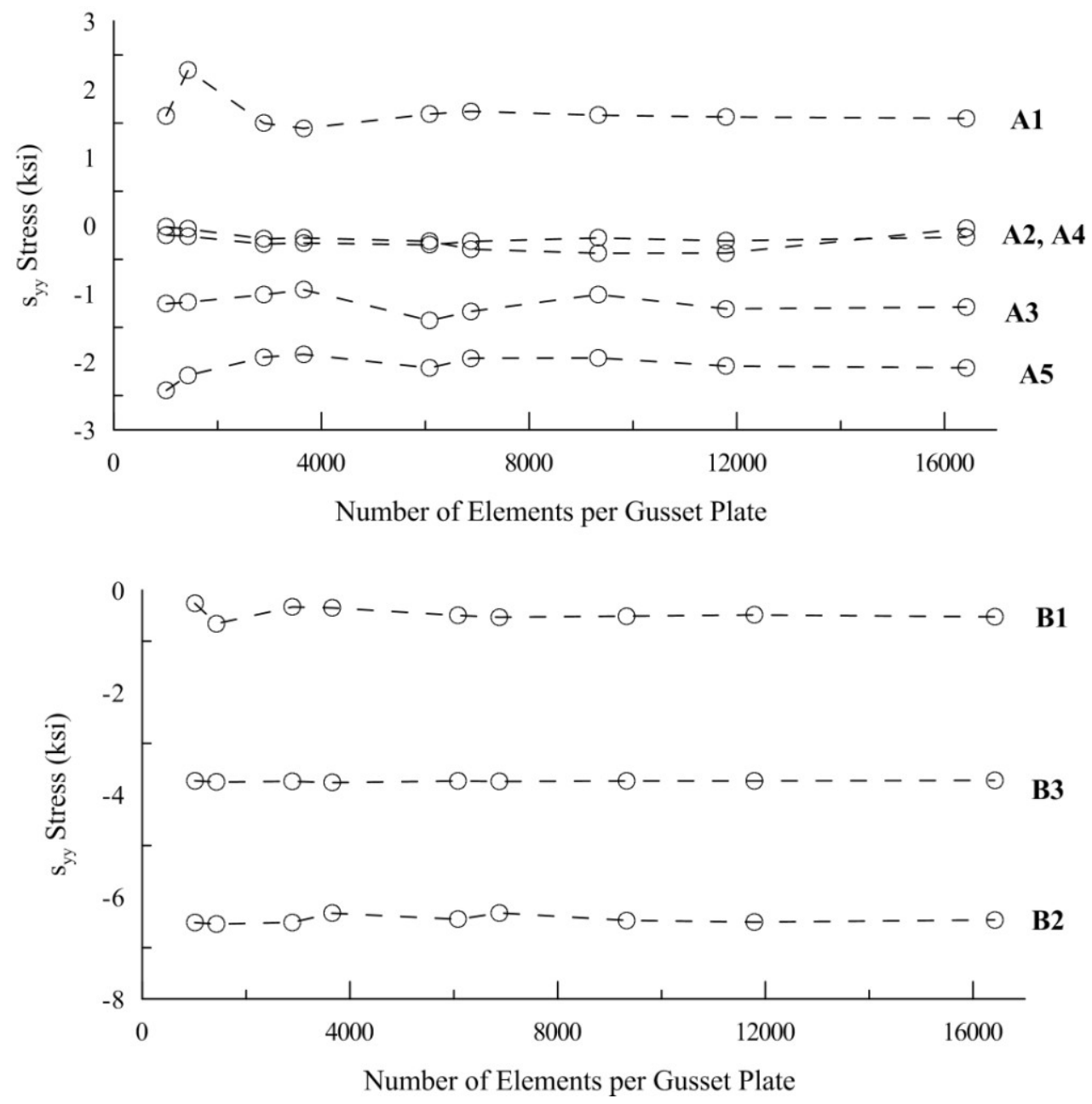

$\mathrm{s}_{\mathrm{yy}}$ stress convergence plots - Planes A and B 

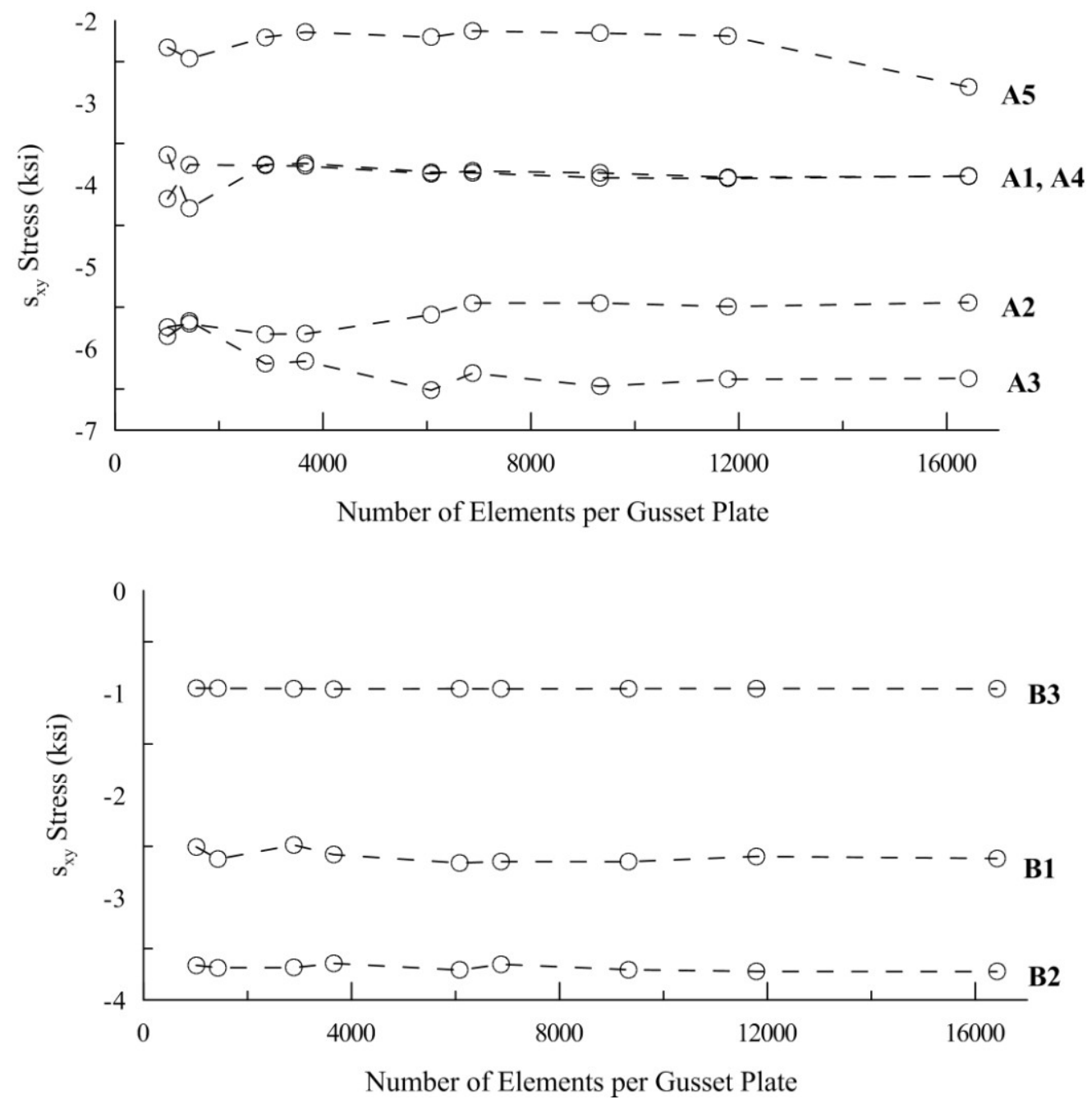

$\mathrm{S}_{\mathrm{xy}}$ stress convergence plots - Planes A and B 

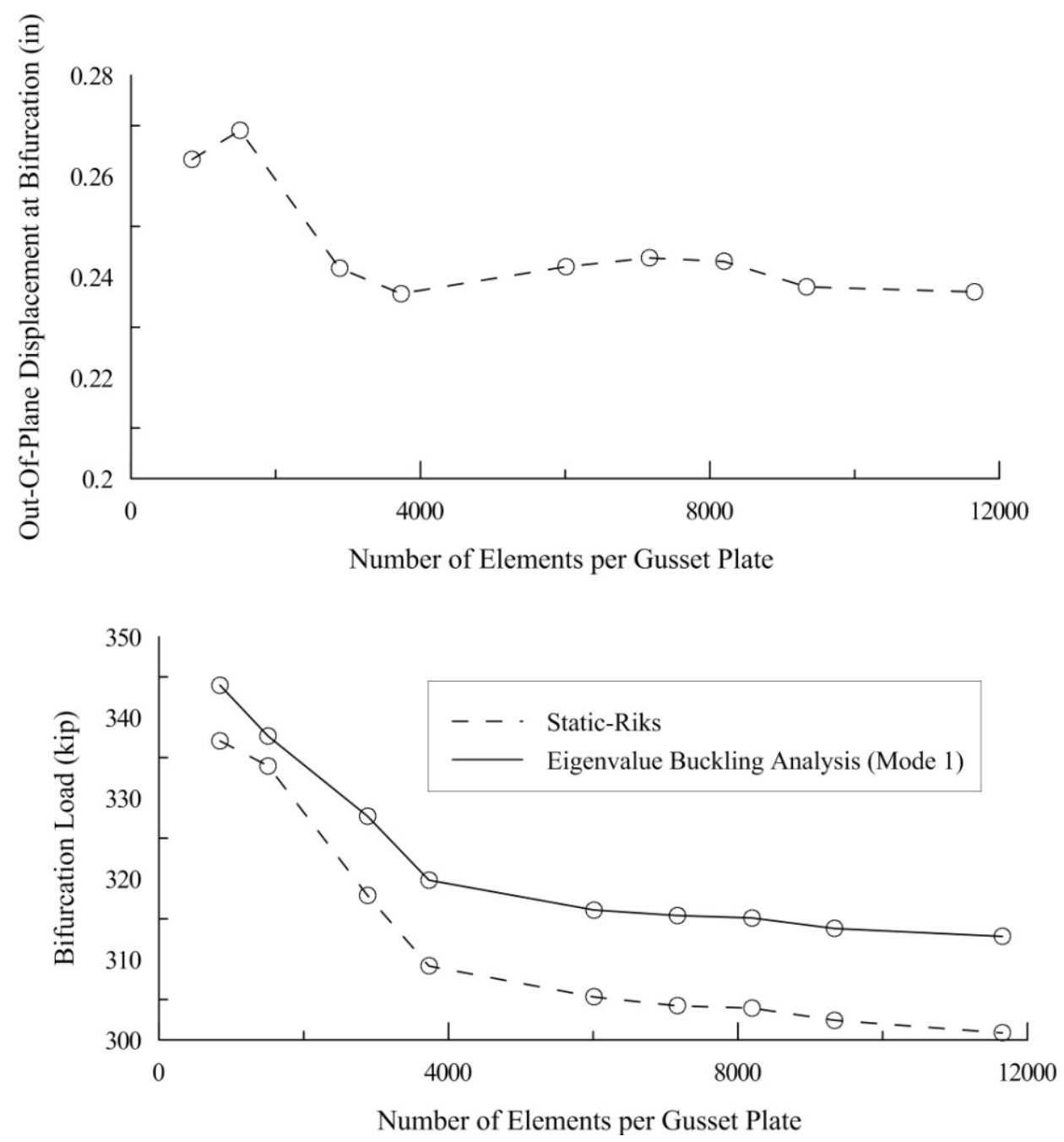

Out-of-plane displacement and bifurcation load convergence plots

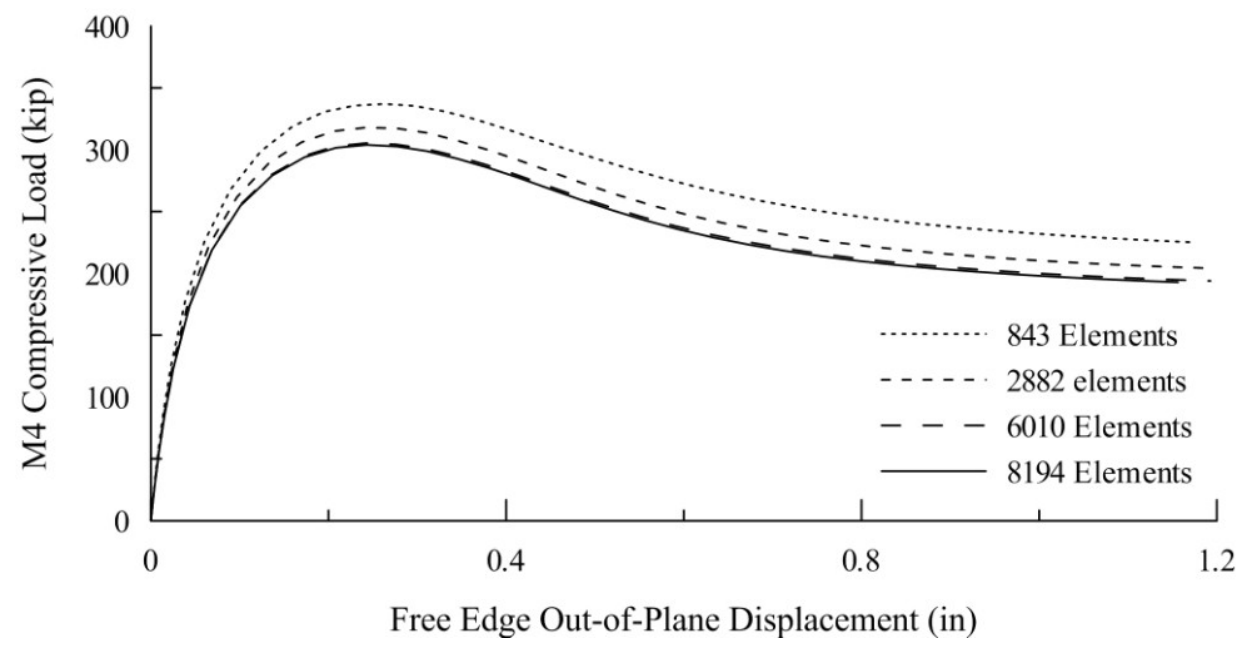

Load-displacement convergence plot 